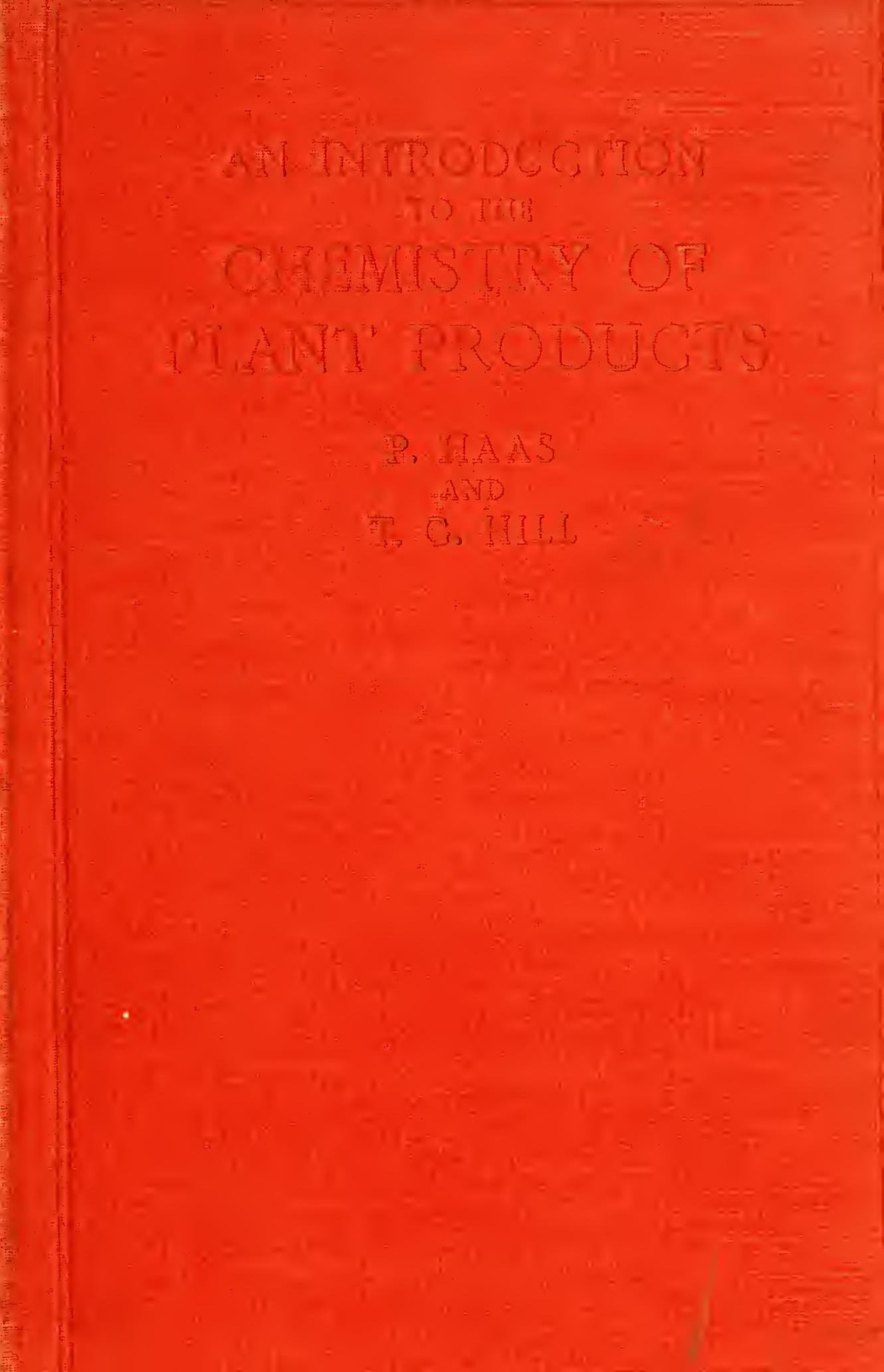




AN INTRODUCTION TO THE

CHEMISTRY OF PLANT PRODUCTS 
LONGMANS, GREEN AND CO. LTD.

39 PATERNOSTER ROW, LONDON, E.C. 4

6 old COURT HOUSE STREET, CALCUTTA

53 NICOL ROAD, BOMBAY

167 MOUNT ROAD, MADRAS

LONGMANS, GREEN AND CO.

55 FIFTH AVENUE, NEW YORK

22 I EAST 2OTH STREET, CHICAGO

TREMONT TEMPLE, BOSTON

210 VICTORIA STREET, TORONTO 
AN INTRODUCTION

TO THE

\section{CHEMISTRY OF \\ PLANT PRODUCTS}

VOL. II. METABOLIC PROCESSES

BY

PAUL HAAS, D.Sc., Ph.D.

READER IN PLANT CHEMISTRY IN THE UNIVERSITY OF LONDON

AND

T. G. HILL, D.Sc., A.R.C.S.

FROFESSOR OF PLANT PHYSIOLOGY IN THE UNIVERSITY OF LONDON

SECOND EDITION

WITH DIAGRAMS

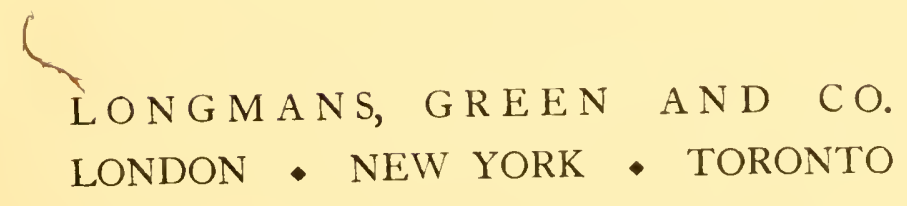

1929 
Made in Great Britain 


\section{PREFACE TO THE SECOND EDITION.}

THE expanding margin of botanical knowledge and the trend of botanical thought have made necessary much revision and rewriting; the original intention of providing a general introduction to the problems of plant metabolism, adequate as a foundation on which to base further study, has, however, been maintained.

January, 1929.

P. H.

T. G. H

\section{PREFACE \\ TO THE FIRST EDITION.}

In the preparation of the present volume on the Metabolic Processes of Plants two alternatives were presented: the one to give as full an account as possible of the literature, the other to give such an account as would form a basis for further study. The latter, and more difficult task, was chosen; for, valuable though a digest of the relevant literature 
would be, it would tend to confuse rather than to assist the student. For this reason we do not profess to have mentioned all research on the subject matter; indeed in some instances, the chapter on Growth for example, some critics will say that too much has been omitted; we trust, however, that no work of outstanding importance and requisite for our treatment has been omitted. Details regarding methods of experiment have been omitted since this aspect of the subject more properly belongs to a practical treatise.

P. H.

T. G. H.

July, I922. 


\section{CONTENTS.}

PREFACE

CHAP.

I. INTRODUCTION : THE LIVING PLANT . • • I

II. THE SYNTHESIS OF CARBOHYDRATES • • $\quad 6$ The factors . . . . . . . . . 8

External factors . . . . . . . . 14

The raw materials $\quad . \quad$. $\quad . \quad$. $\quad$. I4

Water $\quad . \quad$. $\quad . \quad . \quad . \quad 14$

Carbon dioxide $\quad . \quad$. $\quad . \quad$. $\quad . \quad 16$

Temperature • . $\quad . \quad$. $\quad . \quad$. 25

Illumination . $\quad . \quad$. $\quad . \quad 30$

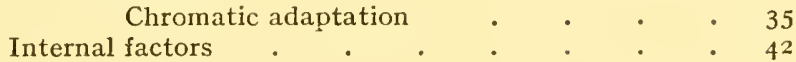

Chlorophyll . . . . . . . 42

The unknown factor . . . . . . 45

The products of carbon assimilation . . . 49

The organic products of carbon assimilation . . . 50

Hypotheses concerning the synthesis of carbohydrates by the

green plant . . . . . . . 56

Origin of the oxygen . . . . . 58

Formation of formaldehyde . . . $\quad$. 59

Polymerization of formaldehyde to sugars in vitro 60

Summary of the evidence relating to the formaldehyde

hypothesis . . . . . . 62

Carbon monoxide $. \quad . \quad . \quad . \quad . \quad .62$

Formaldehyde . $. \quad . \quad . \quad . \quad . \quad 662$

Feeding experiments . $\quad . \quad . \quad . \quad 63$

Production of sugar from formaldehyde . . 63

Summary of the opinion of Willstätter and Stoll . 63

Other opinions . $\quad . \quad . \quad . \quad . \quad .666$

Formic acid . . . . . . . 66

Maquenne's hypothesis . . . . $\quad$. 67

III. THE SYNTHESIS OF FATS.$\quad \cdot \quad \cdot \quad \cdot \quad \cdot \quad 69$

Formation from proteins . . . . . . 70

Origin from carbohydrates . . . • • • $7 x$

IV. THE SYNTHESIS OF PROTEINS . . . . . 8I

Occurrence of nitrate . $. \quad . \quad . \quad . \quad . \quad . \quad 86$

Occurrence of nitrite $\quad . \quad . \quad . \quad . \quad . \quad . \quad$. 87

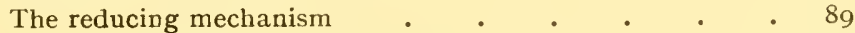

"Reductase" . . . . . . . . . . . 89

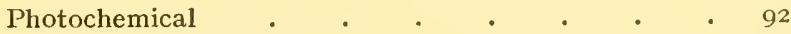

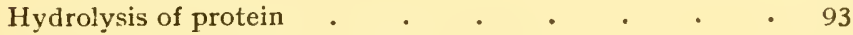

The origin of protein in the seed . . . . 95

vii 
CHAP.

V. RESPIRATION .

Respiratory quotient

Fermentative processes

Intensity

Stimulation

The action of anæsthetics

The action of ionized air

Conditioning factors

Temperature.

Food

Water

Salts

Acidity .

Light

The mechanism of oxidation, and the enzyme systems involved

Dehydrase

The Schardinger reaction

The nitrate-reducing enzyme of the potato ${ }^{\circ}$

Respiratory pigments

Glutathione

Oxidases

Catalase

Fermentation : zymase and carboxylase . . . . 152

Alcoholic fermentation

Lactic acid fermentation .

Butyric acid fermentation $\cdot 154$

Factors influencing alcoholic fermentation by yeast I 55

Current ideas on the mechanism of respiration . . I59

VI. GROWTH

The conditioning factors $\quad . \quad$. $\quad . \quad$. $\quad . \quad$ I87

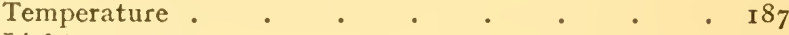

Light . . . . . . . • . 194

Water . . . . . . . . 202

Nutrition . . . . . . . . . . 203

Auximones . . . . . . . . . 209

Hormones . . . . . . . . 2 II

INDE $\mathrm{X}$ 


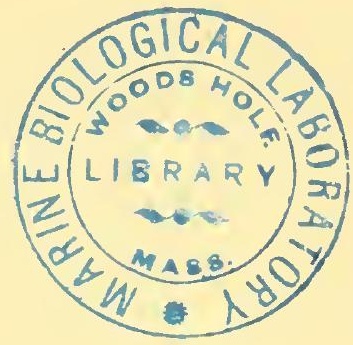

INTRODUCTION: THE LIVING PLANT.

THE problems involved in the study of plant life may best be ordered and formulated by a consideration: intentionally elementary, of the history of a seed planted in good ground. The period of rest completed--a period which varies much in duration and in different species-a sowed seed begins its germination by the imbibition of water, provided the conditions, chiefly of moisture, temperature and aeration, are suitable. When the seed coat is saturated, water is absorbed by the underlying structures both by imbibition and by osmosis, for the seed coat, although it may be impermeable to certain substances, ${ }^{*}$ is permeable to water. Considerable swelling commonly results so that the volume of the seed is much increased and in this swelling a relatively great force is exerted: Stephen Hales in his classical experiment found that the force exerted by swelling peas was sufficient to raise a weight of I 84 pounds. $\dagger$

The second phase in germination now begins, growth starts : but growth is impossible without food to supply the wherewithal for new structures and to make good the waste, for vital activity requires energy which is obtained by various catabolic processes. Thus aerobic respiration, the ordinary oxidative process of green plants, is a marked feature concurrent with growth and may be sufficiently intense to cause an obvious rise in temperature. The required food, chiefly fats, carbohydrates and proteins, are stored in the embryo

* See Adrian Brown : "Ann. Bot.," r907, 21, 790; “ Proc. Roy. Soc.," B, r9o9, 81, 82. Collins: “Ann. Bot.," r9r8, 32, 38г. Wolfe: "Bot. Gaz.," I926, 82, 89. Kotowski: " Plant Physiol.," I927, 2, I 77.

† Hales: "Vegetable Staticks," 3rd Edition, London, I738, p. I02.

VOL. II. - I 
itself or in special tissues, endosperm and perisperm: and since the food is stored in a form mostly insoluble and nonassimilable, water is the first essential and appropriate enzymes the second, for not before it is hydrolized can food be translocated from its storage cells and passed by osmotic processes to the active tissues. The enzymes may be elaborated in the cells or tissues containing the food, or may be secreted by specialized structures, the scutellum for example. Often the products of hydrolysis may be recognized by simple means, sugar for instance, in germinating barley: but sometimes their assinilation may be so rapid that identification is difficult; indeed, on occasion their presence can only be inferred from the results of carefully controlled test-tube experiments, glycerol, for example, in germinating Ricinus. The embryo thus presented with appropriate food, grows and develops. Growth is in some degree an understandable problem which, on the present elementary occasion, can be sufficiently indicated in a few words. Of necessity must a cell be nourished through its surface and growth will take place if assimilation be greater than waste by oxidative and kindred processes. But growth means increase, and as this increase in bulk takes place the surface area of the cell is proportionally lessened. A stage ultimately will be reached when the area of the surface is so limited in proportion to the volume of the cell as to permit the entry of only sufficient food to make good the losses; thus the surface area is a limiting factor. One of three things now is possible: the cell may remain as it is, a permanent tissue element; it may develop further, using up its own contents either entirely or in part in fitting itself for another function, water transport, for instance; or it may divide and by so doing increase its surface area in relation to its volume, in which event the cycle may restart. Growth thus can be interpreted in terms of pliysical chemistry : the first possibility mentioned hardly requires contemplation, since nothing is easicr to do than nothing. The third proposition is less casy to understand; the second is a mystery. Thus, why should the daughter of a merismatic cell develop into a phløem element if it be cut off on the one side of its 
parent and into a xylem element if it be born on the other? Is it due to some subtle influence or stimulus which has its origin in the adjacent structural elements; or is it due to some quality in the cell itself, an heredital predetermination.

To these questions there are no real answers; the facts must be accepted, their explanation must be left to the future.

The embryo grows and develops into the autotrophic organism of a form and structure determined by its conditions of life and by its ancestry and exhibiting those actions and reactions commonly associated with the higher plants. The shoots and roots circumnutate and respond to various stimuli, gravity and light being the most obvious. Circumnutative and other autonomous movements may be explained by such conceptions as rectipetality and associated engrams; whilst in explanation of tropisms various mechanistic hypotheses have been formulated; some chemical, the hormone theory of gravitational stimulus of roots, for instance ; others physical, the statolith theory, for example.

The highly organized root system by means of its root hairs takes up raw material by osmosis in the form of water and its dissolved salts; in many plants, possibly in all, the osmotic strength of the cell sap of the root hairs is continuously adapted and is nicely adjusted to the osmotic strength of the soil water. From the root hairs water is passed on through the cortex to the water-conducting elements of the vascular cylinder, and thus supplies the shoot system. The shoot system, no less highly organized, is, in the first instance, concerned with the manufacture of food, carbohydrate, fat and protein. In this connection the leaf, a marvel of organization -with its chlorophyll apparatus supported by the network of veins which also are the conduits for the conveyance of fluid raw materials and for the elaborated products, and with its mechanism for the regulation of gaseous interchange-is the great synthetic factory, building up food apparently with the greatest ease and certainly with remarkable rapidity.

In due season reproduction takes place. Of the problems here involved the secretion of nectar, when it obtains; the 
facts of fertilization and the stimuli which invoke the segmentation of the egg; the transmission of hereditary characters; the reconstruction of the food destined for the use of the offspring ; and the mechanisms of dispersal, are of fundamental importance.

Of the various aspects of the life of a higher plant outlined in the foregoing fleeting account, it is appropriate on the present occasion to consider those associated with metabolism, the making of food and the procurement of energy.

But before beginning this, it is not altogether out of place to draw attention to ccrtain features which, although obvious, are sometimes overlooked. The investigation of the metabolic processes of plants is pursued by growing the plant in controlled conditions and measuring the effect of a selected factor by varying that factor only. A positive result will be the resultant of the combined action of the factors concerned, and although it may be of the greatest value, it, obviously, can give no information of what happened in the living cells. To ascertain this, other methods, chiefly chemical and physico-chemical, are used: attempts may be made to bring about in the test tube processes which occur in the plant, or analyses may be periodically made of the contents of the tissues where metabolic activity is taking place in order to find the sequence of the chemical change. The former method is of value in giving information of the chemical possibilities and has led to great advances in knowledge ; but it does not follow that because this or that can be accomplished in vitro, the same events happen in vivo, for the conditions obtaining in the active living cell would appear to be of infinite complexity; metabolic activities, both catabolic and anabolic, oxidative and reductive, taking place concurrently, and thus various actions, reactions and digressions may occur which never happen in the relatively simple conditions obtaining in the test tube.

The second method, that of analyses of cell contents, has yielded valuable information about final products, but so far has thrown but little light on the sequence in chemical change since the intermediate phases may be transitory in the plant, 
or, being highly reactive, may undergo change during the process of extraction.

Often the presumed rôle of a compound can only be established after it has been isolated from the organism and its behaviour studied in conditions which never occur in the plant. There is sometimes a tendency to discard such evidence as having no bearing on physiological processes; this is not necessarily sound judgment, for a change which can take place in the unnatural conditions of the test tube may be effected with ease in the living cell.

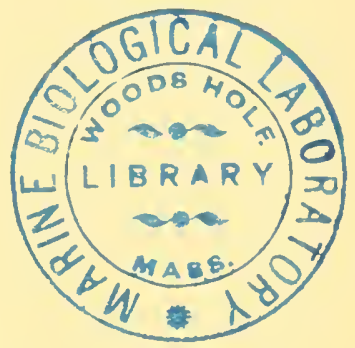




\section{CHAPTER II.}

\section{THE SYNTHESIS OF CARBOHYDRATES.}

THE term carbon assimilation, although unfortunate from some points of view, is employed to designate all those activities, in part physical, in part chemical, which play a part in the anabolism of carbon dioxide by green tissues. The conspicuous facts of the process are that active chlorenchyma on exposure to light forms, by means of its chlorophyll, carbohydrate from the initial substances carbon dioxide and water; oxygen, in volume roughly equivalent to the volume of carbon dioxide consumed, is evolved during the process.* Carbohydrate is the obvious and chief end product, but protein also may be so formed, and such diverse materials as fat, tannin and various organic acids have been considered, probably on insufficient evidence, to be of direct photosynthetic origin. The earlier phases in these synthetic processes are photochemical, a mutation of radiant into chemical energy, and it is during this phase that the oxygen, a waste product, is evolved. The presence of oxygen in the air-space system of the active chlorenchyma may thus be considerably greater than in normal air, and since this gas is continually excreted during the process, it is not surprising to find that the quan. tity of oxygen in the surrounding atmosphere is immaterial to the process and that it may be decreased to 2 per cent. or

* Bonnier and Mangin (" Ann. Sci. Nat. Bot.," ISS6, 3, I) found by various experimental methods that the ratio $\mathrm{O}_{2} / \mathrm{CO}_{2}$ was always greater than unity for ordinary plants; the lilac gave the smallest value, I.05, and the holly the largest, I.24. A similar range was found by Aubert ("Rev. gén. Bot.," I $892,4,203$ ) to obtain in ordinary plants, but succulents, which have a peculiar metabolism, gave generally a higher value, as high as 7.59 in Opuntia tomentosa. Maquenne and Demoussy ("Compt. rend.," 1913, 156, 506) conclude from a large number of observations that the assimilatory quotient approximates to unity. 
increased to 50 per cent. without adverse effect, ${ }^{*}$ and, according to Harvey, $\dagger$ many species of marine algae growing in a medium entirely free from oxygen, but not from carbon dioxide, evolve oxygen on illumination. But since the formation of chlorophyll is dependent upon the presence of oxygen, the prolonged maintenance of a low oxygen pressure will inhibit the development of more chlorophyll and this will in turn react on carbon assimilation.

Carbon assimilation is conditioned by various factors; wherefore the rate of the process will vary considerably according to the inter-relationships of these factors. For this reason it is hardly remarkable to find that different values of the rate of carbon assimilation have been reported by different investigators: differences in value due not only to inappreciation of the conditioning factors, but also to different avenues of attack. To consider a few examples: different values may be expected in leaves of the same plant but of different ages, and also in sun and shade leaves owing, presumably, to their structural differences. Further, carbon assimilation and respiration proceed side by side and are antagonistic with respect to oxygen and carbon dioxide; wherefore to find the true assimilation, the respiration must be ascertained; owing to the normal variation of daylight, a balance between these two processes must be of common occurrence, when, owing to the low light intensity, the rate of evolution of oxygen during photosynthesis is so slow that it is used up in respiration as quickly as it is formed. $\neq$ Finally, different methods of experiment in all probability will give different values for one and the sanie subject.

*Friedel : “U.S. Dept. Agric.," rgor, Bull. 28.

† Harvey : "Plant Physiol.," r $928,3,85$.

+ This light intensity is known as the compensation point and differs in different plants and in the same plant grown in different conditions; also it would appear to be lower in shade plants as the following values, taken from amongst those given by Boysen-Jensen, indicate ("Bot, Tidsk.," rgr8, 36, 219. See also Plaetzer : "Verhand phys. med. Ges.," Würzburg, I91 7, 45, 31; and Harder: "Ber, deut. bot. Ges.," I 923, 4l, 194).

Sinapis alba, a sun plant. - r.o Bunsen units $\times$ roo

Sambucus nigra, sun leaves shade leaves

Oxalis acetosella, a shade plant

$\begin{array}{ll}.0 .7 & \text { ", } \\ .0 .3 & \text { ", } \\ .0 .2 & \text { ", }\end{array}$


The accompanying table gives a selection of values of the rate of carbon assimilation in the open air of detached leaves of the sunflower, Helianthus anmuus, cxpressed in terms of grams of increase in dry weight per square decimeter per hour, obtained by the authorities named :-

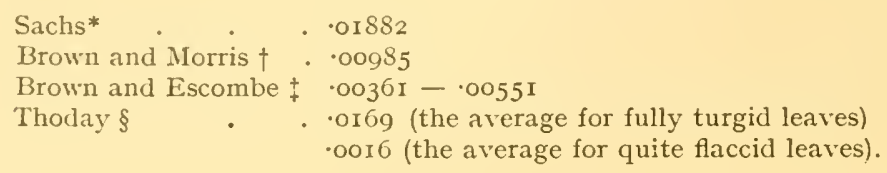

The figures of Sachs and of Thoday were obtained by the dircct determination of the increase in dry weight, whilst the others were calculated from the amount of carbon dioxide absorbed and assuming that carbohydrate only was ultimately formed. Since the ultimate fate of the carbon dioxide is not entirely known, the extent to which it is directly used in the elaboration of fat or protein for example, the dry weight method would appear to give the most accurate results.|l

\section{THE FACTORS.}

It is obvious that little or no profit will accrue from the contemplation of the above figures unless they be correlated with the factors which determine and control the process.

These factors are both external and internal : the external factors are amenable to experimental control whilst the internal are much more evasive and thus are less understood. Of the external factors, the supply of raw materials, the degree of temperature and the intensity and quality of the illumination are the most conspicuous; of the internal factors, the clilorophyll apparatus and the products of carbon assimilation are the least clusive.

The doctrine of limiting factors, now well known, is due

* Sachs: “Arbeit. Bot. Inst.," Würzburg, I 884, 3, 19.

$\dagger$ Brown and Morris: " Journ. Chem. Soc.," I $893,63,604$.

† Brown and IEscombe: "Proc. Roy. Soc,", B, 1905, 76, 29.

\$ Thoday: id., 1910, 82, 421 .

If lior a critical review of Sachs's and Brown and Escombe's methods, see Thoday : "I'roc. Roy. Soc.," B, 1909, 82, I. 
to F. F. Blackman * who enunciated the axiom that when a process is conditioned as to its rapidity by a number of separate factors, the rate of the process is limited by that of the slowest factor. The limiting factor in any definite instance may be identified by the experimental application of the principle that "when the magnitude of a function is limited by one of a set of possible factors, increase of that factor, and of that one alone, will be found to bring about an increase of the function." †

The principle may be illustrated by one of Matthæi's many experiments on the effect of temperature on carbon assimilation in conditions constant except for tempcrature and illumination. In Prunus laurocerasus there was a gradual increase in the assimilation as the temperature was raised; at about $\mathrm{II}^{\circ} \mathrm{C}$. a maximal assimilation of $22 \mathrm{mg}$. of carbon dioxide per 50 square $\mathrm{cm}$. per hour obtained and was not increased even by raising the temperature to $25^{\circ} \mathrm{C}$. By doubling the light intensity, however, the maximal assimilation was equivalent to $37.5 \mathrm{mg}$. of carbon dioxide per 50 square $\mathrm{cm}$. per hour and again there was no increase on raising the temperature. This means that light intensity was a limiting factor and only by its increase could a greater carbon assimilation be obtained. In his original illustration of the principle of limiting factors, Blackman graphically represented the reaction as linear up to the point of limitation and then abruptly horizontal ; and it is this abruptness in the course of the graph which has led to some controversy and has resulted in an accretion of knowledge. But before dealing with this, it must be pointed out that the graph originally presented was an illustration of a principle, not necessarily a precise representation of a reaction: "It is not claimed that a limiting factor curve always adheres rigidly to a typical form with a sharp angle at the point of change of the limiting factor. It

* Blackman : "Ann. Bot.," I905, 19, 28I.

† Blackman and Smith: "Proc. Roy. Soc.", B, I9I I , 83, 389.

+ Matthæi : "Phil. Trans. Roy. Soc.," B, 1904, 197, 47. For the application of the principle to the growth of field crops see Balls and Holton : "Phil. Trans. Roy. Soc.," B, I915, 206, I03, fo3; and Balls: id., I917, 208, I 57 . 
is conceivable, and is indeed probable, that when two factors are close to the limiting value a change in the one not limiting may have some appreciable effect in assimilation. This will show itself about the inflexion of the curve where the limiting factor is changing. For example, when carbon dioxide is limiting, increase of temperature may cause a small increase of assimilation by increasing the rate of diffusion of the carbon dioxide. But all minor details like these apart, the hypothesis of limiting factors ests broadly on the possibility by its means of interpreting simply and logically the greatest number of known facts about the rate of carbon assimilation." *

Boysen-Jensen $\dagger$ studied the carbon assimilation of light and sliade plants: on plotting the rate of photosynthesis in unit time for unit area against light intensity, he found that the graph approximates to a logarithmic curve; at first, when light is limiting, the course is more or less linear; at last, when a factor other than light, temperature or carbon dioxide for example, is limiting the course is again linear and more or less parallel to the abscissa axis. Between these extremes the curve is continuous and not abrupt since it is the resultant, not of a single factor, but of two or more which come into play when their intensity is more or less equivalent to that of the original limiting factor. Harder $\ddagger$ investigated the problem, using, for the most part, the aquatic moss Fontinalis antipyretica which can be continually used in a series of experiments so that the ill-defined factor of variation in material, inevitable when detached leaves are used, is avoided. Using the three factors, light intensity, carbon dioxide supply, and temperature, he found that when two factors were kept constant and the third varied, the curve obtained was approximately logarithmic. Further, he varied light intensity and carbon dioxide supply, using potassium hydrogen carbonate for its source. The following table sets forth some of his results:-

* Smith: “Ann. Bot.," I919, 33, 535. See also Maskell: "Proc.

Roy. Soc.," B, 1928, 102, $48 S$.

† Boysen-Jensen : "Bot. Tidsk.," I918, 36, 219.

† Harler: "Jahrb. wiss. Bot.," I 921 , 60, 531 . 


\begin{tabular}{|c|c|c|c|c|c|c|}
\hline \multirow{2}{*}{$\begin{array}{l}\text { Per Cent. of } \\
\mathrm{KHCO}_{3} \text {. }\end{array}$} & \multicolumn{6}{|c|}{ Light Intensity in Metre Candles. } \\
\hline & 167 & 667 & 2000 & 6000 & 18,000 & 36,000 \\
\hline $0 \cdot 0 I$ & 0.12 & $0.4 \mathrm{I}$ & 0.75 & 0.90 & $I \cdot 06$ & $\mathrm{I} \cdot 07$ \\
\hline 0.04 & 0.26 & $0.9 I$ & $2 \cdot 24$ & $3 \cdot 45$ & $4 \cdot 70$ & - \\
\hline 0.16 & $\cdots$ & $I \cdot 10$ & $3 \cdot 45$ & $6 \cdot 40$ & II 35 & - \\
\hline $0 \cdot 32$ & 一 & $I \cdot 23$ & $4 \cdot 70$ & $8 \cdot 60$ & $15 \cdot 20$ & $16 \cdot 64$ \\
\hline
\end{tabular}

It will be seen that the intensity of carbon assimilation increases both in the vertical and the horizontal directions, i.e. with increase in carbon dioxide and with increase in illumination. Harder concludes that a single factor appears to be limiting only when it is very much weaker than the other factors. Its action is not directly proportional at all concentrations or intensities of the other factors, thus the higher the light intensity, the greater is the augmenting effect of an increase in the concentration of carbon dioxide. That is, both of these factors become interlocked and play a part, so that the rate of carbon assimilation is dependent on the concentration of carbon dioxide as well as the intensity of illumination.

Lundegårdh * found that shade plants such as Oxalis acetosella growing in an atmosphere containing the normal amount of carbon dioxide and in varying intensities of illumination gave a curve of the abrupt type, for in light above one-tenth of full sunlight no increase in photosynthesis was observed unless the amount of carbon dioxide were increased. Sun plants such as Nasturtium palustre, on the other hand, behaved differently: with low light intensities photosynthesis was proportional to the illumination, but with increasing light, photosynthesis was slower than the increase in carbon dioxide concentration; that is, a proportional relationship no longer obtained. And in an atmosphere relatively rich in carbon dioxide, carbon assimilation was observed even in light of an intensity one-fortieth that of direct sunlight. In such instances, the curves are of the logarithmic type and 
Lundegårdh agrees with Harder that the factors of light intensity and carbon dioxide concentration, when above the normal pressure of the natural atmosphere, mutually influence one another. A like difference between sun and shade leaves has been observed by Stålfelt * in the gymnosperms Picea excelsa and Pinus sylvestris; he found that the intensity of photosynthesis was greater in shade leaves than in sun leaves at the same light intensity as is shown by the following table in which the light intensity is in percentages of open daylight and the photosynthesis is in mgs. of carbon dioxide assimilated per hour per gram of fresh weight.

\begin{tabular}{|c|c|c|c|c|}
\hline \multirow{3}{*}{ I.ight. } & \multicolumn{4}{|c|}{ Carbon Assimilation. } \\
\hline & \multicolumn{2}{|c|}{ Picea excelsa. } & \multicolumn{2}{|c|}{ Pinus sylvestris. } \\
\hline & Sun Leaves. & Shade Leaves. & Sun Leaves. & Shade Leaves. \\
\hline I0 & .07 & $\cdot 47$ & 40 & $\cdot 72$ \\
\hline 20 & $\cdot 34$ & $\cdot 93$ & .89 & $I \cdot 25$ \\
\hline 30 & $\cdot 5^{8}$ & $I \cdot 24$ & $I \cdot 24$ & $I \cdot 62$ \\
\hline 40 & $\cdot 78$ & $I \cdot 47$ & $I \cdot 54$ & $I \cdot 9 I$ \\
\hline 50 & $\cdot 95$ & $I \cdot 64$ & $1 \cdot 80$ & $2 \cdot 15$ \\
\hline 60 & $I \cdot I O$ & $I \cdot 78$ & $2 \cdot 02$ & $2 \cdot 35$ \\
\hline 70 & $I \cdot 23$ & $I \cdot 89$ & - & $2 \cdot 53$ \\
\hline 80 & $\mathrm{I} \cdot 33$ & $\mathrm{I} \cdot 97$ & $\cdots$ & $2 \cdot 69$ \\
\hline 90 & $I \cdot 42$ & $2 \cdot 00$ & - & $2 \cdot 8 \mathrm{I}$ \\
\hline
\end{tabular}

The difference in the behaviour of sun and shade leaves presumably is due to the fact that the ground shade flora is, from the character of its habitat, surrounded by an atmosphere richer in carbon dioxide than the upper air and the air of more open situations ; also shade leaves are characterized by a more delicate structure, wherefore impediments to a rapid interchange between the internal atniosphere of the leaf and that of the surrounding air are to a greater or lesser extent removed. This structural factor is of importance, possibly of great importance, in the carbon assinilation of the higher plants, whercfore comparisons of the photosynthetic ability of the leaves of different plants or of the same plant grown in

\footnotetext{
* Stilfelt: “Medd. Stat. Skogsförsölisanst," I 92 I, 2I, 22 I.
} 
different conditions may have no real significance. This was recognized by Warburg * who used in his experiments Chlorella, a green alga of the simplest possible morphology, the sphere. With respect to the factors light intensity and concentration of carbon dioxide, he found that when carbon dioxide was in small amount, the intensity of carbon assimilation was in proportion to this amount; that is, carbon dioxide was a limiting factor. But when the amount of carbon dioxide was progressively increased, the photosynthesis did not correspondingly increase and the curve became logarithmic. Warburg's conclusion is that the intensity of photosynthesis is proportional to the concentration of carbon dioxide and to the concentration of a second substance which enters into combination with it; that is, the intensity of photosynthesis is governed by the rate of a chemical reaction. It will be obvious that the diffusion factor in his experiments is reduced to a minimum.

The balance of evidence relating to the interaction of the light intensity and carbon dioxide concentration factors favours the view that a factor is strictly limiting only when it is very weak, or " in minimum," to use Harder's terminology ; when, however, their intensity or concentration more nearly approach one another, an increase in either will result in an increased photosynthesis; that is, the reaction intensity is controlled by both factors. This relates only to the two factors mentioned; to what extent it applies to combinations of other related factors is uncertain. It is not improbable that the complete process of carbon assimilation consists of separate phases, $\uparrow$ the most obvious of which are diffusion, photochemical, and chemical which is independent of light. The intensity of each phase is conditioned by a set of factors which may be peculiar to itself, thus light is effective in the photochemical but not in the chemical, in which stage temperature is highly important. Further, the intensity of one phase may be governed by the intensity of another, thus the accumulation of sugar in the leaves of the beet may effect a

* Warburg: " Biochem. Zeit.," I919, 100, 230.

† See Briggs: "Proc. Roy. Soc.," B, I920, 91, 249. 
cessation of the process at about noon on a bright day notwithstanding the fact that the conditions for photosynthesis apparently are most favourable.

The importance of the conditioning factors is obvious, and it is clear that the significance of any one cannot be evaluated without reference to others.

\section{EXTERNAL FACTORS.}

THE RAW MATERIALS.

Water and carbon dioxide are the requisite raw materials for carbon assimilation.

WATER. - Water is essential not only as such for the fabrication of food, but also to keep the leaf tissues in a condition mechanically fit for the processes to take place. With regard to the water supply, the transpiration current is the immediate source; it is, however, not convenient on the present occasion to consider the problems presented by this phenomenon.

Thoday found that the rate of carbon assimilation lessened as the leaves of Helianthus anmus lost their turgidity; in an extreme instance, when the leaves were very flaccid, the stomates were all but closed and the increase in dry weight was very small indeed. Some determinations by Thoday of the average increase in dry weight of leaves in different conditions of turgidity have been mentioned. If cells become plasmolysed, constructive activities must cease; if in such cells the turgid condition be not recovered, death supervenes.

Iljin * has obtained results similar to those of Thoday, and his work stresses the indirect action of water, for the loss of water from the leaf results in the closure of the stomates, wherefore the supply of carbon dioxide is diminished and thus the rate of carbon assimilation is depressed. If the loss of water is temporary and not too great, the guard cells regain their turgidity and the stomates open ; but if the loss of water has been excessive, recovery may not take place and the guard cells dic, wherefore the efficiency of the leaf suffers. In such conditions, Iljin considers that the injury to the guard cells

*Iljin: "Jahrb. wiss. Bot.," I922, 61, 670 ; "Flora," I923, 16, 360. 
is caused by the increase in the concentration of the cell sap : a sufficiency of water favours the hydrolysis of starch to sugar, which is, presumably, the active osmotic substance of the guard cells; on the other hand, a defieiency of water, up to a certain point, favours the formation of starch, but if this point be passed, there is an excessive concentration of the cell sap which inactivates the enzyme responsible for the change, which inactivation is not reversible, thus a recovery to the normal conditions is prevented and the guard cells no longer function. It was further observed that in starch-free guard cells, severe desiccation resulted in the disappearance of the sugar, presumably owing to the increased rate of respiration which obtains in these circumstances. Dastur * also finds that the decline in the photosynthetic activity of leaves is due to the shortage of the water supply, the inadequacy of which eventually terminates this particular activity of the leaf. The cessation of photosynthesis is, however, not abrupt; the marginal and intervascular regions are the first to feel the drought and from these regions the ending of photosynthesis spreads towards the centre and the main veins of the leaf. This shortage of water is due to two causes: the increase of the leaf area creates an increased demand for water owing to the increase in photosynthesis and transpiration, but the specific conductivity of the wood $\uparrow$ remains unchanged after the tracheæ have attained their permanent form, hence the increased demand is not satisfied; secondly, as more leaves unfold, the pull exerted by the living cells of the upper leaves on the water of the conducting columns increases whilst the pull exerted by the older leaves remain the same, hence there is a deficient supply to the older leaves.

There is, in fact, a distinct correlation between the decrease in the rate of assimilation and the fall in water content per unit of leaf area, and if the two values for a set of leaves are plotted, the points lie very nearly on a straight line. This is shown by the following observations on Abutilon Darwini made in carefully controlled experiments :-

* Dastur: “Ann. Bot.," 1 924, 38, 779 ; 1925, 39, 769.

† See Farmer: "Proc. Roy. Soc.," B, 1919, 90, $218,232$. 
Water Content per $100 \mathrm{sq}$. $\mathrm{cm}$. of Leaf Area in gms.

$$
\begin{aligned}
& I \cdot 0+3 \\
& I \cdot 053 \\
& I \cdot 058 \\
& I \cdot I I 0 \\
& I \cdot I 22
\end{aligned}
$$

\begin{tabular}{|c|c|}
\hline & $\begin{array}{l}\text { Assimilation per } \\
\mathrm{sq} . \mathrm{cm} \text {. of Leaf } \\
\text { in } \mathrm{gms} \text {. of } \mathrm{CO}_{2} \text {. }\end{array}$ \\
\hline & •OOOI 8 \\
\hline & .00034 \\
\hline & .00043 \\
\hline & .00130 \\
\hline & .0OI 55 \\
\hline
\end{tabular}

Further, leaves with a lower water content, e.g. Abutilon Darwini, have a greater rate of assimilation per unit area than those of species with a higher water content, e.g. Sparmannia africana and Cineraria stellata. Also it was found that the ratios between the decrease in carbon assimilation and the decrease in the water content for different plants is not the same; in other words, there is a specificity in this relationship.

Carbon Dioxide.- In normal conditions, the carbon dioxide for carbon assimilation is derived from the atmos. phere and to a lesser extent from the products of respiration.* The amount of respiratory carbon dioxide is conditioned mainly by the temperature and may be equal to half the possible inflow from the atmosphere at the higher temperatures possible in laboratory experiments. The entry of atmospheric carbon dioxide into the plant is either through the intact epidermis, as in those plants which like certain aquatics lack stomates, or mainly through the stomates and, to a much lesser and negligible extent, provided the amount of carbon dioxide is not unduly increased, through the unbroken epidermis. This cuticular path of gaseous interchange once was thought to be the main route, but the work of F. F. Blackman $\uparrow$ and of Brown and Escombe $\ddagger$ has shown that the stomates are the important paths. F. F. Blackman found by direct measurement that the degree of gaseous interchange was proportionate to the

* In abnormal conditions it appears that plants can make use of carbon dioxide from the soil. Pollacci " Atti. Inst. Bot. Univ. Pavia," I9I7, I7, 30) found that plants grown in soil rich in humus or in water culture enriched with carbon dioxide could form starch and increase in dry weight notwithstanding the fact that their aerial parts were in an atmosphere freed from carbon dioxide. The assimilation, however, was not sufficient for normal growth.

† Blackman: "Phil. Trans. Roy. Soc.," B, 1895, I86, 485, 503.

$\ddagger$ Brown and Escombe: $i d ., 1900,193,223$. 
distribution of the stomates, results which Brown and Escombe confirmed in respect to plants with stomates on but one surface of the leaf, but in plants in which stomates occur on both surfaces of the leaf, they found that in bright sunlight the intake of carbon dioxide into the upper surface is greater than would be expected from the ratio of distribution of the stomates on the two sides; in light of a lesser intensity, however, there is a closer, but not very close, correspondence between the intake of carbon dioxide and the proportional distribution of the stomates. It is suggested $*$ that the greater infusion found to obtain into the upper side of amphistomatous leaves may be accounted for in that partial opening of the stomates is likely when the incidence of illumination is on that side, and that since the palisade parenchyma is the more active part of the mesophyll, there will be a steeper diffusion gradient in the upper side which will promote a more rapid flow of carbon dioxide through the stomates of the upper surface.

The movements of the carbon dioxide are in accordance with the laws of gaseous diffusion; the pressure of carbon dioxide in the active chlorenchyma will be very low, whilst in the atmosphere surrounding the leaf it will correspond to, say, three parts in 10,000 . Thus there are set up diffusion currents the gradients of which vary according to the conditions, rate of use and degree of atmospheric motion. The problem of interchange between the gases contained in the leaf and in the surrounding atmosphere is not, however, so simple as may appear from this statement. Brown and Escombe, experimenting with leaves of Catalpa bignonioides, found that the rate of absorption of carbon dioxide at normal temperature and pressure was about 0.07 c.c. per sq. cm. per hour; since the total area of the stomates was but 0.9 per cent. of the total leaf surface, it follows that carbon dioxide must pass through the openings at the rate of $7 \cdot 77$ c.c. per sq. cm. per hour, an amount so considerable when regard is had to the stomatal area and to the fact that this rate of absorption is about fifty times greater than the absorption of atmospheric carbon dioxide by a normal solution of caustic potash, that it

* Brown and Escombe: "Proc. Roy. Soc.," B, 1905, 76, 29.

VOL, II. -2 
is hardly surprising that earlier physiologists laid much stress on cuticular gaseous interchange.

The conditions obtaining in an active green leaf are briefly these: the active chlorenchyma is absorbing carbon dioxide, which must enter the cell in a state of solution from the airspace systen on which it abuts; hence the pressure of carbon dioxide in the immediate neighbourhood of these surfaces of absorption will have a very low value, possibly approximating to zero under ideal conditions. Diffusion currents are thus set up owing to a falling in the partial pressure of carbon dioxide from the "respiratory chamber" of the stomatal apparatus to the chlorenchyma. Renewal of carbon dioxide is from the external air through the pore of the stomate, a cylinder of a certain length and, in the simplest cases, of approximately uniform diameter when the guard cells are fully turgid. Clearly various tensions of carbon dioxide occur: the maximum in the atmosphere, theoretically at an infinite distance from the leaf but practically at a distance equivalent to five or six times the diameter of the stomate, and the minimum at the absorbing surfaces of chlorenchyma; thus a gradient of density of carbon dioxide is formed so that a drift of this gas from the outer atmosphere to the chlorenchyma obtains. The path followed by the carbon dioxide is obstructed by the stomates and may be divided into three sections: from the remote atmosphere where the pressure of carbon dioxicle is greatest, $\rho$, to the outer opening of the stomate; through the shaft of the stomate when the pressure of carbon dioxide is less, $\rho^{\prime}$; and from the inner opening of the stomatal shaft to the surfaces of absorption where the pressure of carbon dioxide is, ideally, zero. The interposition of the stomata exercises a profound influence on this diffusion. Brown and Escombe * demonstrated that the rate of diffusion through such an absorbing disc as is represented by a stomate is proportional to the diameter of the opening; $\dagger$ they visualize zones of equal density above the

* Loc. cit.

† Larmor's Law of Diameters:- $Q=2 k_{p} \mathrm{D}$ where $\mathrm{Q}=$ amount of $\mathrm{CO}_{2}$ absorbed in a given time; $k=$ coefficient of $\mathrm{CO}_{2}$ in air ; $\rho=$ density of atmospheric $\mathrm{CO}_{2}$ at a point far removed from the absorbing disc ; $D=$ diameter of disc. 
stomate varying from the atmospheric density, $\rho$, to a lower density, $\rho^{\prime}$, at the stomate cut perpendicularly by the lines of flow of carbon dioxide converging to the opening of the stomate * (Fig. I). Thus it is that the increased flow of gas through the stomate is possible.

The second section in the route of the carbon dioxide is through the tube formed by the guard cells. Through this tube the flow is inversely proportional to the length of the tube, but the system of external shells increases the resistance to the flow (Fig. 2). Finally, in the third section the tube opens into the air-space system of the mesophyll bounded by the absorbing surfaces of the chlorenchyma; here the con-

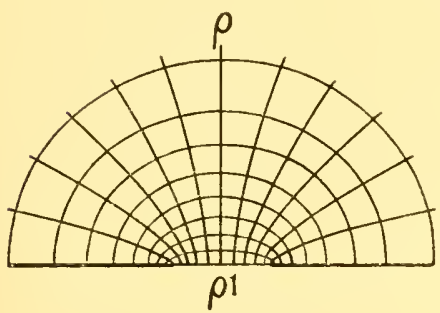

EIG. I.

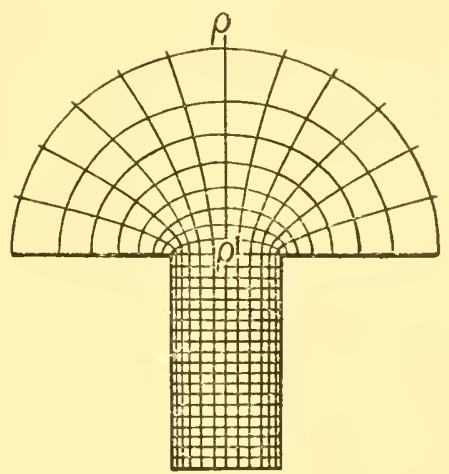

FIG. 2.

verse of the first part of the path obtains, diffusion shells over the lower opening of the stomate, where the density of the carbon dioxide is $\rho^{\prime}$, being formed (Fig. 3). Thus in the whole system there is a gradient of density from $\rho$ to, say, $o$, with a set of shells at both ends of the stomatal tube (Fig. 4).

The obstruction to gaseous diffusion inseparable from a multiperforate septum such as the stomatal epidermis of a leaf, varies according to the distance apart of the perforations: if they are placed at distances roughly equal to ten times the diameter of a perforation, each will act independently without interference by its neighbours and conform to the law of diameters. When situated more closely together, it was found

$$
* Q=2 k\left(\rho+\rho^{\prime}\right) \mathrm{D} \text {. }
$$


that the obstacle to diffusion was much less than the actual obstruction of area by the solid portions of the septum. To quote concrete examples, Brown and Escombe calculated that in Helianthus the leaves could absorb 2.578 c.c. of carbon dioxide per sq. $\mathrm{cm}$. per hour in moving air and 2.095 c.c. per sq. cm. per hour in still air, assuming that the stomates are circular in shape. By actual measurement it was found that in this same plant* in diffused light at a temperature of $19^{\circ} \mathrm{C}$,

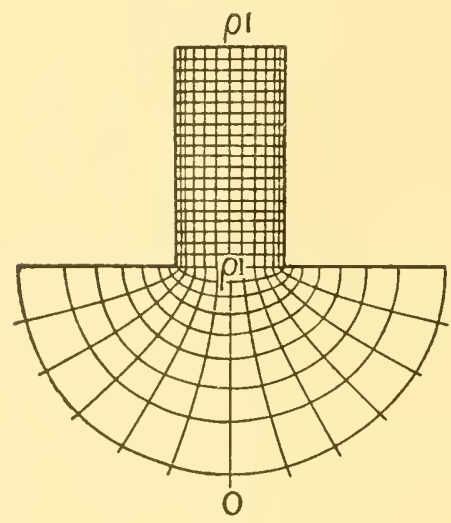

FIG. 3.

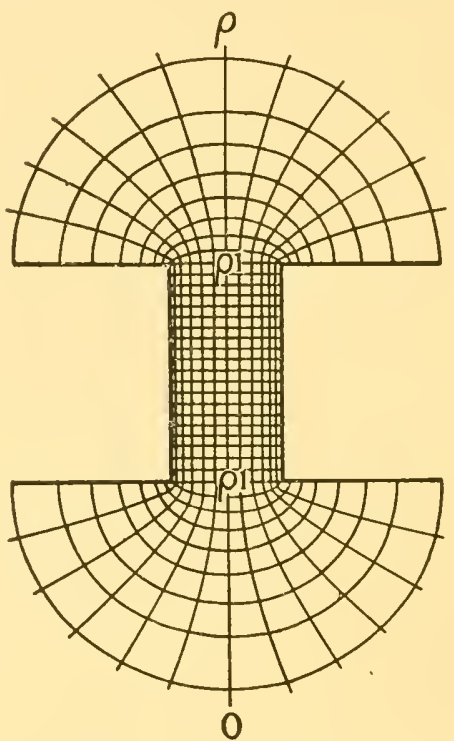

FIG. 4 .

0.434 c.c. of carbon dioxide per sq. cm. per hour was absorbed, an amount much less than the capacity of the stomates to supply. Some of Brown and Escombe's conclusions have been criticized by Jeffreys $\uparrow$ who has made a mathematical study of evaporation, the problems of which are much the same as those of gaseous diffusion. He points out that further investigation is required and remarks that "it is not obvious that the surrounding stomata will not interfere with the action of any individual to an important extent, and a wind blowing

* Brown and Escombe: "Proc. Roy. Soc.," B, I905, 76, 29.

† Jeffreys: "I'hil. Mag.," I9I8, 35, 270. 
over the surface, though unimportant for a single stoma, may be important when there are thousands spread over a considerable area." If there is no interference between the density shells of stomata ten diameters or more apart, so that each stomate acts independently according to the law of diameters, an impossible situation results. Thus if there are more than 600 stomata per sq. cm. of leaf surface, the rate of evaporation from them, which is the same thing as carbon dioxide diffusion, would be greater than that from the whole leaf surface, whereforc it nust be concluded that gaseous diffusion must be greatly impeded by the presence of other stomata. It is not until stomata contract to one-fiftieth of their original diameters, that the rate of evaporation, or gaseous diffusion, will be practically independent of the diameter. When the air is in motion and the stomata are fully open, their total evaporation, or absorption of carbon dioxide, does not differ much from the evaporation, or absorption, from an area equal to the leaf surface; * it is only when the number of stomates per unit area is small, that each may act independently, and the law of diameters obtain.

The conditions of humidity of atmosphere, temperature and illumination, which affect the size of the stomates, obviously will affect the infusion rate of carbon dioxide. $t$ In addition to these movements, traceable to definite external causes, there is sometimes-the leaf of the cherry laurel, for instance-a diurnal rhythm of stomatal opening even when the leaf is grown in controlled conditions and constantly illuminatcd. The result of this is that in a normal atmosphere, when the leaf is in constant light, there is a diurnal rhythm in the carbon assimilation, the rate of which falls to a very low value during the night and rises again next morning. This diurnal, and also seasonal, variation in the assimilation rate runs parallel with the diurnal and seasonal rhythms of stomatal openings. It is only when the external atmosphere

*Cf. Renner: "Flora," I9I0, 100, 45 I.

† See Darwin: "Phil. Trans. Roy. Soc.," B, I898, 190, 531 ; I9I6,

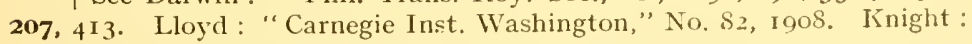
"Ann. Bot.," I916, 30, 57. 
is so enriched with carbon dioxide that light and not carbon dioxide is limiting the rate, that a regular rate of carbon assimilation is maintained for over twenty-four hours in a constant illumination. Maskell, ${ }^{*}$ to whom these observations are due, suggests that the apparent rate of carbon assimilation, when carbon dioxide is limiting, is determined by the external carbon dioxide concentration and a series of resistances which comprise the stomatal resistance to diffusion, the resistance in the intercellular space system and in the liquid diffusion path from the cell surface to the surface of the chloroplast together with the resistances associated with the photochemical and dark phases of the actual process.

In natural conditions carbon assimilation is limited by the low pressure of carbon dioxide in the atmosphere, the high values obtained in experiments in conditions involving an increased supply of the gas never being attained.

In experimental work with land plants a limit is set to the increase of carbon dioxide supply by the narcotic effect of the gas when in excess, $\uparrow 25$ per cent. generally will inhibit growth ; aquatic plants, on the other hand, are able to withstand a relatively high concentration. Blackman and Smith $\ddagger$ found that Fontinalis and Elodea in water, with a carbon dioxide concentration of 33.92 and 35.82 per cent. of saturation, and under identical intensity of illumination and at temperatures of $23^{\circ} \mathrm{C}$. and $28^{\circ} \mathrm{C}$. respectively, assimilated 0223 and $\cdot 0249$ gram of carbon dioxide per hour per standard area of $\mathrm{I} 37$ sq. cm. Fontinalis is less efficient, for reasons not finally determined, than aquatic angiosperms such as Elodea, Potamogeton and Ceratophyllum in utilizing carbon dioxide. Blackman and Smith, experimenting with Elodea and Fontinalis in constant conditions of light and temperature and with a carbon dioxide supply ranging from 0025 to $\cdot 0540$ gram per IOO c.c. of water, found that the carbon assimilation increases steadily in proportion to the increase in the supply of carbon dioxicle. When the assimilation reaches about $\cdot 023$ gram of carbon dioxide

* Maskell : "Proc. Roy. Soc.," B, I928, 102, 467, 488.

$\dagger$ See Chapin : "Flora," I902, 9r, 348 .

† Blackinan and Smith : "Proc. Roy. Soc.," B, I9I J, 8.3, 389. 
per hour, however, there is no further increase with an augmented carbon dioxide supply unless the light intensity be increased. In other words, light intensity in this connection is a limiting factor.

In all such experiments with aquatic plants, it is to be remembered that the conditions are not precisely the same as for a subaerial plant, since the resistance to the diffusion of carbon dioxide to the chloroplast is much less in the aquatic habitat, being only the liquid diffusion phase of the land plant, i.e. the passage of carbon dioxide in solution from the solution in contact with the surface of the plant to the chlorophyll surface. Further, in normal conditions the amount of carbon dioxide dissolved in the water surrounding the assimilating plant depends on the rate of diffusion from the source of supply ; it is, in general terms, slow and is dependent on such factors as temperature, relative gaseous pressures, degree of agitation, and so on. The work of Blackman and Smith has been followed by others, Harder for instance, to whose observations allusion has already been made, some of whom used a bicarbonate solution as a source of carbon dioxide. The results obtained are not always comparable, and the question arises whether the carbon dioxide in the frec state only is assimilable by the plant and not $-\mathrm{HCO}_{3}$ ions and the undissociated fraction of such salts as sodium hydrogen carbonate. A comparison between the two types of solution has been made by James * working with Fontinalis antipyretica in controlled laboratory conditions. He found that a flow of 400 c.c. of sodium bicarbonate solution per hour resulted in a higher rate of carbon assimilation as compared with a solution of pure carbon dioxide of an equal partial pressure when no other factor was limiting; but with a flow of 600 c.c. of bicarbonate solution per hour and with a low intensity of light, and therefore a slow rate of carbon assimilation, the two solutions gave the same assimilation values. An increase in the light intensity resulted in the bicarbonate solution giving a greater rate of carbon assimilation as compared with the carbon dioxide solution. It thus appears that in bicarbonate solutions * James: "Proc. Roy. Soc.," B, I92S, 103, I. 
only the free carbon clioxide is available for carbon assimilation; such a solution when dilute-the range used by James varied between $\cdot 05$ to 0.4 per cent.--is suitable for experimental work. Stronger solutions are to be avoided owing to the injurious effect of the increased alkalinity.

The difficulties inseparable from critical investigations in the field are obvious: of recent work, that of McLean * on the carbon dioxide absorption of Cocos leaves in natural conditions may be mentioned. He found that the rate of absorption is at a maximum in the morning, a depression obtains at mid-day, followed by an increase in the afternoon and then a final decline towards sunset. Similar values were obtained for detached leaves, but the curve showed a single maximum at about noon instead of two maxima which normally obtain with attached leaves, for which difference there is no adequate explanation. Clearly some internal limiting factor is operating, possibly connected with the accumulation of the products of carbon assimilation (p. 49). It was also found that immature and old leaves absorbed carbon dioxide at a lesser rate than leaves of an intermediate age.

In view of the small amount of carbon dioxide in the normal atmosphere, it must not infrequently happen that the intensity of carbon assimilation is limited by this factor, wherefore, since the days of Kreusler, $\uparrow$ who was the first to consider this aspect, much work has been done both on the Continent and, more recently, in this country to increase the crop yield by the enrichment of the atmosphere by the addition of carbon dioxide supplied by artificial means. $f$ The results obtained are in some instances contradictory, presumably owing to the difficulty of control in field cultivation, and also in grecnhouse culture where it is difficult to maintain a constant increased pressure of carbon dioxide although temperature, humidity and soil conditions are amenable to regulation.

* McLean : “Ann. Bot.,” I920, 34, 367.

† Kreusler: "Landw. Jahrb.," I 885, I4, 9 I 3.

† Cerighelli : "Ann. Sci. Agron.," I $921,38,68$. Demoussy : " Compt. rend.," I903, 136, 325; 1904, 138, 291 ; 1904, 139, 883. Fischer: "Beih. deut. bot. Ges.," I927, 45, 331. Lundegärdh: "Der Kreislauf der Kohlensäure in der Natur," Jena, I924. Reinau : " Zeit. angew. Chem.," 1926, 16, 495. Reidel: "Chem. Zeit.," I921, 104, 829. 
In consequence of these divergent results, Bolus and Henderson * have undertaken a critical investigation of the subject in laboratory conditions, and in their preliminary communication they report that the enrichment of the air with carbon dioxide results in a large increase in the dry weight of plants of Cucumis sativa as compared with the plants grown in normal air, which increase is evident within two or three days from the beginning of the experiment. The following table summarizes their results :-

\begin{tabular}{|c|c|c|c|c|c|}
\hline \multirow{2}{*}{$\begin{array}{l}\text { Days in } \\
\mathrm{CO}_{2} \text {. }\end{array}$} & \multirow{2}{*}{$\begin{array}{l}\text { Mlean Day } \\
\text { Temp. }{ }^{\circ} \mathrm{C} \text {. }\end{array}$} & \multirow{2}{*}{$\begin{array}{l}\text { Mean Night } \\
\text { Temp. }{ }^{\circ} \mathrm{C} \text {. }\end{array}$} & \multicolumn{2}{|c|}{$\begin{array}{l}\text { Mean } \mathrm{CO}_{2} \text { Conc. } \\
\text { Parts per } 10,000 \text {. }\end{array}$} & \multirow{2}{*}{$\begin{array}{l}\text { Per Cent. Increase } \\
\text { of Dry Weight } \\
\text { Experimental over } \\
\text { Control. }\end{array}$} \\
\hline & & & Experimental. & Control. & \\
\hline Io & $27^{\circ} \mathrm{O}$ & $22 \cdot 4$ & $25 \cdot 8$ & $4^{\circ} 2$ & $50.4 \pm 3.15$ \\
\hline 8 & $29 \cdot 0$ & $22 \cdot 2$ & $27 \cdot 5$ & $4^{\circ} \mathrm{O}$ & $78 \cdot 7 \pm 6.6$ \\
\hline 9 & $29 \cdot 9$ & $23^{\circ} \mathrm{O}$ & $42 \cdot 4$ & $3 \cdot 6$ & $86 \cdot 3 \pm 6 \cdot 2$ \\
\hline 19 & $25 \cdot 6$ & 14.8 & $28 \cdot 9$ & $4 \cdot 3$ & $42 \cdot 0 \pm 13 \cdot 7$ \\
\hline I 4 & $36 \cdot 2$ & $25^{\circ} \mathrm{O}$ & $3 I \cdot 3$ & $3 \cdot 9$ & $60 \cdot 6 \pm 8 \cdot 5$ \\
\hline
\end{tabular}

\section{TEMPERATURE.}

The statement that chemical change is profoundly in. fluenced by temperature needs no elaboration : in the majority of instances an increased temperature accelerates a reaction; examples in which the contrary occurs are very few. The Law of van't Hoff states that for every rise in temperature of $10^{\circ} \mathrm{C}$. the reaction is increased at a definite rate, in general terms doubled or trebled, the precise value of which is specific to the reaction. $\uparrow$ The plant, however, is not a test tube but a very complex system of reacting substances, wherefore it is only in experiments most carefully controlled and skilfully conducted that approaches to the mathematical preciseness of wellascertained physico-chemical laws will obtain.

Long has it been known that an increased temperature results in an increased carbon assimilation, but it was not

* Bolus and Henderson: "Ann. Bot.", I928, 42, 509.

$\uparrow$ This factor is termed the temperature coefficient and is represented by the symbol $\mathrm{K}$ with a number attached indicating the number of degrees concerned, c.g. $\mathrm{K}_{10}$. 
before F. F. Blackman's experimental researches on vegetable assinilation and respiration that the subject was really critically examined. Matthri * at the outset of her work on the effect of temperature on carbon assimilation found that in addition to the influential external conditions there is an important internal condition of a plant or plant member, the result of previous treatment such as excess of food, starvation, and change in temperature.

This is a common experience; thus Harder $\uparrow$ found that the blue-green alga Phormidium foveolarum, if cultivated in a light of low intensity, can, in the photosynthetic process, make use of light of lower intensities than can plants grown in high light intensity. Similarly plants cultivated in strong light can assimilate more readily in such light than can plants which were previously cultivated in weak light. Likewise for temperature $\ddagger$ : in submerged aquatic plants cultivated for three months at a low temperature, $4^{\circ}-8^{\circ} \mathrm{C}$, carbon assimilation is less at $\mathrm{I}^{\circ} \mathrm{C}$. than at $8^{\circ} \mathrm{C}$, but those cultivated at a high temperature, $20^{\circ} \mathrm{C}$, show a rise in carbon assimilation with increasing temperature. In higher light intensities, on the other hand, both cultures show a rise in carbon assimilation with increasing temperature, but the rise is more rapid in those plants grown at higher temperatures. Warburg and Negelein $\S$ observed that when Chlorella was cultivated in a high light, but a small proportion of the available energy was photosynthetically employed, but when grown under a low illumination the reverse obtained. Stanescue || also found that lilac and other plants if kept in darkness for 48 hours, so that the leaves are freed from starch, show a more rapid carbon assimilation than the leaves of plants grown in normal conditions, although the maximum assimilation is attained at about the same time of day.

Such facts have a most important bearing on experimental results, so that in order to lave comparable figures it is

* Matthai : "Phil. Trans. Roy. Soc.," B, I904, 197, 47.

$\uparrow$ Harder: " 7 eit. Bot.," 1923, 15, 305.

†Harder: “ Jahrb. wiss. Bot.," I924, 64, 169.

§ Warburg and Negelein : “Zeit. phys. Chem.," I923, 106, I91.

"| Stanescue : “Compt. rend. Soc. biol.," I926, 95, I32. 
essential that the previous history of all the material employed should be the same.

In Prumus laurocerasus Matthæi found that for each temperature to which the leaves were subjected there is a definite amount of carbon assimilation, the maximal assimilation for that temperature, which cannot be exceeded and cannot be attained unless the illumination be of sufficient intensity and the carbon dioxide be adequate in amount. These maximal amounts of assimilation increase rapidly with rising temperatures, but at the higher temperatures the initial rate for that temperature cannot be maintained for long but falls off regularly at a rate dependent on the temperature; the higher the temperature the quicker the fall, but the rate of fall is not maintained. Thus there is a time factor for the higher temperatures. Fig. 5 summarizes the results obtained by Matthæi; it will be seen that the turning-point is $37.5^{\circ} \mathrm{C}$. which was found to be within a few degrees of the temperature fatal to the leaf.

The results obtained for temperatures below $25^{\circ} \mathrm{C}$. conformed to van't Hoff's Law, the coefficient of increase in the rate of carbon assimilation for a rise of $10^{\circ} \mathrm{C}$. being $2 \cdot \mathrm{I}$. In subsequent investigations Blackman and Matthæi found the assimilation coefficient for the leaves of Helianthus tuberosus to be $\mathrm{K}_{10}=2 \cdot 3$, whilst for Elodea, $\mathrm{K}_{10}=2 \cdot 05 .^{*}$ The culminating point of the assimilatory curve (Fig. 5) in respect to increasing temperature is important and is paralleled in enzyme action; in view of the results obtained by Willstätter and Stoll, it is not unlikely that the inhibition or destruction of an enzyme at these higher temperatures may be the liniting factor. Osterhout and Haas $\uparrow$ obtained a coefficient of I.8I for Ulva rigida between $17^{\circ}$ and $27^{\circ} \mathrm{C}$., a figure which, according to Snith $\ddagger$ is probably too low. Warburg $\S$ investigated the same phenomenon in Chlorella and thus avoided the difficulties inseparable from morphological complexity with a varying internal temperature and possibly an uneven rate of

* Blackman and Smith: "Proc. Roy. Soc.," B, I9 I I, 83, 389.

† Osterhout and A. R. C. Haas: "Jour. Gen. Physiol.," 1919, I, 295.

¥ Smith: "Ann. Bot.," I919, 33, 517.

§ Warburg: "Biochem. Zeit.," I9r9, roo, 230. 
gaseous diffusion. The values he obtained show that temperature has no effect on the rate of photosynthesis when the illumination is very low; with higher light intensities, the

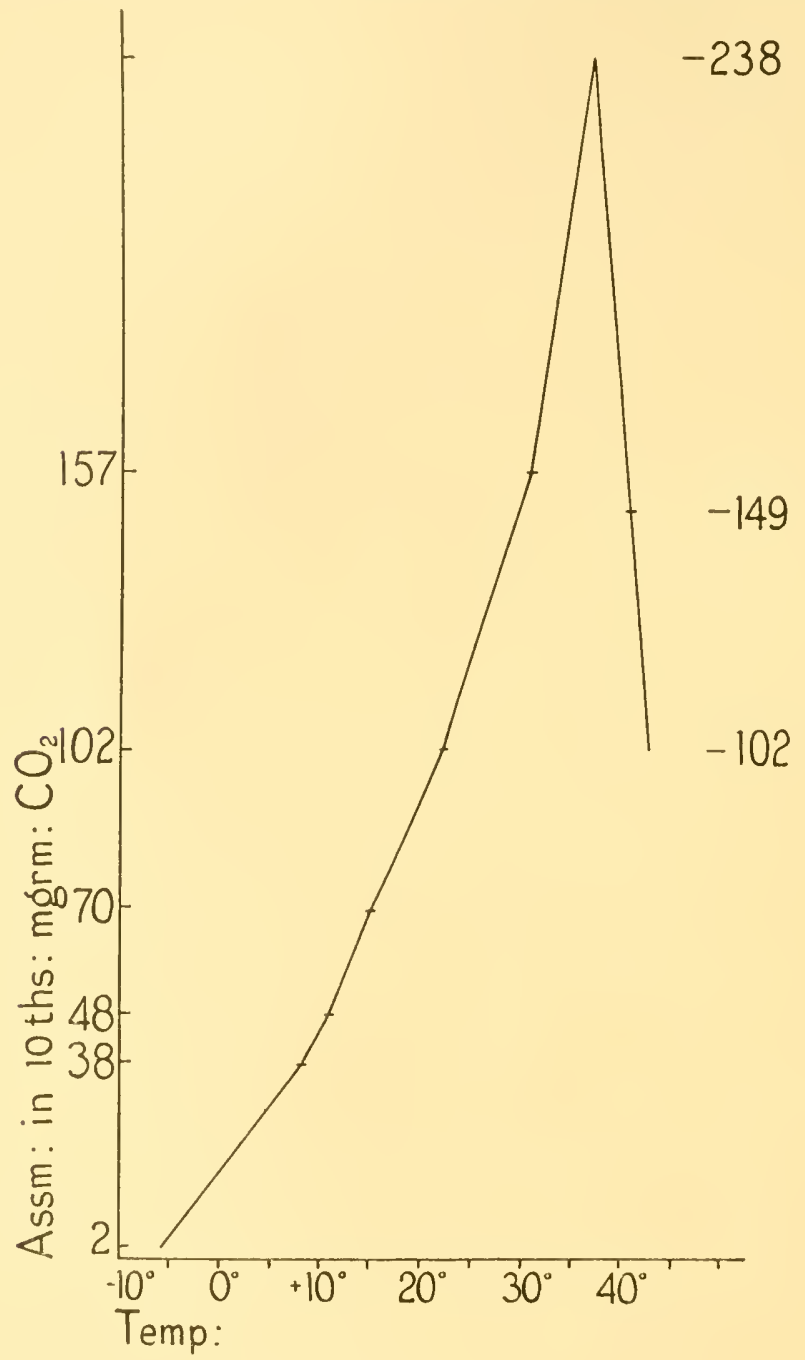

FIG. 5 .

coefficient decreases with increasing temperature. Thus with a relative light intensity of 45 , between $5.4^{\circ}-10^{\circ}, Q_{10}=4 \cdot 5$; between $10^{\circ}-20^{\circ}, Q_{10}=2.1 ;$ and between $20^{\circ}-30^{\circ}$, 
$Q_{10}=I \cdot 6$. Comparable obscrvations have been made by Yabusoe * and also by Lundegårdh $\dagger$ who found the temperature coefficient to be $\mathrm{I} \cdot \mathrm{O} 3-\mathrm{I} \cdot 45$ at $30^{\circ}-35^{\circ}$ in a strong light and with an atmosphere enriched to $\mathrm{I} \cdot 2$ per cent. of carbon dioxide. The maximum rate occurred at $35^{\circ} \mathrm{C}$. and provided that the initial heating was not too prolonged, the time factor was ill-defined. Blackman observed that under strong illumination or in a high concentration of carbon dioxide, a rise of $10^{\circ}$ in temperature, from $15^{\circ}$ to $25^{\circ}$, roughly doubles the velocity of photosynthesis; this is termed by Warburg $\ddagger$ the "Blackman Reaction" and it indicates that in the conditions specified, the rate of carbon assimilation is determined by a chemical rather than a photochemical reaction, for, as has been seen, with a low light intensity a rise in temperature does not affect the rate of the reaction. The Blackman reaction was originally thought by Warburg to be a preliminary reaction which led to the formation of an unstable derivative of carbon dioxide which was decomposed by light, but later he and Uyesugi adopted Willstätter's idea that in an early phase of photosynthesis a peroxide is formed and that the Blackman reaction consists in the separation of oxygen from this peroxide.

$$
\left.\mathrm{CH}_{2} \mathrm{O}_{2} \mathrm{O}_{2}\right] \rightarrow \mathrm{CH}_{2} \mathrm{O}+\mathrm{O}_{2} \text {. }
$$

In much experimental work on photosynthesis, moderate and higher temperatures have, for obvious reasons, been employed; it is, however, to be remembered that carbon assimilation takes place at extreme temperatures according to the specific physiology of the plant. McGee $\S$ found that Opuntia can function at $55^{\circ} \mathrm{C}$. and Matthæi || found a measurable photosynthesis in the cherry laurel leaf at $-6^{\circ} \mathrm{C}$. Henrici similarly observed a definite photosynthesis in lichens at $-20^{\circ} \mathrm{C}$. and in alpine phancrogams at $-16^{\circ} \mathrm{C}$.

* Yabusoe : id., 1924, 152, 498. † Lundegårdh : id., I924, 154, 195.

† Warburg: "Biochem. Zeit.," I919, 100, 230; 1926, 166, 386. Warburg and Uyesugi : $i d ., 1924,146,486$.

\$McGee: "Year-Book Carnegie Inst. Wash.," I921, 20, 47.

|| Matthæi : loc. cit.

† Henrici: "Verhand. nat. Ges. Basel," I919, 30, 43; 1921, 32, 107. See also Ewart: "Journ. Linn. Soc., Bot.," I896, 31, 364. Wurmser and Jacquot: "Bull. Soc. chim. biol.," 1923, 5, 305. 
The internal temperature of assimilating leaves will vary considerably in accordance with such conditions as the intensity and quality of the light, the character of the leaf surface and so on; Blackman and Matthæi * demonstrated, by thermoelectric means, an excess of $7^{\circ} \mathrm{C}$. to $16^{\circ} \mathrm{C}$. in the leaves of Prumus laurocerasus in bright sunlight above the adjacent shade tenperature.

\section{ILLUMINATION.}

The importance of light in the formation of chlorophyll is a commonplace in physiological experience; chlorophyll may, however, be formed in the dark, or in comparative darkness, as was shown by Schimper $\dagger$ for Algx and Burgerstein $\ddagger$ for conifers, and in other plants. $\$$ In the majority of plants, however, some exposure to light is necessary to produce the green pigment, presumably by its action on a precursor, termed chlorophyllogen by Monteverde and Lubimenko,\| according to whom plants grown in darkness for an excessive period lose their ability to form chlorophyll when exposed to light. In passing it may be mentioned that in addition to light, other conditions are requisite for chlorophyll formation, especially an adequate temperature, again a fact of common experience, and a supply of carbohydrate. Mention also may be made of the well-known fact that a high light intensity, presumably owing to its destructive action on chlorophyll, may bring about a cessation of photosynthesis.**

Of the light falling on a leaf, a portion only is available for the chloroplasts since varying amounts, according to the characteristics of the leaf surface, such as the presence of cuticle and of hairs, the thickness of the leaf and so on, will

* Blackinan and Matthæi : loc. cit.

† Schimper: "Jahr. wiss. Bot.," ı $88_{5}$, I6, I.

† Burgerstein: "Ber. deut. bot. Ges.," I900, 18, I68.

§ See Vol. I., p. 3 I I.

If Monteverde and Lubimenko: "Bull. Jard. Imp. Bot. St. Petersbourg," 1909, 9, 27 ; “Bull. Acad. Sci. St. Petersbonrg," 1912, 609.

if See Palladin: "Ber, deut. bot. Ges.," I $891,19,229$. Mansky: "Biochem. Zeit." 1922, 132, 18.

** See Ewart: “Ann. Bot.," IS97, I1, 439; 1898, 12, 379. Pantanelli: "Jahr. wiss. 13ot.," I903, 39, I67. Ursprung: "Ber. deut. bot., Ges.," I917, 35, 57. 
be lost by reflection, absorption or transmission. Of the energy absorbed by the leaf, many have shown that a small proportion only, and this in varying quantity, is used in carbon assimilation. Owing to ignorance of certain factors and the degree of their significance in the sequence of carbon assimilation, it is not possible to give a satisfactory account of the energy relationships of the plant. It may, however, be mentioned that Brown and Escombe, ${ }^{*}$ the first to attempt the drawing of an energy balance sheet of the leaf, concluded that Polygonum Weyrichii used from $\cdot 42$ to I 66 per cent. of the available radiant energy for carbon assimilation, figures based partly on observation and partly on calculation: Puriewitsch, $\dagger$ on the other hand, found that Polygonum Sachalinense similarly employed from $2 \cdot 5$ to $7 \cdot 7$ per cent. of the radiant energy.

In no natural conditions is the full radiant energy made use of by plants: the photosynthetic value of the noontide sunshine at the summer solstice in these latitudes lies, according to Blackman and Matthæi, $\ddagger$ between $\cdot 04$ and $\cdot 05$ gram of carbon dioxide per $50 \mathrm{sq}$. cm. of leaf surface per hour; the highest assimilation actually measured by these workers was -0290 gram.

The general statement that carbon assimilation varies with the intensity of the illumination is true only when light is the limiting factor; other factors, particularly temperature, are intimately associated in the process in nature. For this reason it is impossible to consider the effect of one condition to the exclusion of the other factors, a fact well demonstrated by Blackman and Matthæi.§ In one of their experiments, an abstract of which is given on p. 32, the leaves of Helianthus tuberosus were surrounded by an atmosphere containing on the average 4 per cent. carbon dioxide and the light throughout was diffused and of varying intensity.

It will be seen from observations 2 to 4 and 6 and 7 that the assimilation was remarkably uniform in conditions of

* Brown and Escombe: "Proc. Roy. Soc.," B, 1905, 76, 29.

† Puriewitsch: " Jahrb. wiss. Bot.," I914, 53, 210.

$\$$ Blackman and Matthei : "Proc. Roy. Soc.," B, 1905, 76, 402.

$\S$ Loc. cit. 
constant temperature and varying illumination; this shows that temperature was the limiting factor. The low value in the first observation was due to the low light intensity. In observation 5 in which the illumination was about the same as in 4 , the temperature was raised from $17.7^{\circ}$ to $30.5^{\circ} \mathrm{C}$., with the result that the assimilation was about doubled : but since at this higher temperature an assimilation of at least $\cdot 0289$ gram is possible, it follows that here the illumination was the limiting factor.

An important generalization arrived at by F. F. Blackman and his collaborators is that equal intensities of light incident on equal areas of leaf produce the same amount of assimilation,

\begin{tabular}{|c|c|c|}
\hline 1llumination. & $\begin{array}{l}\text { Temperature of } \\
\text { Leaf }{ }^{\circ} \mathrm{C} \text {. }\end{array}$ & $\begin{array}{l}\text { Real Assimilation in Grams } \\
\text { per } 50 \mathrm{Sq} . \mathrm{Cm} \text {. per Hour. }\end{array}$ \\
\hline $\begin{array}{l}\text { 1. Very overcast } \\
\text { 2. Raining, but lighter } \\
\text { 3. Raining, but lighter still } \\
\text { 4. Raining, heavy clouds } \\
\text { 5. Raining } \\
\text { 6. Much brighter } \\
\text { 7. Sunshine, but leaf in shade }\end{array}$ & $\begin{array}{l}\text { I } 7 \cdot 7 \\
\text { I } 8 \\
\text { I } 8 \\
\text { I } 7 \cdot 7 \\
30 \cdot 5 \\
\text { I } 8 \cdot 2 \\
\text { I } 8 \cdot 4\end{array}$ & $\begin{array}{l}\cdot 0062 \\
\cdot 0089 \\
\cdot 0090 \\
\cdot 0089 \\
\cdot 0163 \\
\cdot 0089 \\
\cdot 0092\end{array}$ \\
\hline
\end{tabular}

provided that light is the limiting factor and that the temperature does not involve the so-called time factor; agreement within 5 per cent. was found to obtain in such diverse instances as Helianthus, Prunus, Bomarea, Aponogeton, Elodea. and Fontinalis. Hence the conclusion is reached that "leaves in general have the same coefficient of economy in the photosynthetic * economy."

The amount of light required by a leaf is a specific value for a given temperature; thus in the examples studied by Blackman and Matthæi, Helianthus and Prumus have at low temperatures similar assimilatory maxima which diverge at higher temperatures. At $29.5^{\circ} \mathrm{C}$. Helianthus can assimilate

* The word "photosynthetic" is here used in its literal sense, that phase of carbon assimilation in which a chemical change is brought about by light alone. This phase is followed by a purely chemical phase, known as the dark phase, which is independent of light but is accelerated by an increase in temperature. 
twice as much carbon dioxide as can Prumus, but in so doing it requires twice the amount of illumination. The difference in the two leaves lies in their having different coefficients of acceleration of their assimilatory activity with increased temperature.

Of the use made by the plant of specific parts of the spectrum, it has been generally accepted that those wave-lengths associated with the prominent bands in the red of the absorption spectrum of chlorophyll were the only ones concerned with carbon assimilation. It is, however, to be remenibered that the light absorbed by such a structure as a leaf is not necessarily all employed in the photosynthetic process, that rays of different wave-lengths are not equally absorbed and that different wave-lengths have different energy values. Further, the most superficial chloroplasts are illuminated by practically unaltered daylight, but those more decply situated receive light from which certain rays have been abstracted in various degrees by the more superficial plastids and thus is of different quality as compared with normal daylight. Wherefore, in relevant investigations, light intensities must be known; the quality of light, i.e. its range in wave-lengths, be ascertained; and light must be, as far as is possible, the factor determining the rate of the process. Since radiant energy must be converted into chemical energy, it is obvious that the essential requirement is the amount of energy used, or at any rate available for the use of the plant; in other words, it is profitless to consider the intensity of carbon assimilation in different coloured lights without determining their energy values.

Ursprung * found that radiant energy of any wave-length, including the greater part of the ultra-violet, is capable of inducing starch formation in green leaves, provided that a sufficient time be allowed. He even found starch to be formed on exposure to infra-red rays ; it is, however, not clear whether this starch was a direct product of carbon assimilation since starch can be formed in the dark from pre-existing sugars. Ursprung found in Phalaris armminacea var. picta, which

* Ursprung : “Ber. deut. bot. Gesells.," I917, 35, 44 ; 1918, 36, 73, 86, III, I22.

VOL. II. - -3 
plant was selected since its variegated leaves permit a comparison between the green and non-green portions, that in the red region of the spectrum the maximum absorption obtains between the $\mathrm{B}$ and $\mathrm{C}$ lines, in the green the absorption is general, whilst in the violet the absorption is greater than between the $\mathrm{B}$ and $\mathrm{C}$ lines of the red, and beyond this there is a rapid fall. Subsequent work on Phaseolus showed a sharp rise in the assimilation curve from the outer limits of the red to a maximum situated near the $\mathrm{C}$ line, from which point there is a gradual fall towards the violet. This curve does not correspond, more especially as regards the region of shorter wave-lengths, with the curve of absorption which rises from $\mathrm{E}$, in the green region, to the violet. In view of the fact that carbon assimilation takes place in this part of the spectrum, it is obvious that some new conditioning factor is operative; it is suggested that this is found in the action of the violet rays causing the stomates partially to close.

Lubimenko* found from controlled experiments that photosynthesis is more active in the red than in the blue rays; it is only in shade plants that the process is equally intense in the two regions. Wurmser, $\uparrow$ in his investigations on the subject, used Ulva lactuca and from his measurements found that the ratio of carbon assimilation to the amount of energy absorbed was I $\mathrm{O}$ for red light, $4^{\circ} \mathrm{O}$ for green and $2 \cdot 35$ for violet light, which means that the green rays although absorbed in a much lesser degree are utilized four times more than the red. From further investigations he found that Ulva has a photosynthetic efficiency of 59 per cent. in red light and 83 per cent. in green light. The value obtained for the red rays does not, he thinks, represent maximum efficiency. He concludes that the efficiency is much the same for all wavelengths and lies between 70 and 80 per cent.

Warburg and Negelein, $\ddagger$ in most carefully controlled ex-

* Lubimenko : "Compt. rend.," I923, I77, 606.

$\dagger$ Wurmser: "Récherches sur l'assimilation chlorophyllienne," Paris, 1921 ; "Bull. Soc. chim. biol.," I923, 6, 487; "Ann. Physiol. Physiochim. Biol.," I925, 1, 47.

‡ Warburg and Negelein : "Zeit. physikal. Chem.," I922, 102, 235 ; 1923, 106, I91 ; "Naturwiss," 1922, 10, 647. 
periments, investigated the quantity of radiant energy absorbed in relation to the work done in carbon assimilation. The ratio between these two values is a measure of the efficiency of the organism in this particular connection; thus if the rad. iant energy absorbed by the plant be $\mathrm{E}$ and the energy utilized be $U$, then the ratio $U / E$ will give an index of efficiency. The greater the value of $\mathrm{E}$, the smaller is the ratio; with decreasing intensity of $\mathrm{E}$ the value rises until it reaches a limit, which limit marks the point of maximum efficiency. Using a culture of Chlorella, which had been grown in uniform conditions with a low light intensity, and keeping the illumination limiting, a mean value of 59 per cent. and a maximum value of 63.5 per cent. was obtained in a red light of a spectral range $570-645 \mu \mu$. Warburg and Negelein also compared the photosynthetic activity of the same plant illuminated with light of different wave-lengths. The accompanying table summarizes their observations :-

\begin{tabular}{|c|c|c|}
\hline & Light. & Per Cent. Efficiency. \\
\hline Red & . 6 Iо $-690 \mu \mu$ & 59 \\
\hline Yellow & $57^{8} \mu \mu$ & $53 \cdot 3$ \\
\hline Green & $54^{6} \mu \mu$ & 44.4 \\
\hline Blue & $436 \mu \mu$ & $33 \cdot 8$ \\
\hline
\end{tabular}

It will be seen that the efficiency decreases with the decrease in the wave-length. Also, these values differ from those obtained by other investigators, mentioned above, using different plants and different methods, a result to be expected for the reasons earlier given.

Chromatic Adaptation.-This consideration of the quality of light naturally introduces the problem of chromatic adap. tation. As is well known, the colour of deep water is green owing to the greater absorption by the water of the long rays, which are strikingly absorbed and utilized by the chloroplasts. A plant growing in deep water, therefore, is handicapped by the different quality of light. Many marine algre have, in addition to their chlorophyll, water-soluble pigments-phycoerythrin for example *-which are complementary in colour to that of the surroundings and thus are able to increase the 
amount of radiant energy absorbed. This, in brief, is Englemann's * theory of chromatic adaptation, a theory which has been extended to include many plants, Phæophyceæ, Bacilliariales, Bacteria, and terrestrial plants which possess these extra pigments. Gaidukov $\dagger$ in his experiments with Oscillaria found that the cultures changed their colour, violet in dirn light, to the complementary colour to that in which they were growing; thus if grown in red light, the new cells would be green, and so on. Whether this is a true example of chromatic adaptation is, perhaps, doubtful, for other authors have found like colour changes to be effected by the conditions of nutrition, a deficiency of iron, by wounding, and so on.

Richter $\ddagger$ considers that the determining factor in the colour of red algæ is the intensity rather than the quality of the light, the water soluble pigments playing no part in the photosynthetic process. Wurmser, $\S$ on the other hand, whilst agreeing that the presence of phycoerythrin is an adaptation to weak light, concludes that it also is an optical sensitizer which aids the chloroplasts to absorb green light.

Harder || studied Phormidium foveolarum, which is purple in blue light, owing to the development of phycoerythrin, and green in red light, owing to the development of phycocyanin. He found that the purple plants have a higher rate of photosynthesis in blue light than in red, whilst the green forms show a higher rate in red than in blue light. He thus supports Englemann's hypothesis, but his experiments also show that light intensity is of great importance, but even so there is always a higher rate of photosynthesis in the plants which have a complementary pigment. On an earlier page mention has been made of Harder's observation that Phormidium when cultivated in a strong light shows a higher rate of carbon

* Englemann: "Bot. Ztg.," I 883, 41, I, I 7; I884, 42, 81, 97.

† Gaidukov: "Preuss. Akad. Wiss.", I902, 5, I ; "Ber, deut. bot. Ges.", I903, 21, 484, 51 7, 535 .

$\ddagger$ Richter: "Ber. deut. bot. Ges.," r91 2, 30, 280.

§ Wurmser: "Recherches sur l'assimilation chlorophyllienne," Paris, I 92 I.

|| Harder: " Ber. deut. bot. Ges.," 1922, 40, 26; "Zeit. Bot.," I923, 15. 305. 
assimilation in a high light intensity than do plants grown in a weak light and vice versa.

The balance of evidence favours the view that complementary chromatic adaptation is a natural phenomenon although not so widely spread as has been supposed, and that it is of little value to study the effect of light quality without considering light intensity.

To return to the main thesis: in all these observations the significant fact is that the longer rays bring about a profound chemical change, whereas in inorganic photochemistry the short rays are by far the most efficient, the longer having little or no action. For this reason not a little work has been done on the action of the short rays, the ultra-violet, in bringing about the formation of organic compounds from carbon dioxide and water. All such work, interesting though it be, throws no light on the fundamental problem of carbon assimilation, since the green plant can effect the transformation in conditions which preclude the presence of ultra-violet illumination. With this caution a brief résumé of such investigations may be given.

Stoklasa and Zdobnicky* brought about the synthesis of carbohydrate in the absence of chlorophyll by passing light from a quartz mercury lamp through a mica window into a vessel containing a mixture of carbon dioxide and nascent hydrogen. Formaldehyde was slowly produced, and this, in the presence of caustic potash, was polymerized with the formation of a sugar or a mixture of sugars which was optically inactive and not fermentable by yeast. The authors suggested that the chlorophyll in plants acts as a means of absorbing ultra-violet rays, a suggestion which has since been found to be true. Bertholet and Gaudechon $\dagger$ found that formaldehyde is produced by the action of ultra-violet rays on carbon dioxide in the presence of a reducing agent, and, reversely, that carbohydrates are decomposed by sunlight and by ultra-violet

* Stoklasa and Zdobnicky: "Chem. Zeit.," I910, 945.

† Bertholet and Gaudechon: "Compt. rend.," I910, 150, I690, I5I, 395; I9I 2, 155, 40 I, 83I. 
light from a mercury-vapour lamp. The products of decomposition are carbon monoxide, carbon dioxide, methane and hydrogen; aldehydic sugars differ from ketonic sugars both in the readiness with which they are decomposed and in the composition of the gaseous mixtures produced.

Usher and Priestley* found that ultra-violet light can bring about the decomposition of aqueous carbon dioxide without the intervention of an optical or chemical sensitizer, a result contrary to that of Stoklasa and Zdobnicky, who found that formaldehyde was not produced by the action of ultra-violet light on carbon dioxide and water. In view of these contrary results, Spoehr $\uparrow$ tried the effect of ultra-violet radiations on carbonic acid and its salts; in no experiment was a sufficiency of formaldehyde produced to give a positive reaction with the reagents employed. In all experiments Spochr found that formic acid was the only reduction product. Attempts to reduce formic acid to formaldehyde by sun or by ultra-violet light failed, but after ten to fifty hours exposure there remained on evaporation a non-volatile yellow syrup, of a composition not yet determined, which reduced Felıling solution.

A further study of the artificial photosynthesis of carbohydrates was undertaken by Baly, Heilbron and Barker $\ddagger$ who by exposing a solution of carbon dioxide in water to ultraviolet light of different wave-lengths obtained evidence of the formation of formaldehyde and also prepared a syrup which, according to Irvine and Francis $§$ consisted of 80 per cent. non-sugars and not more than Io per cent. of a hexoselike material from which ketoses were absent.

The views put forward by Baly and his collaborators concerning the origin and mode of formation of the formaldehyde produced in the experiments mentioned above, were criticized by subsequent workers $\|$ and in later papers Baly,

*Usher and Priestley : "Proc. Roy. Soc.," B, I9I I, 84, IoI.

† Spoehr: "Plant World," I9I6, 19, 1.

† Baly, Heilbron and Barker: "J. Chem. Soc.," I 921 , I 19, 1025.

§ Irvine and Francis: "Ind. Eng. Chem.," I924, 16, 1019.

|l Spoehr: "J. Amer. Chem. Soc.," I923, 45, I I84. Bauer and Rebmann: "Helv. Chim. Acta.," I922, 5, 828. Bauer and Büchi : id., I923, 6, 959. Porter and Ramsperger : "J. Amer. Chem. Soc.," I 925, 47, 79. 
with a number of fellow-workers, ${ }^{*}$ modifies his original views and suggests that the formaldehyde obtained in the earlier experiments arose from the secondary deconiposition of the photosynthesized carbohydrate.

They find, moreover, that if carbon dioxide be exposed to the action of ultra-violet light in the presence of such substances as barium sulphate, aluminium powder, the basic carbonates of aluminium, zinc or magnesium, which present a surface upon which the gas may be absorbed, a condensation compound is produced which is charred by sulphuric acid and reduces Benedict solution after hydrolysis; the exact nature of this substance has yet to be determined, but it possibly contains carbohydrate.

Of more immediate interest in the problem of natural photosynthesis are the results obtained with the use of visible light, from an ordinary tungsten filament lamp or a I00-watt half-watt lamp, in place of ultra-violet radiation; using coloured absorbing surfaces such as the basic carbonates of nickel or cobalt, these authors were able to obtain a larger yield of organic material than with the colourless substances and ultra-violet light mentioned above. This material is a mixture one component of which is a carbohydrate as is indicated by the facts that it gives the reactions of Molisch and Rubner, it reduces Benedict's solution and also forms a solid ozazone. The material also contains a more complex substance which reduces Benedict's solution after hydrolysis with acid. In these experiments no free oxygen is given off ; it is suggested that it is absorbed on the surface of the powder, possibly forming a peroxide, and this in time may poison the surface and stop the photosynthetic action. Thus with a light of medium intensity, photosynthesis stops after two hours; in a stronger illumination the organic material first formed may be decomposed; with a decreasing intensity of light, the amount of material synthesized by unit quantity of light increases.

* Baly, Davies, Johnson and Shanassy : "Proc. Roy. Soc.," I927, A 116, 197. Baly, Stephen and Hood, id., 212 ; Baly and Davies, id., 2 I 9. 
The results obtained by the use of visible light and a coloured surface are of interest in that it would appear that a closer imitation for the first time has been made in the test tube of what occurs in the green cell. In each the process is conditioned by visible light and a pigmented surface; the presumed poisoning effect of the cobalt surface by the oxygen is paralleled by the fatigue effect exhibited by leaves in strong illumination and in both there is a recovery. The maximum yield of organic material obtained by the authors was 0.075 gram in two hours, and assuming that the product be glucose, it is calculated that the gain in calorific valuc is 0.48 calories per sq. cm. of surface per hour, which just falls without the range given by Puriewitsch, ${ }^{*} 0 \cdot 27-4 \cdot 1$ calories, for a number of plants. But this for the time being has no significance; the intensity of carbon assimilation in the plant varies much with the conditions, and, on the other hand, the material obtained by Baly and his fellow-workers is not all glucose. The authors also argue that the constant ratio of chlorophyll $\mathrm{A}$ to chlorophyll B, observed by Willstätter and Stoll, is maintained by the carotin which becomes oxidized to xanthophyll. Since the ratio of xanthophyll to carotin tends to increase during photosynthesis, it is suggested that the slow recovery process in the leaf is that in which the xanthophyll is again reduced to carotin.

Chemical change may be brought about by electrical energy; indeed, in connection with plants, the effect of electrical currents on vegetable growth is a not unimportant branch of applied botany.

Royer $\uparrow$ by electrical means brought about the reduction of carbon dioxide, and similarly Coehn, $\$$ in 1904, produced formic acid from this same compound. Brodic $\S$ found that by means of a silent discharge formaldehyde, together with marsh gas, was produced from a mixture of hydrogen and carbon dioxide; and Löb, || in 1906, found that formaldelyyde may be produced by the action of a silent discliarge of elec-

\footnotetext{
* Puriewitsch : "Jahrb, wiss. Bot.," I9I 4, 53, 229.

† Royer: "Compt. rend.," I870, 70, 731.

† Coehn : "Ber. deut. chem. Gesells.," I904, 34, 2836, 3593.

§ Brodie : "Proc. Roy. Soc.," I $874,22,171$.

|| Löb: “Zeit. Electrochem.," I 906, 12, 282.
} 
tricity through a solution of carbon dioxide in water. Fenton * also has pointed out that the synthetic action of light and of the silent electrical discharge are practically identical. Thus there is evidence which suggests that electric energy may play a part in the earlier processes of photosynthesis ; a suggestion which is supported by the fact that, according to Polacci, $\uparrow$ the formation of carbohydrates is promoted in leaves by electrical energy, provided it be not too intense, especially when a continuous current is made to pass directly into the tissues.

As a result of a number of experiments, Gibson $\$$ comes to the conclusion that the light rays which are absorbed by the chlorophyll are transformed into electrical energy, and it is this transformed energy which brings about the decomposition of carbonic acid to formaldehyde and oxygen. This opinion is based on evidence the details of which apparently have not been published.

Waller $\S$ and others have made many observations on the photo-eleetric responses of plants, but much further investigation is necessary before the correlation of these phenomena with the photosynthetic process is possible. Attention may also be drawn to the work of Kernbaum, \| who found that water exposed to the influence of $\beta$-rays and of ultra-violet rays led to the production of hydrogen and hydrogen peroxide. Usher and Priestley also found that an aqueous solution of carbon dioxide could be decomposed by the $\alpha$ and $\beta$-rays from radium emanation. The action of $\cdot 000$ I c.c. of radium emanation on 200 c.c. of water saturated with carbon dioxide resulted in four weeks in the production of hydrogen peroxide and formaldehyre. Most of the latter was in a polynerized state, but the solution contained no sugar.

The effect of salts of radio-active metals such as potassium and rubidium has been the subject of many investigations but it is inpossible as yet to draw any definite conclusions.

* Fenton: "Journ. Chem. Soc.," I907, 91, 687.

† Polacci : "Atti. Inst. Bot.," Pavia, I905, II., I I, 7.

† Gibson : “Ann. Bot.," 1908, 22, 1 I 7.

$\S$ Waller: $i d$., 1925, 39, $5^{\text {I } 5}$.

II Kernbaum: "Compt. rend.," I909, I48, 755, 149, 273. 
In this connection it may be mentioned that Henrici * concluded that innized air accelerates carbon assimilation of lowland plants, when the illumination is low, but not when the light is of medium intensity; in strong light the ionized air retards the process. In alpine plants, an acceleration was observed both in weak and in medium light, whilst in strong illumination neither increase nor decrease obtained. In some examples the ratio of the rate of carbon assimilation in ionized air to the rate in de-ionized air was as 5 is to $\mathbf{I}$. This work is criticized by Whimster $\uparrow$ who points out that the results are not based on the means of a number of experiments, wherefore it is impossible to calculate the probable error. Further, the figures given by Ienrici represent apparent assimilation, no allowance being made for respiration which, as will be seen later, is markedly affected by an ionized atmosphere. Using the leaf of Pelargonium zonale, Whimster found no further effect on the rate of carbon assimilation under the action of ionized air than a 3 per cent. depression, a value of no significance; the real assimilation, in which the increased rate of respiration is taken into consideration, showed a 5 per cent. increase which again is below the significant level.

\section{INTERNAL FACTORS.}

Cinlorophyl. :-Plant physiologists for long have recognized that the intensity of carbon assimilation must be dependent on the chlorophyll and its amount; it is, however, but recently that the problems involved have been critically examined. Irving, $\S$ who used the leaf's carbon dioxide of respiration in her experiments, found by gasometric methods that etiolated leaves, either when they are orange-yellow or when they have attained a considerable degree of greenness, do not possess any appreciable power of synthesizing carbon dioxide. If there be any photosynthetic activity, it cannot lie greater than one-tenth part of respiration nor come within

* Henrici : "Arch. Sci. Phys. Nat.," I92 I, 3, 270.

† Whimster: "Ann. Bot.," I927, 41, 357.

$\ddagger$ A general account of chlorophyll, its chemistry and constitution, will be found in Vol. 1.

§ Irving: "Ann. Bot.," 1910, 24, So5. 
I per cent. of the activity subsequently developed. Carbon assinilation thus begins only when the leaves are fully green and develops very quickly; wherefore it follows that the first origin of this function is not correlative to the amount of chlorophyll produced, or, in other words, that the amount of chlorophyll is not a conditioning factor in the early stages of carbon assimilation.

Willstätter and Stoll * were the first to make quantitative estimations of the amount of chlorophyll in leaves, by the methods already outlined. $\uparrow$ Also they measured the amount of carbon assinilation of the leaves of different plants and of the same plant in different conditions-normal, etiolated, autumnal, and so on-and thus arrived at the assimilation number which is the ratio between the amount of carbon dioxide assimilated per hour and the chlorophyll content, both expressed in milligrams. A selection of the values obtained are tabulated below.

Willstätter and Stoll, whose experimental methods were similar to Irving's, with the chief exception that they used a 5 per cent. concentration of carbon dioxide, found that leaves with but a small portion of their full chlorophyll content developed can assimilate to a measurable degree.

WILLSTATTER AND STOLL'S ASSIMILATION NUMBERS.

\begin{tabular}{|c|c|c|c|c|c|}
\hline Plant. & & Kind of Leaf. & $\begin{array}{c}\text { Chlorophyll } \\
\text { Content in } \\
\text { Mgms. }\end{array}$ & $\begin{array}{l}\mathrm{CO}_{2} \text { Assimilated } \\
\text { per Hour, } \\
\text { Mgms. }\end{array}$ & $\begin{array}{c}\text { Assimila- } \\
\text { tion } \\
\text { Number. }\end{array}$ \\
\hline Primula & & Normal & $11^{\circ}+4$ & 105 & $9^{\circ} \mathrm{I}$ \\
\hline Rubus & & Normal & $16 \cdot 2$ & 94 & $5 \cdot 8$ \\
\hline Tilia & f & Young & $5 \cdot 2$ & 74 & $14 \cdot 2$ \\
\hline Tilia & í & Older & $22 \cdot 5$ & $14^{8}$ & $6 \cdot 6$ \\
\hline & & Dark green autumn leaves & $15 \cdot 2$ & 152 & $10 \cdot 0$ \\
\hline Populus & \{ & $\begin{array}{c}\text { Yellow-green autumn } \\
\text { leaves }\end{array}$ & $3 \cdot 9$ & $3 I$ & $7 \cdot 9$ \\
\hline Flm & f & Yellow variety & $9 \cdot 5$ & 75 & $7 \cdot 6$ \\
\hline $\mathrm{Em}$ & 1 & Green variety & 13.0 & 80 & $6 \cdot 9$ \\
\hline
\end{tabular}

This conclusion is contrary to that of Irving, a difference probably due to the fact that Irving used young leaves whilst

*Willstätter and Stoll : “ Ber. deut. chem. Gesells.," I9I 5, 48, I 540.

$\dagger$ See Vol. I., Section on Pigments. 
Willstätter and Stoll employed older and sometimes much older material. This explanation is due to Briggs, * in whose memoir a critical examination of the work of the above-mentioned authors will be found; this author demonstrates that the age of a leaf and the lapse of time from the greening to the measurement of photosynthetic activity are all important. If a leaf is cut from a seedling in the dark at an early stage in its development and partly greened by exposure to light, its photosynthetic activity will be zero or very small; if, on the other hand, the same procedure is repeated with a similar leaf from the same plant after an interval of a few days, the photosynthetic activity will be strongly marked. Briggs confirms Irving's main conclusions: a young green leaf may show no or very little carbon assimilation and the power of photosynthesis lags behind the development of chlorophyll. This power increases with age whether the leaf be in the dark or in the light, even though there be no concurrent increase in the chlorophyll content. But the same phenomenon does not necessarily occur in seedlings. In a further communication, Briggs $\dagger$ has shown that in Helianthus, Acer and Cucurbita, for example, where the cotyledons serve as organs of storage and, on becoming green, are the first organs of carbon assimilation, there is no lag between greening and photosynthesis when light or temperature is limiting. On the other hand, in Phaseolus, Ricinus and Zea, plants in which there is formed a carbon-assimilating organ distinct from the storage organ, the photosynthetic power is not developed until some time after germination, and in natural growth conditions the lag obtains. It will be remembered that the cotyledons of Phaseolus are entirely organs of storage, the first foliage leaves being the first organs of assimilation; similarly in Zea, the first foliage leaf is concerned with photosynthesis, the cotyledon being occupied with the absorption of food from the adjacent endosperm; in Ricinus, on the other hand, the cotyledons are embedded in the endosperm and afterwards expand to form the first carbon assimilating organs. In these so specialized plants, the com-

* Briggs : “Proc. Roy. Soc.," B, 1920, 91, 249.

$\dagger$ Ibid., 1922, 94, I2. 
mon fact that the reserve food supply is not contained within the organs of the seedling which are the first to show photosynthesis, suggest that the translocation of food materials to the assimilating structure may be a causal factor in the lag described ; it is, however, very doubtful if it be the only factor. The accompanying table gives some of Briggs's results, in which the carbon assimilation is represented in cubic centimeters of oxygen evolved per hour per $50 \mathrm{sq}$. cm. of surface in a light intensity of 9000 lux.

\begin{tabular}{|c|c|c|c|c|c|}
\hline & & & $\begin{array}{l}\text { Age from } \\
\text { Sowing. }\end{array}$ & Temperature. & Assimilation. \\
\hline \multirow{4}{*}{ Helianthus } & \multirow{4}{*}{. } & \multirow{4}{*}{. } & Days. & ${ }^{\circ} \cdot{ }^{\circ} \mathrm{C}$ & $0.6=$ \\
\hline & & & 6 & $19 \cdot 6$ & 3.00 \\
\hline & & & 7 & $10 \cdot 7$ & $3 \cdot 08$ \\
\hline & & & 14 & I $3 \cdot 3$ & 0.83 \\
\hline \multirow{2}{*}{ Ricinus } & \multirow{3}{*}{ - } & \multirow[b]{2}{*}{ - } & I 5 & I $3 \cdot 7$ & $\mathrm{I} \cdot 5^{8}$ \\
\hline & & & I 6 & $13 \cdot 3$ & $2 \cdot 05$ \\
\hline \multirow{4}{*}{ Zea } & & \multirow{4}{*}{. } & I 7 & I I $\cdot 9$ & $I \cdot 89$ \\
\hline & \multirow{3}{*}{. } & & 8 & $10 \cdot 0$ & $0 \cdot 06$ \\
\hline & & & 19 & I3 & 0.56 \\
\hline & & & 20 & I $2 \cdot 6$ & $0 \cdot 6 x$ \\
\hline
\end{tabular}

Dastur* suggests that the variation in the assimilation numbers obtained by Willstätter and Stoll is due to loss of water, a factor of great importance in photosynthesis. Further, the irregularities observed in autumn leaves and also in normal leaves may be explained by the difficulty in selecting leaves of the same photosynthetic power, for this power is not necessarily the same in leaves of apparently the same age or collected at the same distance from the apices of the shoots, notwithstanding the fact that they may appear equally healthy and fresh.

The Unknown Factor.--The fact that the temperature relations of carbon assimilation are those of a chemical rather than a photochemical reaction indicates the presence of an internal factor, independent of the ehlorophyll and associated rather with the protoplasm, which controls the rate of carbon assinilation. Irving concludes that this factor controls the

* Dastur : “Ann. Bot.," 1925, 39, 769. 
beginning of the process since it is not developed so quickly as the chlorophyll, wherefore the rest of the mechanism must await its appearance.

The assimilation numbers arrived at by Willstätter and Stoll * are inconstant, which is indicative of there being some other operating factor : if they were constants, strong evidence that chlorophyll was the all-important conditioning factor would be provided. According to Willstätter and Stoll $\uparrow$ it is an enzyme which thus limits carbon assimilation. They find that in leaves rich in chlorophyll, increased illumination has but little effect upon assimilation nor is it diminished if the illumination is decreased to one quarter. This indicates that the chlorophyll is present in excess compared with the assimilatory enzyme. The increase in carbon assimilation following an increase in temperature they consider to be due to the stimulation of the enzymatic process.

In leaves containing little chlorophyll and in yellow varieties the conditions are reversed; the enzyme here being in excess, increased temperature has little effect in stimulating assimilation. On the other hand, increased illumination has a very marked effect.

The remarkable phenomena accompanying autumnal changes in leaves are due to the fact that either the chlorophyll suffers more than the enzyme, resulting in increase of assimilation number, or conversely the enzyme suffers most, in which case the assimilation number falls.

The failure to bring about carbon assimilation by means of chlorophyll isolated from the leaf may be attributed, according to the authors, to the absence of the enzyme.

This belief in the existence of a controlling enzyme also is shared by Osterhout and Haas $\$$ who experimented with various plants, both fresh water and marine, grown in a culture solution containing gaseous carbon dioxide. The removal of carbon dioxide was followed by the method of determination of the hydrogen ion concentration in the culture medium. It

* Willstätter and Stoll : “ Ber. deut. chem. Gesells.," I9I 5, 48, I 540.

$\dagger$ Ibid., p. 1552 .

† Osterhout and A. R. C. Haas: " Proc. Nat. Acad. Sci.," I918, 4, 85 . 
was found that photosynthesis began immediately on exposure to light; at first the removal of carbon dioxide was rapid, then more slowly until a maximum was reached when the rate remained constant. These authors consider that under the influence of light some catalyst is developed which facilitates the photosynthetic process. Briggs concludes that the activity of the photochemical phase of the carbon assimilation mechanism in a seedling, as compared with that of more mature leaves, is in some way limited: the photochemical phase depends for its intensity not only on the chlorophyll but also upon some other factor which increases with age during the early stages of leaf development.

The observations of Molisch * that leaves after slow drying or freezing, treatments that do not destroy enzymes, retain some power of carbon assimilation and can evolve oxygen, whereas the same leaves killed by rapid drying or inmersion in hot water show no such power, again indicates the participation of an enzyme in the process.

There is thus strong evidence of the existence of a controlling factor, probably enzymic, essential in the earlier phases of carbon assimilation. Briggs $\dagger$ also draws attention to the probability that the amount of "reactive chlorophyll surface," which is not necessarily the same as the total chloroplast surface, is an important internal factor and anything which influences the amount of this surface, such as age, iron chlorosis and lack of essential elements in the raw food material, is indirectly a factor controlling the rate of carbon assimilation. An increase or decrease in the reactive chlorophyll surface will correspondingly increase or decrease the carbon assimilation when a given temperature is limiting and also, in certain conditions, when a definite light intensity and partial pressure of carbon dioxide are limiting. This conception is an outcome of measurements of the carbon assimilation of Phaseolus grown in culture solutions lacking such essential clements as potassium, magnesium, iron or phosphorus ; in these circumstances the carbon assimilation is always less than in plants grown in

* Molisch : “Zeit. für Bot.," I925, 17, 577.

† Briggs : "Proc. Roy. Soc.," B, I 922, 94, 20. 
a complete culture medium whether light or temperature be limiting. This is shown in the accompanying table of some of Briggs's results which gives the real assimilation per 50 sq. $\mathrm{cm}$. of surface expressed in percentages of the rate observed in plants growing in the normal culture solution or in pot culture when light and temperature were limiting.

\begin{tabular}{|c|c|c|c|c|c|c|c|}
\hline Leaves. & $\begin{array}{c}\text { Factor } \\
\text { Limiting. }\end{array}$ & $\begin{array}{c}\text { Pot } \\
\text { Plant. }\end{array}$ & $\begin{array}{c}\text { Normal } \\
\text { Solution. }\end{array}$ & $-\mathrm{Mg}$. & $-P$ & $-\mathrm{Fe}$. & $-\mathrm{K}$. \\
\hline First & Light & - & 100 & 82 & 103 & $9 I$ & 87 \\
\hline simple & Temp. & - & 100 & 82 & 97 & 82 & 96 \\
\hline First & Light & 100 & 77 & 64 & $6_{5}$ & $5 I$ & 79 \\
\hline pinnate & Temp. & 100 & 79 & 64 & 65 & 55 & 79 \\
\hline
\end{tabular}

It will be seen that photosynthesis is subnormal when light and temperature are limiting, which means that subnormality in the photochemical phase, which is more influenced by illumination, is accompanied by a subnormality in the chemical phase which is mostly influenced by temperature; further, both phases generally show the same degree of subnormality.

In passing it may be observed that the particular form in which an element is presented to the plant may be of importance. This is shown by the following table taken from Maskell's observations on starch production in the leaves of the potato, ${ }^{*}$ from which he concluded that the amount of starch varies not only with the ordinary conditioning factors but also with the nature of the available potash. Thus potassium sulphate when added to the soil was found to be more effective in starch production than treatment with potassium chloride and other potassic manures. The figures given are the mean values of colorimetric estimations made over a period of

\section{Treatment.}

No potash (control)

Potassium sulphate

Potassium chloride

"Potash manure salts"

\section{Starch Production.}

2.013

$2 \cdot 667$

$2 \cdot 139$

$\mathrm{I} \cdot 893$

seventeen days in September; the quantities of added mineral manure were so controlled that the culture plots were given an

* Maskell: "Ann. Bot." 1927, 41, 327. 
amount of potash equivalent to two hundredweight of potas. sium sulphate per acre.

The superiority of the plants treated with potassium sulphate is associated with a more rapid translocation of starch from the leaflets.

The Products of Carbon Assimilation.-Much investigation is necessary before the precise significance of this factor can be determined: of the products of carbon assimilation, carbohydrate and oxygen are the most conspicuous.

It is well known that, according to the law of mass action, chemical action diminishes as the products of the activity accumulate; the initial rate can only be maintained provided the initial proportions of the reacting substances are preserved and the products of the reaction removed. In the leaf a further complication arises since sugar is an osmotic substance and its undue accumulation may lead to a physical disturbance in the synthesizing machine such, for example, as the closure of the stomates. This may be averted by the conversion of the sugar into starch, a marked and well-known phenomenon in many plants, which temporary reserve is translocated at nightfall after hydrolysis. But a great accumulation of starch may inhibit photosynthesis in that, presumably, it reduces the effective surface of the chloroplasts which, according to Briggs, Warburg, Wurmser and others, is the seat of the primary photochemical action. Translocation is most apparent in the dark, but it takes place also by day and it is only in sugar leaves that the undue concentration of soluble carbohydrates, owing to hindrances to rapid translocation, or to a high assimilatory efficiency, is likely to prove an important factor in carbon assimilation. Broock * found that the leaves of the sugar beet on bright sunny days showed a rapid increase in their dry weight up to midday, at which hour there was a sudden decrease: this loss in weight was more or less uniform until about midnight. The sudden drop in the carbon assimilation at noon indicates that the process was brought to a standstill owing, in all

* Broock : " Über tägliche und stündliche Assimilation einiger Kulturpflanzen," Halle, I892. See Thoday: "Proc. Roy. Soc.," B, I9io, $82,4+3$.

VOL. II. -4 
probability, to the closure of the stomates resulting from the accumulation of materials which were produced at a greater rate than that at which they could be translocated.

Kostychew and his collaborators * found that the photosynthesis of Arctium and Phragmites on bright warm days reaches a maximum several hours before sunset, usually in the forenoon; which maximum is followed by a marked retardation owing to the removal of the products of the operation not keeping pace with the formation of new material. An increase in weight of approximately 0.15 gram per $300 \mathrm{sq} . \mathrm{cm}$. of leaf surface is enough to end photosynthesis. When the conditions of photosynthesis are not so favourable, for example in dull weather, the sudden retardation of the process is not observable. Similar results were obtained in the study of various aquatic plants. $\dagger$ It was also found that various algæ, e.g. Mougeotia, Spirogyra, Cladophora and Rhizoclonium, exhibit different assimilation intensities which are invariably greater than those of aquatic phanerogams, e.g. Ceratophyllum, in spite of the fact that the latter generally contain a larger quantity of chlorophyll per gram of dry weight. These observations, together with those of McLean alluded to on an earlier page (p. 24), indicate that the phenomenon is widely spread.

With regard to the oxygen evolved, since carbon assimilation by green leaves is unaffected by various concentrations of oxygen in artificial atmospheres, and since the oxygen pressure of the internal atmosphere of plants is a very variable quantity, it would not appear that the amount of oxygen is a limiting factor of any great significance.

\section{THE ORGANIC PRODUC'TS OF CARBON ASSIMILATION.}

The ultimate products of carbon assimilation are carbohydrates: Brown and Morris, $\ddagger$ in their classical work on the chemistry and physiology of foliage leaves, identified sucrose,

* Kostychew, Kudrivzewa, Moissegewa and Smirnowa: “ Zeit. wiss. Bot.," I926, I, 679.

$\dagger$ Kostychew and Soldatenkow : $i d ., 1926,2, \mathbf{1}$.

† Brown and Morris: "Journ. Chem. Soc.," 1893, 63, 604. 
dextrose, levulose and maltose in the leaves of Tropaolum, the sucrose being in greatest abundance:- These results were generally accepted, reinvestigations of the subject being of recent date. Parkin,* in his investigation of the sugars of the leaf of Galanthus nivalis, selected for its convenience as a sugar leaf, found that a considerable quantity of sugars, 20 to 30 per cent. of the dry weight, occurred in the active leaves ; sucrose, dextrose and levulose were recognized, but maltose was never found, a result which was to be expected, since starch is not formed in the leaves in any appreciable quantity. The amount of sugar increases towards the base of a leaf and concurrently the ratio of the sucrose to the hexoses diminishes. The sucrose increases rapidly in amount after sunrise, reaches a maximum and diminishes during the night; the percentage amounts of the hexoses of the leaf, however, remain fairly constant. As the season advances, the proportion of sucrose to the hexoses decreases, the latter being formed at the expensc of the former. Parkin confirms Brown and Morris in the observation that the levulose is, as a rule, more abundant than the dextrose and supports the contention that sucrose is the first recognizable sugar in carbon assimilation, the hexoses being formed from it by inversion. It has been suggested that the reason for levulose being more abundant than dextrose is that the latter is more used by the leaf in its respiratory processes, the fructose being more suitable for tissue formation. The observations of Robbins $\dagger$ and of Brannon $\ddagger$ however, indicate that fructose is not better than glucose for tissuc formation. In water culture it was found that glucose was the better, whilst fructose may have a temporary toxic effect, especially in the absence of glucose.

Davis, Daish and Sawyer, $\S$ in the instances of the potato and the mangold, agree that sucrose is a primary sugar of carbon assimilation and from it the hexoses arise. The cane sugar and hexose are at their maximum at mid-day and the amounts increase with the season. Unlike Brown and Morris they

* Parkin: "Biochem. Journ.," I9I2, 6, I.

† Robbins: "Bot. Gaz.," I922, 73, 376.

$\ddagger$ Brannon: id., 1923, 75, 370.

§ Davis, Daish and Sawyer: “ Journ. Agric. Sci.," I 916, 7, 225. 
found pentose to be present whilst maltose was consistently absent, both by day and by night, from the leaves mentioned. In vicw of the presence of starch in the potato leaf, it is surprising that the presence of maltose was not established: there is, however, good reason for supposing that maltase is commonly present in plants in which starch occurs and is digested: this enzyme is rather indiffusible, is destroyed by alcohol and chloroform in ordinary conditions, and is very susceptible to heat, a temperature of $50^{\circ} \mathrm{C}$. having a marked adverse effect upon its activity, whilst at $55^{\circ} \mathrm{C}$. it may be destroyed. It is these properties of maltase which account for the varying statements regarding the occurrence of maltose in green leaves : if the procedure of experiment is such as to destroy the maltase, maltose will be found; if, on the other hand, the enzyme is not destroyed, the maltose is converted into hexose sugars. * Davis, Daish, and Sawyer dropped their material of experiment into boiling alcohol and thus destroyed any maltase that might have been present; their inability to detect maltose was therefore not due to the activity of maltase. The conclusions of these authors regarding the presence of pentose-they estimated that pentose represented from 5 to 25 per cent. of the total sugars-is adversely criticized by Colin and Franquet $\uparrow$ who found that the amount of this sugar in the leaves of the potato and of the beetroot is at most less than 0.03 per cent. of the total sugars.

Gast $\ddagger$ examined the carbohydrate content of the leaves of Tropaolum, Vitis, Musa and other plants collected in the early afternoon and early morning: he found that sucrose always was more abundant than maltose and the other sugars identified; he is in accordance with Brown and Morris regarding the absence of pentose. Kylin $\S$ found that in general terms the amount of glucose varies inversely as the amount of starch. Sucrose is generally the most abundant sugar, especially in sugar leaves, but Gentiana brevidens, a sugar leaf, does not

\footnotetext{
* Davis: "Biochem. Journ.," I916, 10, 31, 49, 56.

† Colin and Franquet: "Bull. Soc. chim. biol.," I927, 9, II 4.

† Gast: "Zeit. physiol. Chem.," I 91 7, 99, I.

\$ylin: id., 1918, 101, 77.
} 
contain any sucrose, whilst Tilia europaa, a starch leaf, contains much sucrose.

These authors, together with others, conclude that sucrose is the first sugar of photosynthesis, but, on the other hand, there is evidence which may indicate that hexose, the sugar required on current theoretical grounds, is the first sugar to be formed, and various arguments have been formulated to show that the results of the work outlined above really indicate that hexose and not sucrose is the first sugar formed in the photosynthetic process.

Lepovsky and others * from their study on the sugars of the sugar beet, conclude that reducing sugars are amongst the first products of carbon assimilation. Weevers $\dagger$ compared the nature of the sugars in the green and non-green parts of a number of variegated leaves. In ten out of the twelve examples examined, sucrose was the only sugar identified in the non-green parts, whilst the green portions contained both sucrose and glucose. Further, hexoses were the first sugars to appear and then sucrose in the chlorophyllous parts of these leaves on exposure to light after a period of darkness sufficient to ensure depletion of carbohydrate. Invertase was present both in the green and in the non-green regions, which suggests that this enzyme by a reverse action condenses monosaccharides to disaccharide. Priestley, $\neq$ in his review of the evidence, points out that the sugars formed in the green leaf are intermediate steps in the fornation of more complex bodies, such as polysaccharides and proteins, for the prompt formation of which the intermediate steps must be rapidly accomplished. Wherefore it is reasonable to conclude that the substances formed :n the intermediate stages, including the first sugar of photosynthesis, would show but little change in their concentration; they would not accumulate in the light and thus would not show fluctuation in amount. In other words, the fact that of the sugars of the green assimilating leaf, sucrose shows the greatest fluctuation in amount during the day

* Lepovsky, Schulz and Link: "Journ. Agric. Res.," I 926, 33, 59.

$\dagger$ Weevers : " Proc. Kon. Akad. Wetens., Amsterdam," 1923, 27, I.

† Priestley: "New Phyt.," 1924, 23, 255. 
indicates not that it is the first sugar of plotosynthesis, as earlier workers concluded, but that it is a secondary product; the available evidence, however, does not prove that sucrose is a storage product. Priestley thinks that cane sugar is produced as a secondary product by the activity of the protoplasm more especially of merismatic cells; it, therefore, is not directly concerned with the synthesis or hydrolysis of starch except in so far that starch and other carbohydrate products of photosynthesis are used up in the anabolic processes of the cell which later produces the sucrose as a secondary product. Priestley concludes that neither physiological nor chemical data support the view that cane sugar has its origin in starch. If starch be a glucose anhydride, it follows that if sucrose is formed from starch some of the glucose must be converted into levulose. There is, however, some evidence that starch is converted in sucrose. Schroeder and Horn * found that the cane sugar content in detached starch containing leaves of Tropaolum varies with the water content, an increase occurring with a falling water supply and a decrease with a rising water content. It was also observed that in the detached leaves of many plants the starch disappears more rapidly if the leaves are allowed to wilt. Ahrens $\dagger$ also observed that in the wilting leaf starch was converted into sucrose and hexose, presumably by hydrolysis; but from what is known of enzyme action, the hydrolysis of starch should accompany an excess of water whilst a lack of water should promote synthesis. For this reason Priestley discounts the above work, in so far as it affects the present problem; it has, however, been supported by the observations of de Wolff, $\ddagger$ who found that sucrose was produced from starch grains containing not more than 53 per cent. of dry starch when slowly dried, but if the grains contained more than the stated amount of dry starch, no sucrose was formed on sinilar treatment. This indicates that the relationship between the amount of water and starch is a factor of importance, and presumably in Ahrens's wilting leaves

* Schroeder and Horn : " Biochem. Zeit.," I922, 130, I65.

† Ahrens: "Bot. Arch.," 1924, 5, 234.

$\ddagger$ de Wolff: “Biochem. Zeit.," I926, 176,, 225. 
there was a sufficiency of water for the reaction to take place. Priestley's thesis is examined by Parkin * and by Chapman $\uparrow$ whose papers may be consulted in the original. Attention may be drawn to two facts: that all sorts of mutations, sometimes chemically obscure, obtain between various car. bohydrates both in the plant and in the animal ; and that the methods of chemical analysis are in the main too gross for the identification of the subtle changes which rapidly occur in the green leaf in which in the light anabolic and katabolic changes are taking place together with others concerned in translocation. For these reasons it is not illogical to assume that the results so far obtained have no significant bearing on the point at issue. As Spoehr $\$$ justly remarks, "In a complex system such as that with which we are dealing here, in which the synthesis and hydrolysis of complex compounds are affected by a variety of conditions, the quantity of any particular substance gives little information regarding the rôle of that substance in a series of reactions. All of the carbohydrates, monosaccharides, disaccharides, and starch are capable of conversion into each other quite independently of the photosynthetic process, and even the identity of the hexoses is not fixed, but they may undergo stereoisomeric change. Unquestionably it would be very helpful if it were known just what the first sugar is that is produced in photosynthesis. In the present state of our knowledge glucose fits the theoretical requirements most adequately. Yet the fact cannot be entirely disregarded that the demonstration of glucose actually being the first sugar formed is still wanting."

Fats sometimes have been described as direct products of carbon assimilation, more especially in plants, such as $\mathrm{Vaut}$ cheria, which have an abundance of fat-like substance in their green tissues. The evidence for the contention is anything but satisfactory, especially in view of the transmutation of carbohydrate into fat in various plants and under the influence

* Parkin: "New Phyt.," I925, 24, 57.

$\dagger$ Chapman : id., I925, 25, 308.

† Spoehr: "Photosynthesis," New York, I926, p. 219. 
of certain external conditions such as low temperature. * The problem has been considered by Meyer $\dagger$ who describes the presence of a colourless fluid of unknown composition and having the physical properties of an oil which occurs in the chloroplasts of Tropcolum. This substance, which is not a fat, since it gives on distillation hexylencaldehyde, increases with assimilation, and is considered by Meyer to be a definite product of carbon assimilation.

\section{HYPOTHESES CONCERNING THE SYNTHESIS OF CARBO- HYDRATE BY THE GREEN PLAN'T.}

With the problems associated with the march of events from the initial carbon dioxide and water to the final carbohydrate, the realms of theory are entered. The hypotheses are many and have this in common-none entirely satisfy the plant physiologist; for which reason it is proposed to consider but few in any detail on the present occasion, not that those discarded are barren of ideas-indeed, some contain valuable suggestions-but that their examination, more especially when unsupported by experimental evidence, would tend rather to obscure than to clarify the problem.

In I 870 Baeyer put forward the hypothesis that the carbon dioxide is split up by the plant into carbon monoxide and oxygen, and that the water is concurrently resolved into its constituent elements. The carbon monoxide and hydrogen thus produced then combine to produce formaldehyde, which undergoes polymerization, and so forms a hexose.

These changes may be represented in the following equations :-

$$
\begin{aligned}
& \left\{\begin{array}{l}
\text { I. } \mathrm{CO}_{2}=\mathrm{CO}+\mathrm{O} \\
\text { 2. } \mathrm{H}_{2} \mathrm{O}=\mathrm{H}_{2}+\mathrm{O}
\end{array}\right. \\
& \text { 3. } \mathrm{CO}+\mathrm{H}_{2}=\mathrm{CH}_{2} \mathrm{O} \\
& \text { 4. } 6\left(\mathrm{CH}_{2} \mathrm{O}\right)=\mathrm{C}_{6} \mathrm{H}_{12} \mathrm{O}_{6}
\end{aligned}
$$

Thus, according to the theory, there are two distinct actions, the first leading to the formation of formaldehyde, and the second to the production of sugar.

* See Vol. I. 674 .

† Meyer: "Ber. deut. bot. Gesells.," I9I 7, 35, 586; 1918, 36, 235 , 
Considering the first part of Baeyer's theory, it is seen that both carbon monoxide and hydrogen are supposed to be produced, but carbon monoxide has been found but once in a free state in the living plant (p. 105), and it is a substance which does not lend itself at all readily to constructive metabolism, the evidence as to whether plants are able to make use of it for synthetic purposes being contradictory. Bottomley and Jackson* state that if the carbon dioxide normally present in the atmosphere be replaced by about twenty times as much carbon monoxide-the increase in the amount of the latter being necessary on account of its lesser solubility in water as compared with carbon dioxide-plants of Tropceolum formed starch and flourished. Preliminary analyses also showed that seeds, when germinated in an atmosphere in which the carbon dioxide had been replaced by carbon monoxide, there was an increase of organic carbon in the seedlings. Further, they found that a negative pressure obtained in the vessels containing the plants assinilating carbon monoxide. This was to be expected if the hypothesis be accepted, for if the carbon monoxide be used up in photosynthesis, then the amount of oxygen set free would be half that evolved in normal photolysis. On the other hand, Krashéninnikoff $\uparrow$ has come to the conclusion, based on a number of experiments, that green plants cannot make use of carbon monoxide; he points out, however, that his evidence does not prove that carbon monoxide is not formed in the early stages of photosynthesis. It may also be remarked that according to the investigations of Sulander, \pm carbon monoxide acts as an anæsthetic, but is much weaker in its action than chloroform. He found that 0.5 per cent. of this gas was sufficient to inhibit the growth of seedlings of the lupin and the germination of the spores of many Fungi. On the other hand, Wehmer $\S$ found that the seedlings of cress and barley are not injured by exposure to an atmosphere containing 50 per cent. of carbon monoxide.

* Bottomley and Jackson : “ Proc. Roy. Soc.," B, I903, 72, I 30.

† Krashéninnikoff : " Rev. gén. Bot.," I909, 2 I, I 77.

+ Sulander: "Beih. bot. Centrbl.," I 909, 24, I., 357.

\$ Wehmer : “ Ber. deut. bot. Ges.," I925, 43, I 84 . 
It does not therefore follow that carbon monoxide is not formed in plants. As is well known, carbon dioxide is itself an anæsthetic if present in a sufficient amount, and possibly it is more potent in this respect than is carbon monoxide, for Sulander found that often the streaming movements of protoplasm was not affected even after several hours' exposure to the lastnamed gas.

According to Baeyer's hypothesis oxygen and formaldehyde are early products of the process and these may now be considered.

\section{ORIGIN OF THE ONYGEN.}

On the thesis that there are two phases in the photosynthetic process, one a light reaction and the other a dark, or chemical, reaction, the oxygen may be split off in either the one or the other. Accordingly Warburg* and others tried the effect of increased temperature, poisons and narcotics on Chlorella under high illumination, the Blackman reaction, and under low light intensity. In both conditions carbon assimilation was inhibited by narcotics and the Blackman reaction also by hydrocyanic acid, but not that in low illumination. Further, the former was accelerated by a rise in temperature, the curve showing a linear function of temperature between $10^{\circ}-30^{\circ} \mathrm{C}$. ; but when light was limiting, an increased temperature was without effect on the photochemical reaction. The alga was then grown in the dark with hydrogen peroxide added to the culture solution and the rate of the cvolution of oxygen, by the action of the Chlorella on the peroxide, measured after treatment with narcotics, poisons and varying temperatures. With regard to temperature the same linear function was found as in the Blackman reaction, and the action of hydrocyanic acid and narcotics was the same. In view of this parallelism, these authors support Willstätter's hypothesis that the oxygen evolved during carbon assimilation owes its origin to the splitting of the chlorophyll peroxide combination (p. 65).

* Warburg: "Biochem. Zeit.," 1919, 100, 230; I920, 103, I88; 1926, 166, 386. Warburg and Uyesugi : $i d ., 1924,146,486$. Yabusoc : $i d ., 1924$, 152, $49 \mathrm{~S}$. 


\section{FORMATION OF FORMALDEHYDE.}

Formaldehyde, as is well known, is poisonous, so that, if formed, it must be polymerized before it has time to injure the protoplasm, and experiments have shown that, in certain conditions, formaldehyde may be made use of by the plant. Thus Bokorny* showed that Spirogyra in the absence of carbon dioxide can make starch when supplied with a compound of formaldehyde and sodium hydrogen sulphite; also Treboux $\dagger$ and Bouilhac have stated that Elodea, Sinapis, and certain Algx can form starch in the dark when supplied with dilute (.0005 per cent.) solutions of formaldehyde.

Grafe $f$ found that green seedlings grown in the light, in an atmosphere free from carbon dioxide and containing not more than I.3 per cent. of formaldehyde vapour showed a greater increase in growth and in dry weight as compared with the controls. These results were corroborated by Baker, $\S$ who concluded from most carefully controlled experiments that formaldehyde could be assimilated to a certain extent in the light, but not in the dark, in an atmosphere void of carbon dioxide.

Jacoby $\|$ compared the dry weights of starch-free leaves of Tropaolnim, grown in an atmosphere lacking carbon dioxide, with and without the addition of gaseous formaldehyde. Those treated with formaldehyde were more green and showed an increase in dry weight varying from $1 \cdot 7$ to $5 \cdot 4$ per cent. over the controls. He concluded that in all probability not only was the formaldehyde fixed, but underwent a condensation similar to that formulated by Willstätter and Stoll; in other words, formaldelyde is an intermediate product in carbon assimilation.

Bodnár, Róth and Bernauer If similarly found an increase in the dry weight and carbohydrate content of leaves exposed

* Bokorny: "Biol. Zentrbl.," I 897, I7, I ; I9 16, 36, 385; “ Ber. deut. chem. Gesells.," I891, 24, Iо3.

† Treboux: "Flora," I903, 92, 49.

† Grafe: "Ber. deut. bot. Gesells.," I9I I, 29, I9.

§ Baker: "Ann. Bot.," 19I3, 27, 4 I I.

II Jacoby : “ Biochem. Zeit.," I9I9, I0I, I.

ๆl Bodnár, Róth and Bernauer: "Biochem. Zeit.," I927, 190, 304. 
to the vapour of formaldehyde, and Sabalitschka and Weidling * observed that Elodea is able to build carbohydrate from solutions containing 0.024 per cent. of formaldehyde or 0.032 per cent. of acetic aldehyde in darkness as well as in light.

There is much positive evidence of the presence of formaldehyde in green leaves. Thus Klcin and Werner $†$ from their experiments conclude that formaldehyde and acetic aldehyde thus occur; the former was only found in leaves in which carbon assimilation had taken place; it was absent in leaves kept in an atmosphere free from carbon dioxide, or grown in darkness, and in leaves narcotized by phenyl urethane or by hydrocyanic acid. Acetic aldehyde, on the other hand, was found in narcotized leaves, and also in leaves kept in darkness; it is regarded by the authors as a product of respiration.

Mention has above been made of the formation of formaldehyde and of formic acid from carbon dioxide and water under the influence of different forms of energy.

Willstätter and Stoll $\ddagger$ argue that the " assimilatory ratio," $\mathrm{CO}_{2} / \mathrm{O}_{2}$, should provide evidence regarding the possible intermediate products; they point out that oxalic, formic and glyoxylic acids and formaldehyde are possible intermediate products between the carbon dioxide and carbohydrate. The assimilatory ratios of these substances are respectively, 4, 2, I.33 and I. In their experiments, they found the assimilatory ratio to be $\mathrm{I}$ and it remained constant, even in succulents, in varying amounts of carbon dioxide and oxygen and with the temperature ranging from $10^{\circ} \mathrm{C}$. to $35^{\circ} \mathrm{C}$; it is concluded therefore that the carbon dioxide is reduced to formaldehyde, this being the only product having a single carbon atom.

POLYMERIZATION OF FORMALDEHYDE TO SUGARS IN VITRO.

Laboratory experiments on the polymerization of formaldehyde to sugars not infrequently are quoted in support of the formaldehyde hypothesis.

† Sabalitschka: "Z. angew. Chem.," I922, 35, 684. Sabalitschka and Weidling: "Biochem. Zeit.," I926, 172, 45.

* Klein and Werner: "Biochem. Zeit.," I926, 168, 36r. See also Vol. I., Section on Aldehydes.

‡Willstätter and Stoll: "Ber, deut. chem. Gesells.," I917, 50, I777. 
The first successful attempt to bring about such a polymerization was made by Butlerow in $\mathrm{I} 86 \mathrm{I}$, who, by the catalytic action of lime water, at ordinary temperatures, on trioxymethylene (itself a polymer of formaldehyde), obtained a syrup with a somewhat bitter taste, which he called methylenitan. Subsequently Loew undertook an investigation of the action of milk of lime on formaldehyde, and devised the following experiment. A 4 per cent. solution of formaldehyde is mixed with an excess of milk of lime and repeatedly shaken for about half an hour ; after filtering, the mixture is set aside for some days until the pungent smell of formaldehyde has disappeared. The solution, which will now reduce Fehling's solution, yields a colourless syrup with a very sweet taste.* This substance, which is known as crude formose, was exam. ined by Emil Fischer, who found it to consist of a mixture of various hexoses and succeeded in isolating from it a small quantity of a sugar-acrose. Acrose can also be obtained by the action of dilute caustic soda on glycerose, a substance obtained by the oxidation of glycerol. From the acrose thus formed Fischer was able by an elaborate series of reactions to prepare ordinary fructose or levulose. In respect to the action of weak alkalis, Spoelır found that sunlight had no action on a 3 per cent. solution of formaldehyde in the presence of such salts as calcium carbonate, potassium carbonate, and potassium nitrate in decinormal concentration, no trace of sugar being found after an insolation period of four months.

With regard to the formation of the higher carbohydrates, Fisher and Armstrong $\dagger$ were able to synthesize a disaccharide-isolactose-by the action of an enzyme, Kefir lactase, on a mixture of glucose and galactose; the same authors also synthesized melibiose; similarly isomaltose has been obtained by Croft-Hill $\$$ by the action of maltase on glucose;

* More recently Ewart (" Proc. Roy. Soc.," Victoria, I919, 31, 328) has worked out the best conditions for the polymerization of formaldehyde to sugar, and finds that the most rapid reaction is produced by sodium hydroxide in the presence of a neutral calcium salt.

† Fisher and Armstrong: "Ber. deut. chem. Gesells.," I902, 35, 31 44 .

† Croft-Hill : " Journ. Chem. Soc.," I 898, 73, 634; see also Emmerling: "Ber. deut. chem. Gesells.," rgor, 34, 600, 2206. 
and Pictet and Vogel * have synthesized sucrose from glucose and fructose.

\section{SUMMARY OF THE EVIDENCE RELATING TO THE FORMALDEHYDE HYPOTHESIS.}

It is obvious from this survey that the hypothesis of Baeyer has influenced to a remarkable degree investigations on the synthetic aspects of carbon assimilation ; this to a large extent is psychological, for the hypothesis is attractive in that it is plausible and lends itself readily to test-tube investigation. The evidence readily centres around distinct nuclei-the identification in the plant of the critical initial intermediate products; the effect of presenting the plant with some of these initial substances in place of natural raw material; and the elaboration of the final from the supposed initial products in the laboratory-and may be briefly considered under these heads :-

Carbon Monoxide.-This gas, if produced, must be fixed with extreme rapidity, for there is no evidence of its occurrence as such in assimilating tissues, which is remarkable for a compound so incrt. The evidence for its use by the plant when substituted for carbon dioxide is inconclusive.

Formaldehyde.-There is no doubt that formaldehyde can be obtained from green leaves, there being many compounds which yield it more or less readily on decomposition. The production of formaldehyde in artificial chlorophyll systems was once considered strongly to support Baeyer's hypothesis, $\dagger$ but the work of Jörgensen and Kidd, who were the first to use pure chlorophyll in this connection, seriously discounts the significance of the reactions since the formaldehyde has its origin in the oxidation of the chlorophyll; it is not produced in such systems if oxygen be absent. Much of the evidence relating to the production of formaldelyde from carbon dioxide and water under the influence of radiant energy is contradictory. lts balance strongly supports the view that free formalde-

* Pictet and Vogel : "Compt. rend.," r928, 186, 727. See Vol. I., p. II 3 .

† See, for example, Usher and Priestley: " Proc. Roy. Soc.," B, I9o6, 77, 369; 1906, 78, 3 I8; 19 I , 84, гог. 
hyde is not formed, provided every precaution is taken to ensure the absence of impurities. If it does form a stage in the photosynthetic process, it is immediately condensed to some other substance, possibly sugar, or is used up in some other way.

The contention of Willstätter and Stoll based on the as similatory ratio is ingenious, but, since the formaldehyde was not actually demonstrated, the evidence is not convincing.

Feeding Experiments.-That plants in abnormal conditions, deprived of their natural raw food materials, may make use of other substances in the elaboration of their food shows that the plant is a transcendental chemist and in virtue of its powers can to a certain degree make use of the substitutes. The facts do not prove that these substitutes are normal intermediate products in the natural process. If, on the other hand, it is held that this kind of evidence is of direct value, then the weight of evidence is on the side of formic acid.

The Production of Sugar from Formaldehyde.-The evidence for the condensation of formaldehyde to hexose sugars in the laboratory under the influence of various catalysts is convincing : but valuable though such evidence be, especially in providing points d'appui, it does not follow that such a sequence obtains in the plant. The formaldehyde hypothesis requires a hexose as the initial sugar: the general opinion of those who have concerned themselves with the final products of carbon assimilation is that sucrose, not a hexose, is the first recognizable sugar, but, as has been pointed out on an earlier page, the known facts may equally well indicate that a hexose is the first formed sugar.

SUMMARY OF THE OPINION OF IVILLSTÄTTER AND STOLL.

Willstätter and Stoll agree with Bacyer that formalde. hyde is the intermediate link between the carbon dioxide supplied to the plant and the carbohydrate synthesized with the help of chlorophyll. It has already been pointed out (p. 60) that their chief argument in support of this view is based upon the constant value, I, obtained for the so-called 
assimilatory ratio; this ratio is obtained by dividing the volume of carbon dioxide supplied to the plant by the volume of oxygen evolved; according to theory, the complete reduction of carbon dioxide, i.e. the removal of both oxygen atoms, might proceed through successive stages of oxalic, glycollic and formic acids down to the formaldehyde stage, but in that case the assimilatory ratio would be respectively 4,2 , or I.33 for each of the acids mentioned, whereas formaldehyde alone requires the value I which is the figure actually obtained in a number of experiments in varied conditions. This argument is not based upon the actual experimental denonstration of formaldehyde isolated from assimilating leaves, and, with regard to this particular question, these authors have revised many of the statements made by previous workers. It will be remembered that repeated attempts have been made to demonstrate the formation of formaldehyde by the action of chlorophyll upon carbon dioxide outside the plant. The earlier work of Usher and Priestley, demonstrating the formation of this substance in films of chlorophyll exposed to an atmosphere of carbon dioxide in sunlight, was shown by Wager * and Warner $\dagger$ to be faulty, inasmuch, as Wager showed, that no formaldehyde was produced if oxygen was excluded, whilst Warner showed that carbon dioxide was unnecessary and took no part in the production of the formaldehyde. Warner concluded that the formaldehyde was in fact an oxidation product of the chlorophyll since oxygen was actually absorbed in the process. The experiments of Willstätter and Stoll, show that no formaldehyde at all was formed if pure chlorophyll in colloidal solution was employed, the colloidal solution being considered to approximate most closely to the condition of the chlorophyll in the chloroplast. The formaldehyde described by the earlier workers is attributed to the oxidation of impurities accompanying the samples of chlorophyll used by them.

The failure to obtain any trace of formaldehyde from pure chlorophyll in vitro is attributed by Willstätter and Stoll to

*Wager : “ Proc. Roy. Soc.," B, I914, 87, 386.

$\dagger$ Warner : id., 378 . 
the absence of the essential enzyme which these authors postulate in the green leaf, and this brings us to the consideration of the mechanism of the action of chlorophyll upon carbon dioxide as visualized by these authors.

Experiments in vitro have shown that carbon dioxide can form with chlorophyll (I.) in colloidal solution an additive compound of the type of a bicarbonate (II.) as expressed by the equation

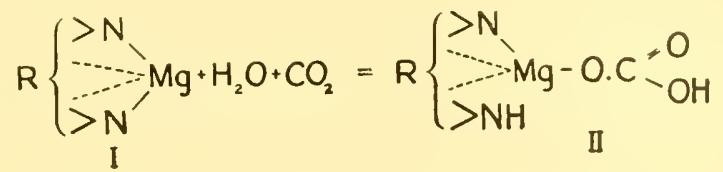

This compound (II.) cannot be imagined to be capable of parting with two atoms of oxygen with regeneration of chlorophyll, so that some intramolecular rearrangement must first take place, and this, according to Willstätter and Stoll, involves the absorption of energy which is supplied by the sunlight. This cluange to a formaldehyde peroxide compound (III.) may be illustrated as follows :-

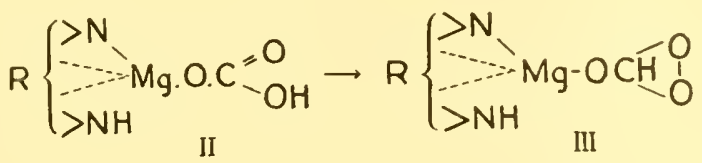

It is true that experiments in vitro have entirely failed to demonstrate the formation of a peroxide compound by means of horse-radish peroxidase, but this is considered to demonstrate the essential differcnce between test-tube experiments and the activity of the living cell. Further, there is no doubt that chlorophyll in the chloroplast is protected from photo-oxidation or decomposition by carbon dioxide in a way that chlorophyll in colloidal solution in vitro is not, since the chloroplast will tolerate concentrations of carbon dioxide which decompose chlorophyll in colloidal solution to the magnesium-free compound phaeophytin (V.) with precipitation of magnesium carbonate as illustrated by the equation

$$
\mathrm{C}_{55} \mathrm{H}_{72} \mathrm{O}_{5} \mathrm{~N}_{4} \mathrm{Mg}+\mathrm{H}_{2} \mathrm{O}+\mathrm{CO}_{2}=\underset{55}{\mathrm{C}_{55}} \mathrm{H}_{74} \mathrm{O}_{5} \mathrm{~N}_{4}+\mathrm{MgCO}_{3}
$$

VOL. II. -5 
Such a peroxidic compound (III.) as is postulated above should be capable of losing oxygen either in one or in two stages with regeneration of unaltered chlorophyll and formation of formaldehyde (IV.)

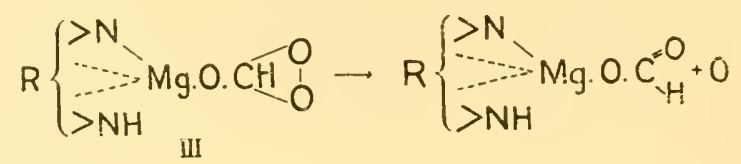

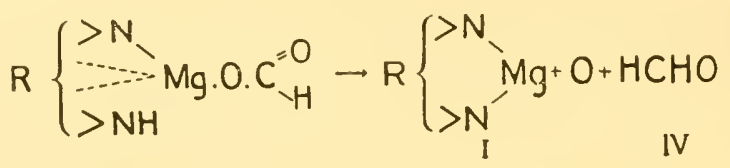

Within the living cell the decomposition of the peroxide formaldehyde compound (III.) is assumed to be brought about by an enzyme, the existence of which enzyme is supported by the experimental evidence relating to the assimilation number which has already been considered (p. 43).

Willstätter and Stoll's views are founded on Baeyer's theory; this formaldehyde hypothesis is certainly attractive and is supported by many and various observations; its degree of probability is a matter of personal opinion, being dependent on the relative values of the known facts. But the attractiveness of a hypothesis, or of a witness, or of an item of evidence must not outweigh the many deficiencies, the fulfilment of which is requisite for a relative scientific proof, an absolute proof being hardly possible; wherefore the conclusion is reached that the formaldehyde hypothesis is not proven.

\section{OTHER OPINIONS.}

FORMIC ACID.

Erlenmeyer was the first to suggest that formic acid is the more likely intermediate product of early origin, but it is only of recent years that renewed attention has been given to the possibility. The work of Spoehr has already been mentioned: he demonstrated that carbon dioxide and water are easily reduced to formic acid by means of radiant energy; 
from formic acid a sugar-like substance is formed, in conditions such as obtain in an active leaf, which the plant can utilize as a foodstuff. He points out that in Grafe's and Baker's work the plants were in reality supplied with formic acid, since formaldehyde is oxidized in the light, and he himself found that plants increased in dry weight in an atmosphere of formic acid. Wislicenus* also supports the formic acid hypothesis. The thesis, however, has attracted but little attention, for which reason there is not enough evidence to warrant a conclusion.

\section{MAQUENNE'S HYPOTHESIS.}

Maquenne $\dagger$ has formulated a theory of photosynthesis which is independent of the formation of formaldehyde or formic acid as intermediate products.

According to current ideas, the conversion of $n$ molecules of carbon dioxide into a compound containing $n$ carbon atoms involves a polymerization which, according to the formalde. hyde hypothesis, is subsequent to the formation of the intermediate compound, formaldehyde. On Maquenne's hypothesis, polymerization may precede or merely accompany the decomposition of carbon dioxide.

Willstätter and Stoll consider that chlorophyll may exist in a true or in a colloidal solution; $\ddagger$ in the former state it is unaffected by carbon dioxide but in the latter state carbon dioxide and chlorophyll combine to form a compound of a bicarbonate type.

Maquenne suggests that colloidal chlorophyll is either a simple hydrate of ordinary molecular chlorophyll or a polymer in which the molecules are united by loose supplementary valencies due, say, to the magnesium becoming tetravalent as in formula III.

On the addition of carbon dioxide and water, a substance of formula I. results which by photochemical action yields a compound of fornula II. which, being unstable, gives off

* Wislicenus: "Ber, dent. chem. Ges.," I9I8, 5I, 942.

$+C f$. Maquenne: "Compt. rend.," I923, I77, 853 .

† See Vol. I., p. 307 . 
molecular oxygen without the formation of hydrogen peroxide, and the carbon chain, formula IV., is disengaged and thus regenerates the original colloidal chlorophyll complex III. The number of carbon atoms in the carbohydrate formed will be the same as the number of magnesium atoms in the colloidal chlorophyll micelle: the process, therefore, does not involve the formation of any intermediate substance, such as formaldehyde, between the carbon dioxide and the final carbohydrate.

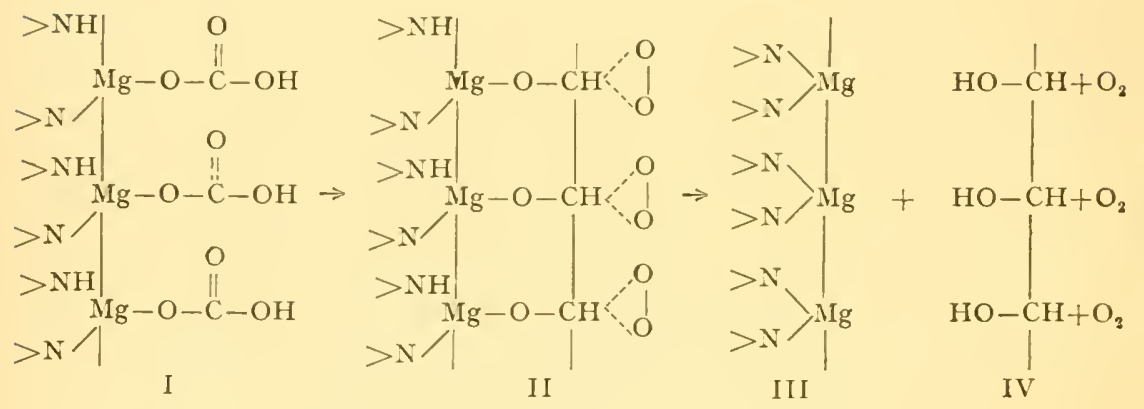

Much physiological evidence is required before this ingenious speculation can be accepted; one point, and that essential, only will here be made : the thesis is founded on the colloidal state of chlorophyll, a foundation which, from the work of Stern * and Noack, $\dagger$ is not certain.

*Stern: "Ber. deut. bot. Ges.," I $920,38,28$; “Zeit. bot.," I92I, I3, 193.

† Noack: "Biochem. Zeit.," 1927, 183, I 35, I 53.

FURTHER REFERENCES.

Stiles: " Photosynthesis," London, 1925.

Spoehr: "Photosynthesis," New York, 1926. 


\section{CHAPTER III.}

\section{THE SYNTHESIS OF FATS.}

A CONSIDERAtion of the salient features of the physiological significance of fats has been given in the first volume, ${ }^{*}$ in which place the consideration was retained for the sake of a closer association of the characterization and other properties of fats with the physiological problems involved. For this reason a general survey only, with such departures into detail as necessity demands, will be given on the present occasion.

In the plant fats are commonly associated with the reserve food in seeds, spores, and vegetative perennating organs, but in smaller quantity they are probably present in all living cells. As a food they have considerable value in that on physiological combustion they yield more energy weight for weight than either protein or carbohydrate, the relative energy. producing values being roughly $5: 3: 2$ respectively. $\dagger$

The immediate question is the origin of fats: Have they a photosynthetic origin from raw material in much the same way as carbohydrates, or have they their origin in the transformation of carbohydrate or of protein?

It was once thought that in some plants fats were direct photosynthetic products; Vaucheria was the prominent example amongst the lower plants and of the higher plants those showing elaïoplasts were quoted. As has been mentioned, there is some doubt regarding the composition of the fat-like body occurring in Vaucheria $\dagger$ and on the available evidence it is impossible to draw a definite conclusion.

*Vol. I., p. 34. See also Terroine: “Ann. Sci. Nat. Bot.," I919, sér. $x ., 1, i$.

† See Terroine, Trautmann and Bonnet: "Compt. rend.," 1925, 180, I181; “ Bull. Soc. chim. biol.," I925, 7, 461 .

$\ddagger$ See Vol. I., p. 35 . 
In the green leaf fat occurs: an examination of the ether extract of the leaf tissue of the cabbage by Chibnall and Channon* has shown it to contain fats whose acids are for the most part unsaturated, namely linoleic and linolenic, but the presence of oleic has not been established. The extract contained no, or very little, phospholipin, but the presence was established of the calcium salt of a diglyceride phosphoric acid of the formula<smiles>[R]C(=O)OCC(COC([R])=O)P(=O)(O)O</smiles>

To this substance the authors give the name of phosphatidic acid and suggest that it may be the precursor of lecithin and kephalin in the animal body. These facts, however, do not provide evidence of the photosynthetic origin of fats, nor do the presence of elaioplasts, which apparently are degraded chloroplasts. It must, therefore, be concluded that the facts relating to the occurrence of fats and kindred substances in chlorophyll-containing cells do not permit the drawing of a definite conclusion in regard to the present problem, and, in fact, there would appear to be no evidence to warrant the conclusion that fats have a synthetic origin from raw materials in the same sense as carbohydrates. For this reason their origin must be sought out elsewhere: the proteins and the carbohydrates are the obvious sources.

Formation from Proteins.-Of the formation of fats from proteins, little is known : the known facts indicate a relationship between these two classes of compounds, but the significance of this relationship is not clear. Evidence is not wanting that proteins, in certain circumstances, may be converted into fats; but this evidence relates to the animal rather than to the plant.

In the plant there would appear to be some correlation, 479.

* Chibnall and Channon: "Biochem. Journ.," I927, 2I, 225, 233. 
although obscure, between protein and fat. Thus Stark* found that the oil and protein content of the soy bean are correlated, in that cultural conditions which influence the one also influence the other in the opposite direction; manuring with lime, phosphate and organic substances results in an increase of protein and a decrease in fat; potash, on the other hand, has an opposite effect.

Origin from Carbohydrates. - The weight of cvidence favours the view that in the carbohydrates is to be found the origin of fats in most instances.

The conversion of carbohydrate to fat in plants, or parts of plants, exposed to a low temperature; the development of fats in immature seed separated from the parent plant; and the fattening of animals on a carbohydrate diet, indicate the close physiological connection between the two classes of compounds.

The evidence given by the facts relating to the development of fats in storage organs such as the seed and structures of vegetative propagation and to the changes which take place in the germination of a fat-containing seed, may here be given.

Fat makes its appearance in the storage organ as that member approaches maturity. There can be but little doubt that it is formed in situ from materials in the immediate neighbourhood, a fact which is emphasized by many observations on the development of fats in seeds isolated from the plant whilst in an immature condition and originally containing little or no fat.

Quantitive results are not wanting. Numerous observations, amongst which those of Schmidt, Le Clerc du Sablon, de Luca, Funaro, and Ivanow may be mentioned, show that in the maturation of the seed, the increase in the amount of fat and the decrease in the amount of carbohydrate are concurrent. This is illustrated in the accompanying tables representing the results of two experiments by Le Clerc du Sablon :-

* Stark: “Journ. Amer. Soc. Agron.," i 924, 16, 636. 
WALNUT.

\begin{tabular}{|c|c|c|c|c|c|c|c|}
\hline \multicolumn{5}{|c|}{ Date of Gathering. } & $\begin{array}{c}\text { Per Cent. } \\
\text { Fat. }\end{array}$ & $\begin{array}{l}\text { Per Cent. } \\
\text { Glucose. }\end{array}$ & $\begin{array}{l}\text { Per Cent. } \\
\text { Sucrose. }\end{array}$ \\
\hline 6 July . & . & . & - & . & 3 & $7 \cdot 6$ & o \\
\hline I August & . & . & . & . & 16 & $2 \cdot 4$ & 0.5 \\
\hline I 5 August & . & . & . & . & 42 & o & 0.6 \\
\hline I September & . & . & . & . & 59 & o & 0.8 \\
\hline 4 October & . & . & . & . & 62 & o & $I \cdot 6$ \\
\hline
\end{tabular}

ALMOND.

\begin{tabular}{|c|c|c|c|c|c|c|}
\hline \multicolumn{3}{|c|}{ Date of Gathering. } & $\begin{array}{c}\text { Per Cent. } \\
\text { Fat. }\end{array}$ & $\begin{array}{l}\text { Per Cent. } \\
\text { Glucose. }\end{array}$ & $\begin{array}{l}\text { Per Cent. } \\
\text { Sucrose. }\end{array}$ & $\begin{array}{l}\text { Per Cent. } \\
\text { Starch and } \\
\text { Dextrins. }\end{array}$ \\
\hline 9 June & . & . & 2 & 6 & $6 \cdot 7$ & $2 I \cdot 6$ \\
\hline 4 July & . & . & I0 & $4 \cdot 2$ & $4 \cdot 9$ & I $4 \cdot \mathrm{I}$ \\
\hline I August. & . & . & 37 & o & $2 \cdot 8$ & $6 \cdot 2$ \\
\hline I September & . & . & 44 & o & $2 \cdot 6$ & $5 \cdot 4$ \\
\hline 4 October. & . & - & 46 & o & $2 \cdot 5$ & $5 \cdot 3$ \\
\hline
\end{tabular}

The carbohydrates which serve as raw material for the elaboration of fats vary with the plant; glucose, sucrose and starch would appear to be most commonly employed in this connection, the last two being initially hydrolysed.

It is a well-known fact that during the germination of fatcontaining seeds, carbohydrates appear and fats disappear. Thus Mazé * found that the isolated cotyledons of arachis seeds increased in their dry weight from $2 \cdot 2613$ to 2.6153 grams, an increase due to the fixation of oxygen, whilst their sugar content increased from 3416 to 4684 gram.

The disappearance of the fats is due, in the main, to their translocation to the meristematic and growing regions of the developing embryo. This conveyance may be effected by the movement of fats as such in addition to the transport of the products of their hydrolysis, which change takes place in the storage organ.

Schmidt $\uparrow$ studied the movement of oils in the intercellular space system of the axis of pea scedlings and found that the rate of movement depended on the amount of fatty acid present ;

* Mazé : "Compt. rend.," I900, 130, 424.

† Schmidt: "Tlora," I891, 74, 300. 
he also found that a neutral oil would not enter the cell unless there were present a minimum of IO per cent. of free fatty acid. It was therefore concluded that the free acid formed a soap which emulsified the fat, in which condition it could move from cell to cell, a conclusion which Schmidt supported by his inability to detect either sugar or starch in the endosperm of germinating fat-containing seeds. Rhine* has repeated Schmidt's work and disagrees with his observations and conclusions. Rhine found that the rise of oils in the intercellular space system was not dependent on the presence of free acid, and that neutral fats do enter the cell from the intercellular spaces, but this is dependent, not on the presence of free acid, but on the water deficiency of the cell wall ; if the cell wall is not allowed to lose water, which, from the experimental procedure, is likely to happen, there is no intake of fat. The presence of relatively large quantities of sugar was established in the endosperm of germinating seeds of the castor oil plant, hemp and flax; Schmidt found none. Rhine also points out that the soap formation would appear to be improbable in view of the $p H$ values which occur. The formation of a soap is dependent on a neutral or alkaline medium, an acid reaction is inhibitive; in the plants examined, the reaction was always on the acid side; in most tissues the $p H$ was $6 \cdot 2$, the highest value observed being $6 \cdot 8$.

As may be read in the chapter on Respiration, the respiratory ratios differ in accordance with the material consumed; from his comparison of these ratios in the hypocotyls of seedlings of fat-containing seeds and of starchy seeds, Rhine concludes that the material respired by the former could not be fat. Thus the general conclusion is reached that in normal conditions fats are not translocated as such, and that the fat contained in a seed undergoes hydrolysis and is converted into sugar before transport takes place.

Le Clerc du Sablon, Ivanow, Miller and others have thrown much light on the hydrolysis of fats in their studies on the germination of various fat-containing fruits and seeds. Lipase

* Rhine : "Bot. Gaz.," 1926, 82, I 54. 
is the enzyme concerned, and by its activity the fat is hydrolysed into glycerol and fatty acid, which products are used either immediately for the needs of the seedings or are first converted into carbohydrate. Agreement is general that as germination proceeds, the acid radicals becomes saturated, as is indicated by the decrease in the iodine value, and the rate of consumption of these acids is inversely proportional to their degree of saturation.

As the fats decrease, the carbohydrates increase, a fact brought out in the following analysis of arachis seedlings by Maquenne :-*

\begin{tabular}{|c|c|c|c|}
\hline Age in Days. & $\begin{array}{l}\text { Per Cent. } \\
\text { Fat. }\end{array}$ & $\begin{array}{l}\text { Per Cent. Carbo- } \\
\text { hydrate other than } \\
\text { Cellulose. }\end{array}$ & $\begin{array}{l}\text { Cellulose and } \\
\text { other Insoluble } \\
\text { Carbohydrates. }\end{array}$ \\
\hline o & $5 I \cdot 39$ & I I 55 & $2 \cdot 5 \mathrm{I}$ \\
\hline 6 & $49.8 I$ & $8 \cdot 35$ & $3.4^{6}$ \\
\hline I0 & $36 \cdot 19$ & I I $\cdot 09$ & $5 \cdot 01$ \\
\hline 12 & 29.00 & I $2 \cdot 52$ & $5 \cdot 22$ \\
\hline I8 & $20 \cdot 45$ & $12 \cdot 34$ & $7 \cdot 29$ \\
\hline 28 & $12 \cdot 16$ & $9 \cdot 46$ & $9 \cdot 4^{8}$ \\
\hline
\end{tabular}

The nature of the carbohydrate formed differs in different plants; glucose would appear to be the most common, but sucrose, starch and dextrins also are described. It is not unlikely, as Maquenne has pointed out, that the nature of the carbohydrate depends upon the kind of fat and its degree of saturation. He considers that the saturated fatty acids contribute in a much lesser degree to the formation of sugars than do the unsaturated acids, and that the saturated fatty acids are principally used for respiratory purposes. Agreement, however, between the authorities in respect to this aspect of the subject does not obtain. Ivanow considers that there is no real difference between the saturated and unsaturated fatty acids in their power to give origin to carbohydrates, the difference in their amounts being due to the more rapid conversion of the unsaturated variety. However this may be, the salient feature in the germination of a fat-containing seed

* Maquenne : "Compt. rend.," I $\$ 98,127,625$. 
is the conversion of the fat into carbohydrate, the reverse to what obtains during the maturation of the seed. The change is effected by the activity of lipase which hydrolyses the fat into glycerol and fatty acid.

The work of Ivanow has shown that lipase has a reversible action, and whether it hydrolyses or synthesizes fats is merely a question of conditions, mainly the presence or absence of water. The glycerol extract of a fat-containing seed, which cxtract contains the lipase, mixed with oleic acid will synthesize a fat: the addition of water will result in the hydrolysis of this fat into glycerol and fatty acid.

In the synthesis of fats, Ivanow considers that higher saturated acids of the fatty series are the first to be formed from the sugar, and these are converted into unsaturated acids which combine with the glycerol to form the fat.

With regard to the origin of glycerol, the chemical relationship between this substance and glucose is so close as to suggest at once the possible inter-relation of the two; further, glycerol may have an origin in respiratory processes as is shown by the production of this substance during the alcoholic fermentation of sugar.

Maclean and Hoffert * have studied the formation of fat in Saccharomyces. When yeast is incubated in oxygenated water, part of the reserve carbohydrate disappears and the amount of fat increases. This change docs not take place if the yeast is grown in M/IO oxygenated solutions of propyl, butyl and isoamyl alcohols, but does happen when the plant is incubated in M/IO solutions of sodium formate, sodium propionate, sodium butyrate, glycerol and acetone. When cultivated in 5 per cent. solutions of ethyl alcohol, sodium acetate, sodium lactate or sodium pyruvate, an increase in the amount of fat occurs similar to that effected by a 0.5 per cent. solution of glucose, but this amount of fat is not further increased by the higher concentration of the substances mentioned. In sugar solutions, on the other hand, the cells incubated in oxygenated solutions store up fat, in addition

* Maclean and Hoffert: "Biochem. Journ.," 1923, 17, 720. See also Maclean : id., 1922, 16, 370 . 
to carbohydrate, in amounts depending on the concentration of the sugar and this is indepcndent of the nature of the sugar.

Maltose is more effective in promoting the storage of carbohydrate and less effective in bringing about the formation of fat as compared with fructose, glucose and sucrose: the presence of phosphate increases the amount of fat and decreases the amount of carbohydrate stored. The presence of oxygen is an essential condition for this fat production.

In the present consideration, the salient points of Maclean and Hoffert's investigation are the relationship between carbohydrate and fat and the possible substitution of carbohydrate in the culture medium by salts of acetic, lactic and pyruvic acids.

Haehn and Kinttof* showed that the fungus Endomyces vernalis was able to build up fat when grown on a medium containing acetic aldehyde and even ethyl alcohol as the only source of carbon, which possibly indicates that acetic aldehyde may be a stage in the conversion of sugar into fats. The sequence they suggest is glucose $\rightarrow$ pyro-racemic acid $\rightarrow$ acetaldehyde $\rightarrow$ aldol $\rightarrow$ glycerol esters.

The evidence outlined above gives strong support to the thesis that fats have their origin in carbohydrates: the chemical aspect of this probability may now be considered.

The striking recurrence of the eighteen carbon atom fatty acids belonging to the various series exemplified by stearic acid $\mathrm{C}_{18} \mathrm{H}_{36} \mathrm{O}_{2}$, oleic acid $\mathrm{C}_{18} \mathrm{H}_{34} \mathrm{O}_{2}$, linoleic acid $\mathrm{C}_{18} \mathrm{H}_{32} \mathrm{O}_{2}$, linolenic acid $\mathrm{C}_{18} \mathrm{H}_{30} \mathrm{O}_{2}$ gave rise to the suggestion that such acids were produced by the direct union of three six-carbon atom sugars; there are, however, several reasons for rejecting this liypothesis. In the first place, there is no particular reason to exclude the association of hexoses with pentoses; thus supposing one hexose and two pentoses to be involved, an acid containing sixteen carbon atoms would result; a difficulty, however, arises in the fact that a single molecule of a hexose and a pentose respectively would result in a fatty acid containing eleven carbon atoms, but it is a well-known fact that

* Haehn and Kinttof: "Ber. deut. chem. Ges.," 1923, 56, 439. 
the acids entering into the composition of the vegetable fats invariably contain an even number of carbon atoms. On these grounds this theory of the formation of the fatty acids must be rejected.

Another question of importance in connection with the fatty acids is whether the acids of lower molecular weight have been derived from those of higher molecular weight; or whether, on the contrary, they represent stages in the building up of acids of high molecular weight. The discovery by Windaus and Knoop that in nature the point of attack upon a fatty acid is the $\beta$-carbon atom, has proved of considerable importance. The process may be illustrated by a concrete example: butyric acid is oxidised in the animal to $\beta$-hydroxybutyric acid

$$
\mathrm{CH}_{3} \mathrm{CH}_{2} \mathrm{CH}_{2} \mathrm{COOH}+\mathrm{O} \rightarrow \underset{\beta \text {-hydroxybutyric acid }}{\mathrm{CH}_{3} \mathrm{CHOH}} \cdot \mathrm{CH}_{2} \cdot \mathrm{COOH}
$$

a reaction which was first effected in vitro by Dakin with the use of hydrogen peroxide. In general terms, an acid of the formula $\mathrm{R}-\mathrm{CH}_{2} \cdot \mathrm{CH}_{2} \mathrm{COOH}$ is thus converted into an acid R. $\mathrm{CHOH}$. $\mathrm{CH}_{2} \mathrm{COOH}$, and this, on further oxidation, yields an acid $\mathrm{RCOOH}$ which, as will be seen, contains two atoms of carbon less than the original acid. This method of oxidation thus accounts for the production by metabolic oxidation only of acids with an even number of carbon atoms, assuming the original acids to have contained an even number.

The alternative suggestion that acids of high molecular weight are built up from those of lower molecular weight is one which is more acceptable in explaining the production of fatty acids from carbohydrates.

It was first suggested by Nencki * that in the production of butyric acid from lactic acid by fermentation, acetic aldehyde was an intermediate stage; the changes involving the formation of a four-carbon fatty acid (butyric acid) from a three-carbon acid (lactic acid) could be accounted for as follows :-

$$
\underset{\text { Lactic acid }}{\mathrm{CH}_{3} \mathrm{CHOHCOOH}}=\underset{\text { Acetic aldehyde }}{\mathrm{CH}_{3} \mathrm{CHO}}+\underset{\mathrm{CO}_{3}}{\mathrm{CH}_{2}}+
$$

* Nencki : "J. prakt. Chem.," 1878, I 7, 105. 
Two molecules of acctic aldehyde then undergo an aldol condensation-

$$
\mathrm{CH}_{3} \mathrm{CHO}+\mathrm{CH}_{3} \mathrm{CHO}=\mathrm{CH}_{3} \mathrm{CHOHCH} \mathrm{H}_{2} \mathrm{CHO}
$$

and the resulting aldol by molecular rearrangement gives butyric acid-

\section{$\mathrm{CH}_{3} \mathrm{CHOH} \mathrm{CH} \mathrm{CH}_{2} \mathrm{CHO} \rightarrow \mathrm{CH}_{3} \mathrm{CH}_{2} \mathrm{CH}_{2} \mathrm{COOH}$.}

The conception of making use of aldol condensations for the successive building up of more and more complex aldols by the serial addition of two atoms of carbon was developed by Magnus Levy* and subsequently by Leathes. $\dagger$ Thus the formation of an eight-carbon fatty acid can be explained by the following changes :-

$$
{ }_{4} \mathrm{CH}_{3} \mathrm{CHO}=\mathrm{CH}_{3} \mathrm{CHOH} \mathrm{CH}_{2} \mathrm{CHOH} \mathrm{CH} \mathrm{CHOH} \mathrm{CH}_{2} \mathrm{CHO}
$$

which, by loss of four molecules of water, would give the unsaturated aldehyde $\mathrm{CH}_{3} . \mathrm{CH}$ : $\mathrm{CH} . \mathrm{CH}: \mathrm{CH}$. $\mathrm{CH}: \mathrm{CH}$. $\mathrm{CHO}$, from which, by the addition of six atoms of hydrogen and one of oxygen, would be obtained the eight-carbon atom fatty acid $\mathrm{CH}_{3} \mathrm{CH}_{2} \mathrm{CH}_{2} \mathrm{CH}_{2} \mathrm{CH}_{2} \mathrm{CH}_{2} \mathrm{CH}_{2} \mathrm{COOH}$, octoic or caprylic acid. An extension of this suggestion is that due to Smedley and Lubrzynska $\ddagger$ according to whom pyruvic acid produced by the decomposition of carbohydrate is the starting-point for the formation of fatty acids; pyruvic acid is known to yield acetic aldehyde by the action of the cnzyme carboxylase, and the aldol condensation of this acetic aldehyde with another molecule of pyruvic acid would yicld a fivecarbon compound according to the following equations:-

$$
\begin{gathered}
\underset{\mathrm{CH}_{3} \mathrm{CO} \mathrm{COOH}}{\text { Pyruvic acid }}=\mathrm{CH}_{3} \mathrm{CHO}+\mathrm{CO}_{2} \\
\mathrm{CH}_{3} \mathrm{CHO}+\mathrm{CH}_{3} \mathrm{COCOOH} \text { COHyde } \\
=\mathrm{CH}_{3} \mathrm{CHOH} \mathrm{CH} \mathrm{CH}_{2} \mathrm{COOH} \text {. }
\end{gathered}
$$

The latter substance by loss of water would give an unsaturated ketonic acid

\section{$\mathrm{CH}_{3} \mathrm{CH}: \mathrm{CH} \mathrm{CO} \mathrm{COOH}$}

which could react in either of the two following ways to give a four-carbon compound.

* Magnus Levy: "Engelmann's Archiv," I902, 365.

† I-eathes: "Problems in Animal Metabolism," London, I 906.

† Smedley and Lubrzynska: "Biochem. Journ.," I913, 7, 364. 
(3) $\mathrm{CH}_{3} \mathrm{CH}: \mathrm{CHCOCOOH}+\mathrm{O}=\mathrm{CH}_{3} \mathrm{CH}: \mathrm{CH} \mathrm{COOH}+\mathrm{CO}_{2}$

$$
\begin{gathered}
\text { Crotonic acid } \\
\mathrm{CH}_{3} \mathrm{CH}: \mathrm{CH} \mathrm{COOH}+2 \mathrm{H}=\underset{\mathrm{CH}_{3} \mathrm{CH}_{2} \mathrm{CH}_{2} \mathrm{COOH}}{\text { Butyric acid }}
\end{gathered}
$$

or

(4) $\mathrm{CH}_{3} \mathrm{CH}: \mathrm{CH} \mathrm{CO} \mathrm{COOH}-\mathrm{CO}_{2}=\mathrm{CH}_{3} \mathrm{CH}: \mathrm{CH} \mathrm{CHO}$.

Crotonic aldehyde

$\mathrm{CH}_{3} \mathrm{CH}: \mathrm{CH} \mathrm{CHO}+\mathrm{CH}_{3} \mathrm{CO} \mathrm{COOH}=\mathrm{CH}_{3} \mathrm{CH}: \mathrm{CH}$. $\mathrm{CHOHCH}_{2} \cdot \mathrm{CO} \cdot \mathrm{COOH}$

yielding a seven-carbon compound which by a series of changes similar to those undergone by the five-carbon compound would give a six carbon acid-

$$
\underset{\text { Caproic acid }}{\mathrm{CH}_{3} \mathrm{CH}_{2} \mathrm{CH}_{2} \mathrm{CH}_{2} \mathrm{CH}_{2} \mathrm{COOH}}
$$

While there may be some difficulty in accepting this theory of the formation of fatty acids in the animal body, owing to uncertainty of the production of pyruvic acid as a normal product of carbohydrate metabolism, as is pointed out by Leathes, this difficulty would not apply to the decomposition of carbohydrate by micro-organisms.

It has already been pointed out in Volume I. that Neuberg has established the production of pyruvic acid in alcoholic fermentation and has shown it to be the precursor of the acetic aldehyde formed in this process; Neuberg and Arinstein, * in an investigation of butyric acid and butyl alcohol fermentation of glucose by Bac. butylicus Fitzianus, have established the fact that here also pyruvic acid is the intermediate substance; this may give rise either to acetic aldehyde or to butyric acid and butyl alcohol, but these products are mutually exclusive, showing that butyric acid and butyl alcolol are not formed by way of acetic aldehyde. This the authors proved as follows: the bacillus when grown on either acetic aldehyde, or its aldol $\mathrm{CH}_{3} \mathrm{CHOH} \mathrm{CH}_{2} \mathrm{CHO}$, produced no butyric acid, but when grown on the aldol of pyruvic acid, it produced butyric acid in quantity. The mechanism of this reaction is explained as follows :-

$$
\begin{gathered}
\mathrm{CH}_{3} \mathrm{CO} \mathrm{COOH}+\mathrm{CH}_{3} \mathrm{CO} \mathrm{COOH}= \\
\begin{array}{c}
\text { Pyruvic acid } \\
\mathrm{CH}_{3} \mathrm{C} \mathrm{OH} \mathrm{CH} \\
\text { Pyruvic acid aldol }
\end{array}
\end{gathered}
$$

* Neuberg and Arinstein: "Biochem. Zeit.," I92 r, II7, 269. 
and the latter by loss of two molecules of carbon dioxide gave

$$
\mathrm{CH}_{3} \mathrm{CHOH} \mathrm{CH} \mathrm{CH}_{2} \mathrm{CHO} \rightarrow \underset{\text { Butyric acid }}{\mathrm{CH}_{3} \mathrm{CH}_{2} \mathrm{CH}_{2} \mathrm{COOH}}
$$

In addition, smaller quantities of caproic and caprylic acids, containing six and eight carbon atoms respectively, were obtained. These investigations, together with those mentioned on an earlier page, provide a fair amount of experimental evidence in support of the view that sugars give rise to fats by an initial breaking down to compounds containing a small number of carbon atoms, and then combining these to form compounds of higher molecular weight. The methods outlined above also account for the loss of oxygen necessitated in passing from a carboliydrate containing six carbon atoms to a fatty acid of the same number of carbon atoms as is shown by the formulæ $\mathrm{C}_{6} \mathrm{H}_{12} \mathrm{O}_{6} \rightarrow \mathrm{C}_{6} \mathrm{H}_{14} \mathrm{O}_{2}$, an operation which would be very difficult by direct reduction, but is overcome by the removal of hydroxyl groups as water. 


\section{CHAPTER IV.}

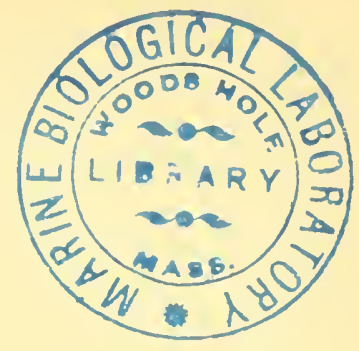

\section{THE SYNTHESIS OF PROTEINS.}

In view of our limited knowledge of the chemistry of proteins, the degree of our ignorance respecting their synthesis in plants is not surprising.

It is generally agreed that the leaves are the important centres of protein formation, and they show a periodicity in their nitrogen content. Otto and Kooper, ${ }^{*}$ Le Clerc du Sablon $\uparrow$ and others $\ddagger$ found that there is a gradually decreasing anount of nitrogen from the spring to the autumn, and that leaves of several different plants, even in different stages of development, exhibit a greater nitrogen content in the morning than in the evening. These observations are confirmed by Chibnall, $\S$ who found that a definite fall in the protein content of the leaves of the runner bean occurs during the night, a fall due to the translocation of the dissociation products of the proteins effected by the presence in the leaves of proteolytic enzymes.\|

This same author also has investigated the relationship between the various combinations of nitrogen in the leaves of Phaseolus vulgaris var. multiflorus at different times of the day and in different stages of development.

With respect to age, Rippel ** found that the protein content of the leaves of Populus canadensis suddenly diminishes as the yellow autumnal colour is assumed, a diminution due to the cessation of protein synthesis rather than to an increased rate of transportation.

\footnotetext{
* Otto and Kooper : "Landwirthsch. Jahrb.," I9 Io, 39, I67.

$\dagger$ Le Clerc du Sablon: "Rev. Gen. Bot.," I904, 16, 34 I.

+ See Chibnall: "Ann. Bot.," I 923, 37, 5II.

§ Chibnall: "Biochem. Journ.," I924, 18, 387, 395, 405.

|| Ibid., 1922, 16, 599, 608.

- Ibid., I922, 16, 344.

** Rippel: "Biol. Zentrlbl.," I92 I, 41, 508 .

VOL. 11. -6 
It must not be concluded from these observations that the making of proteins by the green plant is necessarily a photosynthesis. For the process to take place there must be available the appropriate raw materials and of these carbohydrate and various elements, especially nitrogen, in suitable combinations, are the most significant. The carbohydrate presumably must be a sugar, and provided it be available, protein synthesis is independent of light ${ }^{*}$ and can take place in all parts of the plants although in different degrees. $\dagger$ Since the photosynthesis of carbohydrates is a daylight process, it is not surprising to find that the production of proteins may be four or five times as great in the light as in darkness. $\ddagger$

Schimper,§ experimenting with cut leaves of Sambucus and with potted plants of Pelargonium zonale, found that nitrates were destroyed in green leaves exposed to daylight but were not so destroyed if the leaves were kept in the dark, and in agreement with this, shade leaves were found to be richer in nitrates than sun leaves. Furthermore, no destruction of nitrate occurs in etiolated leaves exposed to sunlight.

The investigations of Ullrich $\|$ indicate that the chloroplasts, the centres of carbohydrate formation, play a part in protein synthesis. Detached leaves of Brassica, Cucurbita, Lactuca, Phaseolus, Tropaolum and Zea, grown in the light and supplied with nitrate, produced protein which probably had its origin in the plastids, for these showed an increase in size in comparison with the plastids of leaves grown in similar conditions but deprived of nitrogen. When proteincontaining plastids were digested with pepsin, the appearance of the remaining structure was like the chloroplasts of the nitrogen starved leaves.

As has been indicated above, protein synthesis can take place in darkness provided that an adequate supply of carbo-

* Jost : “Biol. Centrlbl.," 1900, 20, 625.

† Bombacioni: “Rend. Acc. Lincei Roma," I923, 32, ii., Io8.

† Montemartini: "Atti. R. Inst. Bot. Pavia," I905, 11., 10, 20.

§ Schimper : “ Bot. Zeit.," I 888, 46, I 28.

|| Ulirich : "Zeit. Bot.," 1924, 16, 513. 
hydrate be at hand. Zaleski and Suzuki* found that the leaves of the sunflower floating upon a solution containing sugar and nitrate produced considerable quantities of proteins in the dark, from which it appears that nitrogen assimilation is not a photochemical process, and that light is only of indirect importance in providing one of the means for the formation of carbohydrates.t This opinion also is held by Loew. $\neq$ Using Chlorella as a subject for investigation, Muenscher $\S$ found that it can synthesize protein in total darkness when inorganic salts of nitrogen are supplied and provided that carbohydrate in adequate amount is available. There is thus no doubt that light is inessential for the formation of proteins but Baudisch $\|$ thinks that their formation in darkness is abnormal and provides no proof that the process is not a photochemical one under normal conditions; he considers that the synthesis in darkness is due to some abnormal chemical processes which reduce the nitrates and so aid in the production of proteins. It has also been stated that if but small quantities of carbohydrate are available, the synthesis of proteins, in darkness, may stop at the formation of amides, 9 which some plants, e.g. Algx such as Pleurococcus and Raphidium, and the Fungi Eurotium and Penicillium, can directly assimilate.**

There is available but little exact knowledge regarding the specific action of invisible wave-lengths of radiant energy which may be concerned in the different phases of protein metabolism. Schanz $\dagger \dagger$ finds that ultra-violet light renders proteins less soluble, possibly on account of its deleterious action on enzymes, ++ and in this is found a reason for the dwarf habit of alpine plants which are subjected to a high degree of

* Zaleski and Suzuki : “Ber. deut. bot. Ges.," I $897,15,536$; “ Bot. Centrlbl.," I $901,87,28$ I. Suzuki : "Bull. Coll. Ag. Tokyo," I 898, 2, 409; $3,24 \mathrm{I}$.

† Zaleski : “ Ber. deut. bot. Ges.," r909, 27, 56.

†Lew : $i d$., I9I 7, 50, 909.

§ Muenscher: "Bot. Gaz.," 1923, 75, 249.

|| Baudisch : “Zentr. Bakt. Parasit.," I912, 32, 520.

I Jakobi : “ Biol. Centrlbl.," I 898, 18, 593.

** Lutz: "Bull. Soc. Bot. France," I902, 48, I I8.

t† Schanz: "Ber. deut. bot. Ges.," I9I8, 36, 619.

枯 See Vol. I. 
insolation. Bovie * draws attention to the efficiency of the extreme ultra-violet rays, the so-called Schumann rays, and points out that the photolysis of protein and of protoplasm increases with the diminution in the wave-length of the incident light; in the extreme ultra-violet region, the amount of chemical change is proportional to the product of the light intensity and the time of exposure.

It will be remarked that these observations refer not directly to protein synthesis but rather to the action of these qualities of radiant energy on the general growth of the plant, a subject which will be considered later.

The supply of nitrogen is an essential factor, and this element must be presented in a form suitable for the nutritive processes of the plant. Thus amongst the non-green plants, Saccharomyces is unable to make use of nitrates and but little use of simple amines; urea can be assimilated in certain conditions, but the best results follow the employment of peptone, a culture solution of peptone and sucrose giving $177 \cdot 4$ per cent. increase in dry weight after the completion of fermentation. $\dagger$

There is, however, much variation shown by the lower non-green plants in this respect; Baillus coli will flourish on a diet containing salts either of ammonia, of simple amides or of amino acids, whilst the cholera bacillus can apparently make no use of ammonium salts but is able to utilize amino acids. For the Fungi, Boas $\ddagger$ considers that in general ammonium salts, and especially the ammonium salts of organic acids sucl as quinic acid, are better than amino acids as a source of nitrogen in protein synthesis. He points out that such feeding experiments should be brief, in order to avoid secondary, especially proteolytic, changes, and that the reaction of the culture medium is all-important. Acidity may inhibit the growth of many fungi, so that if ammonium salts of inorganic acids be used as a source of nitrogen, the observed results may be due not to the inability of the plant to employ the

* Bovie : “Bot. Gaz.," 1916, 61, I.

† Bokorny : "Chem. Zeit.," r9I6, 40, 366.

+ Boas: "Biochem. Zeit.," I91\$, 86, I IO. 
particular salt, but to the acidity which develops as the nitrogen is assimilated.

Terroine, Wurmser and Montané* studied Aspergillus niger and found that the nitrogen content of the mycelium decreases to a steady value which is unaffected by large variations in the amount of ammonium sulphate in the culture medium. If the ammonium salt be replaced by sodium nitrate or by urea, the nitrogen content is unaffected, but its substitution by peptone lowers it slightly, while guanidine lowers it much. A considerable increase in the carbohydrate content, glucose or sucrose, of the culture medium causes an increase in the nitrogen content of young cultures but has the reverse effect on old cultures. The substitution of glucose by arabinose or by xylose has no effect, but galactose effects an appreciable decrease in the nitrogen content. These authors consider that the nitrogen metabolism of Aspergillus is similar to that of higher animals.

For ordinary green plants the supply of nitrogen is found in the simple nitrogen-containing salts of the soil water. Thus the fertility of the soil, not only with respect to nitrates but also in regard to other substances, $\dagger$ is an important factor, conditioning the amount of protein found in the plant. In addition to nitrates, some plants can make use of ammonium salts. Hutchinson and Miller $\ddagger$ found this to be true in conditions of culture which precluded the presence of nitrates in the soil. In this respect, however, all plants do not behave alike; whilst some will grow equally well whether supplied with nitrates or ammonium salts, others flourish best when supplied with the former, and others seemingly prefer ammonium salts to begin with and then nitrates.

Mention has just been made of the importance of soil sub. stances other than nitrates in the protein synthesis of plants: potassium may be taken in illustration. Species of bacteria grown in the dark in culture media containing the requisite

* Terroine, Wurmser and Montané : "Bull. Soc. chim. biol.," I922, 4, 623.

†Whitson and Stoddart: "Ann. Rep. Wisconsin Exp. Sta.," I904, I 93.

¥Hutchinson and Miller: "Journ. Agric. Sci.," I909, 3, I 79. 
organic food materials and salts, but lacking potassium, show but poor development and no protein synthesis. In similar cultural conditions seedlings of the beet showed seven times less protein and eighteen times less sugar, when grown without potassium, as compared with the controls; when grown in sterile conditions in a culture medium containing a sugar and supplied with known amounts of carbon dioxide, it was found that those grown in the light were independent of potassium as regards the synthesis of protein, and that the addition of sugar to the culture medium resulted in an increase of protein. In darkness, on the other hand, a less vigorous development occurred and only those plants supplied with potassium salts showed protein formation.

It would therefore appear that the action of potassium is partly indirect, and only in darkness does it play an important rôle in the production of proteins. Since potassium is mildly radioactive, it may possibly serve as a source of energy in promoting metabolic activity, but, as has been remarked on a previous page, no definite conclusion can be drawn from the available evidence. ${ }^{*}$

\section{OCCURRENCE OF NITRATE.}

The obvious essentiality of nitrogen in the building of proteins and the fact that in general the element is absorbed by the plant in the form of nitrate has been remarked upon.

The work of Anderson $\dagger$ and earlier authors has demonstrated the presence of nitrate in a large number of plants; but a review of the literature shows some discordance, which is probably due to the fact that the amount of discernible nitrate in leaves varies according to the season of the year, the richness of the soil, and the conditions of growth, more especially the degree of insolation. To cite but two examples: Suaeda fruticosa growing in its natural habitat, a shingle beach from which salts are readily leached and exposed to maximum insolation, gave negative results when tested for nitrate; the same plant growing in garden soil and in a certain amount

\footnotetext{
* See Stoklasa: "Binchem. Zeit.," I9I6, 73, 107.

tAnderson: "Ann. Bot.," r924. 38, 699.
} 
of shade gave strong positive reactions. Rumex conglomeratus growing on an old manure heap gave mucl stronger reactions for nitrate than another plant of the same species growing a few yards away in a hedgerow. From these and many sinilar observations, the conclusion is warranted that the presence of detectable free nitrogen only is to be expected when the uptake from the soil is greater than its rate of elaboration, and this relationship in vigorous vegetation is determined by the quality of the soil and the habitat of the plant particularly with regard to illumination. With respect to diurnal and seasonal vari. ation, Anderson observed that in Solanum dulcamara the amount of nitrate in the morning may be considerably less than in the late evening; and Mercurialis perennis gave positive reactions in October and negative in June. Further, there is a localized distribution in the plant; thus although nitrate was found in the leaves of various Solanaceae, none was found in the young green berries; similarly although nitrate occurred in the etiolated inner leaves of a cabbage, none was found in the outer green leaves.

Nitrate as such is a comparatively inert substance and does not readily lend itself to chemical change, wherefore in the plant it must presumably be changed into a more labile substance before it is elaborated into proteins; nitrite imnediately is suggested on chenical grounds, so that two problems arise : the occurrence of nitrite in the plant and the mechanism which effects the reduction of nitrate to nitrite.

\section{OCCURRENCE OF NITRITE.}

The literature of the subject shows some disagreement about the presence of nitrite in the green plant. This is due to the following facts. The amount of nitrite is always small, so that its presence must be detected by delicate colour reactions; Griess Ilosvay reagent is commonly used; it gives a pink colour with dilute solutions of free nitrite, but it is acid in reaction, and thus a pink colour also is given if traces of anthocyanins are present.

The expressed juice of the plant must be used; this is a solution of various substances which may react with the 
nitrite on the contact inevitable after expression; thus if tannins be present they and the nitrite would interact so that no reaction for nitrite would be given on testing. Also a mechanism may occur in some plants, e.g. Allium, which prevents the detection of nitrite added to the plant juice.

The sap must be examined immediately after expression ; a plant juice, e.g. Sambucus, may give a positive reaction when first extracted, but a negative reaction after the lapse of a few hours.

There is, however, no doubt that free nitrites are of common occurrence in the green plant. Aso * established their occurrence in etiolated potato shoots, and Klein $\dagger$ detected them in Erythrina and other plants, but he points out that in some plants, more especially those with root tubercles, the presence of nitrite may be due to the activity of bacteria. Taling such precautions as are indicated above, Anderson found that more than 20 per cent. of the angiosperms of diverse affinity $\ddagger$ examined, gave positive reactions for nitrite.

It is sometimes assumed that nitrites are toxic to the plant, and that they must be quickly elaborated in a healthy plant and not allowed to accumulate. From culture experiments, it would appear that nitrite is poisonous if supplied to the plant above a certain limit, but this limit apparently varies with the conditions of the liabitat of the plant. Fehér and Vági § found that no ill-effect followed when nitrites were adder to the scil in amounts up to 1 gram per kilogram. They later observed that 0.88 per cent. of nitrite, calculated as $\mathrm{N}_{2} \mathrm{O}_{3}$, in clay and sandy soils, and 95 to I.OI per cent. in garden soils rich in humus poisoned the plant. When grown in water culture a greater amount of nitrite is tolerated; $1 \cdot 25$ to 3.73 per cent. was found to be injurious to growth but not so far as to cause death.

*.Aso: "Beih. Bot. Zentr.," 1903, 15, 20S; 1914, 32, I 46.

$\dagger$ Klein : id., 30, I4 $\mathrm{I}$.

¥ Aroidex, Caryophyllacex, Compositx, Cucurbitacer, Leguminosa, Iythraceæ, Resedaceæ, Rosaceæ, Salicacex, Scrophulariaceæ, Solanacea. Ulmacee and Urticaceæ.

§ Felıér and Vági: "Biochem. Zeit.," I924, 153, I56: 1926, 174, 262. 
THE REDUCING MECHANISMI.

If the formation of nitrite is the first stage in the synthesis of proteins, the question arises as to the mechanism in the plant which effects the reduction of nitrate to nitrite. The reduction may be due to the action of an organic "reductase," or it may be a photochemical reaction. If it be the latter, the process must take place in the subaerial parts, essentially in the leaves, and since proteins are formed in structures far removed from light, it follows that the nitrite must be removed to those places where the elaboration is taking place. This presents certain difficulties, but is not altogether to be dismissed since nitrite has been detected in stem and roots. Also nitrite has been found in the sap exuded by root pressure from the cut ends of the fuchsia and the vine, ${ }^{*}$ but since the flow of sap is upwards, the observations have, in all probability, no bearing on the immediate problem, although they indicate that the recluction of nitrate to nitrite occurs in the root, where it is dark, as has been found by Thomas $\uparrow$ in Pyrus malus.

Considering now the evidence.

"Reductase."- The ability of the plant to convert nitrate into nitrite was first observed by Laurent, $\ddagger$ and later, Irving and Hankinson, $\S$ working on Elodea, canie to the conclusion that nitrite must be an intermediate compound in the metabolism of nitrates.

Kastle and Elvove || were the first to show that the expressed sap of potato tubers and etiolated shoots, and the sap of other plants, was able to effect the change from nitrate to nitrite, especially in the presence of acetaldehyde and other like bodies. Their observations were confirmed by Bach who worked on potato tubers. Anderson ** following the work of Bach $\dagger \dagger$ and of Haas and Hill $\ddagger \ddagger$ on milk, found in twenty-three

* Kastle and Elvove: “Amer. Chem. Journ.," 1904, 31, 606 ; Priestley and Armstead: "New Phyt.," 1922, 21, 62.

† Thomas : "Science," I 927,66 , I 15.

+ Laurent: "Ann. Inst. Pasteur," I 890, 4, No. II.

§ Irving and Hankinson: "Biochem. Journ.," I 9o8, 3, 87.

II Loc. cit.

** Loc. cit.

- Bach: "Biochem. Zeit.," I9I 3, 52, 4 r2.

$\ddagger$ Haas and Hill : "Biochem. Journ." 1923, 17,67r. Also Haas and Lee: $i d ., 1924,18,614$. 
angiosperms of varied affinity the power to bring about the reduction, the best results being given by the potato, tubers and shoots, and shoots of Solanum dulcamara. There is in some instances a seasonal variation, thus Solanum dulcamara was just active in October, but in June the same species, gathered from various localities and at all times, gave good positive results. The "reductase" is a thermolabile oxidizable substance precipitated from its solution by saturation with ammonium sulphate. The best conditions for the manifestation of its ability are a temperature of $45^{\circ} \mathrm{C} .{ }^{*}$ and the presence of an accelerator, such as acetaldehyde, which, obviously, are artificial conditions; at ordinary temperatures in the absence of an accelerator the reaction is very slow. In the majority of its properties it rescmbles the aldehydase of animal origin, e.g. that of milk. If this be the mechanism for the reduction of nitrate to nitrite in the plant, it must be assumed that the conditions obtaining in the living cell are muclı more favourable for the reaction to take place. The elucidation of the problem was carried further by the concurrent work of Eckerson $\uparrow$ on tomato plants; he found that the plant juice in the presence of fructose, or glucose, and free oxygen easily reduced nitrate to nitrite in a slightly alkaline medium, the best reaction occurring at $p H 7 \cdot 6$; the juice of nitrogen high plants, containing nitrates and sugars in abundance, rapidly reduced nitrate at $50^{\circ} \mathrm{C}$. at $p H 7 \cdot 6$, and in these conditions boiled juice was as effective as unboiled. In carbohydrate high plants, containing much sugar but no nitrate, the reduction of added nitrates was localized to those regions which gave a slightly alkaline reaction, i.e. the stem tip just belind tlıe growing region, cells of the leaves especially near the phloem, cortical cells of the petioles, phloem parenchyma of the stem bundles and adjacent cortical cells in the nodal regions. It was also observed that newly formed amines and amino acids, aspartic acid, asparagine, alanine, etc., appeared in the regions of the nodes; and in the petioles, in the

* In experiments with plant juices, especially if continued over relatixely long periods of time, due precaution must be taken against bacterial activity which may give rise to nitrite.

† Eckerson: "Bot. Gaz.," 1924, 77, 377. 
blades of young leaves and immediately behind the stem tips in carbohydrate high plants three or four days after nitrate had been supplied to the soil. Never was the process of reduction affected by the presence or absence of light, and in these experiments an activator such as acctaldehyde was not used. From these observations it would appear that the degree of activity of the "reductase" is much affected by the reaction of the medium and that possibly sugar takes the place of acetaldehyde. The process is thus brought closer to natural conditions, but the best results were obtained at unnaturally high temperatures.

In an attempt to correlate the action of the potato "reductase" with the aldehydase responsible for the reduction of methylene blue to the lcuco compound (see p. I39), Michlin * and Bernheim $\dagger$ made preparations of the "reductase" of the potato, the former by the precipitation by acetone from an aqueous extraction and the latter by precipitation by ammonium sulphate, dissolving in water, and treatnent with charcoal ; after which the enzyme was precipitated by saturation with ammonium sulphate, centrifuged, dried in a vacuum desiccator and dissolved in water as required. Bernheim found his preparation to have a wide $\mathrm{pH}$ range, 3 to $8 \cdot 6$, with an optimum at $5 \cdot 5$, with respect to nitrate reduction; at $\mathrm{pH} 7$ to $7 \cdot 5$ there was a good nitrate reduction, in the presence of acetaldehyde, which corresponds sufficiently closely with Eckerson's observations. $\ddagger$ The action of the enzyme is independent of traces of iron, as is indicated by the addition of $\mathrm{KCN}$. Bernheim finds that there is a close relationship between this potato aldehydase and typical aldehydase of animal origin, the hitherto assumed difference between them disappearing when the $p H$ is adjusted.

In the reaction, on Wieland's thesis (see p. I38), nitrate is the hydrogen acceptor, and in these test-tube experiments aldehyde is the hydrogen donator; in the plant some other

* Michlin : "Biochem, Zeit.," 1927, 185, 216.

† Bernheim : "Biochem. Journ.," 1928, 22, 344.

$\ddagger$ It is to be remembered that the optimum reaction varies with the degree of purity of the enzyme and upon the nature of the substrate see Vol. I., p. 468). 
donator must be found; from Eckerson's work and on theoretical grounds sugar is indicated, but Bernheim found that, in ritro, both glucose and sucrose gave negative results. To summarize these observations : there occur in a number of plants a reducing mechanism, generic with aldehydase of animal origin, capable of reducing nitrate to nitrite, provided an hydrogen donator is present. There are, however, certain difficulties to its unqualified acceptance as the mechanism used by the plant in the first stage of protein synthesis : in vitro the action is very slow at air temperature and in the absence of acetaldehyde, but at higher temperatures (Anderson, $45^{\circ}$; Eckerson, 50 ; and Bernheim, $37^{\circ} \mathrm{C}$.) the reaction is relatively rapid, especially in the presence of acetaldehyde. Further, in the test tube, the activity of the mechanism falls off in time for a reason unknown, but this may not occur in the very different conditions obtaining in an active plant cell.

Photochemical. - The evidence in support of the thesis that the reduction of nitrate to nitrite is a photochemical reduction is not extensive.

It was first shown by Thiele * that potassium nitrate, on exposure to the rays from a quartz mercury vapour lamp, was reduced to potassium nitrite with evolution of oxygen. With a view to the further study of the photochenical decomposition of nitrites, Baudisch $\dagger$ exposed mixtures of potassium nitrite and methyl alcohol in aqueous solution to diffused daylight and to ultra-violet light and found that the methyl alcohol became oxidized to formaldehyde at the expense of the nitrite which was reduced to hyponitrite, and this latter, at its moment of formation, reacted with the formaldehyde to produce the potassium salt of formhydroxamic acid-

$$
\begin{aligned}
& \mathrm{KNO}_{2}+\mathrm{CH}_{3} \mathrm{OH}=\mathrm{KNO}+\mathrm{HCHO}+\mathrm{H}_{2} \mathrm{O} \\
& \mathrm{KNO}+\mathrm{HCHO}=\mathrm{H} \cdot \underset{!}{\mathrm{C}} \cdot \mathrm{OH} \\
& \mathrm{NOK}
\end{aligned}
$$

The reduction of nitrate or nitrite in the presence of alcohol is

* Thiele: "Ber, reut. chem. Gesells.," I907, 40, 491 4. See also Moore and Webster: "Proc. Roy. Soc.," R, I919, 90, I58.

† Baudisch: "Ber. deut. chem. Gesells.," I9I I, 44, I0o9. See also loc. cit., $1916,49,1176$, and $1918,51,793$. Baly, Heilbron and Hudson, "Journ. Chem. Soc.," 1922, 121, 1078. 
a purely photochemical reaction since no such change could be produced in the dark even if the solutions were boiled.

It will be observed that the evidence mainly relates to ultra-violet radiation, in the absence of which the plant can flourish and form proteins. For this reason, and especially in view of the facts relating to the occurrence of nitrites and the formation of proteins in the dark places of the plant, the conclusion is justified that in the plant the photochemical reduction of nitrate is without significance.

Assuming that the reduction of nitrate is the beginning of protein synthesis, the further sequence of reactions is a matter of speculation. If the doctrine of the reversibility of enzyme action be held, as it generally, if not always is, the reversal of the changes effected by the plant, by means of its enzyme mechanisms, in the dissociation of the protein molecule, may throw light on the formation of proteins; for this reason these changes may first be considered.

\section{HYDROLYSIS OF PROTEIN.}

The protein content of a seed or other storage organ, whether temporary, as the leaf, or more permanent, is a reserve food which must be hydrolysed before it can be trans. located and made available for the growing parts. The cleavage products of proteins yield a large number of amino acids (Vol. I., p. 443) and a number of amides. The following amino acids have been identified in the plant: arginine, glycine, histidine, leucine, lysine, phenyl alanine, tryptophane, and tyrosine. Of the amides, asparagine and glutanine are important members, from the point of view of plant physiology, and of these asparagine is the more conspicuous.

This dissociation of protein takes place with some degree of rapidity; Jodidi * found that after eight days' germination in darkness, 48 per cent. of the proteins originally present in the fruit of the maize was hydrolysed to water-soluble diffusible compounds. The evidence of his analyses indicate that proteoses and polypeptides are amongst the first degradation 
products, and that the amino acids and acid amides are formed from the polypeptides.

In Cicer arietimum, there is a marked increase in the amount of amino acids and their amides during germination, which increase is at the expense of the proteins.* Similarly there is an accumulation of amides in the shoots of germinating peas; the amount of amide nitrogen in the seed leaves fluctuates much at first but in the later stages of germination there is a marked increase, whilst, concurrently, the $a$-amino acids decrease in amount and finally disappear. From these relationships between the amides and amino acids, Sure and Tottingham $\uparrow$ consider that amino acids serve for the production of amides.

Of the cleavage products of proteins, asparagine is amongst the more conspicuous in the plant. It occurs in the developing parts $\ddagger$ in greater abundance than in the members where the reserve proteins are stored; Schulze $\S$ found that only 7.62 per cent. of asparagine occurred in the cotyledons, whilst $3 \mathrm{I} \cdot 8 \mathrm{I}$ per cent. occurred in the axis of the lupin. Also the relative amounts of asparagine and aspartic acid show considerable variation during germination and, in the last stages, the amount of asparagine formed is in a proportion greater than the amount of protein decomposed.

Asparagine is possibly a secondary product. According to Prianischnikow, in the germination in darkness of leguminous seeds, its origin is due to the oxidation of the amino acids derived from the protein reserves, ammonia being formed and then elaborated into asparagine. When etiolated seedlings are illuminated the asparagine disappears, being used in the construction of new protein.

The above facts relate to reproductive organs; on the

* Zlataroff: "Biochem. Zcitsch.," 1916, 75, 200.

† Sure and Tottingham: " Journ. Biol. Chem.," I9r6, 26, 535.

¥ This may easily be shown by germinating a lupin seed in the dark until the hypocotyl is a few inches in length. On mounting a section of the hypocotyl in strong alcohol and examining under the microscope, a large number of crystals of asparagine will be seen.

\$Schulze: "Landw. Jahrb.," $1878,411$.

|| Sce Choate: "Bot. Gaz.," I921, 71, .709.

"Prianischnikow : "Binchem. Zeit.," I924, 150, 406. 
vegetative side similar changes occur. Chibnall, ${ }^{*}$ worlking on the protein metabolism of the runner bean, found that the decomposition products of the proteins of the leaf consist of asparagine and other bodies containing free amino nitrogen. He considers that asparagine is the chief form in which nitrogen in a state capable of resynthesis is translocated through the plant. Detached leaves kept with their petioles in water, translocation thereby being excluded, contain, after a few days, little or no asparagine, whilst other amide nitrogen is more abundant than in the leaves attached to the plant.

The consideration of these facts fully warrants the conclusion that in the plant protenlysis yields amino acids with amides, especially in the form of asparagine, of, possibly, secondary origin. Does a reversal of this sequence occur when proteins are laid down as reserves in storage organs?

\section{THE ORIGIN OF PROTEIN IN THE SEED.}

From the facts of animal physiology there is no doubt that anino acids, the products of the hydrolysis of protein food in the alimentary tract, are reconstructed to form protein in the various tissues after their passage through the walls of the intestine into the blood stream. There is reason to suppose that the same sequence obtains in the plant. Thus Zaleski $\dagger$ found that during the ripening of pea seeds there is an increase in the amount of the protein at the expense of the anino acids and organic bases, as is indicated by nitrogen determination of these compounds.

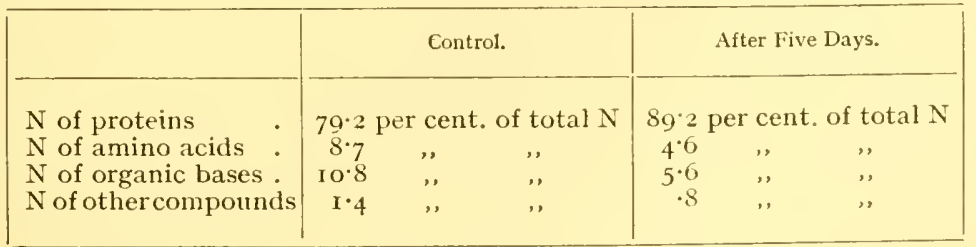

The results were not so well marked for all seeds; thus in similar conditions but little protein synthesis took place

* Chibnall : “ Biochem. Journ.," I 924, 18, 387, 395, 405.

† Zaleski : "Ber. deut. bot. Gesells.," I905, 23, I 26 ; " Beih. bot. Zentrbl.," I9I I, 27, 63. 
in the maize, whilst in the sunflower there was a diminution of protein. Woodman and Engledow, ${ }^{*}$ in their detailed biochemical study of the development of the wheat grain, found that there was a regular increase in total nitrogen and in the percentage of protein nitrogen during development. The nitrogen enters the developing grain, which contains no nitrate, in the form of asparagine, and they conclude that the asparagine is oxidized to ammonia which is the startingpoint of the protein synthesis. They also observed that gliadine was greater in amount than glutenine, and that these two substances increased at much the same rate until the beginning of the desiccation of the grain, after which the glutenine remained constant and gluten appeared. Smirnow $\dagger$ compared the nitrogen metabolism of etiolated seedlings of high carbohydrate content, c.g. barley, and of low carbohydrate content, e.g. lupin, which were grown in sterile culture solutions in controlled conditions. It was found that the barley seedlings readily absorb ammonia, which is followed by an increase in the amount of asparagine. The rate of absorption depends on the amount of sugar contained in the plant; at first it is rapid and then falls off and stops as the sugar content diminishes to a certain limit. The presence of calcium salts promotes the formation of asparagine, but the process ends sooner since the sugar is more rapidly used up.

The degree of uptake of ammonia by lupin seedlings is dependent on the presence of sugar in the culture medium. Seedlings given ammoniun salts and glucose show a higher asparagine content, a higher protein content, and a lesser accumulation of ammonia in the tissues than seedlings given ammonium salts but no sugar. Further, the ratio of asparagine nitrogen to ammonium nitrogen is twice as great in the seedlings given sugar in addition to the ammonium salts. Younger seedlings after being given ammonium and glucose also showed a higher amino acid content, but the amount fell off with age as the proteins are regenerated.

These works indicate that in the plant amides and amino

* Woodman and Engledow : "Journ. Agric. Sci.," I924, 1.4, 563.

† Smirnow : "Biochem, Zeit.," r923, 137, 1. 
acids are reconstructed into proteins; that carbohydrate is essential to the process, and corroborate the conclusion arrived at on an earlicr page, that light as such is of no direct consequence; and that asparagine plays a prominent part.

As has been seen, asparagine may be produced from amino acids, possibly by the combination of ammonia and aspartic acid * to form ammonium aspartate which gives origin to the asparagine by the loss of a molecule of water. Prianischnikov, $\uparrow$ whilst recognizing in ammonia the end product of protein dissociation, considers that it also is an initial stage in the formation of proteins, and, according to him, asparagine is the form in which it is stored.

Asparagine lends itself to condensation more or less readily, and by simply boiling a solution, the dipeptide of aspartic acid is formed.

There is no definite information of the details of amino acid synthesis in the plant. In the laboratory the following synthesis have been effected (see Vol. I., p. 450) :-

Ammonia + glyoxylic acid $\rightarrow$ formylglycine and acetyl alanine

Ammonia $+\beta$-vinyl acrylic acid $\rightarrow$ diamino valeric acid.

Ammonia + fumaric acid $\rightarrow$ aspartic acid.

If like synthesis occur in the plant, ammonia and unsaturated acids are requisite.

Nothing is lnown of the combination of amino acids into the final protein; it will, however, be remembered that Fischer synthesized a number of polypeptides, some of considerable complexity, from amino acids in the laboratory (see Vol. I., p. 447).

To summarize our little knowledge of the synthesis of protein in the plant: nitrate is reduced to nitrite and possibly to ammonia, which reacts with sugar, or a degradation product of sugar, possibly an unsaturated acid, to form simple amino acids which may give rise to asparagine, or other amines, a temporary phase which can easily be decomposed

* Schulze : loc. cit. Prianischnikov: "Ber. deut. bot. Gesells.," I904, 22, 35. Treboux: id., 570 .

† Prianischnikov: "Bull. Agric. Intell.," I917, 8, 204.

I Ravenna and Bosinelli: "Rend. R. Acad. Lincei.," I919, 28, ii, I I3.

VOL. II. -7 
again to amino acid. The amino acids then combine to form polypeptides which in turn give rise to the proteins.

With regard to other views concerning the synthesis of proteins, Treub, ${ }^{*}$ from his investigations on the distribution of, the periodic variation in the amount of, and cognate observations on the cyanogenetic glucosides, $\dagger$ concluded that hydrocyanic acid is the first recognizable product of nitrogen assimilation, and possibly is the first organic nitrogen compound formed. Whilst on purely chemical grounds it is not impossible that acetone cyanhydrin, $\left(\mathrm{CH}_{3}\right)_{2}: \mathrm{C}(\mathrm{OH}) \mathrm{CN}$, may be a stage in protein syntheis, Treub's conclusions are not convincing: free hydrocyanic acid has not been identified in plants, and its compounds may equally well result from the oxidation of amino acids: in other words, the known facts regarding compounds of hydrocyanic acid in the plant neither prove nor disprove Treub's hypothesis. $f$

*Treub: “Ann. Jard. Bot. Buitenzorg," I895, I3, I ; I904, 19, $86 ; 1907,21,107$.

$\dagger$ See Vol. I., p. 253.

† Rosenthaler: "Schweiz. Apoth. Ztg.," I920, 58, I37 ; I921, 59, I0, 22 ; “Biochem. Zeit.," 1923, 134, 21 5, 32 I. 


\section{CHAPTER V.}

\section{RESPIRATION.}

THE maintenance of life is impossible without a supply of energy. This energy is acquired by various chemical reactions of an exothermic character whereby substances of different nature are converted into compounds of lower thermal energy, and thus energy is released. This is more obvious in an animal than in a plant, which generally is less obtrusive in its movements and various activities and may make use of radiant energy, more particularly in the production of food.

That energy may be produced by the combustion of a suitable fuel is a commonplace and is illustrated in the steam engine, the boilers of which are heated by the thermal energy liberated by the combustion of fuel which varies according to local circumstances. The heat-producing power, or calorific value, of fuels varies, the most efficient material is that which produces the maximum number of heat units or calories for a given weight of substance.

The heat produced in the combustion of a fuel is due to the chemical reaction of oxidation, or, in other words, the heat given out when the constituent elements of the fuel severally combine with oxygen to form the corresponding oxides. The heat of combustion of a compound will, therefore, depend upon the heat of combustion of its corrstituent elements and is greater the richer the compound is in elements possessing a high heat of combustion. The most cconomic fuel is, thercfore, that which contains a mininum of constituents which cannot yield heat on combustion with oxygen; of these water is the most significant, followed by various metallic elements which form the so-called ash constituents. It is obvious that the more complete the combustion, the greater is the energy 
set free, wherefore the heat enginecr devises the complete oxidation of available fuel, wond, coal, coke, and mineral oil, to carbon dioxide and water. In the living organism, on the other hand, this combustion may not be so complete and may stop at a phase several stages short of the ultimate, a portion of the total potential energy of the material physiologically consumed being sufficient for its needs. For instance, Bacillus coli and B. pyocyaneus in the resting condition obtain sufficient energy in oxidizing succinic acid to fumaric acid, but if these bacteria are proliferating the fumaric acid is also oxidized as soon as it is produced.*

It is a principle in physical chemistry that the heat of any chemical reaction depends solely upon the initial and final products, and the total heat evolved is the same by whatever method the final products are obtained, i.e. whether in one single process or by a series of intermediate stages, and also whether the reaction proceeds rapidly or so slowly that there is no perceptible rise in temperature. In view of these facts it will be clear that the same laws hold for the low temperature of oxidation of various substances in the living cell as for the combustion of these substances in air or oxygen.

The heat of combustion of an element is determined by causing it to combine with oxygen in a closed chamber and measuring the heat evolved calorimetrically. The two equations-

$$
\begin{aligned}
& \mathrm{C}+\mathrm{O}_{2}=\mathrm{CO}_{2}+94 \cdot 8 \mathrm{~K} \\
& \mathrm{H}_{2}+\mathrm{O}=-\mathrm{H}_{2} \mathrm{O}+69 \mathrm{~K}
\end{aligned}
$$

indicate that by the complete oxidation of 12 grams of carbon or 2 granis of hydrogen 94.8 and $69 \mathrm{~kg}$. calories $\uparrow$ are evolved.

These equations may be expressed in another form :-

I gram of hydrogen on combustion yields $34.5 \mathrm{li}$

I ", , carbon ", ., , $7 \cdot 9 \mathrm{~K}$

* Quastel: "Biochem. Journ.," $1924,18,365$. Quastel and Whetham : id., 1924, 18, 519; 1925, 19,519,645.

$\dagger \mathrm{A}$ kilogram calorie is the amount of heat required to raise the temperature of $\mathrm{I} \mathrm{kg}$. of water through $\mathrm{I}^{\circ} \mathrm{C}$. A statement to the effect that the complete oxidation of glucose, for example, liberates $709 \mathrm{~kg}$. calories therefore means that the heat energy liberated during the combustion of $\mathrm{I} 8 \mathrm{o}$ grams of glucose is sufficient to heat $709 \mathrm{kgs}$. of water through $\mathrm{I}^{\circ} \mathrm{C}$. 
From which it will be seen that hydrogen on combustion yields relatively much more heat than carbon; consequently compounds rich in hydrogen have a ligh calorific value. Moreover, since oxygen and nitrogen have no calorific value, it follows that the presence of these elements in compounds reduces their calorific value. Thus it comes about that fats which contain only about I I per cent. of oxygen have a considerably higher heat of combustion than carboliydrates which contain as much as 53 per cent. of this element. The actual values of the heat obtainable by the combustion of some of the more important fuel substances of the living cell are as follows :- -

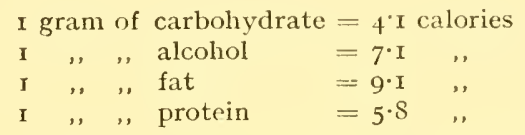

In the procurement of energy the plant exhibits a wider range than does the animal, and this to a larger extent than is often thought; thus Ramann and Bauer* have estimated that young saplings of deciduous trees may show a loss of 20 to 45 per cent. of their dry weight during the burst of activity which follows the winter sleep.

The term respiration here is used to include all those processes which involve a liberation of energy employable by the organism in its various activities. Respiration is not merely the absorption of oxygen and the excretion of carbon dioxide, as is too often supposed, an idea having its origin in the lungs of an animal being termed the organs of respiration. Respiration is essentially a catabolic process, and any organ of a plant or of an animal which is doing work is an organ of respiration in that it cannot accomplish its task without the energy obtained by the exertion of appropriate niechanisms. The lungs and the respiratory tract, on the one hand, and the stomates, lenticels, "respiratory chamber," and the intercellular space system on the other, are strictly comparable: they are organs of breathing; structures, reservoirs, and surfaces for the conveyance and initial absorption of oxygen, and for

* Ramann and Bauer: "Jahrb. wiss. Bot.," i9i r, 50, 67. 
the ultimate elimination of the gascous waste of physiological combustion.

This motive power commonly is obtained by the physiological combustion of carbohydrate, by which, theoretically, a molecule of sugar is completely oxidized by 6 molecules of oxygen giving origin to 6 molecules each of carbon dioxide and water with the liberation of a considerable quantity of energy :-

$$
\mathrm{C}_{6} \mathrm{H}_{12} \mathrm{O}_{6}+6 \mathrm{O}_{2}=6 \mathrm{CO}_{2}+6 \mathrm{H}_{2} \mathrm{O}+674 \mathrm{~K} .
$$

The liberation of these 674 calories by the complete oxidative degradation of a molecule of carbohydrate will involve the production of tempcratures far above thesc observed in the living plant, but, as has been indicated above, the same amount of thermal energy will be set free when the process takes place in slow stages with a hardly perceptible rise in temperature. This oxidation is effected by the plant by means of enzymes, and when the respiration is intense a considerable amount of heat is evolved and dissipated, but these aspects will be considered later.

\section{RESPIRATORY QUOTIENT.}

The above equation shows that the volume of carbon dioxide evolved is equal to that of the oxygen absorbed; in the plant this correlation provides a well-known avenue for investigating certain aspects of the respiratory processes.* This fact, first appreciated by de Saussure, is commonly called the Respiratory Quotient, in the consideration of which it is well to realize that it has but little value in indicating the essential parts of the process, correlating as it does merely a final product, carbon dioxide, of a long series of changes with the absorbed oxygen, the two being but remotely related. The ratio $\mathrm{CO}_{2} / \mathrm{O}_{2}$ is variable not only in different plants but also in the same plant at different phases of its existence; in other words, the value of the ratio is subject to the conditioning factors. Puriewicz, for instance, found that the

* See Bonnier and Mangin: "Ann. Sci. Nat. Bot.," I $\$ 8_{4}$, vi,, 19, 217 ; r885, vii., 2, 3r 5 ; r886, vii., 3, 5 .

† Puriewicz: “Jahrb. wiss. Bot.," I 900, 35, 573. 
amount of carbon dioxide evolved showed a much greater range in variation than did the absorbed oxygen in the same plant in different conditions, the figures obtained in a series of experiments showing a variation of - I 4 to 120 per cent. of the average for carbon dioxide, whilst the oxygen varied from o to 48 per cent. of the average. Ruby* observed in the olive that the ratio remained practically constant and was but little affected by the age of the plant or of the organ examined; generally it is rather higher in leaves from fruiting branches, a fact possibly connected with the greater abundance of available food, and in the early season of the year it is less than unity but later rises to unity.

In the germination of the white mustard, Brassica alba, Stalfelt $\dagger$ observed that an increase in the partial pressure of oxygen from 20 to 50 per cent. led to an increase in oxygen absorption. In normal conditions, he found that the maximum absorption of oxygen occurred on the fourth day of germination when the ratio $\mathrm{CO}_{2} / \mathrm{O}_{2}$ was about $0 \cdot 50$.

When the carbon dioxide evolved is due to the immediate physiological combustion of available substances, it will be apparent that the respiratory quotient will vary according to the nature of this food.

Thus, in general terms, if carbohydrate is the immediate respirable substance, the respiratory quotient will be in the neighbourhood of unity; on the other hand, if fat is consumed the ratio will be less than unity owing to the fixation of oxygen by unsaturated fatty acids. Thus in germinating flax, which is fat containing, figures varying from 0.3 to 0.64 were obtained by Bonnier and Mangin.

These ratios are applicable only in those instances where the physiological combustion is complete. But the process may stop at an intermediate stage; thus the following acids,

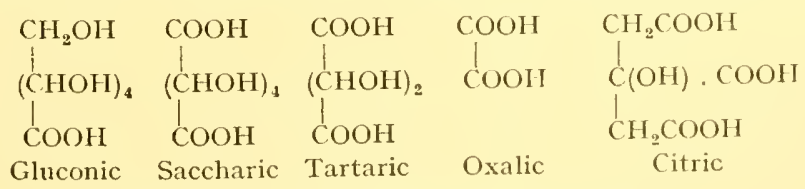

* Ruby : “Ann. Sci. Nat. Bot.," I9I 7, 20, I.

† Stalfelt: "Biol. Zentrlbl.," I926, 46, 1. 
can be produced from sugar both in vitro and in vivo, for all have been identified in the degradation products of various strains of Aspergillus niger* grown on carbohydrate substrates. $\dagger$ It is obvious that in all such examples the respiratory quotient will be less than unity. Oxalic, malic, citric and tartaric acids are of frequent occurrence in the higher plants. True it is, that it is difficult to decide whether these, in common with other products isolated from the plant, are of catabolic or anabolic origin. In the ripening of fruit, the disappearance of organic acids is concurrent with the appearance of sugar; it is an open question whether the acids give origin to the sugar or are used up in respiration.

If these acids are used in respiration, it is worthy of note that malic acid is the most easy to oxidize and citric acid the most difficult, tartaric acid being intermediate; the question arises whether this circumstance is in any way connected with the fact that apples and pears, whicl chicfly contain malic acid, can ripen in northerly regions; that grapes, which contain tartaric acid, require a warmer climate and do not ripen so effectively as the apple in the northern temperate zone, whilst the orange and lemon, which, contain citric acid, are confined to tropical or sub-tropical countries.

Succulent plants provide examples of a normal stoppage of the respiratory process at an intermediate stage. Members of the Crassulacex do not give off carbon dioxide when first placed in darkness, although the absorption of oxygen is active ; there is, however, an accumulation of organic acids, malic and oxalic, and it is not until these have accumulated in relatively large quantities that carbon dioxide is evolved as in a normal plant. $\neq$ The peculiar metabolism of these plants is generally associated with and explained by their massive structure rendering the movement of gases a relatively slow process, the catabolism stops at an intermediate stage and

* The respiratory activities of this and other moulds are commercially exploited.

†Franzen and Schmidt: “Ber. deut. chem. Ges.," I925, 58, 222. Amelung: "Zeit. physiol. Chem.," I927, 166, I61. Butkewitsch: " Biochem. Zeit.," I927, 182, 99.

† See Nicolas: "Compt. rend.," I918, 167, I31. 
thus forms a reserve of carbon which is converted into carbon dioxide, available for carbon assimilation, by the decomposition of the acids when photosynthetic conditions supervene. Comparable phenomena occur in bacteria in certain conditions, the formation of acids being a well-known occurrence in their oxidative activities.

Of other products of respiration, carbon monoxide has been described by Langdon and Gailey in the pneumatocysts of Nereocystis Luetkeana, ${ }^{*}$ a unique example as far as is known. The bladders contain a mixture of nitrogen, oxygen, carbon monoxide, but no carbon dioxide. An analysis of the gaseous contents of over a thousand of these floats showed the carbon monoxide to vary from I to 12 per cent. by volume, whilst the oxygen ranged from i 5 to 25 per cent. Only when oxygen is present does carbon monoxide form in the bladders ; if the oxygen be replaced by nitrogen or hydrogen, no carbon monoxide results. The gas is produced naturally both by day and by night but it is not formed when the plant is ground and allowed to undergo autolysis or decay, in which circumstances carbon dioxide and hydrogen are produced. From these facts it is concluded that the gas is a respiratory product and has no connection with carbon assimilation.

In further illustration of the respiration of fats, the work of Stephenson and Whetham $\dagger$ on the Timothy grass baccillus, which is characterized by a high fat content, may be mentioned. It was cultivated at $37^{\circ}$ on a medium containing ammonium phosphate as the sole source of nitrogen, and glucose as the only source of carbon, the $p \mathrm{H}$ being maintained at 8.0. The periodic analyses of the proteins and fats of the plants and analyses of the medium showed that the sugar was completely used in about three weeks, during which period the amounts of fat and protein synthesized gradually increased to a maximum until no sugar remained in the culture medium. Then the amount of fat contained in the organism rapidly decreased,

* Langdon: "Journ. Amer. Chem. Soc.," I9I 7, 39, I 49. Langdon and Gailey : "Bot. Gaz.," 1920, 70, 230.

$\dagger$ Stephenson and Whetham: "Proc. Roy. Soc.," B, I922, 93, 262 : $1923,95,200$. 
but not so the protein. Carbon dioxide was continually given off, but no intermediate products were detected. In the earlier phases, when the sugar is consumed, and fat and protein synthesized, the respiratory quotient is high: but in the later phases, after the sugar has been used up, the amount of carbon dioxide emitted falls off and the respiratory quotient drops. This change in the respiratory quotient supports the view, based on chenical analyses, that fat is the respirable material of the plant.

De Boer, ${ }^{*}$ in his investigation of the respiration of Phycomyces, found that the respiratory quotient varied according to the food consumed; on a linseed substratum, on which the respiration is more intense than on a carbohydrate medium, it ranged from 0.65 to about 0.75 , while on bread, an essentially carbohydrate diet, its average was I rising to $\mathrm{I} \cdot 2 \mathrm{O}$ at the peak of respiratory activity.

With regard to the physiological consumption of proteins in lower organisms, Terroine, Wurmser and Montané $\dagger$ found that Aspergillus niger in conditions of starvation lost relatively much protein; this fact, taken in conjunction with the observations that on a medium containing glucose the respiratory quotient is in the neighbourhood of unity and falls to 0.8 during starvation, $\neq$ leads the authors to conclude that the plant uses protein rather than carbohydrate as a reserve material. Further, when Aspergillus is grown on a medium containing proteins as the sole source of food, the products of respiration are carbon dioxide, ammonia and water.

\section{FERMENTATIVE PROCESSES.}

The equation given on page 102 represents the result of exhaustive aerobic consumption of carbohydrate. Less economic methods of obtaining energy from carbohydrate are also employed by the plant, the carbohydrate being broken down to products of lower heat energy, but still having considerable potential energy which is possible of exploitation by further

* De Boer: "Rec. Trav. bot. Néerland.," 1928, 25, I 7 .

$\dagger$ Terroine, Wurmser and Montané: "Bull. Soc. Chim. Biol.," I922, 4, 623.

+ See Kosinski : "Jahrbüch. wiss. Bot.," I 902, 37, I 37. 
oxidation. Such processes may be effected without the intervention of atmospheric oxygen and are commonly known as fermentations. Alcoholic, lactic and butyric fermentation of sugar are well-known examples; in all the amount of energy released is much smaller than that from complete oxidation; this is shown in the following equations:-

$$
\begin{aligned}
& \mathrm{C}_{6} \mathrm{H}_{12} \mathrm{O}_{6}=\underset{2}{2} \mathrm{C}_{2} \mathrm{H}_{6} \mathrm{O}+2 \mathrm{AlO}_{2}+28 \mathrm{~K} \\
& \mathrm{C}_{6} \mathrm{H}_{12} \mathrm{O}_{6}={ }_{2} \mathrm{CH}_{3} \mathrm{CHOHCOOH}+\mathrm{I} 8 \mathrm{~K} \\
& \mathrm{C}_{6} \mathrm{H}_{12} \mathrm{O}_{6}=\mathrm{CHI}_{3} \mathrm{CH}_{2} \mathrm{CH}_{2} \mathrm{COOH}+{ }_{2} \mathrm{CO}_{2}+2 \mathrm{H}_{2}+{ }_{1} \mathrm{~K}
\end{aligned}
$$

In illustration, the fermentation of sugar by yeast may be briefly considered.

As in normal oxidation of sugar, the fermentation process is accompanied by the evolution of heat, although to a much lesser extent, a gram molecule of maltose yielding $42.7 \mathrm{~kg}$. calories, taking Brown's * value of the heat of fermentation of I gram of maltose as being 125 calories. The alcoholic fermentation of sugar is therefore a wasteful process for obtaining energy when compared with oxidation, since by its means nearly thirty-one times as much sugar must be consumed to obtain as much energy as is yielded by the direct oxidation of sugar. The significance of this figure of the heat of fermentation of maltose may be realized by Brown's observations that between the temperatures of $14^{\circ}$ and $16^{\circ} \mathrm{C}$. the time required by a yeast cell to ferment its own weight of sugar varies from eighteen and a half to nineteen and a half hours and that the heat generated during one hour is sufficient to raise the temperature of the cell by $15^{\circ}$ or $16^{\circ} \mathrm{C}$. From such obcervations Brown estimates that at $30^{\circ} \mathrm{C}$. yeast can ferment its own weight of maltose in $2 \cdot 2$ hours and the potential rise in temperature in the cell in one hour will be $75.5^{\circ} \mathrm{C}$. under adiabatic conditions, figures indicative of an intense metabolism and, apparently, a great waste of energy. Brown suggests that the explanation for this waste is to be found in the fact that brewers' yeast is a cultivated plant grown in unnatural conditions. The wild yeasts lead a quiet life on the

* Brown : "Ann. Bot.," 1914, 28, 197. 
skin of, say, the grape : rupture of the skin of the fruit provides a nutrient medium eminently suitable for growth and reproduction accompanied by a free access of oxygen. A period of intense activity immediately supervenes and budding takes place, under the continued action of the oxygen, with remarkable rapidity: this activity necessitates a continuous supply of energy, which is provided by fermentation. Reproduction and fermentation thus are correlated. "That we can by means more or less artificial keep the reproductive power of a yeast in abeyance, whilst still availing ourselves of its fermentative power, has hitherto obscured the relation of the two functions, and hence has given rise to the somewhat exaggerated idea of the purposeless and prodigal waste of the yeast cell regarded as a living unit."

In view of the definition given above, it is obvious that any process, oxidative or reductive, which liberates energy available for use by the plant is to be included amongst res. piratory processes, irrespective of the initial products consumed and the final products evolved. Thus, in addition to the oxidative processes of the higher plants in which fats, carbohydrates, proteins, and, in extreme circumstances, even protoplasm may he physiologically consumed, the diverse metabolic processes of bacteria and comparable organisms in reduc. ing sugar to alcohol, sulphate to sulphide, or oxidizing alcohol to acetic acid, lactose to lactic acid, ammonium salts to nitrites, nitrites to nitrates, and so on, are all processes of respiration, notwithstanding the fact that many of these activities may be extra-cellular. For green plants, oxygen is a common essential, although, as is well known, certain organisms, such as the lactic bacteria, can only flourish in the absence of oxygen, whilst others, although oxygen is essential normally, have the faculty of tiding over a period of its absence. Hence respiration may be distinguished as aerobic, anaerobic, ${ }^{*}$ and facultative anaerobic. The final waste products are diverse and depend upon the chemical nature of the material consumed

* The use of the term, "intra-molecular respiration" for anaerobic respiration is wrong since all forms of respiration are essentially intramolecular. 
and the method of its physiological combustion, whether by aerobic or anaerobic means.

The ordinary green plant, and certain non-green plants, in their respiration absorb oxygen and ultimately give off carbon dioxide and water. This respiration is unceasing and is continued in all living members whether active or passive until death ensues. If oxygen be entirely withheld, growth, movement, irritability and activity in general ultimately will come to an end.*

The accumulation of the products of physiological combustion will bring about a modification, if not a complete cessation of the process, which will lead to the termination of other activities. Thus rotation of protoplasm in the cells of Elodea will come to an end in the presence of an undue amount of carbon dioxide. The germination of seeds is retarded or inhibited by high partial pressures of carbon dioxide in the atmosphere: this inhibition may remain in force only so long as the seeds are exposed to the enriched atmosphere, germination taking place after removal to a normal atmosphere as in the bean, cabbage, barley, pea, and onion; or, the inhibition may continue indefinitely after removal to normal surroundings, germination only taking place after complete drying and re-wetting or by the removal of the testa as in Brassica alba. The degree of increase in the partial pressure of carbon dioxide required to effect inhibition of germination varies for different plants, and the retardation of germination depends on the time of exposure and the character of the seed. Similarly the sprouting of a potato is inhibited by an increase of 20 per cent. in the carbon dioxide of the atmosphere. A higher concentration causes marked injury and ultimately death. $\dagger$

* The irritability of plants is outside our present consideration : an introduction to the problems regarding the minimum pressure of oxygen necessary to maintain movements, the streaming of protoplasm in chlorophyll-containing cells in darkness and in an atmosphere free from oxygen, and similar subjects will be found in the larger text-books on general plant physiology.

† Kidd: "Proc. Roy. Soc.," B, 1914, 87, 408; "New Phytol., 1919, $18,248$. 
Spoehr and McGee * examined the effect of varying the partial pressure of carbon dioxide on the respiration of leaves : they found that when the amount of carbon dioxide is increased, the amount of carbon dioxide enitted from the leaf is reduced for a while and then rises to the original rate. Conversely when the partial pressure of the carbon dioxide of the surrounding atmosphere is reduced, the rate of evolution of carbon dioxide is increased for a time and then falls to the original rate.

These facts are of considerable importance, not only as regards the economic aspect but also in their bearing on experimental work: results obtained for subjects contained in closed vessels, as is not infrequent in experiments on respiration, in which the products of the oxidative processes accumulate, may be an expression of the plant's activity not in a normal but in a pathological condition and, therefore, may be valueless. Further, a state of carbon dioxide anaerobosis may be set up.

\section{INTENSITY.}

In general terms, the more active the body the more intense the respiration, provided that the conditioning factors, such as temperature, food, facility of gaseous exchange and circulation in the plant, and so on, are favourable. Considering the plant as a whole, Bonnier and Mangin $†$ recognize two respiratory maxima in its seasonal development, the first at germination, or on the unfolding of the leaf buds, and the second at the opening of the flower buds. Ruby $\ddagger$ found that the intensity of respiration was greater in leaves of young than of old plants; thus the amount of carbon dioxide evolved per hour per gram of fresh weight of leaves from trees one year old, three years old, and many years old was respectively .200 c.c., I 50 c.c., and 100 c.c. In all instances the growth period showed a one-and-a-half to two-fold increase in respiration as compared with the non-growing periods. Nicolas $\$$ com

\footnotetext{
* Spoehr and McGee: "Amer. Journ. Bot.," I924, 11, 493.

$\dagger$ Bonner and Mangin: "Ann. Sci. Nat. Bot.", I 8. $5,5,315$.

\$ Ruby: id., 1917, 20, I.

$\S$ Nicolas: "Rev, gén. Bot.," I918, 30, 209.
} 
pared the respiration of the vegetative parts of annual, biennial, and perennial plants and found that leaves and portions of stems of the same branch varied according to their age, those from the apical regions showing a three to seven-fold intensity of respiration as compared with sinilar structures from the basal parts.

Kidd, West, and Briggs * studied the respiration of Helianthus annums both in the laboratory and in the field. They point out that the factors which may affect the rate of respiration per unit of dry weight of tissue are the concentration of the respirable material, the concentration of oxygen, the temperature, and the cffective amount of respiring cell matter per unit of dry weight. This last is the internal factor, the resultant of many factors, none of which as yet fully understood and some of which probably not yet formulated. The internal factor can only be accurately measured when the other factors are not conditioning respiration. For purposes of measuring its effect, Kidd, West, and Briggs employ a respiratory index which is the respiration, measured by the rate of carbon dioxide produced, per gram of dry weight at $10^{\circ} \mathrm{C}$. when the amount of respirable matcrial is not limiting and when the external concentration of oxygen is that of the atmosphere. From a large number of observations they conclude that the respiratory index of the entire plant continuously declines with increasing age. For example, entire plants 2 days from germination gave $3 \mathrm{mg}$. carbon dioxide per gram of dry weight per hour, whilst plants i 36 days from germination yielded but $\cdot 39 \mathrm{mg}$. carbon dioxide per gram of dry weight per hour. A similar decrease in the respiratory index is exhibited by the stem, leaves and flowers. In the stem the value fell from $\cdot 8 \mathrm{mg}$. on the 36 th day from germination to $08 \mathrm{mg}$. on the $136 \mathrm{th}$ day from germination; during the same period the measure for the leaves decreased from $\mathrm{I} \cdot 56$ to $\cdot 44 \mathrm{mg}$. The fact that the initial respiratory index of successive leaves decreases with the age of the plant indicates a respiratory decrement of the merismatic tissue with age and from this it follows that the fall in the respiratory

* Kidd, West and Briggs : "Proc. Roy. Soc.," B, I92 I, 92, 368. 
index of the wholc plant is not duc to the proportionate increase with age of dead tissue, sclerenchyma and trachea, for instance.

Hover and Gustafson* have made the interesting observation that not only does the rate of respiration of the leaves of maize, wheat, oat and sorghum fall off with age, but that there is a gradual incrcase with increasing age after middle age. This, however, is not shown by the leaves of the sunflower and by the stems of maize.

Blackman and Parija $\uparrow$ have studied the respiration of stored apples. When maturity has been passed the organism, or a part of the organism such as an apple, enters the phase of senescence in which the general tone becomes gradually less owing to the increasing relaxation of the control of what may be termed the protoplasmic factor. One result of this spontaneous change is an increased rate in the hydrolysis of reserve food whereby there is formed more material available for respiration and this leads to a greater production of carbon dioxide. But stored apples are isolated structures, wherefore the only material available for their respiration is that which they themselves contain. It follows that a time will come when starvation begins and this results in a fall in the rate of respiration. This rate at any moment is thus the resultant of two opposed factors, increased hydrolysis which accelerates and starvation which hinders. This generalization is based on many experimental observations on apples at a temperature of $22^{\circ} \mathrm{C}$. : these show that there is at first a slow incrcase in the rate of respiration which progresses quickly and then more slowly to the maximum value, after which there is a falling off, slow at first and then faster, towards zero. This sequence is comparable to that observed by Hover and Gustafson mentioned above. Blackman and Parija do not claim that their generalization is fully established by the evidence produced; it is, however, a hypothesis which explains the observed facts.

* Hover and Gustafson: “Journ. Gen. Phys.," I926, I0, 33.

† Blackman and Parija: "Proc. Roy. Soc.," B, 1928, 103, 42. 
Nicolas * found that the presence of anthocyanins was a factor, or rather the symptom of an internal factor, of importance in determining the intensity of respiration. Leaves containing a red pigment either as a youth form or as a permanent character absorbed more oxygen and exhibited an increased respiration as conpared with green leaves, whilst leaves turned red either by accident or by stress of conditions $\dagger$ showed a decreased respiration as compared with green leaves, the amount of carbon dioxide being smaller.

The intensity of respiration commonly is measured by the amount of an end product given off in unit time: in aerobic respiration the final product measured is carlon dioxide, or, in special cases, temperature is measured; in anaerobic respiration, the production of alcohol may be estimated.

It is clear that the results obtained by the measurement of carbon dioxide may not be a true expression of the respiratory activity since the exhalation of the gas may be greatly hindered by various circumstanees. The surface of the respiring organ is one such: Hoffmann $\ddagger$ found that the amount of carbon dioxide evolved in twenty-four hours per kilogran of large, medium and small-sized potatoes was 259, 3I4 and $326 \mathrm{mg}$. respectively; barley gave confirmatory results. He also found that the nitrogen content was important. Further, a depression of the carbon dioxide output is associated with the succulent habit, hence in order to obtain a figure representing a true measure of the activity of respiration, the increase in organic acid content in addition to the gaseous carbon dioxide should be determined. This aspect is considered by Maige and Nicolas, $\S$ who point out that in the flowers they examined, the respiration intensity increased with age when stated in terms of gaseous exchange, but showed a decrease with age when measured in terms of wet and dry weight. The gynæcium shows, as might be expected from the activity of the contained

* Nicolas: "Compt. rend.," 1918, 167, 131.

$\uparrow$ See Vol. I., p. 336.

+ Hoffmann: "Journ. f. Landw.," I9I6, 64, 289.

§ Maige: " Rev. gén. Bot.," I907, r9, I ; "Ann. Sci. Nat. Bot.," I9I I, I4, I. Maige and Nicolas: "Rev. gén. Bot.," I 9 IO, 22, 409.

VOL. II. -8 
structures, a real increase with age, whilst the other parts of the flower exhibit a decreasing respiration with age.

It is easy to demonstrate by relatively simple means, due precautions being taken against loss, that the evolution of lieat is a concomitant of respiration. The temperature attained is cumulative, and a remarkable rise may result which may be realized by thrusting the naked arm into a barrow load of fresh lawn cuttings, especially if there is a good admixture of clover. Exact measurements have been made by various investigators : Molisch * found that the bulked leaves of Carpimus betulus reached a tempcrature of $5 \mathrm{I}^{\circ} \mathrm{C}$. in fifteen hours, a fall then took place so that at the end of forty-eight hours the tempcrature was $34^{\circ} \mathrm{C}$. After the lapse of one hundred and four hours a sccondary maximum at $47^{\circ} \mathrm{C}$. was attained, the temperature again showed a fall to $3 \mathrm{I}^{\circ} \mathrm{C}$. after one hundred and eighty hours. Of these two maxima, the first is an expression of the true respiration intensity of the leaves, whilst the cause for the second is to be found in bacterial activity. Pierce $\uparrow$ found that in germinating peas the greatest average gain in heat was 923.9 calories accumulated in 23.5 hours, which is about equivalent to 8.55 calories per minute per kilogram of peas, a measure roughly one quarter less than the amount of heat given off by a mouse under similar experimental conditions. It was further found that the amount of heat liberated by germinating peas decreased with age.

Since respiration is a means of obtaining energy for the needs of the plant, the evolution of heat represents excess of energy and is a waste product, for which reason the temperature of a normally respiring plant is not by itself a sure guide to the amount or intensity of physiological combustion but rather a measure of the inefficiency of the organism.

\section{STIMULATION.}

The stimulation of the plant accelerates respiration, which acceleration is marked by a rise in the output of carbon dioxide

* Molisch : “Bot. Ztg.," I908, 66, 2 II.

† Pierce: “Bot. Gaz.," I912, 53, 89. See also Bonnier: "Ann. Sci. Nat. Bot.," 1893, I8, 12. 
and generally also by a rise in temperature. The intensification of respiration resulting from traumatic stimulation long has been known and now is not an uncommon laboratory exercise. Richards * found a gradual rise in temperature following the stimulus, attaining its maximum about twentyfour hours after the infliction of the injury. In massive tissues the effect is local, but in less compact structures, an onion bulb for example, the rise in temperature may be demon. strated over a more extensive area. The rise may be two or three times as large as the difference between the normal temperature of a potato and that of the surrounding air. The precise increase in respiration depends on the extent of the injury and the nature of the tissue operated on. There is an initial outburst of carbon dioxide, followed by a fall, a feature not at all uncommon after drastic stimulation, and the absorption of oxygen is rather greater than the amount theoretically required for the quantity of carbon dioxide evolved. Richards considers that the initial outburst of carbon dioxide in part is due to the release of the gas normally enclosed within or absorbed by the tissues, the "residual" carbon dioxide which normally is not exhaled.

In the potato, Hopkins $\uparrow$ demonstrated an increase in the sugar content of the tuber after wounding, it gradually rises to a maximum and then falls. He considers that the increased intensity of the respiration is explained, at any rate in part, by the increase in the sugar content.

Muller $\ddagger$ investigated the respiration of trees after lopping, and found a seasonal variation in the traumatic reaction: the reaction of Picea is about the same all the year round, whilst Fagus and Fraxinus show the greatest reaction in spring and autumn, and the least in summer, as estimated by the output of carbon dioxide at the mean temperature of the montl.

White $\S$ found that pollination produces a rapid increase in respiratory activity and affects the $\mathrm{CO}_{2} \mathrm{O}_{2}$ ratio which generally

* Richards: “Ann. Bot.," I 897, II, 29.

† Hopkins: "Bot. Gaz.," I927, 84, 75.

+ Muller: "Dansk. Botanisk Ark.," I92.4, 4, I.

\$ White: “Ann. Bot.," 1907, 21, 487. 
is greater in pollinated carpels as compared with unpollinated gynæcia. The most striking instance was afforded by the Pelargonium, the pollinated carpels of which evolved from five to eight times as much carbon dioxide as the unpollinated.

Mention also may be made of Schley's * observations, who found that the respiration of a geotropically stimulated root is greater than that of an unstimulated root, the respiration rate of the convex side being greater than that of the concave side during the period of perception and response.

Products of the plant's own metabolism may stimulate its respiration. Thus Spoehr and McGee $\dagger$ observed that when detached leaves of the sunflower and the bean were grown in a nutrient solution containing sugar and amino acid, the rate of respiration increased with that of the amino acid in the culture medium even when the leaves contained supplies of carbohydrate. When grown in darkness, when carbohydrate decreases and amino acid increases, there is a like stimulation which tends to maintain a relatively higher rate of respiration. From such observations they conclude that carbohydrate alone does not determine the intensity of respiration, but that there is an accessory stimulating factor, amino acid, in the plants examined. On the other hand, Hafenrichter $\ddagger$ concludes that in the soy bean grown in darkness, the accumulation of amino acids is incidental rather than necessary to respiration; he obtained no evidence that amino acids stinulate respiration.

Although vegetable pathology is without our present province, mention may be made of the fact that, as in the animal, disease is frequently marked by an increased respiration intensity. $\S$

\section{THE ACTION OF ANASTHETICS.}

The action of anæsthetics on the output of carbon dioxide is partly stimulatory and partly narcotic. Irving || found that

* Schley: “Bot. Gaz.," 1920, 70, 69.

† Spoehr and McGee: "Carnegie Inst. Wash.," No. 325, 1923.

+ Hafenrichter: " Bot. Gaz.," I928, 85, 27 I.

$\S$ See, for example, Weimer and Harter: "Journ. Agric. Res.," I92 I, 21, 627. Davis: "Bot. Gaz.," 1926, 81, 323.

|l Irving: "Ann. Bot.," 1911, 25, 1077. 
the effect of a single dose depended on its strength: a dose of $\mathrm{O} \cdot \mathrm{I}$ c.c. of chloroform in 970 c.c. of air brings about an immediate rise in the output of carbon dioxide; this cffect subsequently disappears and the leaves then evolve as much carbon dioxide as in normal respiration. In medium doses, 0.2 c.c. of chloroform in 970 c.c. of air, there obtains the same initial outburst of carbon dioxide, which falls away more quickly than after a small single dose and for a time remains below normal; after about six hours recovery is complete and the evolution of carbon dioxide is normal. With a dose of I c.c. of chloroform in 970 c.c. of air, the initial outburst of carbon dioxide is carlier and its curve is steeper, the production of carbon dioxide slowly diminishes and there is no recovery. Following a strong dose of chloroform, IO c.c. in 970 c.c. of air, there is no detectable initial outburst and the carbon dioxide output quickly falls to zero. The administration of a continuous dose of chloroform produces the sanie effect as a single dose two or three times as strong. Thoday* likewise found that in Prunus laurocerasus, Helianthus tuberosus and Tropceolum majus a small dose of chloroform leads to an immediate stimulation of respiration, the evolution of carbon dioxide and the absorption of oxygen increasing in like proportion, which indicates that the two are co-ordinated. If, however, the dose is sufficiently large to effect a visible disorganization, such as change in colour, $\uparrow$ there is an initial outburst of carbon dioxide then a fall to a very low level and the absorption of oxygen no longer shows any co-ordination with the amount of carbon dioxide evolved. The absorption of oxygen in some way is connected with the cell contents, especially tannin. In the Tropaolum leaf, which is free from tannin, the absorption of oxygen is much lower than the output of carbon dioxide, whereas in the cherry laurel and the artichoke, both of which contain tannin, the initial up-take of oxygen is very rapid, then it declines but

* Thoday : “Ann. Bot.," I913, 27, 697.

$\uparrow$ The change in colour is due to the oxidation of tannins and glucosides by appropriate enzymes, oxidases for example (see Vol. I., p. 498). It may be conveniently seen by exposing the flowers of the white lilac to the fumes of phenol under a bell glass. 
remains at a level much higher than the output of carbon dioxide.

Similar observations have been made by others, thus Thomas * found that wheat subjected to the action of ether shows an increase of respiration followed by a decrease.

Exposure to $7 \cdot 3$ per cent. of ether is only stimulatory provided it be of short duration, an exposure of more than thirty minutes resulting in death. Similarly the main observations of Thomas have been corroborated and extended by Smith $\dagger$ who used the hydrogen ion concentration method in finding the rate of production of carbon dioxide in wheat seedlings. It was found that the first effect of ether, used in concentrations of I per cent., 3.65 per cent. and 7.3 per cent., was to depress the rate of respiration; this was followed by a rapid increase to above the normal rate, which was in turn followed by a decline to much the same level in all concentrations of anæsthetic, in times varying with the dose employed; the stronger the solution of ether used, the quicker the fall.

Irwin, $\ddagger$ using the corolla of Salvia, found that the effect of a high concentration of ether is an increased intake of oxygen and output of carbon dioxide, whilst at the same time the acidity of the cell sap is reduced. The action of anæsthetics on the lower plants results in reactions similar to those exhibited by higher plants under like treatment.

Gustafson $\S$ found that Aspergillus niger, subjected to the action of ether, acetone, or formaldehyde, exlibits an increase in its respiratory activity followed by a decrease. The use of caffeine in saturated solution similarly brings about an increase followed by a decrease, whilst a 0.5 per cent. solution results in a decrease of respiration intensity.

Similar results were obtained by Brooks $\|$ in his experiments with Bacillus subtilis, for which plant ether is toxic in low, $0 \cdot 037$ to $\mathrm{I} \cdot \mathrm{I}$ per cent., and in high, 3.65 to $7 \cdot 3$ per cent., concentration. In strengths intermediate between these, the drug acts as a stimulant to growth. Further, the action of ether

* Thomas: “Journ, Gen. Physiol.," I $918,1,203$.

† Smith: id., I92 J, 4, 157. ‡Irwin: id., I919, 1, 399.

§ Gustafson: "Journ. Gen. Physiol.," I 919, I, I81.

II Brooks : id., 1919, 1, I93. 
varies according to the presence or absence of other substances: thus whilst the respiratory activity may be fifty times as great as the normal under the action of a 7.5 per cent. solution of ether, this high intensity is considerably reduced if 0.85 per cent. of sodium ehloride be added.

According to A. C. R. Haas, ${ }^{*}$ small doses of anæstheties are without result on the respiration of Laminaria, doses sufficiently large to produce a measurable result effect a prolonged increase in respiration, whilst strong doses result in an initial increase followed by a decrease ultimately to zero. In no experiment was it found that the initial effect of an anæsthetic was a lowering of the respiration intensity, from which it is concluded that the state of anæsthesia is not brought about by the lowering of the respiration. It is clear from these results that in general anæsthetics have a twofold action: a small dose is a stimulant, a large dose is a nareotic. And this is true not only for respiration but also for other expressions of plant activity such as the circulation of protoplasm within the cell.

THE ACTION OF IONIZED AIR.

Spoehr $\dagger$ was the first to observe that the respiration of the plant is regularly higher in conditions which vary only as regards dayliglit and darkness, differing, in other words, only in the degree of ionization. The differences observed were, however, not considerable; in the wheat plant the ratio day rate/night rate was found to be $\mathrm{I} \cdot 042$ in normal air and $\mathrm{I} \cdot \mathrm{OIO}$ in deionized air.

Stoppel $\ddagger$ found a 0.3 to I.I3 per cent. increase in the respiration of eut shoots when supplied with air ionized by passing through a tube containing carnotite, a radio-active mineral. In the earefully controlled experiments of Middleton, $\S$ barley seedlings were grown on stcrilized glass wool and glass beads watered with a culture solution. The culture was made in a glass box and supplied with a eurrent of air

*A. C. R. Haas : “Bot. Gaz.," I919, 67, 377.

† Spoehr: id., I 91 5, 59, 366.

+ Stoppel : "Bot. Zeit.," I920, 12, 1920.

§ Middleton: "Ann. Bot.," I927, 4 I, 345 . 
ionized by polonium deposited on copper foil. The ionized air was supplied for one hour, intermitted for one hour and then again supplied for one hour. There always obtained an increased respiration, the greatest percentage observed being $29 . \mathrm{II} \pm 5.62$ during the second period. This acceleration varies according to the degree of ionization: with air ionized 20,000 times above that of the surrounding air, an increased rate followed each application of the polonium; with I00,000 times that of normal air a markedly significant increase obtained in the second period only, and when the air was ionized a million times there was no significant increase in respiration. Similar results were obtained by Whimster * with the leaf of Pelargonium zonale, who found a percentage increase of $85.7 \pm 7.1$ in the respiration rate at $25^{\circ} \mathrm{C}$. in air ionized from 364 to 728 times that of normal air. The reason for the difference is not obvious: ionized oxygen is more potent than deionized oxygen so that the ionized oxygen of the daytime air, according to Spoehr, possibly accelerates the purely oxidative process of respiration, not the initial disruption of the respirable material. But until it can be said with certainty at what stage in respiration oxygen becomes operative, an adequate explanation is not possible.

\section{CONDITIONING FACTORS.}

TEMPERATURE.

In general terms an increase in temperature results in an increase in the respiratory activity until death takes place. The following figures, given by Matthæi, $\uparrow$ represent the mean value of carbon dioxide evolved by 2 grams of cherry laurel leaf per hour at the temperature specified :-

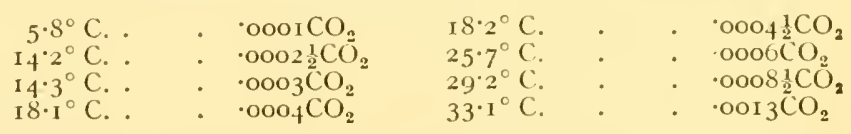

The inspection of these figures shows that for the low and medium temperatures employed there is a gradual increase in

* Whimster : "Ann, Bot.," I927, 41, 357.

† Matthei: "Phil. Trans. Roy. Soc.," B, I904, 197, 47. 
the respiration activity. At higher temperatures variation obtains and it was found that the respiration intensity rapidly changed with the time of exposure and that leaves in precisely the same external conditions gave varying results due to some internal factor. This is illustrated by the following results of certain experiments on isolated cherry laurel leaves exposed to light and carbon assimilating. The respiration values represent the carbon dioxide given off by 2 grams of leaf per hour :--..

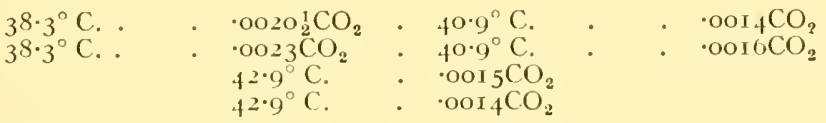

Also it was found * that the leaves of this plant in their respiration exhibit the sane relation to temperature as they do in their carbon assimilation in that the initial value at higher temperatures is not maintained but falls away, the higher the temperature the steeper the fall.

An increased temperature must be operative for some time before the stimulation of the respiratory process is noticeable, a sharp variation in temperature is without effect and a change in the respiration intensity after transference from one temperature to another is gradual. $\uparrow$

Müller-Thurgau and Schneider-Orelli $\ddagger$ in their investigation on the respiration of potatoes found much the same phenomena: mere variation in temperature effected by heating and cooling is without result unless the exposure to the higher temperature be sufficiently prolonged. Potato tubers, after an exposure to a temperature of $40^{\circ} \mathrm{C}$. for several hours and then transferred to room temperature, show a gradual increase in respiration intensity which reaches its maximum after a lapse of twenty-four hours. Exposure to higher temperatures, e.g. $44^{\circ} \mathrm{C}$, results in a permanent increase in the intensity of respiration which indicates a permanent change in the organism. To obtain this stimulation the temperature must be sufficiently high, no effect being

* See Blackman: “Ann. Bot.,” r 905, 19, 28 r.

† Blanc: “Rev. gén. Bot.," ı э $6,28,65$.

† Müller-Thurgau and Schneider-Orelli : "Flora," i 9 Io, Ioเ, 309. 
observed for temperatures below $38^{\circ} \mathrm{C}$. This is the minimal temperature for the phenomenon described in the potato, but the value probably varies in different plants. In the potato, the difference between the maximum intensity of respiration of heated tubers and that of unheated tubers is proportional to the difference between the minimal temperature and the increased temperature to which the tubers were exposed. Thus it was observed that after exposure to $44^{\circ} \mathrm{C}$. the respiration was two and a third times as great as after an exposure to $40^{\circ} \mathrm{C}$. These authors consider that the effect of the high temperature is adversely to affect the protoplasm in much the same way as does old age: as a result of this decadence, less starch is formed by the leucoplasts; also the enzymes are less active so that there is less invert sugar for the leucoplasts to fix. For instance, at $\mathrm{I} 8^{\circ} \mathrm{C}$. previously heated potatoes contain a relatively large amount of sugar; at $\mathrm{o}^{\circ} \mathrm{C}$., which temperature inhibits starch formation in normal tubers, ${ }^{*}$ the much slower formation of sugar indicates that the increased temperature also has had an injurious effect on sugar formation although the amount of diastase apparently is unaltered. The weakening due to high temperatures also is seen in the respiratory activity of wounded potatoes: the general effect of wounding (see p. I I5) is to increase the intensity of respiration, which increase is maintained; after wounding there is no immediate respiratory response in previously heated tubers, and even when recovery from the heating had apparently been made, the maximum intensity of respiration due to the traumatic stimulus never reached so high a degree as in unheated wounded tubers.

Dormant structures were the subjects of this investigation ; the subjects for the work of Kuijper, $†$ on the other hand, were active seedlings of the lupin, pea, and wheat. The seeds were germinated at about $20^{\circ} \mathrm{C}$. and then exposed to various temperatures, the carbon dioxide being estimated hourly for six hours (Fig. 6). At temperatures not exceeding $10^{\circ} \mathrm{C}$. the output of carbon dioxide is constant; from $10^{\circ} \mathrm{C}$. to $20^{\circ} \mathrm{C}$.

* See Vol. I., p. I 77.

† Kuijper : “Extr. Trav. Bot. Néerland.," I9ro, 7, Iзо. 
there is a continuous rise in the respiration of seedlings of all ages, which rise is followed by a fall; at temperatures above $20^{\circ} \mathrm{C}$. and up to $40^{\circ} \mathrm{C}$. the amount of carbon dioxide evolved

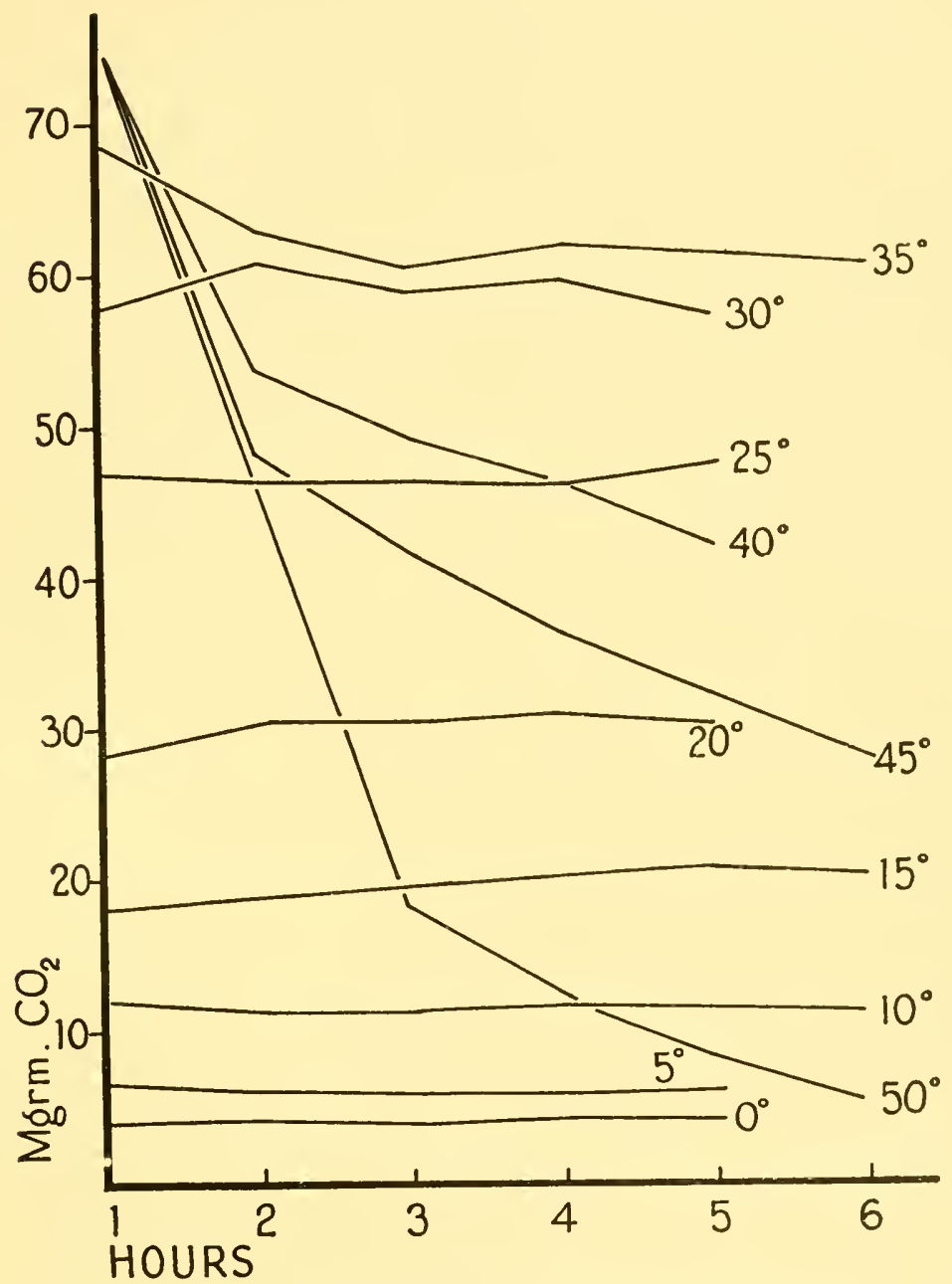

Fig. 6.-Respiration of the pea at varions temperatures.

fluctuates: a rapid fall occurs in the first two hours, then a rise for one or two hours, followed by a continuous fall. At still higher temperatures there is a continuous reduction in the 
evolution of carbon dioxide, a result which is in accordance with the observations of Blackman mentioned above.

These observations are different from those made by MiillerThurgau and Schneider-Orelli who observed a permanent increase in respiration after due exposure to high temperatures, whilst Kuijper found a decrease to obtain. This discrepancy may be due to the fact that Kuijper's seedlings were subjected to the increased temperature for a lesser time than the potatoes of Müller-Thurgau and his collaborator, and, as has already been remarked, the material employed was in active growth on the one hand whilst on the other it was resting. Kuijper explains his results on the hypothesis that there are two distinct processes concerned in respiration which are affected differently by a continuance of high temperature, one phase being early depressed whilst the other is stimulated; there is here a possible correlation with the dual origin of the carbon dioxide of respiration, which, according to Palladin, arises from the activity of an oxidase and of a carboxylase. Like MüllerThurgau and Schneider-Orelli, Kuijper recognizes the interrelation of temperature and the nature of the available respirable material. Thus of the seedlings examined, the lupin showed a rise in the respiration intensity from $15^{\circ} \mathrm{C}$. to $20^{\circ} \mathrm{C}$, the pea from $20^{\circ} \mathrm{C}$. to $25^{\circ} \mathrm{C}$, and the wheat at $30^{\circ} \mathrm{C}$. The fluctuation period was well marked at $25^{\circ} \mathrm{C}$., $30^{\circ} \mathrm{C}$. and $35^{\circ} \mathrm{C}$. respectively, and the continual fall in carbon dioxide output obtained at $25^{\circ} \mathrm{C}, 35^{\circ} \mathrm{C}$. and $40^{\circ} \mathrm{C}$. respectively. Of the food available, the lupin has 37 per cent., the pea 22 per cent., and the wheat 12 per cent. of protein, whilst of starch the lupin has none, the pea 54 per cent. and the wheat 74 per cent.

If respiration be a purely chemical process, a combustion of, say, sugar, van't Hoff's law should apply throughout the process : the evidence shows, however, that the law is followed only for lower temperatures; at higher temperatures, as has been seen, fluctuations occur and correlation comes to an end, which is indicative of the intervention of internal factors, the nature of which is not clearly understood. Clausen * found

\footnotetext{
*Clausen : "Landw. Jahrb.," 1890, 19, 893.
} 
the rate of evolution of carbon dioxide from seedlings and buds to be about doubled with an increase of $10^{\circ} \mathrm{C}$, and Kuijper found the law to apply at temperatures between $0^{\circ} \mathrm{C}$. and $20^{\circ} \mathrm{C}$. in the pea and wheat, and between $0^{\circ} \mathrm{C}$. and $25^{\circ} \mathrm{C}$. for the lupin, the coefficient lying between 2 and 3 for a difference in temperature of $10^{\circ} \mathrm{C}$. According to Lundegärdh, ${ }^{*}$ the respiratory curve falls into four regions: there is at first a gradual increase with rising temperature from the minimum to the first optimum at $40^{\circ} \mathrm{C}$, in this phase $Q_{10}$ varies from $I^{\circ} 9$ to 3.3 ; there next follows a rapid increase from $40^{\circ}$ to $46^{\circ} \mathrm{C}$.; the third phase is characterized by a marked increase to the second optimum at $50^{\circ} \mathrm{C}$; finally at temperatures above $50^{\circ}$ there is a rapid fall in the respiration intensity. Lundegardh explains the results obtained at temperatures above $40^{\circ} \mathrm{C}$. on the assumption that at about this point the protoplasm enters into a more labile phase comparable to that of a colloid whose viscosity suddenly changes at a high temperature.

In passing, it may be mentioned that the maintenance of a relatively high temperature is one of the factors which is responsible for physiological diseases, e.g. blackheart in potato tuber.t

With regard to low temperatures, it is a well-known fact that seeds, lichens, mosses, etc., especially when dry, retain their vitality on exposure to intense cold; even so low a temperature as $-250^{\circ} \mathrm{C}$. will not cause death. Since respiration is in its complete expression a concomitant of life, the process must continue in an attenuated form even at so low a temperature as that of liquid air.

FOOD.

The continuance of respiration ultimately depends upon adequate food supplies, and the intensity of respiration may be much influenced by the presence of substances immediately available as respirable material. Formerly it was considered

* Lundegårdh : “ Biochem. Zeit.," 1924, I54, I95.

$\uparrow$ See, for example, Bennett and Bartholomew: "Univ. California Publications," Technical Paper, No. 14, I924. 
that sugar, more especially dextrose, was essentially the respirable material, but no statement of general application can be made. The action of foods in this connection varies with different plants and their physiological condition, and is influenced by the operation of various natural internal factors, such as acidity, which are not directly controllable in experimental work, together with external factors such as temperature; thus in Phycomyces the normal combustion of fats changes to the consumption of carbohydrates at high temperature.*

But notwithstanding this, general physiological experience slows that carbohydrates are highly important in aerobic respiration. Palladin, $\uparrow$ for instance, found that 100 grams of etiolated bean leaves, with depleted carbohydrate, gave off I02.8, $95^{\circ} 9$ and $70.2 \mathrm{mg}$. of carbon dioxide respectively for three successive hours; but after these leaves had been grown in darkness on a solution of cane sugar for two days, by which means their carbohydrate content was increased, the rate of evolution of carbon dioxide was I $52 \cdot 6,147 \cdot 5,146 \cdot 8$ and 144.5 mgs. respectively for four successive hours.

A more prolonged culture on cane sugar does not result in a corresponding increasc in the rate of carbon dioxide production although the carbohydrate reserve is greater; thus after a treatment over a period of forty hours, the leaves evolved no more carbon dioxide than they did after four hours. Such observations indicate that a certain content of carbohydrate is necessary, but an increase above this value, which is a variable figure, is mercly increasing the respirable capital of the organ.

Müller-Thurgau and Schneider-Orelli $\ddagger$ found that the respiration of swect potatoes is very high compared with normal tubers; in the autumn, when little if any sugar is present, the respiration is low, but as the tubers increase in age and sugar accumulates there is concurrently a more intense respiration. According to Knudston $\S$ the respiration of the

* See De Boer : " Rec. Trav. bot. néerland.," I928, 25, 1 I 7 .

† Palladin : “Rev. gén. Bot.," 1893, 5, 449.

+ Müller-Thurgau and Schneider-Orelli : loc. cit.

§ Knudston: "Cornell Agric. Exp. Sta. Mem.," I9r6, 9, I. 
vetch is intensified to different degrees by saccharose, glucose and maltose, the last mentioned being less effective than the others. Spoehr, ${ }^{*}$ from lis investigations on the carbolıydrate economy of the Cactacex, concludes that the rate of respiration is not controlled by any one group of sugars, thus hexose sugars, which often are considered to be of exceptional importance in respiration, occur in the Cactaceæ in variable amounts in varying conditions of existence and sometimes may be almost absent, but the respiration intensity is not thereby reduced in any marked degree. In conditions which involve a poor supply of hexose sugars, the polysaccharides are consumed in the respiratory processes and such conditions are possibly connected with the formation of pentosanes. The conditions referred to are temperature and water: a low water content accompanied by a high temperature bring about a decrease of monosaccharides and an increase of polysaccharides and of pentosanes, whilst the contrary conditions, a high water content and low temperature, are associated with an increase of monosaccharides and a decrease of polysaccharides and of pentosanes.

With regard to the proteins, Palladin $\uparrow$ has shown that during the germination of wheat in darkness the total protein content and the soluble carbohydrates diminish, whilst the evolution of carbon dioxide and proteins insoluble $\ddagger$ in pepsin, increase in amount. As development proceeds, the carbohydrates, which originally were abundant, become depleted and the decomposition of protein is less vigorous and may even cease. Hence in the later stages of germination there is a more vigorous respiration in conditions of low protein content than in the early phases of germination when more protein occurs. The proteins which disappear are those of the reserve food, not those which are presumably members of the protoplasmic complex and which show a direct relation to the amount of carbon dioxide evolved. This is shown in the following table which relates to wheat germinating at

* Spoehr: "Carnegie Inst. Pub.," I919, No. 287.

† Palladin : “Rev. gén. Bot.," I 896, 8, 225.

$\ddagger$ The solubility being determined in vitro. 
$20^{\circ}$ to $21^{\circ} \mathrm{C}$. and gives the ratio of the carbon dioxide evolved per liour to the amount of protein unacted upon by pepsin :-

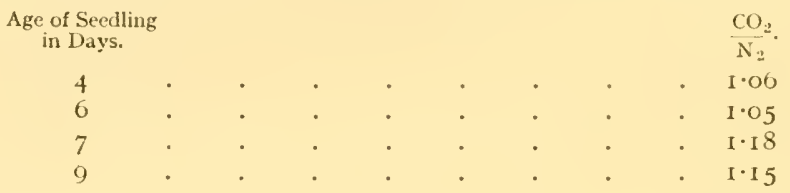

Palladin found a similar ratio to obtain in other plants, the following being some of the values obtained:-

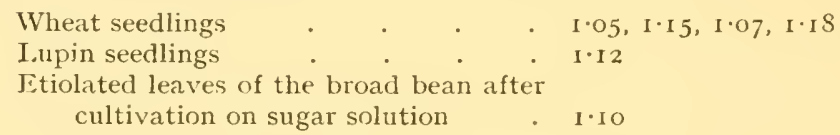

The differences between these observed ratios are not considered to be significant by Palladin in view of the experimental difficulties. From his observations he draws the general conclusion that for a given temperature and with an adequate amount of carbohydrate, the relation between the quantity of carbon dioxide evolved by different plants in one hour and the quantity of protein unacted upon by gastric secretion, in vitro, is a constant. For a temperature of $19^{\circ}$ to $20^{\circ} \mathrm{C}$., $\mathrm{CO}_{2} / \mathrm{N}_{2}=: \mathrm{I} \cdot \mathrm{I}$.

The amount of the protein referred to, as Kidd, W'est and Briggs have pointed out, is a measure of the amount of respiring cell matter.

With regard to the fats, there is but little precise information available from the point of view of respiration. Their conversion to carbohydrate may be one phase of the involved problems, and necessitates a much greater up-take of oxygen where fats are tlie predominating respirable material as compared with those in which carbohydrate is the prime respirable substance, that is, the respiratory quotient of a fat-containing seed is of a comparatively low value. To what extent the products of the hydrolysis of fats are immediately respirable, is another aspect of the subject awaiting investigation.

The observed differences in the respiratory activity is sometimes ascribed to the difference in the quantity of the material available for physiological combustion. According 
to Hafenrichter, ${ }^{*}$ this is not so in the two varieties, Manchu and Midwest, of the soy bean examined by him. The manchu variety has a high oil and low protein content, and the Midwest variety has a low oil and a high protein content.

It was found that the intensity of respiration of these two varieties was not the same at the same temperature, nor through a range of temperatures; further, the effect of temperature varied at different stages of development, and is not the same for each variety. According to the author, his results support the view that in respiration the material to be consumed is selected from those available for physiological combustion. It was also observed that the seedlings when starved, by continuous growth in darkness, showed a marked increase in respiration prior to the complete exhaustion of the plant.

\section{WATER.}

Since an ordinary living plant is mostly water, it is obvious that any circumstance which leads to a marked increase or decrease of water may alter profoundly the expressions of life; thus if water be removed from a plant to an extent sufficient to make the cells flaccid, growth will come to an end, and therefore the respiratory activity will be ultimately considerably lessened. This statement is intentionally qualified, for an increase and also a decrease in the water supply may lead to an immediate amplification in the intensity of respiration. Maige and Nicolas $\nmid$ found in several instances that a rise in turgescence is followed by an increase in respiratory activity, and a similar result obtains, although to a lesser degree, when a decrease in turgescence is brought about in similar material either by natural evaporation or by the action of a miidly plasmolyzing sugar solution. If a further removal of water be effected by the use of a Io to 20 per cent. solution of glucose, a decrease in respiration, as indicated by a smaller intake of oxygen and output of carbon dioxide, results. Smith $\$$ similarly observed that vegetative organs of the snowdrop, the bean, and Tropcolum, after drying in a desiccator until a

* Hafenrichter: “ Bot. Gaz.," I928, 85, $27 \mathrm{I}$.

† Maige and Nicolas: "Rev. gén. Bot.," I 9 Io, 22, 409.

+Smith: "British Ass. Rep.," I916, 85, 725.

VOL. II. -9 
third to a half of the water had been removed, showed a greater respiration as compared with normal members of the plants mentioned. Up to a loss of 30 per cent. of water the respiratory activity increased in proportion to the amount of water lost; from 30 to 60 per cent. loss of water the respiration was uniform at the increased rate attained with the 30 per cent. loss ; finally, with a loss of from 60 to IOO per cent. of water the respiration decreased proportionately to the amount of water removed. Iljin, ${ }^{*}$ in a large number of observations on various plants, both mesophytic and xerophytic, also observed that a loss of water from the shoots stimulates respiration, which is more considerable in mesophytes than in xerophytes. In the latter plants, which from their habitat have a relatively low reserve of food, the increase in respiration may cause a 20 per cent. depletion in the reserve food in the course of a day. All plants do not behave alike in these respects; the paeony and the asparagus show no increase in respiration following removal of water, and Palladin and Sheloumova $\dagger$ found that potato tubers exhibited a lowering of respiration on dehydration in the conditions of their experiments which were not the parallels of those of the authors just quoted.

There is no agreed explanation of these facts: Smith suggests that the phenomenon is due to changes effected in the activity of the enzymes involved, whilst Maige and Nicolas consider that the increased turgescence increases growth and consequently respiration whilst the decreased turgescence stimulates respiration since the respirable materials are concentrated. If this be so, it is reasonable to suppose that there is, mutatis mutandis, an optimal concentration of these substances, and it is the passing of this strength which accounts for the diminution in respiration in tissues subjected to the plasmolyzing action of strong sugar solutions.

The long periods of time through which certain plants can sustain life on a diminished water supply are remarkable: Long $\ddagger$ found that a shoot of Echinocactus retained life and

* Iljin : "Flora," I923, 16, 379.

† Palladin and Sheloumova: "Bull. Acad. Sci. Petrograd," I918, 801.

+ Long: "Bot. Gaz.," I 9 I $8,6.5,35 \%$. 
exhibited respiration after a period of desiccation of thirty months, the first eight in full sunshine and the remainder in a dark room at air temperature. Seeds, however, provide the most striking instances and the importance of a knowledge of the conditions affecting respiration, and consequently heating, of stored seeds is great. It is not unlikely that the respiration of really dry seeds is, to a large extent, anærobic; in airdry seeds there is a small evolution of carbon dioxide which may have its origin in the testa only.*

Jacquot and Mayer $\dagger$ observed the respiration of the dried seeds of the bean, maize, etc., and found that, as in plants periodically subject to desiccation (see below), respiration progressively increases with the increase in the amount of water to a maximum which is characteristic of the plant. A further increase of water leads to a diminution of the respiratory rate. They consider that the intensity of respiration depends not only on the contents, including water, of the cell, but also on their relative properties. Bailey and Gurjar $\$$ find that the spontaneous heating of damp grain when bulked is chiefly due to the activity of the embryo in oxidizing sugars, the degree of respiration increasing with the amount of available water. Up to 14.5 per cent. of water there is a uniform and gradual rise in the intensity of respiration; in greater proportions, water will produce a marked respiratory acceleration. In this respect glutenous material is important in that its degree of viscosity is lowered as it takes up water; this permits a more rapid diffusion and hence a greater respiration. This is illustrated by the fact that soft starchy varieties of wheat exhibit a higher respiration intensity than hard vitreous wheats with the same percentage of water. The embryo is the seat of enzyme secretion ; shrivelled wheat, which contains less endosperm and the same amount of embryo as compared with plump wheat, shows a respiratory activity twice or thrice as much as plump with the

* Becquerel : "Ann. Sci. Nat. Bot.," 1907, 5, I93. 408 .

† Jacquot and Mayer: "Ann. physiol. physichim. biol.," I926, 2, † Bailey and Gurjar: " Journ. Agric. Res.," 1918, 12, 685. 
same water content, If per cent. ; with less water than I 4 per cent., there is little or no difference between the two kinds of grain. The effect of respiration in bulked grain is a rise in temperature; this is cumulative and causes an acceleration in respiration up to about $55^{\circ} \mathrm{C}$., which temperature also has the effect of stimulating diastatic activity and hence rendering available more inmediately respirable material. On the other hand, the resulting accumulation of carbon dioxide has a narcotic effect and reduces the rate of respiration.

Some reference may now be made to lower plants, many of which, from the nature of their habitat, have to withstand long periods of desiccation. Long has it been known that dry mosses show a very low rate of respiration, which rises with the increase of the water content of the plant.* Accord. ing to Mayer and Plantefol, $\uparrow$ the respiratory quotient of mosses varies according to the degree of imbibed water, and may be higher than unity wlien the water content is low. They also came to the interesting conclusion that the respiration of dry moss is anaerobic, as is possible also in dry seeds, since the yield of carbon dioxide in vacuo is as much as it is in air.

In the lichens, the increase in respiration also depends on the amount of water contained in the plant. Jumelle $\ddagger$ found that on addition of equal amounts of water to material having respectively a low water content and a high water content, the rate of respiration was greater in the former than in the latter. The addition of water beyond a certain point is without effect on the respiration rate; there is, moreover, a period of lag shown by lichens subjected to prolonged drought, some time elapsing after the addition of water before the res. piration rate is equal to that of fresh material of equal water content. Fraymouth $\$$ likewise observed that the lichen Parmelia physodes showed no great increase in the rate of respiration until a water content of 60 per cent. was reached;

\footnotetext{
* Bastit: "Rev. gén. Bot.," т 89t, 3, 255. Jönsson : "Comp. rend.," I894, 69, 440.

† Mayer and Plantefol: "Ann. physsiol. phỵsichim. biol.," I925, I, 361.

† Jumelle: “Rev. gén. Bot.," т 892, 4, 350.

EFraynouth: "Ann. Bot.," 19:8, 42, 75.
} 
with continued absorption of water, there is an acceleration in the respiration until a water content of 200 per cent. is reached, after which the respiration rate is slower. The alga constituent of Parmelia physodes is a species of Trebouxia which Fraymouth found to be less capable of responding to drought conditions than the free growing Trebouxia which showed a maximum rate of respiration when the water content was about 30 per cent. The alga Prasiola crispa behaved similarly; as in Trebouxia, after severe and prolonged drought, the respiration is so feeble as to be hardly determinable, but immediately on the access of water the respiration rate rises to a value equal to that of the fresh plant with an equivalent water content. Comparable results were obtained with the moss Hypmum.

\section{SALTS.}

The action of salts on the intensity of respiration varies according to their chemical nature, their concentration and their association with other salts; thus salts of the heavy metals are very toxic whilst those of the alkali metals and alkaline earths accelerate or retard according to their concentration and association. Lyon * found that phosphate accelerates both the aerobic and anaerobic respiration of Elodea. Nitrosomonas shows a maximum respiration in $\mathrm{N} / 200$ ammonia, whilst a strength of $\mathrm{N} / \mathrm{IO}$ depresses respiration in a marked degrec. $\dagger$ Similarly the respiration of Bacillus sublilis is constant in the presence of low concentrations of the chlorides of sodium, potassium and calcium; an increase in concentration leads to a reduction in respiration. Compared with cultures lacking these salts, the respiration intensity is increased by the presence of sodium chloride, potassium chloride, calcium chloride or magnesium chloride in concentrations of $\cdot 2 \mathrm{M}, \cdot{ }_{5} \mathrm{M}, \cdot_{5} \mathrm{M}$, and $\cdot{ }_{0} \mathrm{M}$ respectively. In higher concentrations the rate of respiration is clecreased. With regard to concentration, Inman $\S$ studied the behaviour of Laminaria and Chlorella.

* Lyon : “Journ. Gen. Physiol.," I024, 6, 299.

† Meyerhof: "Pfluger's Archiv," I917, 166, 240.

† Brooks: “ Journ. Gen. Physiol.," I919, 2, 5; I920, 2, 33I.

§ Inman: id., I92I, 3, 533; 4, I7I. 
The respiration of Laminaria is depressed after treatment with either hypotonic or hypertonic solutions, the depression being greater in the latter concentration and shows a linear relationship. With hypotonic solutions the relation between concentration and respiration is more complex. In Chlorella the respiration is depressed on exposure to hypertonic solutions: if the period of treatment is short, the original rate of respiration is attained on removal from the solution; if the exposure is prolonged, the respiration rate does not rise to the original level after removal from the solution, a permanent change in the organism has been effected, a lowering of the rate of metabolism. Since the concentration of the surrounding solution has effect on the water content of the tissues, this aspect is clearly connected with the relationship of respiration and water content.

The use of mixtures of salts also accelerate or retard according to the degree of their antagonism: thus the normal respiration rate of Aspergillus niger in a culture medium containing 19 c.c. of $\cdot 5 \mathrm{M}$ sodium chloride and I c.c. of $\cdot 5 \mathrm{M}$ calcium chloride is maintained, although each of these salts in these concentrations and acting alone will accelerate respiration. ${ }^{*}$ The chlorides of magnesium and sodium, of sodium or potassium and calcium exhibit a conspicuous antagonism, whilst the chlorides of magnesium and calcium and of sodium and potas. sium are antagonistic but slightly in their effect on respiration.

\section{ACIDITY.}

The degree of acidity of the cell sap shows much variation and is an expression of the physiological condition and of particular metabolism. Thus the acidity of anthocyanin containing leaves may be double that of green leaves of the same species, and the acidity of fleshy plants is greater by night than by day.

In some plants the hydrogen ion concentration may profoundly modify the respiration intensity; Nitrosomonas, for example, shows the greatest rate of respiration in a medium in which the $p H$ value is between 8.4 and $8 \cdot 8$, beyond the limits

*Gustafson : “Journ. Gen. Physiol.," 1919, 2, 217. 
of $p \mathrm{H} 9 \cdot 4-7 \cdot 6$ the process comes to a standstill.* In Penicillium chrysogenum variations in the value of $p H$ between 4 and 8 do not affect the normal rate of respiration, that is, the rate at neutrality, $p H=7$; an increase of the value to 8.8 results in the respiration decreasing to 60 per cent. of the normal, at which level it remains; a decrease, on the other hand, in the value of $p H$ to 2.65 causes a gradual rise in the respiration rate followed by a gradual fall to the normal. At $p \mathrm{H} \mathrm{I} \cdot \mathrm{IO}$ to I.95 the preliminary rise, amounting to 20 per cent., is followed by a fall to below normal. The depression brought about by a concentration $p \mathrm{H}=\mathrm{I} \cdot 95$ or less is irreversible, whilst the similar decrease effected by a $p H$ value of 8.8 is reversible, the respiration rate returning to normal after the plant is placed in a neutral solution. In acid solutions there is an increase in the production of carbon dioxide and a decrease in alkaline solutions, a phenomenon which may be paralleled in the test tube : a neutral solution of dextrose and hydrogen peroxide shows an increase in the evolution of carbon dioxide on the addition of acid but not on the addition of alkali. $t$ Witzemann $\ddagger$ also has demonstrated the oxidation of sugar by hydrogen peroxide in the presence of disodium hydrogen phosphate. Whether the phosphate here plays any part in the formation of a hexose phosphate such as is known to occur in alcoholic fermentation $\S$ has yet to be demonstrated.

\section{LIGHT.}

That plants respirc both by day and by night is a wellknown fact from which it would appear that radiant energy as such is not a conditioning factor in respiratory activity; its action is indirect in providing through its photosynthetic activity a supply of respirable material. Thus an isolated green leaf in darkness shows a continuous fall in respiration; in the light, on the other hand, the respiratory values during a carbon assimilation experiment are continually changing by virtue of the carbon assimilation and may be doubled by an

* Meyerhof : loc. cit.

† Gustafson : “Journ. Gen. Physiol.," I920, 2, 6I 7 ; 3, 35.

+Witzemann: “Journ. Biol. Chem.," I920, 45, I.

$\S$ Vol. I., p. 494. 
exposure of four or five hours to light and carbon dioxide. This is possibly due to the production of new carbohydrate, although the observed increase is not proportional to the amount of carbon dioxide decomposed.* The high intensity of respiration sometimes observed in green plants in bright sunshine $\dagger$ is due, at any rate in part, to the copious supply of sugar. In such conditions, however, other factors are operative: the higher temperature, for instance, would increase the respiration intensity; whilst if the illumination, the temperature and humidity conditions of the atmosphere were operative all in the same direction to cause undue loss of water, the flaccid leaves would ultimately show a respiratory depression.

Lundegardh $\ddagger$ has shown that the respiration of shade plants, e.g. Oxalis, is lower than in sun plants, e.g. Nasturtium and Atriplex. In the former an equilibrium between respiration and carbon assimilation, the compensation point (see p. 7), occurs in normal air at a light intensity of I/I 20 to I/I 40 that of direct sunshine, whilst in sun plants the equilibrium is reached in a light intensity of $\mathrm{I} / 40$ to $\mathrm{I} / 60$. In order that the carbon assimilation of shade plants may compensate the respiration during the night, an average intensity of illumination of $\mathrm{I} / 93$ that of sunshine at a temperature of $\mathrm{I} 8^{\circ} \mathrm{C}$. is necessary and an increase of this light intensity is requisite for the maintenance of growth. Of shade plants in general, Oxalis has a great power of carbon assimilation and this helps to explain why it can grow in places where the light intensity is very low.

\section{TIE MECIIANISM OF OXIDATION, AND THE ENZYME SYSTEMS INVOLVED.}

The catabolic processes of plants may be directly referable to specific enzymes, zymase for instance in alcoholic fermentation; but in the respiratory activities of higher plants, their rôle is not defined witl that precision and degree of completeness

\footnotetext{
* Matthæi : loc. cit.

† See Rosé : "Rev. gén. Bot.," I 9 ro, 22, 385.

‡ Lundegårdh: "Svensk. bot. Tidskrift.," I921, I5, 46 .
} 
which is desirable, although it is generally agreed that enzyme action plays an important part in the process. Enzymes associated with the common end products of respiration are subjects for first consideration and of them most attention has been given to dehydrase, oxidase, catalase, zymase, and carboxylase.

In considering the possible mechanisms of oxidation it must be bornc in mind that they have a physical as well as a chemical aspect. The former aspect has been specially emphasized by Warburg, who considers oxidation to be largely a question of surface catalysis in which some form of iron plays an important part. From experiments on pigeon's blood, Warburg * showed that when the corpuscles are hæmolysed by alternate frcezing and thawing, and the blood then centrifuged, respiration was continued on the tissue residues, nuclei, etc., of the lower layer, while the supernatant serum, containing the hæmoglobin, showed no respiration; this difference in activity he considered to indicate the significance of solid surfaces; similar conclusions were arrived at from experiments on sea-urchin's eggs.

Warburg also showed that the oxidation of amino acids could be carried out at ordinary temperatures by adsorbing them upon charcoal and exposing to air, whereby they yiclded the same oxidation products as when oxidized in the living cell, namely, carbon dioxide, water and ammonia.

The well-known depression of respiratory activity in the living cell produced by narcotics Warburg attributes to the fact that these substances are readily adsorbed upon the oxidizing surface and so reduce their oxidative efficiency. 'This view he supported experimentally on the carbon model by showing that dimethyl urea, and similar narcotic substances, which were readily adsorbed by the charcoal, greatly reduced its oxidizing powers for amino acids.

Warburg, moreover, showed that iron played an important part in this charcoal model, since if chemically pure carbon, obtained by igniting benzoic acid, be employed, practically

*.IVarburg: "Biochem. Zeit.," I92 I, I19, I34; "Zeit. Electrochem.," I $922,28,7$ o. See also Vol. I., P. 4II 
no oxidation is effected, whereas blood charcoal containing iron was very active. Further, the activity of a pure charcoal could be greatly increased by steeping it in an iron salt and then heating to a red heat; such an artificially produced carbon was affeeted by narcotics in the same way as the blood eharcoal. Hydrocyanic acid was found to depress the oxidative activity of the charcoal to a remarkable degree, due, in Warburg's opinion, to its conıbining with the iron to form complex ferrocyanides; the depression was, however, not of a permanent nature, since the charcoal regains its original activity after some time. Warburg's opinion is that the active surface of a cell is to be regarded as a mosaic of areas, some rich and some poor in iron; the colloidal conditions being the same, both areas equally adsorb dissolved constituents of the cell sap, but metabolic changes only take place in those regions where iron is present, for the addition of a small amount of hydrocyanic acid brings the activity to an end owing to the inactivation of the iron; there is, however, no measurable reduction in the amount of material adsorbed, since the iron areas form but a small part of the entire surface.

While this theory fits the facts fairly well as regards the oxidation of amino acids, it is less satisfactory when applied to the oxidation of carbohydrates, since the carbon model has practically no action upon glucose and still less upon fructose, although hexosephosphates are attacked, a fact of some interest in connection with the significance of the hexosephosphates as an intermediate stage of carbohydrate metabolism in general ; furthermore, some substances such as oxalic or formic acids which are oxidised with difficulty in the living cell are fairly easily attacked by the carbon model.

\section{DEHYDRASE.}

The underlying idea of Warburg's theory is that for oxidation to take place atmospheric oxygen has to be activated at some surface by iron, possibly by the formation of an unstable peroxide which sets free active oxygen. A theory entirely opposed to that of Warburg is that of Wieland* 3331.

*Wieland: "Ber. deut. chem. Ges.," I912, 45, 679, 2613 ; I91 3, 46, 
according to which the activation of hydrogen is the all-im. portant preliminary condition for oxidation. It is well known that the oxidation of a substance may be effected either by the addition of oxygen or the removal of hydrogen ; as an example of the latter type may be taken the conversion of hydroquinone into quinone-

$$
\bigcap_{\mathrm{OH}}^{\mathrm{OH}}+\mathrm{O} \rightarrow \mathrm{H}_{2} \mathrm{O}+\overbrace{\mathrm{O}}^{\mathrm{O}}
$$

or the conversion of ethyl alcohol into acetic aldehyde-

$$
\mathrm{CH}_{3} \mathrm{CH}_{2} \mathrm{OH}+\mathrm{O} \rightarrow \mathrm{CH}_{3} \mathrm{CHO}+\mathrm{H}_{2} \mathrm{O} \text {. }
$$

But even the conversion of acetic aldehyde into acetic acid,

$$
\mathrm{CH}_{3} \mathrm{CHO}+\mathrm{O}=\mathrm{CH}_{3} \mathrm{COOH}
$$

which might be regarded as a direct addition of oxygen, must, according to Wieland, be regarded as a dehydrogenation, since he has slown that the reaction

$$
\mathrm{CH}_{3} \mathrm{CHO}+\mathrm{Ag}_{2} \mathrm{O}=\mathrm{CH}_{3} \mathrm{COOH}+2 \mathrm{Ag}
$$

cannot take place in the entire absence of water; this he regards as evidence for the preliminary formation of a hydrate which may then be oxidised by dehydrogenation according to the following stages :-

$$
\begin{aligned}
& \mathrm{CH}_{3} \mathrm{CHO}+\mathrm{H}_{2} \mathrm{O}=\mathrm{CH}_{3} \mathrm{C} \underset{\mathrm{H}}{\angle \mathrm{OH}} \\
& \mathrm{CH}_{3} \mathrm{C} \underset{\mathrm{H}}{\angle \mathrm{H}}+\underset{\mathrm{H}}{\mathrm{OH}}+\mathrm{O}=\mathrm{CH}_{3} \mathrm{C}<{ }_{\mathrm{O}}^{\mathrm{OH}}+\mathrm{H}_{2} \mathrm{O} .
\end{aligned}
$$

This conversion of aldehyde into acid may be effected in the entire absence of oxygen, provided some other acceptor for the hydrogen is substituted; such a substance is methylene blue, which, provided a suitable catalyst be present, will remove the hydrogen, becoming itself reduced to the colourless leuco-compound :--

$$
\mathrm{CH}_{3} \mathrm{C}<\underset{\mathrm{OH}}{\mathrm{OH}}+\mathrm{MB}=\mathrm{MBH}_{2}+\mathrm{CH}_{3} \mathrm{C}<_{\mathrm{O}}^{\mathrm{OH}}
$$


Palladium black will serve as the catalyst; the known affinity of this element for hydrogen enables it to eliminate hydrogen according to the equation

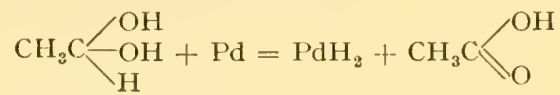

but unless methylene blue, or some other hydrogen acceptor, is present to remove the hydrogen from the palladium, the reaction soon comes to an end. The part played by water is convincingly shown by the fact that whereas chloral $\mathrm{CCl}_{3} \mathrm{CHO}$ is unacted upon by palladium and methylene blue, chloral hydrate $\mathrm{CCl}_{3} \mathrm{CH}(\mathrm{OH})_{2}$ is at once oxidised.

Even the oxidation of carbon monoxide to the dioxide

$$
\mathrm{CO}+\mathrm{O}=\mathrm{CO}_{2}
$$

has been shown by Wieland* to involve the intermediate formation of formic acid

$$
\mathrm{CO}+\mathrm{H}_{2} \mathrm{O}=\mathrm{H} \cdot \mathrm{C} \ll \mathrm{OH}
$$

which is then further oxidized to carbon dioxide and water,

$$
\mathrm{H} \cdot \mathrm{C} \overbrace{\mathrm{O}}^{\mathrm{OH}}+\mathrm{O}=\mathrm{H}_{2} \mathrm{O}+\mathrm{CO}_{2} \text {. }
$$

The principles outlined above have been applied by Wieland to explain enzymic oxidations; in his opinion oxidizing enzymes are in reality activators of hydrogen, and he terms them dehydrases. Two examples will suffice to illustrate this, the Schardinger reaction of milk $\dagger$ and the nitrate-reducing enzyme of the potato.

The Schardinger reaction was originally designed for distinguishing boiled from unboiled milk; it depends upon the fact that the latter, when warmed with methylene blue and a drop of acetic aldehyde, decolorizes the dye, whereas boiled milk produces no such change. According to Wieland this reaction is due to a dehydrase which activates the hydrogen of the aldehyde hydrate, thus enabling the nethylene blue to exert its action as hydrogen acceptor.

* Wieland: "Per. deut. cliem. Ges.," I912, 45, 679, 2613.

†Ibid., 1914, .17, 2085. 
By slightly varying the conditions, the same enzyme is able to produce from two molecules of salicylic aldehyde one molecule each of the corresponding acid and alcohol. This reaction, which is of the type known as a Cannizarro reaction, is usually represented by the equation

$$
{ }_{2} \mathrm{C}_{6} \mathrm{H}_{4}(\mathrm{OH}) \mathrm{CHO}+\mathrm{H}_{2} \mathrm{O}=\mathrm{C}_{6} \mathrm{H}_{4}(\mathrm{OH}) \mathrm{COOH}+\mathrm{C}_{6} \mathrm{H}_{4}(\mathrm{OH}) \mathrm{CH}_{2} \mathrm{OH}
$$

and was originally attributed by Parnas * to a special enzyme to which he gave the name of aldehyde mutase. According to the view of Wieland, however, the reaction may be explained by assuming that one of the two molecules of salicylic aldehyde merely acts as the liydrogen acecptor to the hydrate of the other molecule as follows :-

$$
\begin{array}{r}
\mathrm{C}_{6} \mathrm{H}_{4} \cdot \mathrm{OH} \cdot \mathrm{C}=\frac{\mathrm{OH}}{\mathrm{OH}}+\mathrm{C}_{6} \mathrm{H}_{4} \cdot \mathrm{OH} \cdot \mathrm{CHO} \\
=\underset{\text { Salicylic acid }}{\mathrm{C}_{6} \mathrm{H}_{4} \cdot \mathrm{OH} \cdot \mathrm{C}_{\mathrm{O}}^{\mathrm{OH}}+\mathrm{C}_{6} \mathrm{H}_{4} \cdot \mathrm{OH} \cdot \mathrm{CH}_{2} \mathrm{OH} .} \text { Salicylic alcohol }
\end{array}
$$

The Nitrate-reducing Enzyme of the Potato.-The existence of this was first demonstrated by Bach in the following simple experiment. One gram of freshly pounded potato is heated in a test tube to $60^{\circ} \mathrm{C}$. with Io c.c. of 4 per cent. aqueous solution of sodium nitrate together with 3 drops of Io per cent. solution of acetic aldehyde. After two minutes the solution gives a strong reaction for nitrite by the Griess llosvay reagent. This reaction was originally thought to be due to a so-called hydrolytic oxidation reduction-as expressed by the equation

$$
\mathrm{NaNO}_{3} \stackrel{\leftarrow}{-} \mathrm{H}_{2} \mathrm{O}+\mathrm{CH}_{3} \mathrm{CHO}=\mathrm{NaNO}_{2}+\mathrm{H}_{2} \mathrm{O}+\mathrm{CH}_{3} \mathrm{COOH}
$$

according to which the sodium nitrate and acetic aldehyde between then shared the hydrogen and oxygen of a molecule of water, thereby becoming reduced and oxidized respectively.

On Wieland's hypothesis, however, this is simply explained by the dchydrase activating the hydrogen of the aldehyde hydrate whilst the sodium nitrate acts as the hydrogen acceptor. $\dagger$

* Parnas: "Biochem. Zeitsch.," I910, 28, 274.

$\dagger$ The ability to oxidize acetic aldehyde and effect the simultaneous reduction of nitrate to nitrite is not uncommon in vegetable and animal 
I.

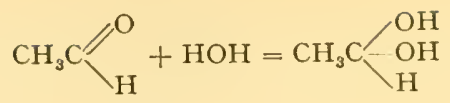

2.

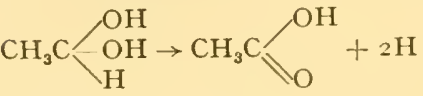

3. $\mathrm{NaNO}_{3}+2 \mathrm{H}=\mathrm{NaNO}_{2}+\mathrm{H}_{2} \mathrm{O}$.

Even the biological conversion of alcohol into acetic acid by the vinegar plant, Bacterium aceti, was shown by Wieland to be a dehydrase action which could be effected in an atmosplere of nitrogen by leaving freshly washed cultures of the plant in contact with alcohol and methylene blue in a flask from which air had been displaced by nitrogen. In a comparatively short time the methylene blue was decolorized and after some days a measurable quantity of acetic acid had been produced.*

It is evident that the theories of Warburg and Wieland are fundamentally different, the former insisting upon the activation of oxygen while the latter postulates the activation of hydrogen.

Warburg's criticism of Wieland's hypothesis is that activated hydrogen when finally oxidized should produce hydrogen peroxide and not water, and that hydrogen peroxide is not found in living cells. To this Wieland replies that all aerobic

tissues. Thus milk in anaerobic conditions can reduce nitrate, the nitrate acting as the hydrogen acceptor; if, however, the reaction is allowed to take place in the presence of air a peroxide is formed (Haas and Hill, "Biochem. J.," 1923, 17, 67I, and Haas and Lee," Biochem. J.," I924, 18,614) which was shown by Thurlow (id., 1925, 19, I 75) to be hydrogen peroxide resulting from atmospheric oxygen acting as hydrogen acceptor in place of the nitrate; in such circumstances no nitrate is reduced.

It has since been shown by Thurlow (loc. cit.), Dixon and Thurlow (" Biochem. J.," 1924, I8, 989), and Bernheim (" Biochem. J.," I928, 22. $344)$ that, in the nitrate-reducing system, either xanthine or hypoxanthine or adenine may replace the aldehyde as hydrogen donator and methylene blue may replace nitrate as hydrogen acceptor.

Subsequently Bernheim, comparing the Schardinger reaction of milk with the nitrate-reducingaction of potato in the presence of aldehyde, arrived at the conclusion that the potato enzyme is able to reduce methylene blne in the presence of aldehyde as hydrogen donator in the same way as the Schardinger enzyme of milk. Bach (" Biochem. Zeit.," I913, 52, 4I2) and Michlin (id,. 1927, 185,216), who had tried unsuccessfully to do this, failed, prestumably owing to their working at an unsuitable $p \mathrm{H}$ range, Bernheim having shown that the methylene blue reducing range of the enzyme of the potato to be $5^{.6}$ to $7^{\cdot 8}$, while the nitrate reducing range is from 3 to $8 \cdot 6$, with an optimum at 5.5 .

* VVicland: "Ber. deut. chem. Ges.," I913, 46, 3336. 
cells contain catalase, an enzyme whose function it is to destroy hydrogen peroxide as it is formed.

In support of his own theory Warburg points out that while it is true that the oxidation of succinic acid in the presence of methylene blue proceeds both in the absence and in the presence of hydrocyanic acid, the latter substance inhibits the reaction when oxygen is employed as the hydrogen acceptor in place of methylene blue; this, according to him, shows that the oxygen is unable to function when the iron is inactivated by hydrocyanic acid. Wieland, on the other hand, explains the action of hydrocyanic acid as being due to its destructive effect upon catalase which is thereby rendered unable to prevent the accumulation of hydrogen peroxide, which substance is toxic to the cell. To this suggestion Warburg objects on the ground that such an effect would be permanent whereas he has shown the retarding effect of hydrocyanic acid to be temporary.

A difficulty in the way of accepting the idea that iron is an essential element in any oxidizing mechanism is also presented by the fact that Willstätter has shown that the purest preparations of peroxidase are free from iron. Furthermore, it has been pointed out that the action of hydrocyanic acid is not always to depress oxidation; it may occasionally stimulate $^{*}$ A further obstacle in the way of interpreting the inhibiting action of hydrocyanic acid as being due to its combining with iron, is the observation of Moureu and Dufraisse $\uparrow$ that hydrocyanic acid, in the entire absence of iron, is able to act as a powerful depressant of oxidation; it is as these authors describe it, an antoxygen. According to the theory of Dufraisse and Moureu, most oxidizable substances remain unattacked by atmospheric oxygen owing to the presence of traces of a negative catalyst or antoxygen; a substance which is particularly active in this respect is hydroquinone, which, in small quantity, is able to prevent entirely the autoxidation of benzaldehyde through benzaldehyde peroxide to benzoic acid, a reaction which, as is well known, takes place very

* Buchanan: "Science," I927, 66, 235.

† Moureu and Dufraisse: "Compt. rend.," r926, $183,685$. 
readily in ordinary circumstances. Dufraisse and Moureu have shown that not only hydrocyanic acid but the ferrocyanides, which according to Warburg should be without action of any kind, act as depressants of oxidation. The same authors * draw attention to the fact that among the most active antoxygens are the phenols and tannins and they suggest that the wide distribution of these substances in the plant world may be the cause of the relatively slow rates of oxidation in the plant as compared with the animal; they also suggest that the toxic action of phenols is due to their antoxygenic property.

Support for Wieland's theory of dehydrogenation is furnished by the work of Thunberg, who lias shown that freshly minced and washed muscle contains an enzyme which in the presence of methylene blue, acting as a hydrogen acceptor, is able to convert succinic acid into fumaric acid :-

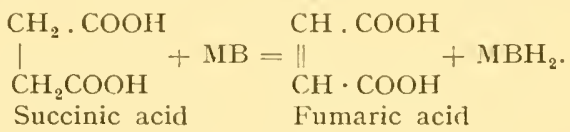

Thunberg $t$ regards hydrogen as the essential fuel of the living cell and considers only those substances as possible intermediate metabolites which when left in contact with methylene blue in the absence of oxygen decolorize this substance and therefore act as hydrogen donators. His technique consists in placing the material under examination in a test tube with freshly washed frog's muscle, to supply the dehydrase, and methylene blue, filling the tube with boiled water, and leaving the whole in a thermostat and examining at intervals. If the methylene blue is decolorized, the substance in question is a hydrogen donator and consequently a possible intermediate metabolite.

It will be noted that the theory of Wieland envisages only the activation of hydrogen atoms, thus making the substance activated for the time being a hydrogen donator. Quastel, +

* Moureu and Dufraisse: "Comp. rend.," I922, 174, $25 \mathrm{~S}$.

†Thunberg: "Skand. Archiv. Physiol.," 1920, 40, I ; "Naturwiss.," $1922,10,417$.

$\mp$ Quastel: " J. Hygiene," 192S, 28, 3 39, and the literature there quoted. 
however, from his observations on the oxidative activities of bacteria, found that fumaric acid could be activated as a hydrogen acceptor, a state of affairs not provided for by the Wieland theory. To quote the author's own words: "The inadequacy consisted in confining the activation only to hydrogen atoms. A more reasonable interpretation of the phenomena was that activation of the substrate molecule as a rohole occurred, the activated molecule behaving as a hydrogen donator or acceptor, according to the nature of the molecule and the general circumstances under which the reactions occurred. Further investigations with bacteria showed that a variety of substances are activated as hydrogen acceptors, e.g. nitrates and chlorates."

\section{RESPIRATORY PIGMENTS.}

Palladin * observed that a boiling water extract of many plants contains a colourless chromogen which by the action of a mixture of a peroxidase and hydrogen peroxide undergoes a series of colour changes and ultimately produces a more or less deeply coloured substance known as a respiratory pigment. These pigments are concerned with the oxidation of hydrogen, not with the oxidation of the carbon of organic compounds. The rôle of respiratory pigments is therefore that of hydrogen acceptors whereby they are reduced to the chromogen

$$
\mathrm{R}+2 \mathrm{H}=\mathrm{RH}_{2} \text {. }
$$

The chromogens are then oxidized by active oxygen arising from the activity of an oxidase which results in the regeneration of the pigment

$$
\mathrm{RH}_{2}+\mathrm{O}=\mathrm{R}+\mathrm{H}_{2} \mathrm{O} .
$$

These chromogens, which occur in the plant in the form of glucosides, are supposed to belong to the group of polyhydric phenols and are therefore bodies of a tannin-like nature. During regular respiration an equilibrium obtains between the oxidation and reduction; but if the oxygen absorption is

* Palladin: "Ber. deut. Bot. Ges.," I 908, 26a, I 25, 378, 389 ; I909, 27, г 10 ; see also "Jahrb. wiss. Bot.," $1910,47,431$; "Zeit. Gärungs. Physiol.," I9I2, I, 9I.

VOL. II.-IO 
excessive, aerobic respiration ends, since the respiratory chromogen is transformed into the stable pigment.

Palladin thinks that most pigments take part in respiration, but the essential character of such bodies, that of reversible oxidation and reduction with great ease, is not possessed by them; only by drastic chemical operations is the reversibility effected. But three pigments which meet with physiological requirements have since been discovered, namely chlorogenic acid, cytochrome and hermidin. Oparin * isolated from sunflower seeds the depside chlorogenic acid which acts like a respiratory pigment; by oxidation it loses four atoms of hydrogen and is converted into a green pigment.

Oparin considers that aerobic respiration essentially consists of two phases: the respiratory chromogen is oxidized to a pigment by atmospheric oxygen in the presence of a phenolic oxidase; and that the pigment is reduced to the chromogen by the hydrogen contained in the water molecule, the oxygen being taken up by the living cell. From Oparin's experiments it would appear that chlorogenic acid is more particularly active in the oxidation of natural amino acids and other compounds (see p. I67).

Cytochrome is oxidized by a thermolabile indophenol oxidase and is reduced by a dehydrase, it appears to act as a carrier between the two activating mechanisms of oxidase and delydrase respectively. $\dagger$

But this, together with hermidin, has already been commented on. +

\section{GLUTATHIONE.}

Glutathione is the name given to a substance first isolated by Hopkins $\S$ from yeast. It is a thermostable substance, and consequently non-enzymic, whose function would appear to facilitate the oxidation of hydrogen by alternately combining with and yielding up this elcment, in this way acting as an hydrogen transporter. The constitution of glutathione

* Oparin: "Biochem. Zeit.," I921, 124, 90 ; 1927, I 82, I 55.

† Keilin: "Proc. Roy. Soc.," B, 1929, 104, 206.

$\ddagger$ Vol. I., 305, 343.

§ Hopkins : " Biochem. Journ.," I921, I5, 286. 
is that of a dipeptide of cystein and glutamic acid and is represented by the formula

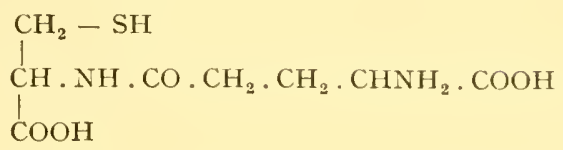

This substance, when oxidized by the removal of the hydrogen between two molecules, yields the compound

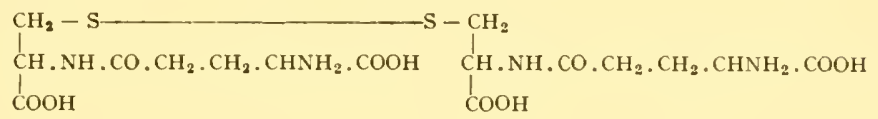

For simplicity of expression these changes may be represented as follows :-

$$
2 \mathrm{GSH} \underset{+2 \mathrm{H}}{\stackrel{2 \mathrm{H}}{\rightleftharpoons}} \mathrm{GS} . \mathrm{SG}
$$

In its oxidized form, GS. SG, it serves as an acceptor of the hydrogen set free from, say, succinic acid by the dehydrase which occurs in minced muscle, giving rise to the reduced form, GSH, but it is not by itself able to remove this hydrogen in the absence of the enzyme succinic acid dehydrase. The reduced form is then ready to give up its hydrogen to oxygen activated by iron with the formation of GS.SG and water. The optimum $\mathrm{pH}$ for the reaction involving the remioval of hydrogen

$$
2 \mathrm{GSH} \rightarrow \mathrm{GS} . \mathrm{SG}+2 \mathrm{H}
$$

is $7 \cdot 4$, and at $p \mathrm{H} 6$ it is much retarded, and below this the reduced form GSH is stable; on the other hand, the acceptance of hydrogen by the oxidized form

$$
\mathrm{GS} . \mathrm{SG}+2 \mathrm{H} \rightarrow 2 \mathrm{GSH}
$$

is much the sane at $p \mathrm{H} 6$ and $p \mathrm{H} 7 \cdot 4$.

The question whether glutathione is able to act in the absence of metals has been much discussed, and it would appear that the balance of evidence is in favour of an essential part being played by iron; this could be explained by assuming that its function is to activate the oxygen, as postulated by Warburg, previous to its oxidising the hydrogen

$$
2 \mathrm{GSH}+\mathrm{O}=\mathrm{GS} . \mathrm{SG}+\mathrm{H}_{2} \mathrm{O} .
$$


Further, this view is supported by the fact that hydrocyanic acid retards the activity of glutathione as it does other oxidations supposed to be dependent upon iron.

The exact function of glutathione in the respiratory mechanism is still largely a matter of speculation; it has been suggested that it acts only as a carrier in transferring hydrogen from the substance to be oxidised to the activating iron surfaces where the hydrogen is to be oxidized, the iron being supposed to be localized upon surfaces and thus to be incapable of moving towards the oxidizable materials, a function which is broadly comparable with that assigned to the respiratory pigments.

Glutathione is not uncommon in plant tissues although the coloration by which it is recognized usually is far less intense in vegetable than in animal tissue. Its presence in yeast may be demonstrated by grinding the cells in a mortar with a little sand and some saturated solution of ammonium sulphate. On pouring off and adding to the supernatant liquid a few drops of 5 per cent. solution of sodium nitroprusside and a little strong ammonia, a pink colour is produced. This colour reaction, which also is given by a number of other reducing substances such as aldehydes, acetone, hydrogen sulphide, etc., is only given by the reduced or cysteine form of the dipeptide and not by the cystine or oxidized modification.

\section{OXIDASES.}

Oxidases * are of wide occurrence in the vegetable kingdom, as should be the case if they are primarily concerned in aerobic respiration, but whether they are present in all living cells is doubtful. According to Atkins t they are absent or inactive in tissucs markedly acid in reaction or containing large amounts of reducing substances. Bunzel $\ddagger$ also has shown that the activity of these enzymes is inhibited by acids, their greatest activity being at or near the point of ncutrality; the limits of the $\mathrm{pH}$ value corresponding to complete inlibition in the

* See Vol. I., p. 498.

† Atkins: "Proc. Roy. Dublin Soc.," r9r3, 1.4, I44.

† Bunzel: "Journ. Biol. Chem.," 1916, 28, 153. 
various subjects of experinent are narrow and the figure of acid sensitiveness is almost invariable in a particular genus.

Two kinds of oxidases are generally recognized in the plant world, namiely, the direct acting oxidases which turn blue an alcoholic solution of guaiacum without the addition of hydrogen peroxide, and the indirect acting peroxidases whicl are unable to produce a change in colour until hydrogen peroxide has been added.

The direct acting oxidases are supposed to consist of two parts :-

(a) An autoxidisable thermostable substrate which is generally considered to be a derivative of catechol

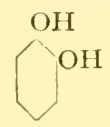

(b) The enzyme proper or peroxidase, which is thermolabile.

The function of this enzyme $(b)$ is to liberate active oxygen by decomposing the peroxide formed according to $(a)$ in the direct acting oxidase, or by decomposing hydrogen peroxide when added to the indirect oxidase systen.

It is to be remenbered that the distinction between the direct and indirect oxidase depends upon the reagent guaiacum ; it may be that the indirect oxidases differ only in strength fron the direct oxidases, or, alternatively as has been suggested by Szent Györgyi, that the indirect acting enzynes differ from the direct acting in the nature of their substrate which may not be of a catechol nature (see Vol. I., p. 50I).

The mechanism of the "direct" and "indirect" oxidases has been questioned by Pugh and Raper, ${ }^{*}$ but the views of these authors are disputed by Onslow and Robinson. $\dagger$

\section{CATALASE.}

Catalase has the power of setting free gaseous oxygen from hydrogen peroxide; although of common occurrence, it is not universally present in living cells and is often associated with oxidase. For this reason many observations have been

\footnotetext{
* Pugh and Raper: "Biochem. J.," 1927, 21, I370.

† Onslow and Robinson: id., 1928, 22, 1327.
} 
made on their distribution and relation to the oxidative aspects of respiration.

Wieland * has drawn attention to obscrvations by Lesser, $\uparrow$ Rywosch, $\ddagger$ and Jörns $\S$ that anaerobes such as Bacillus tetanus and $B$. botulinus are deficient in catalase whilst aerobic organisms such as Pneumococcus and Sarcina, and facultative aerobes such as yeast contain catalase in quantity. It is considered that the occurrence of catalase in those cells and tissues which require oxygen is necessary for the twofold purpose of preventing the accumulation of hydrogen peroxide which is toxic to the ccll, and for the liberation of oxygen. Hydrogen peroxide is regarded as the first product of the oxidation of hydrogen by oxygen which acts as the hydrogen acceptor in the cell,

$$
\mathrm{O}_{2}+2 \mathrm{H}=\mathrm{H}_{2} \mathrm{O}_{2} .
$$

The catalase then acts upon the resulting hydrogen peroxide, breaking it up into water and oxygen, which latter is then available for further oxidation,

$$
\mathrm{H}_{2} \mathrm{O}_{2}=\mathrm{H}_{2} \mathrm{O}+\mathrm{O} \text {. }
$$

This cycle of changes does not occur in anaerobic oxidations, which may explain the absence of catalase in these conditions.

Appleman \|f found that the oxidase content of the expressed juice of the potato is not indicative of the intensity of the respiration of the tuber, whilst the catalase activity shows a striking correlation. Similarly for sweet corn, in which instance the respiration in the milk stage is high when first collected but in storage rapidly decreases, the decrease being accompanied by a nearly proportional fall in catalase activity. In the pine-apple, Reed found that oxidase and catalase are independent; the amount of the former remains constant during ripening of the fruit whilst the catalase increases. In the wheat and certain allied plants, the embryo shows a twentyeight to twenty-nine-fold greater catalase and oxidase activity

*Wieland : “Ber. deut. chem. Gesells.," I 921,54, [B], 2353.

† Lesser: "Zeitsch. Biol.," I 906, 48, I.

+ Rywosch: "Zentr. Bact.," 1907, 44, 295.

§ Jörns: "Archiv. d. Hyg.," 1908, 67, 134.

|| Appleman : "Amer. Journ. Bot.," 1916, 3, 223 ; I91 8, 5, 207.

If Reed : "Bot. Gaz.," I916, 62, 409. 
than the endosperm, and this also holds for the intensity of respiration. In air-dry fruits of Andropogon halepensis, catalase activity runs parallel to respiration, a correlation which does not obtain in the secds of Amaranthus. * In Acer saccharinum, Jones $\uparrow$ found that the intensity of respiration of sceds during the process of desiccation at $25^{\circ} \mathrm{C}$. at first decreases, then rises to a maximum and finally gradually declines to zero: with regard to the catalase activity, there is a slight initial increase, then a decrease as desiccation proceeds, during which process there is also a gradual decrease in peroxidase activity. Nemec and Duchon $\ddagger$ state that the catalase activity of secds is closely correlated with their vitality as measured by the percentage of germinations. Gračanin, $\S$ on the other hand, finds that this activity is not a good index of vitality since dead seeds may possess active catalase. Shull and Davis \| find that the upper seeds of Xanthium, which have a delayed germination, exhibit a lower catalase activity than the lower seeds, which on germination show an increased catalase activity. Rhine observed a decrease in catalase during the early stages of germination, followed by an increase in the later stages; there is thus a wide divergence in the respiration and the catalase curves. Lautz ** also draws attention to this initial decrease, followed by an increase, in the catalase activity of germinating seeds; he also observed that the rapid increase in respiration following a rise in temperature is not accompanied by a corresponding increase in catalase activity. This is contrary to the observations of Burge and Burge $+\dagger$ who found that the catalase of Spirogyra varies directly with tempcrature and illumination, temperature having the greater effect. They conclude that whatever affects respiratory metabolism, similarly affects catalase activity, and suggest that catalase is of prime importance in respiration.

* Crocker and Harrison : “Journ. Agric. Res.," I9I 8, 15, 137.

† Jones : "Bot. Gaz.," I919, 69, I27.

† Nemec and Duchon: "Compt. rend.," I922, 174, 632.

§ Gračanin: "Biochem. Zeit.," 1927, 180, 205.

II Shull and Davis: "Bot. Gaz..," I923, 75, 268.

II Rhine : id., 1924, 78, $4^{6 .}$

"* Lautz: “Amer. Jonrn. Bot.," I927, 14, 85 .

†† Burge and Burge: "Bot. Gaz.," 1924, 77, 220. 
Drain * finds no clear correlation between catalase activity and respiration of apples, and the same lack was observed by Davis $\dagger$ in potato tubers suffering from the blackheart disease. Rhine $\ddagger$ observed that catalase markedly decreases when oxygen is withheld from seeds by prolonged soaking in oxygen-free water, and Morinaga $\S$ concluded that increase in catalase activity is a function of free oxygen from the facts relating to the germination of rice. Rice is grown on swampy ground and is capable of germination and subterranean growth in lower oxygen pressures than land plants. Rice grains contain about one-tenth the amount of catalase as wheat, oat, rye and like cereals which are grown on dry land; but when rice is germinated in aerobic conditions, the amount of catalase rises to about seven-tenths of that of the other cereals mentioned. If germinated in an atmosphere with a low oxygen pressure there is still an increase in catalase, which does not obtain if germinated in anacrobic conditions; indeed, the increment due to acrobic cultivation rapidly decreases in the absence of oxygen. It was further observed that seedlings with a higher catalase content use more oxygen in their growth than those with a lesser amount of catalase.

It is lardly possible to draw definite general conclusions from these facts, many of which are contradictory. The evidence does not show that catalase is chiefly concerned in respiration, and the same applies to the oxidases, but catalase may, as Lautz suggests, be a regulatory force preventing excessive oxidation by removal of superabundant hydrogen peroxide.

FERMENTATION: ZYMASE AND CARBOXYLASE.

An account of zymase and alcoholic fermentation has been given in Vol. I. ; it is, however, desirable again to consider the subject in view of the place it occupies in current opinions on the mechanism of respiration.

Zymase hardly requires introduction, it is the enzyme

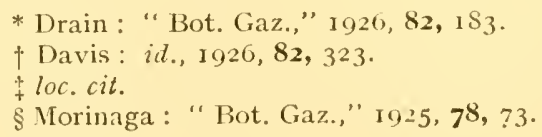


particularly associated with yeast and is responsible for the alcoholic fermentation of sugar. It has been described as occurring in higher plants such as the bectroot, potato, lupin, and others, ${ }^{*}$ and has been isolated from germinated seeds; in general the presence of a zymase like enzyme is concluded from the appearance of alcohol in plant tissues kept in anaerobic conditions. A large quantity of zymase, comparable to that which occurs in yeast, is not to be expected in the higher plants, since its function is apparently only that of preparing material for oxygen respiration.

Carboxylasc has the property of removing carbon dioxide from carboxyl groups, thercby converting pyruvic acid, for example, into carbon dioxide and acetic aldehyde; it occurs in yeast, where it is associated with zymase, and, according to Bodnar, $f$ in the bectroot and potato tuber.

On an earlier page mention has been made of the formation of lactic and butyric acids in addition to alcohol from sugar, Kostytschev considers that these fermentative mechanisms are fundamentally similar and are based on one and the same initial stage, the breaking of a molecule of sugar into two molecules of pyruvic acid with the liberation of four atoms of hydrogen-

$$
\mathrm{C}_{6} \mathrm{H}_{12} \mathrm{O}_{6}=\underset{\text { Pyruvic acid }}{2 \mathrm{CH}_{3}} \cdot \mathrm{CO} \cdot \mathrm{COOH}+{ }_{4} \mathrm{H} .
$$

The subsequent reactions varies according to the conditions which determine the formation of the three different end products.

I. Alcoholic Fermentation.-This will result if the pyruvic acid is decomposed before the hydrogen has time to exert its reducing action-

$$
{ }_{2} \mathrm{CH}_{3} \cdot \mathrm{CO} \cdot \mathrm{COOH}=2 \mathrm{CH}_{3} \mathrm{CHO}+2 \mathrm{CO}_{2} .
$$

The hydrogen then reacts with the acetaldehyde to form alcohol-

$$
{ }_{2} \mathrm{CH}_{3} \mathrm{CHO}+{ }_{4} \mathrm{H}={ }_{2} \mathrm{CH}_{3} \mathrm{CH}_{2} \mathrm{OH} \text {. }
$$

* Palladin and Kostytschev: "Ber, deut. bot. Gesells.," I 9o6, 24, 273. Stoklasa and Chocensky : $i i_{.,}, 1907,25,122$.

† Bodnar: "Biochem. Zeitsch.," I016, 73, 193. See also Zaleski: "Rer. deut. bot. Gesells.," 1913, 31, 349. 
2. Lactic Acid Fermentation.--Here the action of the hydrogen is immediate, the pyruvic acid being reduced to lactic acid before either of the two other alternatives is possible-

$$
{ }_{2} \mathrm{CH}_{3} \cdot \mathrm{CO} \cdot \mathrm{COOH}+{ }_{4} \mathrm{H}={ }_{2} \mathrm{CH}_{3} \cdot \underset{\text { Lactic acid }}{\mathrm{CHOH}} \cdot \underset{\mathrm{COOH}}{\mathrm{CH}}
$$

3. Butyric Acid Fermentation.-This results from the slow reducing action of the hydrogen : acetaldehyde is first formed-

$$
{ }_{2} \mathrm{CH}_{3} \cdot \mathrm{CO} \cdot \mathrm{COOH}+{ }_{4} \mathrm{H}={ }_{2} \mathrm{CH}_{3} \mathrm{CHO}+{ }_{2} \mathrm{CO}_{2}+{ }_{4} \mathrm{H} \text {. }
$$

The acetic aldehyde then undergoes an aldol condensation,

$$
{ }_{2} \mathrm{CH}_{3} \mathrm{CHO}=\mathrm{CH}_{3} \text {. } \mathrm{CHOH} \text {. } \mathrm{CH}_{2} \text {. } \mathrm{CHO}
$$

which, by molecular rearrangement, gives rise to butyric acid-

$$
\mathrm{CH}_{3} \cdot \mathrm{CHOH} \cdot \mathrm{CH}_{2} \cdot \mathrm{CHO}=\mathrm{CH}_{3} \cdot \mathrm{CH}_{2} \cdot \mathrm{CH}_{2} \cdot \mathrm{COOH} \text {. }
$$

These three reactions can be expressed by the single equation-

$$
\mathrm{C}_{6} \mathrm{H}_{12} \mathrm{O}_{6}=\mathrm{CH}_{3} \cdot \mathrm{CH}_{2} \cdot \mathrm{CH}_{2} \cdot \mathrm{COOH}+{ }_{2} \mathrm{CO}_{2}+{ }_{2} \mathrm{H}_{2} \text {. }
$$

Reverting to the subject of alcoholic fermentation, the views of Kostyschev are not shared by Neuberg who considers that pyruvic aldehyde is first formed by the removal of two molecules of water-

$$
\mathrm{C}_{6} \mathrm{H}_{12} \mathrm{O}_{6} \rightarrow 2 \mathrm{CH}_{3} \cdot \mathrm{CO} . \mathrm{CHO}+2 \mathrm{H}_{2} \mathrm{O} \text {. }
$$

Assuming one molecule of pyruvic aldehyde to act in its tautomeric form, the two molecules are supposed to react in the presence of water according to the Cannizarro reaction-

$$
\begin{array}{cl}
\mathrm{CH}_{3} \mathrm{COCHO}+\mathrm{O} & \mathrm{CH}_{3} \mathrm{CO} \mathrm{COOH} \\
\mathrm{CH}_{2}=\mathrm{COH} \mathrm{CHO}+\mathrm{H}_{2}+\mathrm{H}_{2} \mathrm{O} & \begin{array}{l}
\mathrm{CH}_{2} \mathrm{OH} \text {. CHOC acid } \\
\text { Glycerol }
\end{array}
\end{array}
$$

The pyruvic acid thus produced is decomposed by the enzyme carboxylase into acetic aldehyde and carbon dioxide -

$$
\mathrm{CH}_{3} \mathrm{CO} \mathrm{COOH}=\mathrm{CH}_{3} \mathrm{CHO}+\mathrm{H}_{2} \mathrm{O} \text {. }
$$

The acetic aldehyde then becomes reduced to ethyl alcohol by acting as hydrogen acceptor for the hydrogen set free from water when a second molecule of pyruvic aldehyde becomes oxidised-

$$
\underset{\mathrm{CH}_{3} \cdot \mathrm{CO} \cdot \mathrm{CHO}+\mathrm{O}}{\mathrm{CH}_{3} \mathrm{CHO}+\mathrm{H}_{2}} \rightarrow \begin{aligned}
& \mathrm{CH}_{3} \mathrm{CO} \cdot \mathrm{COOH} \\
& \text { Pyruvic acid } \\
& \mathrm{CH}_{3} \mathrm{CH}_{2} \mathrm{OH} \text {. } \\
& \text { Ethyl alcohol }
\end{aligned}
$$


By causing fermentation to take place in the presence of sodium hydrogen sulphite or of dimethyl-dihydroresorcinol, either of which combine with acetic aldehyde, Neuberg increased the yield of glycerol produced in alcoholic fermentation. This, he suggests, is due to the hydrogen-which would normally reduce the acetic aldehyde to ethyl alcohol-being forced to find some other acceptor which he presumes is an aldehydic precursor of glycerol.

The main result of his experiments indicate that acetic aldehyde is an intermediate product of alcoholic fermentation, and he provided the means of establishing the presence of small quantities of acetic aldehyde which has proved of great value in determining indirectly whether, in any process of carbohydrate degradation, a change of the nature of alcoholic fermentation is operative-the significance of this will be seen later (p. I60).

Factors infuencing alcoholic fermentation by yeast.-Some space must be devoted to a consideration of the influence of oxygen upon alcoholic fermentation with a view to tracing the relation between the oxygen respiration of the yeast plant with its activity in alcoholic fermentation, which, according to the equation

$$
\mathrm{C}_{6} \mathrm{H}_{12} \mathrm{O}_{6}=2 \mathrm{C}_{2} \mathrm{H}_{5} \mathrm{OH}+{ }_{2} \mathrm{CO}_{2} \text {, }
$$

does not involve atmospheric oxygen.

Pasteur, to whom we owe much of our earlier knowledge of alcoholic fermentation, held the opinion that alcoholic fermentation was a mode of life of the yeast plant when unable to obtain air, "la vie sans air," but he also knew that when air is entirely withheld the plant sooner or later stops growing and gradually dies, but the introduction of a little oxygen, if not too late, restores the plant to activity. During fermentation in anaerobic conditions, although the breakdown of sugar continues, the reproduction of the cells stops. In attempting to explain the rôle of oxygen in fermentation, subsequent workers came to the erroneous conclusion that oxygen stimulated fermentation since they obtained an increased yield of alcohol when the fermenting liquors were aerated, 
but in their observations they omitted to take account of the increase in the number of yeast cells consequent upon the stimulation of reproduction by the oxygen. So for years the matter rested; brewers and distillers, aware of the beneficial action of oxygen, continued to practise a certain degree of aeration of the fermenting liquor, a process which has the additional advantage of stirring the liquid and removing excess of carbon dioxide.

The difficulty encountered by Pasteur in his theory of "vie sans air" was that a plentiful supply of air should suppress alcoholic fermentation rather than stimulate it. An explanation of this apparent contradiction was furnished from an entirely different source, namely from animal physiology.

Fletcher and Hopkins * in a study of the relationship between muscular contraction and lactic acid production, showed that lactic acid is formed by resting muscle, and this in increased quantity in an atmosphere of nitrogen; on exposing the muscle to air, the lactic acid disappears with the formation of carbon dioxide and water. The lactic acid is derived from a precursor, or lactacidogen, which is probably a hexosephosphate, the hexose constituent of which is formed from the store of glycogen contained in the muscle. A. V. Hill $\dagger$ by accurate measurements found that when a muscle is stimulated, heat is liberated and continues to be liberated so long as contraction is maintained and also while the muscle relaxes. This constitutes the initial process in muscular contraction, and it is noteworthy that the production of heat occurs in the absence of oxygen, the process being anaerobic. Recovery next follows: the muscle after relaxing ccases to give off heat, but after a short interval heat production begins again, provided oxygen is present, reaches a maximum and then falls away to zero. This second evolution of heat, which is about $1 \cdot 5$ times as great as that occurring in the initial stage, is accompanied by an absorption of oxygen and a disappearance of lactic acid; the amount of lieat evolved is, however, only sufficient to account for the

* Fletcher and Hopkins: " J. Physiol.," I907, 35, 247.

$\dagger$ A. V. Hill : id., I914, 48, Io. 
oxidation of about one-fiftl of the total amount of lactic acid which has disappeared.

About the same time, Meycrhof * showed that when muscle contracts glyeogen disappears in an amount exactly equivalent to the lactic acid produced, and that during the recovery process the lactic acid disappears only in part by oxidation, the remainder being resynthesized to glycogen.

He found, moreover, that for every molecule of oxygen absorbed, one and a half molecules of lactic acid disappeared; but from the equation

$$
\mathrm{C}_{3} \mathrm{H}_{6} \mathrm{O}_{3}+3 \mathrm{O}_{2}={ }_{3} \mathrm{CO}_{2}+3 \mathrm{H}_{2} \mathrm{O}
$$

one molecule of oxygen could only oxidize one-third of a molecule of lactic acid, hence the ratio

$$
\frac{\text { Lactic acid disappeared }}{\text { Lactic acid oxidized }}=\frac{\mathrm{I} \frac{1}{2}}{\frac{1}{3}}=4 \cdot 5 \text {. }
$$

Hill's experiments show that this ratio is approximately 5; thus it appears that four-fifths of the lactic acid produced are reconverted into glycogen at the expense of the energy supplied by the oxidation of one-fifth, hence the anaerobic process is reversed by the acrobic phase introduced by the oxygen. Expressed in another way, when the oxidative process keeps pace with the anaerobic stage the products of that stage will not accumulate. Meyerhof $\uparrow$ subsequently found that much the same phenomena occur in yeast. This he was only able to establish on realising the fact, ignored by earlier workers, that some yeasts are more sensitive to the influence of oxygen than others. Thus he established that ordinary brewers' yeast, the so-called bottom fermentation yeast, the type used by Pasteur in his experiments, oxidises only one molecule of sugar for every 99 molecules of sugar which it ferments ; in this type of yeast oxygen respiration is, therefore, very low, a state of affairs which Meyerhof considers to be due to long-continued selective cultivation in special conditions with the result that the yeast has almost lost the habit of

* See A. V. Hill and Meyerhof: "Ergeb. Physiol.," I923, 22, 299.

† Meyerhof: "Biochem. Zeit.." I925, 162, 43 ; "J. Gen. Physiol.," $1927,8,531$. 
oxygen respiration. On the other hand, distillers' top fermentation yeast was found to ferment only 80 per cent. of the sugar available, the remaining 20 per cent. being oxidized. In wild yeasts, Torula so called, oxygen respiration is much higher, and in these plants oxygen is able to depress alcoholic fermentation to cxtinction. These obscrvations provide experimental proof of Pasteur's thesis "la vie sans air" which he could not establish owing to his use of a yeast whose oxygen respiration was too small for detection by his experimental procedure.

Meyerhof also showed that for each molecule of oxygen taken up in the oxygen respiration of yeast, one molecule of sugar less is fermented, but, since according to the equation

$$
\mathrm{C}_{6} \mathrm{H}_{12} \mathrm{O}_{0}+6 \mathrm{O}_{2}=6 \mathrm{CO}_{2}+6 \mathrm{H}_{2} \mathrm{O}
$$

one molecule of oxygen is only able to oxidize one-sixth of a molecule of sugar, it would appear that the oxidation of only one-sixth of a molecule of sugar is sufficient to protect from fermentation one molecule of sugar; otherwise expressed, one molecule of sugar by oxidation protects six molecules from fermentation, a figure approximately equivalent to that found by Meyerhof and by Hill to hold good for muscle contraction.

The close connection between the chemical changes in muscle and those occurring in alcoholic fermentation is shown by the fact that yeast whose fermenting power has been destroyed by washing out the thermostable coenzyme can be restored to activity by the addition of an aqueous extract of muscle; similarly, the addition of the coenzyme of yeast to a washed muscle will restore its power of respiration.

Furthermore, in both there is an intermediate formation of a hexose phosphate, which in muscle gives rise to lactic acid, and is hence termed lactacidogen, but in fermentation gives rise to alcohol.

If respiratory processes are essentially enzymatic, it is natural to suppose that the respiration intensity would increase in the presence of accelerators : various substances have been 
so described, amongst them being phosphates * which are important accelerators in zymase action. $\dagger$

Palladin looks upon lipoids as being of the nature of coenzymes, since the more they are extracted from the plant tissue, the greater is the reduction in the intensity of respiration although not in an exact proportion.

Galitsky and Wassiljeff $\S$ observed that the addition of boiled water extracts of bean seeds and wheat grains increased the output of carbon dioxide in living and in dead seedlings to a degree depending on the acidity of the culture medium: in neutral cultures the increase reached II 7 pcr cent., whilst in a slightly alkaline medium an increase of 86 per cent. obtained as compared with an increase of 60 per cent. in a slightly acid medium.

\section{CURRENT IDEAS ON THE MECHANISM OF RESPIRATION.}

Modern views on the mechanism of respiration include an anaerobic phase even in organisns which are obligate aerobes. It is therefore desirable to draw attention to the salient phenomena presented in the anaerobic respiration of higher plants, an extravagant method of obtaining energy giving origin to carbon dioxide and ethyl alcohol which, in a sense, is wasted unless further oxidized to carbon dioxide and water.\|

It has previously been mentioned that the higher plants, although normally aerobic, may be facultatively anaerobic; the anaerobic respiration of germinating pea seeds, for example, is a commonplace of the laboratory. To take a specific example. Parija has compared the respiration of the apple fruit in normal air and in an atmosphere of nitrogen. The work of Blackman and Parija on the aerobic respiration of the

*Iwanoff : “Biochem. Zeitsch.," I910, 25, I 7 I ; I9I 1, 32, 74 ; Zaleski and Reinhard: id., 1910, 27, 450.

† See Vol. I., p. 494.

† Palladin: "Ber, deut. bot. Gesells.," I910, 28, I20.

$\S$ Galitsky and Wassiljeff : $i d$., $\mathbf{1} 82$.

|| See Kostytschev : "J. Russ. Bot. Soc.," I9I6, I, I82.

II Parija : "Proc. Roy. Soc.," B, 1928, 103, $44^{6}$. 
apple has been mentioned on an earlier page ; they found that at a temperature of $22^{\circ} \mathrm{C}$, , the rate of respiration followed a certain definite course. Parija found that in general a long period in an atmosphere of nitrogen has no permanent effect on metabolism, for when the apple is replaced in air, the rate of respiration returns to that level of intensity it would have attained in aerobic conditions in the same period of time. This recovery of position may take two days and may be associated with a temporary phase of very low production of carbon dioxide. On the other hand, transference from aerobic to anacrobic conditions is accompanied by a short transition phase. Thus on plotting the experimental results, two types of anacrobic respiration are demonstrated. In the one there is an initial outburst of carbon dioxide when the apple is placed in nitrogen, the curve then drops and coincides with the line of normal respiration in air; after a time it gradually descends below this line of normal respiration. When the apple is replaced in air, the respiration curve fluctuates and ultimately coincides with the normal acrobic curve. The other type shows the same early burst of carbon dioxide followed by a fall, but the curve remains above the normal aerobic curve. When the apple is replaced in air, there is a depression to below the normal line, followed by a gradual rise leading to coincidence with the curve of respiration in air.

The main conclusion drawn from this conparative study is that the metabolic factors which determine the progress of respiration with time are different for the acrobic and anaerobic conditions. A consideration of these facts has led to certain generalizations which will be dealt with later.

Comparison of anaerobic respiration with the alcoholic fermentation of sugar is an obvious pursuit and the two phenomena show remarkable resemblances. The occurrence of acetic aldehyde in respiring poplar buds was observed by Godlewski and Polzeniusz.* Neuberg and Gottschalk $\nmid$ germinated seeds of pea and of bean, previously sterilized by

\footnotetext{
* Gollewski and Polzeninsz: " Zeit. physiol. Chem.," I9I 3, 83, I05.

† Neuberg and Gottschalk: "Biochem. Zeit.," I924, I5I, Íf7; 1925, 160,256 .
} 
washing with mercuric chloride, in sterile conditions in a sugar solution in the absence of oxygen. In other experiments the seeds or seedlings were coarsely grown and suspended in the nutrient solution, with all precautions against bacterial activity, in anaerobic conditions. It was found that alcohol was produced together with some acetaldehyde; the addition of calcium sulphite led to a considerable increase in the amount of acetaldehyde. Klein and Pirschle * established acetic aldehyde as an intermediate product in the respiration of cereals and pulses, and Pirschle $\dagger$ states that larger quantities are present in germinating fatty seeds, but here some of the aldehyde may represent a stage in the conversion of fat into sugar previous to the respiration of the sugar.

Thomas $\ddagger$ found that in the respiration of apples in inornal aerobic conditions, neither alcohol nor acetaldehyde accumulated, but in the absence of oxygen the respiration is of the zymasic type, and both ethyl alcohol and acetaldehyde are formed and accumulate; even if much oxygen be present in artificial mixtures of oxygen and carbon dioxide, the zymasic form of respiration may occur owing to the increased amount of the latter gas. In a mixture containing ro to 20 per cent. of carbon dioxide, the results are irregular, but when the amount of carbon dioxide exceeds 50 per cent., the zymasic type of respiration begins, and in such a mixture the ratio ethyl alcohol/acetaldehyde $=2$. This is called, by Thomas, carbon dioxide zymasis. In anaerobic zymasis, i.e. complete absence of oxygen, the ratio is 50 .

Karlsen $\S$ studied the problem by ascertaining the effect of ether, benzene and alcohol on the aerobic respiration of wheat seedlings. He found they yielded results similar to those obtaining in anaerobic conditions, and concluded that the fundamental processes in aerobic and anaerobic respiration are essentially the same.

The amount of alcohol and carbon dioxide produced is a variable quantity depending on the amount of carbohydrate

* Klein and Pirschle : "Biochem. Zeit.," i 926, 168, 340.

$\uparrow$ Pirschle : id., I926, 169, $4^{82}$.

† Thomas: "Biochem. Journ.," I925, 19, 927.

§ Karlsen: "Amer. Journ. Bot.," I925, 12, 6r9.

VOL. 1I.- I I 
available for reduction in the plant and on the experimental conditions employed. ${ }^{*}$ Thus the amount of carbon dioxide evolved from etiolated bean leaves, in an atmosphere free from oxygen, is negligible, but if kept with their petioles immersed in a solution of sugar for some time previous to their being placed in anaerobic conditions much carbon dioxide is produced and their life is prolonged. With regard to alcohol, a similar correlation obtains; in a specific instance etiolated bean leaves in anaerobic conditions gave $256.8 \mathrm{mgs}$. carbon dioxide and $68.3 \mathrm{mgs}$. of alcohol in thirty hours, a ratio of $100: 26 \cdot 5$, whereas leaves previously given sugar yielded in precisely similar conditions $782.4 \mathrm{mgs}$. of carbon dioxide and $724.6 \mathrm{mgs}$. of alcohol, a ratio of $\mathrm{I} 10: 92 \cdot 6 . \dagger$

Boysen-Jensen, $t$ from his study on the relationship of the alcohol produced in anaerobic respiration and the carbon dioxide evolved in aerobic respiration, divides the higher plants into two classes in which the ratio anaerobic alcohol/ aerobic carbon dioxide is respectively $>0.35$ and $<0.35$. To the first group belong most of the classical examples of anaerobic respiration and to the second group those plants which show a weak anaerobic respiration, such as potato tubers, leaves of Tropaolum, seedlings of Sinapis alba, and fungi such as Aspergillus and Penicillium. He selected alcohol for a measure of anaerobiosis in that it has its origin in monosaccharides, wlilist the carbon dioxide produced in the absence of oxygen may have diverse origins.

In the lower plants this parallelism is not so obvious, thus Kostytschev $\S$ found that mushrooms containing no sugar \| give origin to much carbon dioxide but no alcohol when grown in anaerobic conditions, possibly because the alcohol

* Palladin : "Rev. gén. Bot.," 1894, 6, 201.

† Palladin and Kostyschev: "Abderhalden's Handbuch," 1910, 3, 479 .

† Boysen-Jensen : “ Kgl. Dansk. Videns. Selskab. Biol.," I923, 4, I.

§ Kostytschev.: " Ber. deut. bot. Ges.," 1908, 25, I88 ; 26a, I674; "Zeit. physiol. Cliem.," I910, 65, 3.50.

I| Glucose has been described as occurring in the mushroom and allied plants. The amount varies greatly, according to the conditions in which the plants are grown, and varies, not only in different batches, but also in individual plants of one batch. These fungi also contain carbohydrates capable of yielding sugars. 
is oxidized almost as soon as it is formed: but however this may be, more information is necessary before an adequate attempt can be made to correlate the catabolic processes of these and like plants possessed of such plastic metabolic methods.

The work of Blackman and Parija on the respiration of ripening apples has been mentioned on earlier pages. From the results obtained, Blackman * has formulated a working hypothesis of respiration. The phenomenon is a series of phases, the ultimate products of one being the reactants of the next, but the fate of the reactants of the last phase, being controlled by the supply of oxygen, is diverse.

A.-The first phase is essentially that of hydrolysis, the splitting of various carbohydrate reserves to form free hexose which is not directly respired.

B.-The hexose is activated to a "heterohexose" possessed of a less stable type of internal ring structure.

C.-The heterohexose undergoes disintegration, glycolysis, to various intermediate products, of which methyl glyoxal, lactic acid, pyruvic acid and acetaldehyde are examples, which form the raw material for the last phase D. This glycolysis proceeds at a greater rate in air than in nitrogen and is still further accelerated by higher oxygen pressures. This acceleration is not due to oxidation but to the hastening of the rate of production of the substrate for glycolysis.

D.-The fate of the intermediate products of the phase C is dependent on the absence or presence of oxygen. In anaerobic conditions alcohol and carbon dioxide are produced; in aerobic conditions water and carbon dioxide are the final waste products, together with an oxidative anabolite.

The early processes are reversible reactions; hexoses by condensation can give rise to the original carbohydrate reserve, and the heterohexoses can pass back to hexoses. The other phases are considered to be irreversible.

The oxidative anabolism in the last phase is a deduction to explain the differences which obtain in aerobic and anacrobic

* Blackman : "Proc. Roy. Soc.," B, I928, 103, 49I. 
conditions. It will be remembered that in the apple the formation of carbon dioxide in an atmosphere of nitrogen is greater than in air, but in air the only detectable final products are carbon dioxide and water, no other carbon derivative accumulates in the tissues; it is therefore concluded that some of the intermediate products in the phase $C_{\text {. }}$, in the presence of oxygen, undergo an oxidative anabolism and are passed back into the system.

Of this hypothesis the following are significant: Emphasis is laid on the rate of glycolysis, which is regarded as the common measure of respiration in all conditions. (b) Hexoses are not the immediate substrate for glycolysis: they are first converted into the more reactive "hetero hexoses."

(c) That in the final phase there is an oxidative anabolism.

This scheme is an hypothesis based on the observed facts of respiration of isolated structures: it includes certain deductions which are yet to be proven, a point fully appreciated by its authors. Exigences of space forbid a full consideration of the arguments advanced in its support, even if it were desirable in this general survey; it may, however, be remarked that Blackman apparently accepts Meyerhof and A. V. Hill's hypothesis that there is a re-oxidation of reduced material.

The view is generally held that respiration is not a single operation but two groups of events controlled by enzymes, some closely associated with the protoplasm and others independent of the protoplasm and therefore not concomitant with life. The first phase is of the nature of fermentation and the last is oxidative. This is illustrated by the following observations :-

Palladin and Kostytschev showed that germinated peas which had been killed without injury to the enzymes may give off more carbon dioxide than during life, and so also may the bulb of an onion, killed by exposure to a temperature of $-20^{\circ} \mathrm{C}$. on thawing, although in this instance the amount of oxygen absorbed is less than in the living condition. A. R. C. Haas * found that plants of Laminaria poisoned by various substances such as ethyl bromide, acetone, or alcoliol first showed a rise

\footnotetext{
* Haas, A. R. C.: "'Bot. Gaz.," 1919, 67, 347.
} 
in respiration followed by a smooth decline to zero; at the death point the evolution of carbon dioxide was not markedly smaller, and it may be considerably greater, than the normal rate in living tissue. But this post-mortem respiration is not shown in all instances. Palladin observed that the evolution of carbon dioxide from finely ground wheat is less than from the living intact grains.

He also made a comparative study of the effects of various poisons on the evolution of carbon dioxide from living and dead tissues : quinine hydrochloride in a .09 per cent. solution gave a threefold increase in the output of carbon dioxide from living stem apices of the broad bean, but was without effect on killed apices; a dose of I per cent. gave the same increased yield from the live stems and reduced the evolution of carbon dioxide from the dead. Arbutin in a $\mathrm{I}$ to 2 per cent. solution depressed the respiration of wheat seedlings to a greater degree in dead than in live seedlings.

Quastel* remarks on the fact that if a suspension of Bacillus coli be shaken up with toluol or with ether, the organism is no longer capable of reproduction; it is, in ordinary parlance, dead; but it can still activate formic, lactic and succinic acids and this at rates not markedly divergent from those due to the untreated organism.

The parallelism between alcoholic fermentation and anaerobic respiration is so close that the common opinion is that in the ordinary plant the first phase of respiration is anaerobic. As has been described elsewhere, $\uparrow$ the precise sequence of events in alcoholic fermentation is a matter of opinion, but of the end products, alcohol and carbon dioxide, there is no doubt. The carbon dioxide evolved in respiration has its origin in this anaerobic phase by the action of carboxylase upon the carboxyl groups, produced in the disruption of the sugar. If oxygen be withheld, the non-gaseous products of the anaerobic phase will accumulate and ultimately kill the plant if it be a typical aerobe. The second phase is aerobic and is concerned with the oxidation of the products of anaerobiosis.

* Quastel: " J. Hgyiene," I928, 28, I 39.

+ See Vol. I., p. $4^{89}$. 
And here opinions differ as to the starting-point of oxidation. In all probability it is not alcohol, but a precursor of alcohol ; and in tracing the various stages in the oxidative degradation of these substances, the realms of speculation are entered. Of the suggestions made, the following have the merit of at least being within the range of possibility :-

The close connection between sugar and organic acids has been remarked upon on an earlier page, and also the formation of aldehyde in fermentation: the oxidation of aldehyde to acetic acid is a familiar activity of bacteria.

The dehydrogenation of two molecules of acetic acid would give rise to succinic acid-

$$
\underset{\mathrm{CH}_{3} \cdot \mathrm{COOH}}{\mathrm{CH}_{3} \cdot \mathrm{COOH}} \underset{\substack{\mathrm{CH}_{2} \cdot \mathrm{COOH} \\ \text { Succinic acid }}}{\mathrm{CH}_{2} \cdot \mathrm{COOH}}+2 \mathrm{H} \text {. }
$$

The latter, as shown by Thunberg, ${ }^{*}$ is readily converted by the enzyme contained in muscle into fumaric acid-

$$
\underset{\mathrm{CH}_{2} \cdot \mathrm{COOH}}{\mathrm{CH}_{2} \cdot \mathrm{COOH}} \underset{\substack{\mathrm{CH} \cdot \mathrm{COOH} \\ \text { Fumaric acid }}}{\mathrm{CH} \cdot \mathrm{COOH}}+{ }_{2} \mathrm{H} .
$$

It has further been found by Quastel and Whetham $\dagger$ that resting Bacillus coli and $B$. pyocyantus are able to effect the same conversion of succinic into fumaric acid. These authors also found evidence of the conversion of fumaric into malic acid by these bacteria, and Batelli and Stern $\ddagger$ have shown that muscle also contains an enzyme capable of bringing about this change by the hydration of the fumaric acid-

$$
\underset{\mathrm{CH} \cdot \mathrm{COOH}}{\mathrm{CH} \cdot \mathrm{COOH}}+\mathrm{HOH} \rightarrow \underset{\substack{\mathrm{CHOH} \cdot \mathrm{COOH} . \\ \text { Malic acid }}}{\mathrm{CH}_{2} \cdot \mathrm{COOH}}
$$

Malic acid, as was shown by Hahn and Haarmann, $\S$ yiclds on dehydrogenation oxalacetic acid--

$$
\begin{aligned}
& \mathrm{CH}_{2} \cdot \mathrm{COOH} \\
& \mathrm{CHOH} \cdot \mathrm{COOH}
\end{aligned} \rightarrow \underset{\mathrm{CO} \cdot \mathrm{COOH}}{\mathrm{CH}_{2} \cdot \mathrm{COOH}}+2 \mathrm{H}
$$

* Thunberg: “Zentrlbl. Physiol.," I916, 31, 9 I.

† Quastel and Whetham: "Biochem. Journ.," I924, I8, 519.

+ Batelli and Stern: "Compt. rend. Soc. biol.," I921, 84, 305.

$\S$ Hahn and Haarmann: " Zeit. Biol.," r $928,87,465$; 88, 91. 
which is known to be attacked by carboxylase giving rise to pyruvic acid -

$$
\underset{\mathrm{CO} \cdot \mathrm{COOH}}{\mathrm{CH}_{2} \cdot \mathrm{COOH}} \rightarrow \mathrm{CO}_{2}+\underset{\mathrm{CO} \cdot \mathrm{COOH} \text {. }}{\mathrm{CH}_{3}}
$$

The resulting pyruvic acid can then be further converted into acetic aldehyde which is itself broken down by a repetition of the cycle of changes outlined above.

Although the scheme appcars to lead back to the original matcrial, it will be noted that two molecules of acetaldeliyde were involved at the beginning, but only one remains at the end of the cyclc.

It will be noticed that many of these oxidative processes are effected by the removal of hydrogen; but since in the respiration of the green plant hydrogen, as such, is never set free, the hydrogen must in some way be fixed; the current view is that it is oxidized to water with the intervention of a respiratory pigment, glutathione or some other mechanism. Palladin was the first to visualize that atmospheric oxygen was concerned only with the oxidation of the hydrogen of the respirable material to water, a view supported by Thunberg who regards hydrogen as the essential fuel of the living cell.

The above considerations in the main are concerned with sugar as the respirable substance; but, as has already been mentioned, fats and proteins are also available to meet the energy requirements of plants, concerning which there is less precise information. Oparin * has examined chlorogenic acid, $\mathrm{C}_{32} \mathrm{H}_{38} \mathrm{O}_{19}$, which he has found to occur in over a hundred different plants, and finds it to be a substance which readily oxidizes in the air, losing 4 atoms of hydrogen and forming a green pigment. The latter can act as a hydrogen acceptor and so act as an oxidizing agent. The calcium salt of the fully oxidized acid is represented by the formula $\mathrm{CaC}_{32} \mathrm{H}_{32} \mathrm{O}_{19}$ $+2 \mathrm{H}_{2} \mathrm{O}$, whilst the salt of the unoxidized acid has the formula $\mathrm{CaC}_{32} \mathrm{H}_{36} \mathrm{O}_{19}+2 \mathrm{H}_{2} \mathrm{O}$. Chlorogenic acid is more particularly active in the oxidation of natural amino acids,

* Oparin : "Biochem. Zeitsch.," I921, 124, 90. Gorter: "Annalen d. Chemie," 1908, 359, 217. 
peptides and peptones giving origin to ammonia, carbon dioxide, and an aldehyde

$$
\mathrm{R} \cdot \mathrm{CH} \cdot \mathrm{NH}_{2} \cdot \mathrm{COOH}+\mathrm{O} \rightarrow \mathrm{R} \cdot \mathrm{CHO}+\mathrm{NH}_{3}+\mathrm{CO}_{2} \text {. }
$$

The process is accelerated by the presence of certain reagents such as phosphoric acid.

Pirschle * has shown that in the respiration of many fat-containing seeds such as Helianthus, Linum, Cannabis, Brassica, Raphanus, and Cucurbita there is produced, as in the germination of carbohydrate and protein-containing seeds, acetic aldehyde; it is, however, not certain whether the acetic aldehyde in this instance is a direct product of the respiration of the fat, it may in part be an intermediate product in the transformation of fat into sugar previous to the respiratory consumption of the resulting sugar.

The foregoing account is almost entirely confined to the activities of higher plants. The lower plants, more especially the bacteria, obtain their respiratory energy in diverse ways as is indicated by their physiological classification into sulphur, iron and nitrifying bacteria. For information on this, text-books on bactcriology must be consulted.

*Pirschle: "Biochem. Zeit.," I926, 169, $4^{82}$. 


\section{CHAPTER VI.}

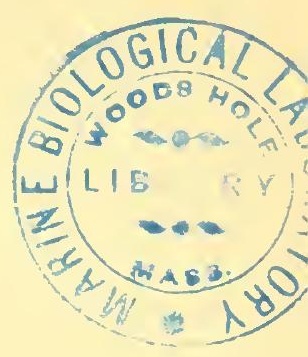

\section{GROWTH.}

THE term growth not infrequently is used to imply mere increase of the plant or plant member in various directions with little or no attempt to correlate or to analyse these and other related expressions of the activity of the organism. Thus increase in surface is not necessarily growth: a pound pat of butter may be spread over a number of slices of bread whereby its area is increased but not its mass. An etiolated seedling may show a much greater length of internode than its fellow of the same age grown in normal conditions: but the comparison of the dry weights of the two will show no increase in mass in the etiolated example.

From considerations such as these, the conclusion is reached that growth is properly speaking an expression of the metabolism of the organism.

Metabolism has two sides, debit and credit: if the anabolic processes are more intense than the catabolic, growth will result; if the catabolic processes are in the ascendant, decretion results. From this it follows that the sure index of growth is increase in dry weight, the credit balance of the two opposing activities. Thus Boysen-Jensen * found that under maximum illumination the carbon assimilation of Sinapis, a sun plant, was $6 \mathrm{mg}$. of carbon dioxide per $50 \mathrm{sq} . \mathrm{cm}$. of leaf surface per hour at $20^{\circ} \mathrm{C}$., whilst the respiration at the same temperature and for the same units of surface and time was $0.8 \mathrm{mg}$. of carbon dioxide. This means that for an average plant of Sinapis, the amount of dry matter made in one day in July is $60 \mathrm{mg}$. whilst the loss of dry matter due to respiratory processes is $14 \mathrm{mg}$., leaving a balance of $46 \mathrm{mg}$., which

* Boysen-Jensen : "Bot. Tidsskr.," r919, 36, 2 r9. 
is equivalent to 16.5 per cent. of the dry weight of the plant. A similar relation is shown by Oxalis, a shade plant, but the amounts are much smaller; $0.8 \mathrm{mg}$. of carbon dioxide being assimilated per $50 \mathrm{sq} . \mathrm{cm}$. per hour at $20^{\circ} \mathrm{C}$., whilst the loss due to respiration is $0.15 \mathrm{mg}$. at the same temperature for the same units.

The following table gives Boysen-Jensen's results for various plants. The figures for respiration are milligrams of carbon dioxide given out per $50 \mathrm{sq}$. $\mathrm{cm}$. of leaf surface per hour at $20^{\circ} \mathrm{C}$, and those for assimilation are milligrams of carbon dioxide synthesized by the same area, in the sanie time and at the same temperature. All the figures are maximal values :-

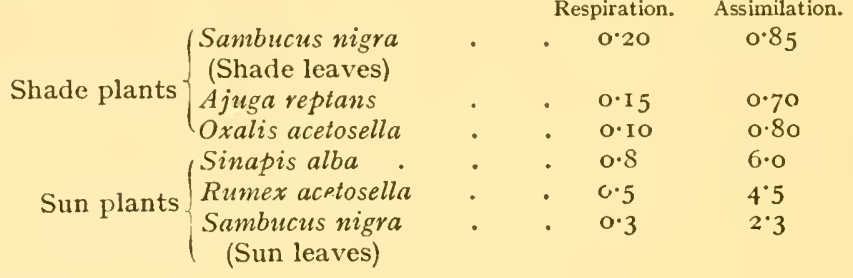

In all these plants the carbon assimilation is much greater than respiration, and since the an ount of synthesized material is more than enough to provide for respiration during the hours of darkness, growth takes place. This is illustrated in the following table which represents the percentage of increase in the dry matter of Sinapis alba.

Period.

Dec. $I-20$

Dec. 22 -Jan. 15

Jan. $2 \mathrm{I}-\mathrm{Feb} . \mathrm{I}_{4}$

Feb. I9-March I 4 .

March 2I-April 20 .

April 24 -May 22.

June 5
Percentage Increase in Dry Weight.

I.05

$1 \cdot 30$

- $1 \cdot 30$

- 3.50

. $7 \cdot 50$

. $16 \cdot 70$

. $\mathrm{I} 8 \cdot 80$

The flowering period occurred carly in June which resulted in a fall (Fig. 7). When these figures are plotted, an S-shaped curve is formed which, as will be seen later, is typical of growth curves.

In further illustration a saprophyte may be taken: Ter- 
roine and Wurmser * in their work on Aspergillus niger used the dry-weight method which they considered in relation to the amount of organic matter used up in growth; the ratio of the dry weight of the organism to the organic matter consumed, giving the coefficient of utilization. For Aspergillus grown in a culture medium of salts together with 3 per cent. glucose, the sole source of carbon, and $0 \cdot 05$ per cent. ammonium sulphate, the only source of nitrogen, the coefficient of utilization was found to be $0 \cdot 44$. This value is unaltered when

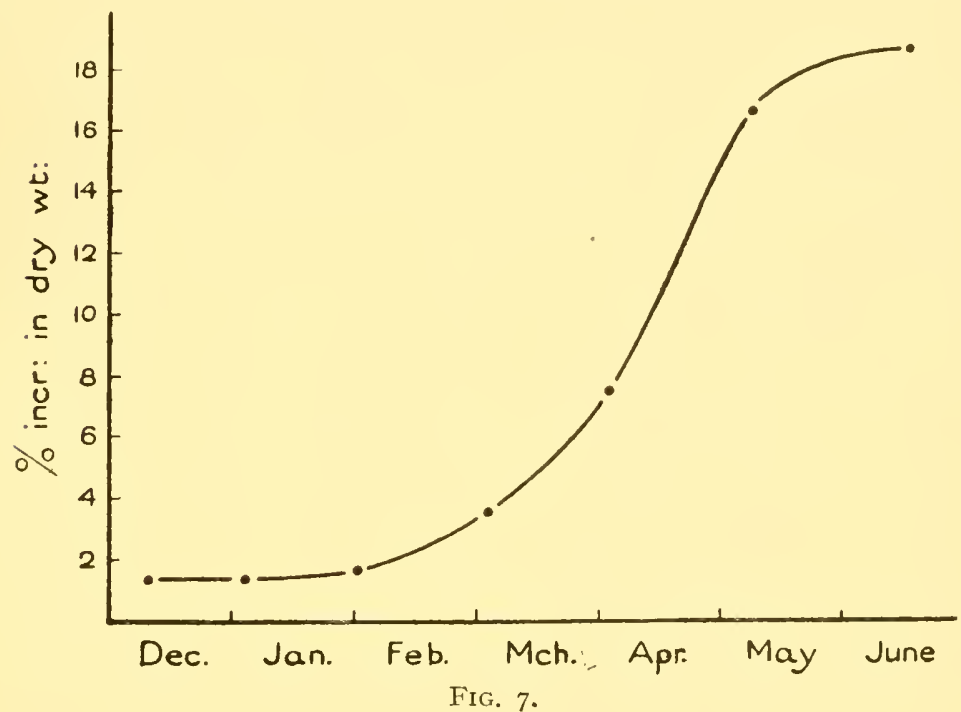

glucose is replaced by other sugars and when the concentration of the ammonium sulphate is much increased or is replaced by guanidine, urea or nitric acid; nitrates, on the other hand, bring about a reduction in the coefficient. For the production of I gram of mycelium in ordinary conditions of growth, $2 \cdot 3$ grams of glucose are used; $2 \cdot 2$ grams are required for actual growth, the rest being consumed in respiratory processes.

The rate of growth of Aspergillus niger is influenced by the hydrogen ion concentration of the culture mediun ; a range

*Terroine and Wurmser : “ Bull. Soc. Chim. Biol.," I922, 4, 519. 
in $p H$ from $7 \cdot 7$ to $I \cdot 7$ is without effect, but at $p H \mathrm{I} \cdot 2$ the growth is much slower and the coefficient of utilization falls to 0.29 . The influence of temperature will be considered later.

A disposal to go further may be evinced and to select the number or weight of offspring as being the true measure of a naturally growing organism's growth, since the selfish needs of the parent are thereby eliminated. For obvious reasons such a measure is impracticable except in special cases where reproduction takes place with extreme rapidity, as for instance in bacteria, or where crop yield in response to methods of cultivation is required.

The employment of the dry weight method has a disadvantage in that it forbids the study of progressive change in one and the same member, since to find the dry weiglit, the plant or plant member must be killed. For this reason other indices sometimes must be employed. Thus change in the size and area of leaves in certain investigations serve as a reliable measure, a fact which becomes evident when it is realized that an increase in the size of a leaf, or of the entire chlorenchyma system of the plant, means an increase in the plant's factory and all that this connotes. Thus Johnston * found that the total dry weight and total leaf-area of the buckwheat ran on parallel lines during the season February to October, the greatest rapidity of growth occurring in the sumner months.

In further illustration the observations of Briggs, Kidd and West, $\uparrow$ based on the investigations of Kreusler and others on the maize, may be considered. Briggs, Kidd and West analysed the growth of the maize in terms of dry weight, leaf area and time, and employed the relative growth rate and the leaf area ratio. The relative growth rate curve is the weckly percentage increase in dry weight plotted against time, and the leaf area ratio curve is the leaf area in square centimetres per gram of dry weight plotted against time.

The growth rate of the maize varies much in magnitude at

* Johnston: "Johns Hopkins Univ. Circ.," r917, 211 .

† Briggs, Kidd and West : "Ann. Appl. Biol.," I920, 7, 103, 202. 
different periods of its life. This is expressed in a generalized form in Fig. 8.

The early seedling stage is shown by the portion $a b$, and is characterized by a decretion owing to the young leaves being in a low phase of carbon assimilation activity, and providing less material than is consumed in respiratory processes, an observation which confirms the results of Irving and of Briggs. The phase $b c$ corresponds to the morphological development of the plant during which the leaf area per unit dry weight increases to a maximum. Finally the phase $c d$ is the latter part of the plant's life and includes the formation of the

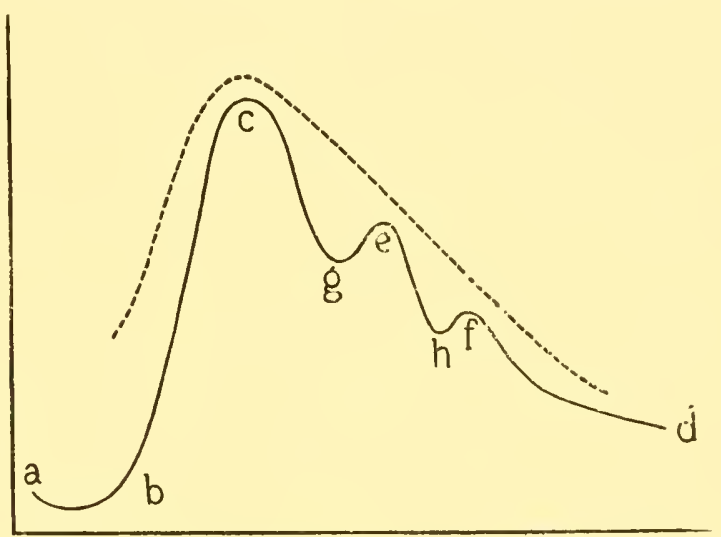

FIG. 8.-The continuous line represents growth rate and the broken line leaf area per unit dry weight.

flower and the seed. This portion shows two secondary maxima at $e$ and $f$ which are respectively coincident with the appearance of the male and female inflorescences and each is precedeci by a minimum, $g$ and $h$, which corresponds to the early stages of flower development at which epoch there is a marked increase in respiration activity.

The incidence of the maxima is dependent on environmental conditions operating not at the time but at a previous stage in the life of the plant.

The fact that the curve for leaf area per unit dry weight corresponds with the growth rate curve, indicates the close physiological connection between the relative growth rate and 
carbon assinilating area per unit of dry weight (Fig. 8). The correspondence, however, is not precise; instead of showing a definite type of variation, as does the relative growth rate, the leaf area per unit dry weight curve fluctuates about a mean value. These fluctuations are due to the conditioning factors of growth of which factors temperature is amongst the more significant. The importance of leaf area in the econony of the higher plant is so obvious that no elaboration of the statement is required. The growth in area of the leaves of the cucumber has been closely studied by Gregory* and may be alluded to at this stage in that it introduces some aspects of growth which properly belong to a general consideration. But before this is done, the "grand period of growth " must be recalled to memory. As is well known, Sachs used this expression to designate the period through which the plant, or plant member, exhibits its sequence of growth rates. Thus the growth rate of the first internode of Phaseolus multiflorus is at first slow, then quickens to a maximum, after which a decrease in the rate to zero obtains, which point is coincident with the attainment of maturity. The sequence is illustrated in Fig. 9 which is based on Sachs's measurements.

The grand period of growth does not include an analysis of the fluctuations in the rate during the periods between the measurements; thus the growth rate between the third and fourth day is the summation of the growth during that period. Priestley and Evershed $t$ in their study on the root growth of Tradesiantia and tomato, based on the increase in dry and wet weights of the roots produced on cuttings, find the curves obtained are a sequence of these grand period curves which are a series of $S$ curves, a type which is very common in graphs illustrating growth phenomena (see Figs. 7 and IO). The time of transition from one $\mathrm{S}$ curve to the next coincides with the time of appearance of a crop of roots of a subordinate branch order.

Gregory found that the growth in length, in breadth, and in area of the leaves of Cucumis sativus show a grand period

* Gregory : "Ann. Bot.," I 92 I, 35, 93.

† Priestley and Evershed : id., 1922, 36, 225. 
of growth when grown in natural conditions; but, when continuously illuminated by electric light, a method sometimes adopted by market gardeners to secure early crops, the rate of increase falls from the first measurement of area. The curves of increase in linear dimensions and in area can be

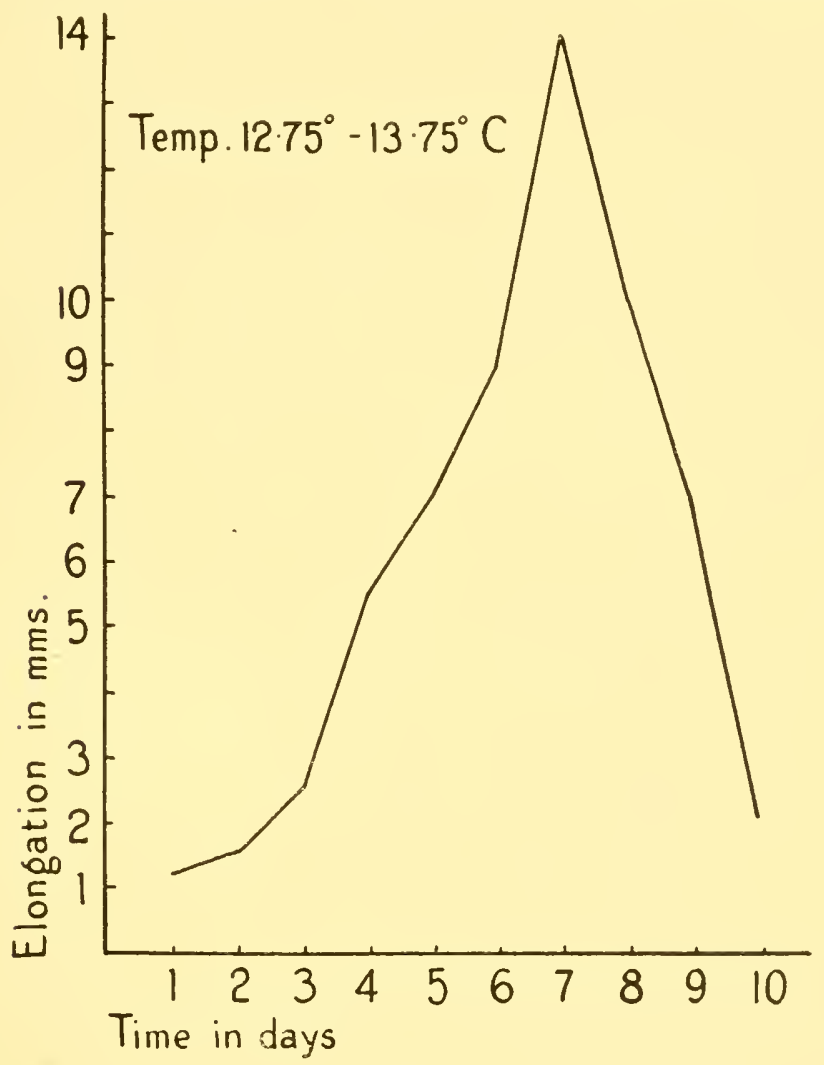

FIG. 9.

represented by the formula of an autocatalytic reaction.* The increase in area of the total leaf surface varies with the season of the year: in March and June in daylight, the rate of increase is proportional to the area existing at that time, that is, the growth follows a compound interest law; but during December a detrimental factor intervenes so that the rate of

* This term is explained on p. $17^{8}$. 
increase, although still proportional to the extant leaf area,

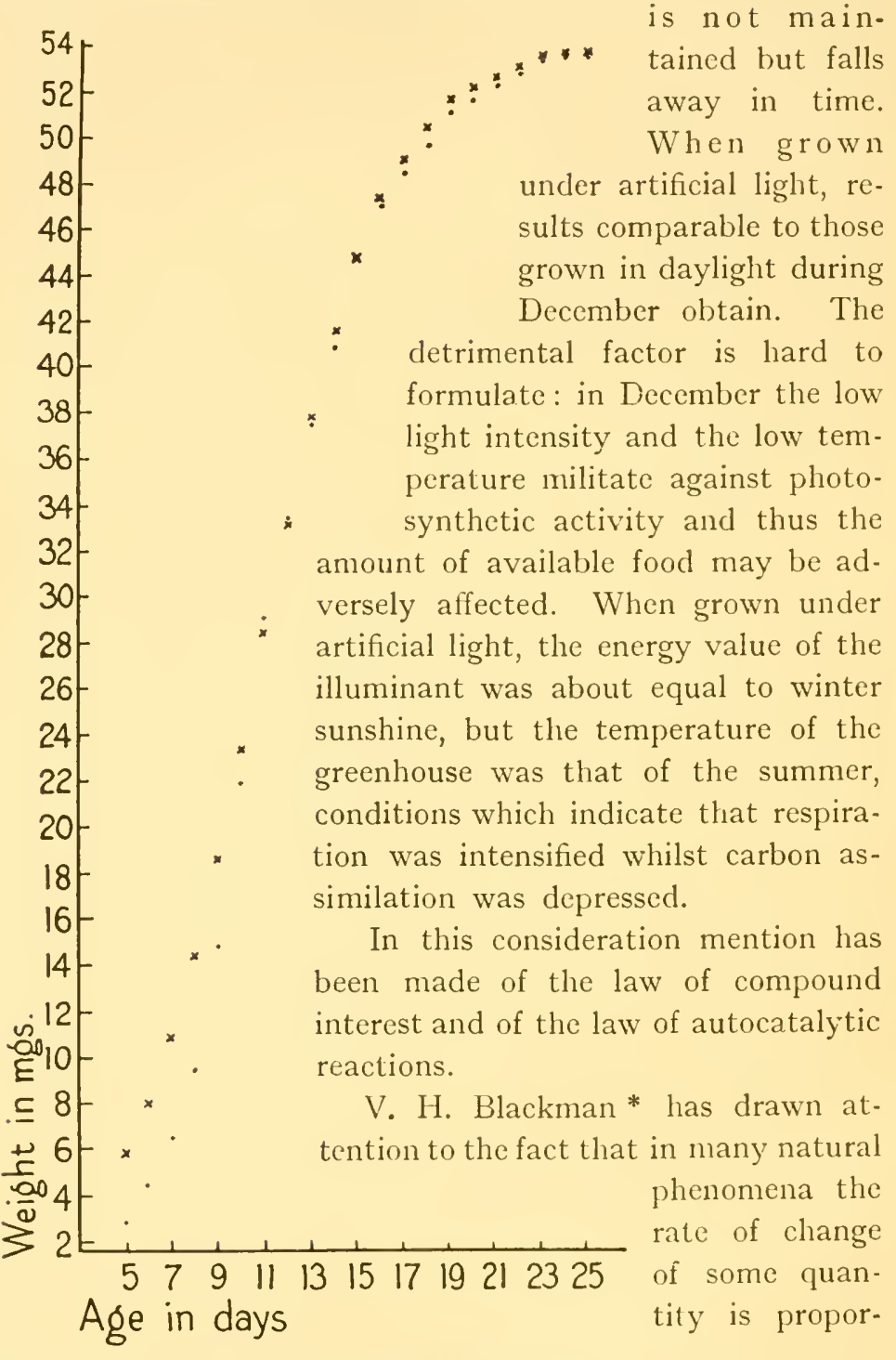

FIg. Io.-Growth of the fruit of Cucubita pepo; . . observed value, $\mathrm{x} \times \mathrm{x}$ calculated value.

* Blackman : "Ann. Bot.," I9r9, 33, 353; “New Phytol.," I920, 19, 97. See also Kidd, West and Briggs: id., 88; Schmidt: "New Jersey Agric. Exp. Sta.," Bull. 404, 1924. 
tional to the quantity itself. This is the law of compound interest; money left to accumulate at compound interest increases to an amount the magnitude of which depends on the initial capital, the rate of interest and the time the money is accumulating; the dry weight of an annual plant depends upon the dry weight of the food reserves in the seed, the percentage increase in the dry weight over the selected period, and the time during which the plant is increasing in weight. This may be represented by the equation

$$
\mathrm{W}_{\mathbf{1}}=\mathrm{W}_{0} e^{r t}
$$

where $W_{1}$ is the final weight, $W_{0}$ the initial weight, $r$ the average rate of interest, $t$ time, and $e$ the base of natural logarithms.*

The rate of interest is obviously of first-rate importance and if constant the final weight will vary directly as the initial weight, wherefore a large seed, with more initial capital, will give a much larger plant than a small seed with a relatively smaller initial capital.

From considerations such as these Blackman arrives at the conception that the rate of increase observed in the plant is the index of efficiency of the plant, a conception whicl gives a useful basis for comparison but which is not a constant since it is the average of a number of rates which may show variations through a wide range, for it is affected by the external conditions. The rate of increase is highest in the early stages of growth and falls with the inception of the reproductive period.

The laws governing autocatalytic reactions are the logical outcome of the laws of monomolecular reactions. $\dagger$ An auto-

* Tilis equation is perhaps the simplest suggested for a mathematical expression of growth; but simple or complex, the objection may be justly raised that in view of the impossibility of evaluating many of the factors governing the rate of growth, more particularly environmental and internal factors, all formule, even at their best, are mere approximations and therefore of but little scientific value. However this may be, many authors give a mathematical consideration of their measurements, which, with one exception, are excluded from the following pages. In some instances, such expressions have become polemical (see, for example, Briggs : “Ann. Bot.," I 925, 39, 475 ; “Proc. Roy. Soc.," B, 1928, 102, 280 ; Gregory : "Ann. Bot.," 1926, 40, I ; 1928, 42, 53I).

$\uparrow$ Vol. I., p. 469.

VOL. II. $-\mathrm{I} 2$ 
catalytic reaction is one in which one of the products of dissociation of the original material acts as a catalyst on the material which is obviously decreased in amount as the reaction proceeds. Thus a solution of methyl acetate undergoes autodissociation into methyl alcohol and acetic acid; of these products the acetic acid catalyses the methyl acetate so that the rapidity of the reaction is continually accelerated, owing to the diminishing amount of methyl acetate and the increasing amount of acetic acid, until the whole of the substrate is dissociated.

From his study of the growth of various organisms, Robertson * concludes that in any particular growth cycle, either of an organism or of a member of an organism, the maximum increase in volume or in weight in a unit of time occurs when the total growth duc to the cycle is half completed. Such a cycle of growth conforms to the formula

$$
\log \frac{x}{\mathrm{~A}-x}=\mathrm{K}\left(t-t_{1}\right)
$$

where $x$ is the amount of growth in weight or volume which has been attained in time $t$. A is the total amount of growth attained during the cycle, $\mathrm{K}$ is a constant and $t$ is the time at which growth is half completed. These relations are such as would be expected to hold good were growth the expression of an autocatalytic chemical reaction, and the growth of the organism should, from the hypothesis, remain constant, having once attained its maximum. But the contrary obtains, in senescence a loss of weight occurs; this is supposed to be due to the action of secondary factors which are imposed on the phenomena of growth itself.

An inspection of Robertson's figures, for example those given for the oat, $\uparrow$ or for Cucurbita, shows differences between the observed and calculated growth values of varying magnitude, and these differences when expressed in percentages sometimes appear too large to support the thesis; but when the observed and the calculated values are expressed in the

* Robertson: "Arch. Entwicklungsmech. Org.," I 908, 25, 581. $\dagger I d ., 26,108$. 
form of a curve (Fig. IO) their incidence is sufficiently close to give support to the thesis, especially when allowance is made for the experimental errors.

To what extent and in what degree growth processes may be correlated with this law is uncertain. The observations of Gregory show that the curves of increase in the area of the leaf surface of cucumber plants are of the $\mathrm{S}$ form and can be represented by the formula of such a reaction. In the earlier stages of growth this increase also is in accordance with the law of compound interest. There is thus a choice between the two expressions: the compound interest law is a conception rather than a physiological constant, but even so Gregory considers it to have the advantage over the law of autocatalytic reactions in that it is independent of hypothetical mechanisms of growth. For it is obvious that if growth is an expression of the activity of some catalytic agent, that agent must be sought out; according to Robertson* the lipoids may subserve the required function.

Robertson's thesis, in essentials, is supported by the observations of many investigators: Rippel $\uparrow$ finds it more satisfactory than others, and has applied it to his and Oskar's $\ddagger$ observations on the increase of growth in response to nitrate manuring. Prescott $\S$ is satisfied that the flowering curve of the cotton plant can be accurately expressed by an equation which is essentially that of an autocatalytic chemical reaction. Reed and Holland $\|$ found that the rate of growth of the sunflower closely approximates the course of such a reaction. Reed 9 also observed that the rate of increase in the height of walnut and pear trees showed growth cycles throughout the growing season; in each cycle the growth rate corresponded to an autocatalytic reaction. Similar results have been obtained by Gustafson ** for Cucurbita Pepo

* Robertson : "Arch. Entwicklungsmech. Org.," I9I3, 37, 497.

† Rippel : "Ber. deut. bot. Ges.," I 919, 37, I69.

† Rippel and Oskar : “ Biochem. Zeit.," I925, I55, I 33.

§ Prescott: “Ann. Bot.," I 92 I, 36, I 2 I.

|| Reed and Holland : “Proc. Nat. Acad. Sci.," I9I 9, 5, I 35.

if Reed: "Journ. Gen. Physiol.," I 920,2 , 545 ; "Amer. Naturalist," $1924,58,337$.

** Gustafson: "Plant Physiol.," 1926, 1, 265; see also id., I 927, 2, I 53. 
var. condensa, Cucumis Melo, C. Sativus, and Lyopersicum esculentum.

On the other hand, van de Sande-Bakhuyzen * considers that the formula is but an approximation, and that it is incorrect to regard growth as a simple autocatalytic process, whilst Hooker, $\dagger$ considers that growth is best considered as a consecutive reversible monomolecular reaction.

Returning to the terms in which increase in growth may be expressed, allusion has been made to offspring especially of unicellular organisms in which the unit grows to a certain size and then divides. The yeast plant may be selected for illustration, more especially as a consideration of its reproduction rate will introduce other aspects of the subject of growth.

A young yeast cell on being placed in a suitable medium increases to a certain size, the magnitude of which depends to no small extent upon the osmotic strength of the medium, and then reproduces itself by gemmation. The phenomenon may be illustrated by the accompanying Fig. II which is based upon observations made by Slator.§ This figure represents the offspring of a single cell up to and including the fourth generation. The cycle was completed in 232 minutes from the second generation, the average time for the interval between one generation and the next, that is the generation time, being seventy-six minutes.

Elaborating this general statement, the growth of the yeast exhibits a sequence of phases the conspicuousness and duration of which varies with the conditions. The "seed" on being sown in the wort may remain inactive for a time; this is the lag phase, the duration of which depends in the main on the age of the seed, old plants showing a longer quiescent period than young plants grown from spores which may show no lag phase. When once growth has started, it is unrestricted and follows the logarithmic law, for which reason this phase often

* Van de Sande-Bakhuyzen: "Science," I926, 64, 653.

† Hooker: " Proc. Nat. Acar. Sci. Wash.," I925, 11, 7 10. $22 \mathrm{I}$.

+ See Drabble, E. and H., and Scott: "Biochem. Journ.," 1907, 2,

$\S$ Slator: id., I9I8, 12, 248. 
is termed the logarithmic phase. This is followed by a period of retardation due to the operation of factors such as the accumulation of carbon dioxide and the lack of oxygen. This

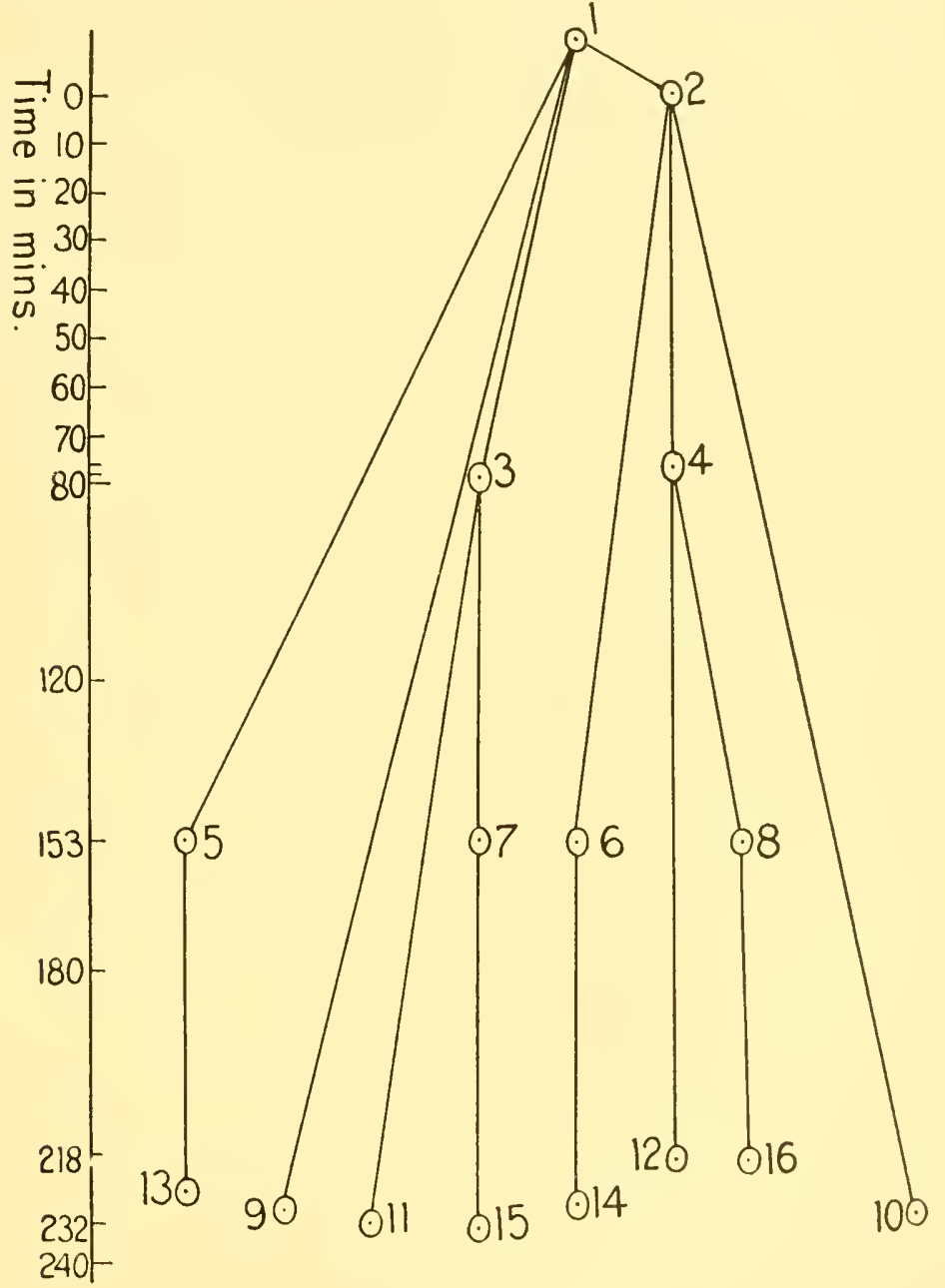

FIG. II.

is a normal sequence: but departures from the normal may result on varying the conditions of growth; thus if the seeding be heavy, but not excessive, the logarithmic phase may disappear and retardation set in immediately after the 
lag phase. If the seeding be excessive, the retarding factors may prevent any measurable growth.* Priestley and Pearsall $\uparrow$ look upon the logarithmic phase as the natural rate of increase where increase in mass is an exponential function of time; the retardation phase, in which the growth rate is directly proportional to time, is due to adverse operatnig factors, such as the accumulation of end products, which are the outcome of the earlier unrestricted growth. In addition to the obvious products, carbon dioxide and alcohol, of the activity of yeast, oxygen and sugar may also influence its growth.

The influence of oxygen is important, and this notwithstanding the fact that yeast is capable of action in anacrobic as well as in aerobic conditions. The growth exhibited in these different circumstances is not the same: when grown anaerobically, yeast cells quickly acquire a static condition of equilibrium with regard to the medium in which they are suspended; $\neq$ the lack of oxygen, especially prior to the beginning of gemmation, arresting the reproduction function. It is the small amount of oxygen initially present in the wort which is considered to explain the fact that in fixed conditions the maximum cell increase is independent of the number of cells of seed yeast per unit volume of yeast. Thus Horace Brown $\S$ found that up to 65 or 70 per cent. of complete aeration, the cell increase is a linear function of the available free oxygen at the beginning of growth. In other words, during the period of active reproduction in a suitable medium in which access to oxygen is limited to that initially present in solution in the liquid and in conditions of culture which eliminate the competition factor, the number of yeast cells present at any moment is directly proportional to the time. Reproduction can, however, take place to a small extent in anaerobic conditions: Horace Brown found the limit to be 6.5 cells for each initial cell of seed yeast. This is ex-

* Slator: "Biochem. Journ.," I918, 12, 248.

† Priestley and Pearsall : “Ann. Bot.," I922, 36, 239.

† Adrian Brown: "Journ. Chem. Soc.," I905, 87, I 395.

§Horace Brown : "Ann. Bot.," I9I 4, 28, 197. 
plained by the fact that before reproduction takes place, the cells of the seed yeast absorb and fix oxygen which renders possible this limited reproduction in anaerobic conditions. This absorption of oxygen, which is a linear function of time, takes place with great rapidity; thus in one instance it was found that 3 gram of pressed yeast per 100 c.c. of liquid completely absorbed the oxygen in two and a half hours. Horace Brown concludes that the power of reproduction is impressed in the cell at the very outset by the absorbed oxygen and that a quantitative relation exists between this absorbed oxygen and the number of units which the initial yeast cell can finally gemmate. The action of the oxygen is one of induction and, according to Horace Brown, all the known facts can be explained on the assumption that the available oxygen is equally divided between the initial cells and the consequent variation in the oxygen charge which these cells must receive when the ratio of the seed yeast to the available oxygen varies.

The amount of oxygen in aerated wort may be very small, but its effect may be very great: thus I c.c. of oxygen in aerated wort brings about a growth sixty times greater than the same amount of oxygen in non-aerated wort.* Slator is impressed by the importance of carbon dioxide as a conditioning factor in the growth of yeast, and he considers that the influence of this gas is much greater than is generally supposed, and that some of the observed effects generally ascribed to the direct influence of oxygen may be due to its indirect action in lessening the supersaturation of the wort with carbon dioxide. For measurements of the rate of growth in wort and in wort saturated with carbon dioxide show much retardation, possibly due to the carbon dioxide rather than to the lack of oxygen. These measurements are confirmed by controlled experiments in which the carbon dioxide was the limiting factor. In fact, a correlation can be made out between the crop of cells and the concentration of carbon dioxide in the medium :-

* Slator: "Journ. Chem. Soc.," I921, 1 19, I1 5. 


$\begin{array}{ccc}\begin{array}{c}\text { Proportionate Concentration } \\ \text { of Carbon Dioxide }=a .\end{array} & \begin{array}{c}\text { Crop of } \\ \text { I.08 }\end{array} & \text { Cells.* } \\ \mathrm{I} \cdot 08 & 3 \cdot 0 & \alpha \\ \mathrm{I} \cdot 46 & 3 \cdot 0 & 2 \cdot 8 \\ \mathrm{I} \cdot 48 & 4 \cdot \mathrm{I} & 2 \cdot 8 \\ 2 \cdot \mathrm{I} 3 & 4 \cdot 5 & 2 \cdot 8 \\ 2 \cdot 33 & 6 \cdot \mathrm{I} & 3 \cdot \mathrm{I} \\ & 6 \cdot 5 & 2 \cdot 9 \\ & & 2 \cdot 8\end{array}$

With regard to the influence of sugar, there is, according to Slator, a proportion between the size of the crop and the initial concentration of glucose up to about I per cent. The

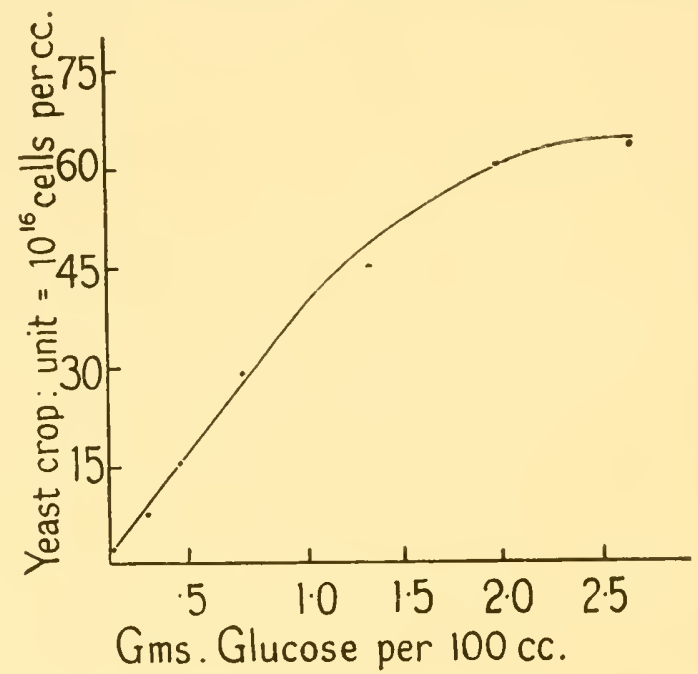

FIG. I2.

accompanying curve (Fig. I2) shows the retarding influence of sugar in increasing concentration, when sugar is the limiting factor. Its slope corresponds to $3900 \times 10^{16}$ cells per gm., a figure in fair agreement with the calculated number.

In ordinary conditions of brewing the accumulation of alcohol is never so great as to be a significant factor in the growth of the yeast; if, however, alcohol be present in excessive amount, it has a limiting action; thus the presence of 8 per cent. of alcohol in the fermenting liquor may inhibit reproduction, especially if the supply of oxygen is limited.

* Unit of crop of cells $=7.65 \times 10^{6}$ cells per c.c. 
Richards * also has studied the growth of yeast by ascertaining the increase in the number of cells and also by finding the volume of the population per unit volume of $\mathrm{I} / 25 \mathrm{cmm}$., the separation of the cells from the nutrient medium being effected by the centrifuge with appropriate precautions and a standardized routine. By both methods it was found that the growth curve was asymmetrically S-shaped, attaining a maximum yield within 100 hours at a temperature of $30^{\circ} \mathrm{C}$. At first the increase in volume is greater than the increase in cell number, which is presumably due to the increase in size of the individual cells before gemmation begins. After I 5 hours the increase in the cell volume becomes slower until it equals the increase in cell number at about 90 hours. The complexity of the growth curve is due to a limiting factor, possibly the accumulation of the products of the plant's metabolism in a limited environment.

This survey, incomplete though it be, shows the usefulness of offspring as an index of growth $\dagger$ and emphasizes the importance of various conditioning factors in the governance of life processes. It must, however, be pointed out that the number of offspring is not always a true index of growth. This is shown in the accompanying table which relates to the

\begin{tabular}{|c|c|c|c|}
\hline Solution & & $\begin{array}{l}\text { Per cent. Increase } \\
\text { in Numbers. }\end{array}$ & $\begin{array}{l}\text { Per cent. Increase or Decrease in } \\
\text { Dry Weight of Crop. }\end{array}$ \\
\hline $\begin{aligned} & \text { Normal } \\
& \text { - Calcium } \\
& \text { - Nitrogen } \\
& \text { - Phosphorus } \\
& \text { - Potassium }\end{aligned}$ & $:$ & $\begin{array}{l}300 \\
\text { I I I } 25 \\
287 \cdot 5 \\
210 \cdot 0 \\
250 \cdot 0\end{array}$ & $\begin{array}{l}+150 \\
-37 \cdot 5 \\
+25 \\
+25 \\
+87.5\end{array}$ \\
\hline
\end{tabular}

growth of Lemna in a normal culture solution and in solutions lacking various essential elements. $\$$ It will be seen that the percentage increase in the number of plants is ever greater

* Richards: "Ann. Bot.," I 928, 42, 27 I.

$\dagger$ A little thought will show that measurements of increase in length and girth of those parts of plants exhibiting merismatic activity are in reality measurements of offspring of the dividing elements.

\Based on observations made by Messrs. Williams and Cole in the laboratory of the authors. See also Ashby, Bolas and Henderson : "Ann. Bot.," I928, 42, 771. 
than the percentage increase in the dry weight of the offspring. An extreme case is presented when calcium is lacking, for although the number of offspring is more than double the number of the parent plants, the dry weight of the offspring is 37.5 per cent. less than the original dry weight of the parent plants.

The growth rate of a plant varies with the age of the organism and also may show periodic and seasonal variation.

Eucalyptus regnans shows the greatest rate of increase of area between the age of forty and fifty years. ${ }^{*}$ The measurement of the diameter of the annual rings indicates that the growth rate falls off with time. In many examples growth in thickness is periodic through the seasons on account of climatic factors, thus at Peradeniya Hevea brasiliensis shows no growth in thickness during the dry season January to March. From the end of March to the beginning of October, the wet season, growth is uniform; whilst during the dry season, October to December, growth is considerably less and sometimes may cease altogether.t In instances such as this it would appear that climate is all-important, especially as regards the provision of adequate supplies of soil water. Thus the erratic growth of Hevea observed during the second dry season may be pre-determined by the amount of rainfall during the previous wet season.

In more temperate climates, soil temperature is a significant factor; the observations of McDougall $\ddagger$ show that the root growth of forest trees begins in the early part of the year when the soil temperature reaches a degree sufficiently high for absorption of water to take place, and stops in the autumn when the soil becomes too cold. There is no inherent tendency to periodicity, and when a resting period obtains during the summer months, its cause may be found in the decreasing water supply. There is, however, as Petch has shown for Hevea, a personal as well as a specific physiology of plants,

* Patton: "Proc. Roy. Soc. Victoria," I917, 30, I.

† Petch: "Ann. Roy. Bot. Gard. Peradeniya," 1916, 6, 77.

$\ddagger$ McDougall: "Amer. Journ. Bot.," 1916, 3, 384 . 
an almost untrodden field, and some of the results observed may be ascribed to individual peculiarity rather than to this or to that factor.

Gregory, ${ }^{*}$ in his study of the effect of climatic conditions on the growth of barley, recognizes eight environmental factors : maximum day temperature, average day temperature, minimum night temperature, average night temperature, total radiation in calories per sq. cm. per week, hours of bright sunshine, evaporating power of the air and the nitrogen factor, which is important in the rate of growth of the leaf.

Allusion has been made to the importance of the previous history of the conditions and of the plant in determining the activity of the plant at any moment. In the present connection, the important and extensive work of Balls on the cotton plant must be mentioned. $\dagger$ From a long series of observations, Balls concludes that the different behaviour of the plants, as indicated by the crop of cotton, are the inevitable consequences of the known environmental conditions, provided that proper regard is paid to the distinction in time between the incidence of the conditioning factor and its manifestation in the crop. Thus the daily fluctuations in the flowering curve are predetermined and controlled by the weather conditions which obtained a month before the flower opens. This is the principle of predetermination: its importance is obvious; an accurate knowledge of predetermining factors will amongst other things give to certain aspects of physiology, ecology, and agriculture a precision which now is sometimes lacking. $\ddagger$

\section{THE CONDITIONING FACTORS.}

Temperature.

The factors which condition growth and its rate are precisely those which influence anabolic and catabolic activities,

* Gregory : "Ann. Bot.," I926, 40, I.

† Balls: "Phil. Trans. Roy. Soc.," B, 1917, 208, I 57.

† For an application of this principle, see Appleman's paper on "Forecasting the Date and Duration of the Best Canning Stage for Sweet Corn" (" Univ. Maryland Agric. Exp. Sta.," 1923, Bull. 254). 
and the effect of any one sucl factor on growth is the resultant of its action on the opposing components of growth. Thus temperature accelerates respiration and also carbon assimilation, but since in a vigorous green plant the products of one hour's carbon assimilation is a sufficient provision for many hours' respiration, ${ }^{*}$ there will be a balance on the credit side; wherefore an increased temperature will result in an increased rate of growth, other things being equal. But there is a limit to the height of the temperature; if a certain degree be exceeded, growth will be retarded, come to a halt, and ultimately a decrement will result. In illustration, it is a common laboratory experience that the increase in length of the radicle of a seedling is a linear function of time and that there is a gradual increase in the rate of growth up to about $28^{\circ} \mathrm{C}$. Talma $\dagger$ observed the growth of the radicle of Lepidium sativum from $0^{\circ}$ to $40^{\circ} \mathrm{C}$. In conditions of constancy of temperature for at least three and a half hours, it was found that measurable growth occurred at $0^{\circ} \mathrm{C}$. and that the greatest rate was at $28^{\circ} \mathrm{C}$. Van't Hoff's law is applicable only for small ranges of temperature and, in general terms, the temperature coefficient decreases with a rising temperature.

The same general observations have been recorded for lower plants. Thus Fawcett $\ddagger$ found that the radial growth rate of cultures of the fungus Pythiacystes atrophthora remained constant as long as the environmental conditions did not change. With increasing temperature a greater rate of growth is exhibited up to a certain degree; when this is passed, the rate of growth falls off. Thus-

At $10^{\circ} \mathrm{C}$, radial growth rate $=2.5 \mathrm{~mm}$. per 2.4 hours.

, $20^{\circ} \mathrm{C}$., ", , $=6.0$, ". ," ,

, $28^{\circ} \mathrm{C}$., , , , , $=7.5 \quad, \quad, \quad, \quad$,

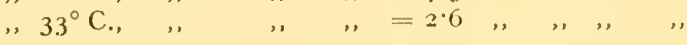

In Aspergillus niger Terroine and Wurmser $\S$ found that the influence of temperature on the rate of growth varies with

* See Boysen-Jensen : “ Bot. Tidsskr.," I9I8, 36, 2 19.

†Talma : "Koninkl. Akad. Wetensch.," I 916,24, I 840.

\$Fawcett: "Johns Hopkins Univ. Circ.," $1917,193$.

§ Terroine and IVurmser: "Bull. Soc. Chim. Biol.," 1922, 4, 519. 
the stage of development; in the earliest phase, when the spores are germinating, $Q_{10} \equiv 2 \cdot 8$; when the mycelium is established and growing well, $\mathrm{Q}_{10} \equiv \mathrm{I} \cdot 6$.

Balls * measured the growth in the length of the hyphx of the fungus causing "sore skin" on the cotton plant. The growth rate at different temperatures is what might be expected from van't Hoff's law; but at higher temperatures, $38^{\circ} \mathrm{C}$, there is a decrease in growth followed by complete cessation probably due to the accumulation within the cell of certain products of catabolism; these deleterious substances presumably are formed at lower temperatures but at a much slower rate; they diffuse out into the surrounding medium, especially at higher temperatures, possibly on account of alterations in the permeability of the protoplasm at these higher temperatures. $f$ In higher plants, the outward diffusion of these harmful bodies, provided they be formed, must be slower on account of the more massive nature of the structures, or they are oxidized within the tissues themselves.

As Balls points out, since the conditions in which this decomposition takes place must be fairly uniform in a higher plant, growth optima are shown which are the expressions of the internal struggle between the increasing rapidity of chemical change with the rise in temperature and the inhibitory action of the accumulating products of catabolism.

Brown $\ddagger$ in his study of the growth of various fungi, as indicated by the increase in the diameter of the colonies growing in the culture media and by the estimation of the amount of rotted portions of fruits artificially infected, paid particular attention to the relation between temperature and carbon dioxide concentration, which factors are of great economic significance in the storage of fruit. His main conclusion is that the relative retarding effect of a given concentration of carbon dioxide on the growth of fungi is greater at a low than at a high temperature, which can only partly be explained by the fact that this gas is more soluble in water at a low than

* Balls : "Ann. Bot.," I $908,22,557$.

† See Eckerson: "Bot. Gaz.," I914, 58, 254.

$\ddagger$ Brown : “Ann. Bot.," I922, 36, 257. 
at a higher temperature. The following figures, illustrating the phenomenon in a culture of Botrytis, are relative to the growth in air which is taken as IOO:-

$\begin{array}{rrcc} & \text { Air. } & \text { Io per Cent. } \mathrm{CO}_{2} . & \text { 20 per Cent. } \mathrm{CO}_{2} . \\ \mathrm{I} 5^{\circ} \mathrm{C} . & \text { I } 00 & 59 & 30 \\ 3^{\circ} \mathrm{C} . & \text { 1 } & 2 \mathrm{I} & 0\end{array}$

It is hardly necessary to remark that temperature and concentration of carbon dioxide are but two of the several factors which influence the growth of these plants; in addition, those of nutrition, moisture and illumination are of importance.*

To return to the higher plants, the investigations of Leitch $\dagger$ on the influence of temperature on the rate of growth of the roots of Pisum sativum, show that the relationship can be expressed as a uniform curve for the range of temperature $-2^{\circ} \mathrm{C}$. to $29^{\circ} \mathrm{C}$. and resembles those of Kuijper for respiration. Above $29^{\circ} \mathrm{C}$. there is so much fluctuation that relationship cannot be expressed in a single curve, wherefore for each higher temperature a different curve must be made to express the rate of growth in successive periods of time. This is owing to the operation of one or more of those imperfectly known factors termed by F. F. Blackman the time factor. For instance, at $30^{\circ}$ and $35^{\circ} \mathrm{C}$. the rate of growth in the first ten minutes is the highest attained, in the first half hour there is a rapid fall followed by a recovery marked by a rise to a second maximum, after which there is a gradual fall. At $40^{\circ} \mathrm{C}$. the decrease in growth rate is uniform and rapid, there being no recovery. $\ddagger$ As in the cress, observed by Talma, so in the pea ; the coefficient for a rise in the temperature of ten degrees shows a distinct falling off as the temperature rises, and, according to the observations of Leitch, it is only between $10^{\circ}$ and $22^{\circ}$ that the coefficient value lies between 2 and 3 , for which reason the complete curve is not regarded as a van't Hoff curve. The extremes of measurable growth was observed at $-2^{\circ}$ and $44.5^{\circ} \mathrm{C}$, the highest rate being at $30.3^{\circ} \mathrm{C}$. With reference to these observations, Leitch distinguishes four

* See, for example, Robinson: "Ann. Bot.," I926, 40, 245.

$\dagger$ Leitch : id., I9I6, 30, 25.

¥ See also Sierp: "Ber. deut. bot. Ges.," I 9 I 8,35 , 3 ; "Bot. Zentrlbl.," I $920,40,433$. 
cardinal points: the minimum temperature, the maximun temperature, the optimum temperature and the maximum rate temperature. The minimum temperature for any physiological process is the lowest temperature at which the process takes place; the maximum temperature is the highest temperature at which the process takes place; the optimum temperature is the highest temperature at which there is no time factor operating; and the maximum rate temperature is that temperature at which the process attains its highest intensity.

The fluctuations observed at higher temperatures may be due to several factors; in such conditions some biochemical reactions may be intensified but not necessarily at the same rate; and some may be inhibited in varying degrees. The operations of enzymes, for example, are not affected in precisely the same way by the same high degree of temperature. Such a contingency may interfere with the supply of soluble food, and, concurrently, the rapid accumulation of the products of respiratory processes, which also are accelerated by an increased temperature, may have a toxic action. In a few words, up to a certain degree a rise in temperature accelerates physiological actions and here a van't Hoff curve may be expected: beyond this degree, co-ordination becomes less and less, owing to metabolic derangement. Priestley and Pearsall, ${ }^{*}$ in their examination of Leitch's results, point out that the growth rate of radicles is dependent on the chemical reactions involved in the merismatic activity of the growing point and on the hydrolysis of the reserve food in the seed and the translocation of the products to the growing parts. The situation therefore is this: the increase in temperature accelerates both growth and hydrolysis, but the merismatic tissue quickly uses up the food immediately available, wherefore a decrease in the rate of growth must ensue for that period of time taken by the food materials in their translocation from the seed to the apical regions of the root. The arrival of this food accounts for the second maximum in Leitch's curves. Finally, 
the growth rate is diminished by the dislocation of the metabolic processes. If this contention be correct, a close correlation between the length of the root and the time of the incidence of the second maximum should obtain.

In further illustration of the interaction of temperature with other factors, the work of Bushnell, Tottingham and Gregory may be referred to. Bushnell * examined the growth of the potato in controlled conditions at temperatures varying between $20^{\circ}$ to $29^{\circ} \mathrm{C}$. Both the leaves and the tubers decreased in size with increasing temperature, no tubers being formed at $29^{\circ} \mathrm{C}$. Respiration in the sub-aerial parts also increased with rising tempcrature, which means a greater consumption of carbohydrate and thus a reduction in the amount of material available for translocation which roughly corresponded to the reduction in tuber growth in the expcrimental conditions employed; for although the carbon dioxide of respiration during the day is immediately available for resynthesis, that emitted during the night is not. It thus appears that the excessive respiration at higher temperatures is an important factor, if not the limiting factor, in the growth of the potato.

Tottingham $\dagger$ studied the effect of temperature and light on the growth of the wheat plant. When the light intensity is low a lower temperature is favourable to the production of dry matter, and in these conditions the tissues show a higher percentage and yield of protein. When the light intensity is high and the temperature low, young plants contain more sucrose and protein and mature plants contain more carbohydrate and give a higher yield of grain : at higher temperatures the percentage of protein is increased, although the total amount may be less owing to the increased loss of carbohydrate duc to the more intense respiration.

Gregory, $\ddagger$ in continuance of lis study of the energy relations of plants, has investigated the effect of temperature on the increase in the area of the leaf surface of Cucumis sativus.

* Bushnell : “ Univ. Minn. Agric. Exp. Sta.," Technical Bull. 34, 1925.

† Tottingham: "Plant Physiol.," I926, I, 307.

† Gregory: "Ann. Bot.," J 928, 42, 469. 
He finds that at sub-optimal temperatures, $17 \cdot 3^{\circ}$ to $2 \mathrm{I} \cdot 6^{\circ} \mathrm{C}$, the relative growth rate of the leaf is controlled by light intensity not by temperature. At this sub-optimal range, temperature affects leaf growth by its action on the rate of development in the apical bud, thus controlling the rate of unfolding of the first foliage leaf. In other words, the delay in the development of the first foliage leaf is determined by the temperature coefficient of developmental processes; with higher temperatures the development of the first foliage leaf is progressively delayed owing to the derangement of developmental processes leading to a fall in the temperature coefficient. This is illustrated by the following figures:-

$$
\begin{aligned}
& \text { At sub-optimal temperatures }\left(\mathrm { I } 7 \cdot 3 ^ { \circ } \text { to } 2 1 \cdot 6 ^ { \circ } \mathrm { C } \text { ) } \quad \text { . } \left\{\begin{array}{l}
Q_{10}=2 \cdot 8 \\
O_{10}=2 \cdot 4
\end{array}\right.\right. \\
& \text { At supra-optimal temperatures }\left(2 9 ^ { \circ } \mathrm { I } ^ { \circ } \text { to } 3 2 \cdot 4 ^ { \circ } \mathrm { C } \text { .) . } \left\{\begin{array}{l}
Q_{1 \mathrm{C}}=\mathrm{I} \cdot 0 \\
\mathrm{O}_{10}=0.5
\end{array}\right.\right.
\end{aligned}
$$

This retardation in the apical development at supra-normal temperatures is partly responsible for the reduction in the relative growth rate of the leaf, which also is retarded by a redistribution of material, more growth being made by the stem. These higher temperatures thus introduce a time-factor. At all temperatures, with the light intensity used, a fall in the relative growth rate of the leaf occurs. A second timefactor is thus operating due to the low light intensity, for it disappears on increasing the amount of light. There would thus seem to be a minimum light intensity below which normal growth cannot proceed, and unless this degree of light intensity be maintained, a time-factor appears which continually reduces the relative rate of growtl of the leaf surface. This detrimental effect is not due to a derangement of the correlation between stem and leaf growth, nor does it appear to be due to incipient starvation following the low rate of carbon assimilation. The detrimental effect of a low light intensity possibly indicates an effect on the root system, for, in the barley, there is a close relation between leaf growth and root growth which, possibly, is reciprocal, the leaf supplying carbohydrates, which are of great importance in deternining root growth, and the roots supplying the nitrogen requisite for the growth and

VOL. II. - I 3 
expansion of the leaf. If a shortage of carbohydrate leads to a fall in the growth rate of the root, a fall in the relative growth rate of the leaf would follow owing to an increasing disproportion of available nitrogen.

From his own observations, coupled with those of Priestley* and others, Gregory favours the conception of a growth stimulating photochemical reaction, independent of carbon assinilation, acting on a nitrogenous substrate.

\section{LIGHT.}

The influence of light on growth is a subject of considerable magnitude, especially when the term growth is used in its general sense: the directive action of light in tropistic and kindred phenomena, its influence in the determination of growth form and the facjes of a flora are aspects of the subject outside the scope of the present consideration.

The action of light on growth is both direct and indirect, and its action is most marked in those members which use light as a source of energy. Thus for the ordinary green plant, increase without light is an impossibility since light is the source of energy for the making of food; in non-green members of plants, in total parasites, and saprophytes, on the other hand, light, for obvious reasons, is not a factor of consequence. It is a laboratory commonplace to find that for the subjects generally used for experimental purposes, light influences growth, as indicated by its external expression of increase in length and area, in various ways. Thus internodes in darkness attain a much greater length than in light; leaves may develop hardly at all in darkness, as in the pea, whilst in other plants, the wheat for example, the leaves attain a size more or less equal to those grown in light. This difference in behaviour is possibly due to the amount of carbohydrate, relatively large in the wheat and relatively small in the pea, available for structural purposes. $\dagger$ To take a specific instance,

* Priestley: "New Phyt.," I925, 24, 27 I.

† The work of Priestley ("New Phyt.," 1925, 24, 27I) indicates that very special precautions must be taken to exclude light and thus to see the true etiolated condition. As will be seen later, a very small exposure to light may have a morphological effect. 
Popp * grew soy beans in light of intensities varying from 4285 to 26 foot candles; measurements of stem lengths showed that the lower the light intensity the faster was the rate of elongation of the internodes during the initial period of growtl. The greatest general height was attained by plants grown in a light intensity of about 560 f.c. and the lowest in an average illumination of 26 f.c. The thickness of the stem was directly proportional to the light intensity, being greatest in an illumination of 4285 f.c. and least in an illumination of 26 f.c.

In general terms the plants grown in the strongest light were the most vigorous, showing the best vegetative development and producing the best fruit. A decrease in vigour occurred with decreasing light, and plants grown in light of 26 f.c. were completely etiolated and died in the course of a month. In all illuminations except the lowest, the length growth curves followed the general course of a monomolecular autocatalytic reaction; the first phase, associated with the beginning and development of independence of the seedling, is effected by the photosynthetic ascendancy, whilst the falling off in the last phase is associated with the reproductive processes. In passing, attention may be recalled to the fact that the humidity of the atmosphere is an important factor in the configuration of a plant, wherefore in experiments on living plants in closed chambers, allowance must be made for the humidity conditions.

It is commonly accepted that of the different qualities of light, growth is promoted by the blue and violet rays, whilst those less refrangible retard. Here again care must be taken to ensure a just comparison : to judge the effect of, say, blue light and red light, the intensities of cach must be the same or, at any rate, known; further, in such an experiment due allowance for the different heating effects of light of different wave-lengths must be made, and in some cases, if not in all, the internal temperature must be observed rather than the temperature of the surrounding medium.

The problem presents three aspects: intensity, duration

$$
\text { * Popp : “Bot. Gaz.," 1926, 82, I } 54 .
$$


and quality. Sierp * found that the general effect of an increase in light intensity is to accelerate the rate of growth of the coleoptile of Avena sativa and to shorten the time within which the maxinum rate occurs and that the incidence of this maximum is earlier as the light intensity increases. The net result is that the total growth is reduced as the intensity of light increases.

Of the effect of duration of light on plant growth, Garner and others $\dagger$ conclude from their observations on the tobacco, soy and other plants that the amount of vegetative growth is proportional to the duration of exposure to daylight, short exposures resulting in small slender plants exhibiting a slower rate of growth. They also find that the duration of light is an important factor in instituting the reproductive phase; by modifying the periods of exposure, biennials may be made to complete their life histories in a few months, and, on the other hand, annuals may be converted into biennials. To take a few examples. The soy bean illuminated for twelve hours daily blossomed in I IO days, but with a five-hour illumination daily, the flowering began in 27 days; a variety of tobacco plant subjected to the same periods of daily illumination flowered after the lapse of I 52 to I 62 days and 55 to 6I days respectively. Thus it is seen that shortened periods of daily lighting results in earlier flowering in these plants. But this is not necessarily so for all plants: Lespedeza, a leguminous plant useful as fodder, does not thrive with shortened periods of light; red clover, many grasses and the radislı when given shortened days show a retardation in flowering, and the groundsel, foxglove and tomato are more or less indifferent to either long or to short days. +

Results contrary to some of these are recorded; thus Adams $\S$ found that mustard, soy, flax, tomato, sunflower

* Sierp : "Ber. deut. bot. Ges.," I9I $8,35,8$; “ Bot. Zentrlbl.," I920, 40, 433 .

† Garner and Allard : " Journ. Agric. Res.," I 920, 18, 553 ; " Science," I 927,66, I 40. Garner, Bacon and Allard: "Journ. Agric. Res.," I924, 27, 119.

\# Adams: "Amer. Journ. Bot.," I924, II, 229. Tincker: "Ann. Bot.," I925, 39, 721 ; 1928, 42, 101 .

§ Adlams: "Ann. Rot.," I923, 37, 75; I924, 38, 509. 
and other plants showed a greater average weight, a greater average lieight, and earlier flowering when exposed to long periods of illumination. In fact, the phenomenon of photoperiodism * is bound up with and is influenced by other factors, especially nutrition, the carbohydrate/protein ratio, temperature and humidity. $\dagger$

The photoperiodicity of plants taken in conjunction with temperature and humidity is clearly of importance in relation to the geographical distribution of plants, and a knowledge of these factors is of economic significance in that it will indicatc the varieties of crop plants suited for cultivation in different latitudes.

The results obtained by Blaauw $\ddagger$ and of Vogt $\S$ from their studies on the growth of the sporangiophore of Phycomyces and on the coleoptile of Avena respectively are important. According to Blaauw, the effect of light on growth is an acceleration followed by a retardation to a rate lesser than the normal, followed by a gradual increase to the normal rate. The time of incidence of the initial accelcration varies with the intensity of the illumination; thus on exposure to a light intensity of one unit, the acceleration begins in about eight minutes, but in an intensity of fifteen units, the acceleration begins in about three and a half minutes. The amount and duration of the reactions vary with the degree of illumination: for the lower light intensities the total acceleration of growth exceeds the total retardation; and for the higher light intensities the total retardation exceeds the total acceleration. For the former, Blaauw finds that the increased growth is proportional to the cube root of the amount of light. These results are extended by Vogt, who not only

* In passing, it may be mentioned that this duration of illumination is reflected in the reaction of the plant juices, thus a short-day plant in response to lengthened periods of illumination, which produce excessive vegetative growth, shows an increase in acidity; on the other hand, a short-day plant induced to early flowering by shortened times of illumination has an acidity much below that of the vegetative plant; the same applies to long-day plants.

† See Gilbert: "Ann. Bot.," I926, 40, 315.

\Blaauw: "Zeitsch. Bot.," I9I4, 6, 64I.

§ Vogt: id., I915, 7, 193. 
finds the same acceleration and retardation in the growth of the colcoptile of Avena sativa, but also a considerable initial decrease in growth rate on temporary exposure to a sufficiently strong illumination. There is first a rapid decrease, immediately followed by an acceleration, which is in turn followed, especially in increased or more protracted illumination, by a second inhibition phase which exceeds the previous acceleration; hence the total effect may be a considerable fall in the rate and in the amount of growth. For a given reduction in growth, the product of the light intensity and its duration is a constant. Gregory* also found that in comparable conditions the average leaf area of the cucumber is determined by the product of the intensity and the duration of the light radiation.

The initial decrease in the growth rate is considered by Vogt to be due to the action of light alone, not to the combined effect of alternating light and darkness nor to increased transpiration.

The following observations of Vogt illustrate the phototonic reaction: when the coleoptile of the oat was alternately illuminated by light of the same intensity, and darkened for periods of fifteen, thirty, and sixty minutes, lesser growth was found only in the two latter periods of illumination. In these instances the greater growth in darkness is considered to be due to the stimulation of the previous exposures to light. The slower growth in periods of illumination is merely a part of the complete reaction, an acceleration being followed by a depression.

Mention has been made of the morphological appearance of seedlings, such as the pea, when grown in the dark. The work of Trumpf $\uparrow$ and Priestley $\ddagger$ shows that if such etiolated plants are exposed to light for a short period daily, $\S$ normal

* Gregory : “Ann. Bot.," I $914,35,97$.

† Trumpf: "Bot. Archiv.," 1924, 5, 38 r, 4 ro.

+ Priestley: "New Phyt.," I925, 24, 271: 1926, 25, 213 . See also Priestley and Ewing : id., 1923, 22, 30 .

$\S$ The period varies according to the sensitivity of the plant to light; with the pea and broad bean Priestley found a response after a period of two minutes exposure. 
leaves will be developed, although the period of exposure is much too short for the development of chlorophyll, and the internodes will become shorter. The quantity of light required is very small and the change effected is independent of the products of photosynthesis. Further, if the plant be exposed to light after growth has been stopped by low tem. perature or by the action of anæsthetics, the morphological change still takes place when growth is resumed, which indicates that the action is not exerted on the "living metabolic machinery." Priestley considers that the response is due to a photocatalytic action on some metabolic product, a view which is supported by Gregory.*

This work introduces questions relating to the irritability of the plant in response to the action of light, on which there is a voluminous literature, a problem which is outside our present survey. $\dagger$

From these investigations it is clear that the reaction of the plant to light is very complex; that the total effect observed is the balance of the measures of the accelerating and depres. sing influences of light; that the magnitude of the effect depends upon the intensity and the duration of light; and the possibility of a photocatalytic reaction.

The above observations relate to ordinary white light; the quality of radiation affects the growth of plants according to the wave-length and to the physiological peculiarity of the species.

Schanz, + in continuance of his earlier work, $§$ grew Begonia, Cucumis, Lobelia, Petunia, and other plants in frames arranged in a series of eight; by means of glass of different opacities, all but the first, which was uncovered, were illuminated by light from which certain rays had been abstracted :-

I. Unaltered daylight.

2. Rays longer than $320 \mu \mu$.

3. Rays longer than $380 \mu \mu$.

4. Rays longer than $420 \mu \mu$.
5. Rays longer than $560 \mu \mu$.

6. Yellow light.

7. Green light.

8. Blue-violet light.

* Gregory : “Ann. Bot.," I928, 42, 469 . cited.

$\dagger$ See Priestley: "New Phyt.," I926, 25, 227, and the literature there $\S I d$. I91 $8,36,6$ I9. 
The plants mentioned showed a regular increase in length from I to 5 inclusive and a decrease from 6 to 8 inclusive. The behaviour of all plants, however, was not the same; the beetroot and the potato developed better in the blue-violet than in the green, and better in the green than in the yellow. In general terms, the more the short rays, especially the ultraviolet, were removed, the greater the growth up to a certain limit. It also was observed that earlier flowering was promoted by culture under 3 and 4 of the series.

Similarly Popp * grew plants in precisely the same conditions except the quality of the illumination. In light from which all rays shorter than $529 \mu \mu$ had been abstracted, the plants, as compared with those grown in normal conditions, showed thinner stems, fewer branches, curled leaves, but with a good development of chlorophyll, a reduction in the amount of anthocyan, less differentiation in the tissue of the leaf and stem, less compact and thinner walled cells, and a reduction in mechanical tissue. There was also a delay in flowering; the flowers were fewer, the fruit weak and the seed poor. There was also a decrease in the fresh and dry weight, a deficiency in total carbohydrate and an increase in total nitrogen. It would, therefore, appear that the blue-violet part of the spectrum is requisite for normal development but not the ultra-violet, for when these rays were excluded the plant growth was normal.

In addition to the above-mentioned observations, the effect of ultra-violet radiation on the growth of the plant has been the subject of many investigations. In general, the effect of these rays is to promote a dwarf habit which is accompanied by various structural changes. Since plants flourish in the absence of ultra-violet light, the natter is a subject of special rather than of general interest, for which reason it is not necessary to pursue it further on the present occasion. $†$

Of encrgy other than light, field experiments with wheat

* Popp : “Amer. Journ. Bot.," 1926, 13, 706.

$\dagger$ See Delf, Ritson and Westbrook: "Brit. Journ. Exp. Biol.," 1927, 5, 138 , and the literature there quoted. Also Nadson and Philippov: "Compt. rend. Soc. Biol.," I928, 78, 366. 
and other crops show the beneficial action of overhead electric discharge. ${ }^{*}$ In the year 1915 the increase in grain and in straw was 30 and 50 per cent. respectively greater than the control, and in I9I 6 the corresponding figures were 49 and 88 per cent. The effect of the discharge also showed itself in the year subsequent to its application; thus in the clover and grass crop there was a marked increase in 1916, the year following the treatment. Continued observation confirms this earlier work: of eighteen field experiments $\uparrow$ with various crops, fourteen gave increased yiclds; of these three only gave increases of less than Io per cent. and the rest gave increases of over 30 per cent., sometimes of over 50 per cent. Four experimental plots showed a decreased yield of less than Io per cent., compared with the controls.

Like results were obtained with pot cultures, $\ddagger$ thus the percentage increase in the dry weight of maize grown under glass was $27 \pm 5 \cdot 8$, whilst barley under the same conditions gave a percentage increase of $18 \pm 2 \cdot 4$.

The effect of these minute electric currents is not always the same; in one experiment with barley the increase in the yield of grain was greater than the increase in the total dry weight. This was due not to an increase in the number of ears but to an increase in the percentage of fertile flowers per ear.ई The effect of electro-culture is stimulative, for the energy supplied is out of all proportion to the energy value of the additional plant material produced; to take one example, the additional energy supplied by the electric discharge to a culture of maize at most was I 5 calories; the calorific value of the extra material produced, calculated on dry weight, was of the order of 9000 calories. The results obtained from field experiments, pot cultures and laboratory experiment, $\|$ leave no doubt about the beneficial action of electric discharge; but the reasons for this are still unknown.

* Blackman and Jörgensen : "Journ. Board Agric.," I916, 23, 671 ; I 9 I $7,24,45$.

† Blackman : “Journ. Agric. Sci.," 1924, 14, 240.

¥ Blackman and Legg: id., 1924, 14, 268.

$\S$ Private communication from the authors.

|| Blackman, Legg and Gregory: "Proc. Roy. Soc.," B, 1923, 95,

214. Gregory and Batten: id., 1926, 99, 122. 
A number of observations on the effect of $\mathrm{X}$-rays on the growth of plants liave been made, ${ }^{*}$ but since these radiations do not appear to be a normal factor in the plant's habitat, unless potassium is beneficial in its mild radio-activity, $\dagger$ further mention is unnecessary in this reconnaisance.

\section{WATER.}

Common experience shows that growth is only possible provided that the living cells are in a turgid condition, wherefore circumstances which promote this condition will promote vegetative growth, but not necessarily reproduction. The circumstances to which allusion is made are humidity, adequate soil water, absorption of water and transpiration. A humid atmosphere promotes vegetative growth in that it reduces transpiration; adequate soil water is necessary if transpiration be high; the absorption of water and its conveyance to the transpiring surfaces is in part a question of osmosis and this is bound up with permeability. In illustration some observations by Pearsall and Hanby $\ddagger$ may be mentioned. They found that increased growtl took place when the shoots of a variety of plants were grown in a culture solution under increased pressure, 15 to $25 \mathrm{~cm}$. of mercury; contrariwise, small negative pressures are sufficient to reduce or even stop growth. The available evidence indicates that the positive pressure, which obviously leads to a greater turgidity, promotes the rate of cell division and the formation of a larger number of veins. Incidentally it may be mentioned, for causal morphology does not form part of the present consideration, that after treatment with negative or reduced pressures, palmate leaves become smaller, more dissected, and have reduced basal lobes when compared with similar leaves after treatment with a positive pressure.

Although biophysical problems are outside the present province, it may be remarked that any factors which inter-

* See Johnson: "Bot. Gaz.," I926, 82, 373; "Amer. Journ. Bot.," I928, 15, 65. Van Heijningen, Blaauw and Hartsema: "Kon. Akad. Wetens. Amsterdam," I 928, 26, I.

+ See Blackman: “Ann. Bot.," I920, 34, 299.

† Pearsall and Hanby: $i d ., 1926,40,8_{5}$. 
rupt the normal osmotic adjustments of a plant must adversely affect its vegetative growth. Thus Dufrénoy has pointed out * that growth is a function of at least six factors and a variation in any one of these will influence the velocity of growth. He considers that growth rate depends upon the balance betwecn the sum of imbibition, the osmotic pressure of colloids and of the salts of the cell sap, and the sum of the tension of membranes, the osmotic pressure of the salts of the surrounding medium and the mechanical resistance of the medium.

It is obvious that water content and sap concentration are interlocked factors. Reed $\dagger$ investigated the growth of shoots of the apricot, orange and walnut throughout the growing season and at the same time followed the concentration of the expressed sap. In general terms, he found that rapid growth was associated with a low concentration of sap, higher concentrations are associated with the formation of fruit buds as well as with slow vegetative growth. In fact it is a matter of almost common observation that the vegetative and reproductive phases of a plant are antagonistic, for which reason conditions which promote the one will degrade the other $f$

\section{NUTRITION.}

The importance of food is so obvious a factor governing growth that its consideration would appear to be unnecessary: but the significance of certain raw materials, more especially inorganic substances, is so marked as to warrant some mention.

The importance of various salts, especially phosphate and nitrate in combination with such essential bases as potassium, calcium and magnesium, on the growth of plants is a commonplace of the physiological laboratory and is easily demonstrated by the use of sand and water cultures in controlled conditions. By using different combinations of salts in such experiments, the effect of single nutricnt ions on plant yicld can be asccrtained, a subject of some complexity. $\$$

* Dufrénoy: “Rev. gén. Sci.," r918, 29, 323.

$\dagger$ Reed: "Journ. Agric. Res.," 1921, 21, 8 I.

+ See Klebs: “ Flora," I 9 I 8, I 1, I 2 S.
\$ See Johnston: "Univ. Maryland Agric. Exp. Sta.," I924. Gregory:

"Proc. Roy. Soc.," B, I928, 102, 3iा. 
In addition to the normal ingredients of the usual culture solutions, traces of other substances may be requisite for the normal development of many plants. The amount of these substances necessary for the exercise of their beneficent action is so small, that the chemicals used in culture experiments must be of the highest order of purity before the effect of their absence can be ascertained.

The work of Brenchley, Thornton and Warington* has shown the importance of boron for the well-being of many plants: for Glycine hispida, Phaseolus multiflorus, Trifolium spp. and Cucumis melo, boron is a necessity; without it the shoot apex dies, the root system is ill developed and flowers are not formed. In other plants, Iberis umbellata, Pisum, and various cereals, boron has a beneficial effect but is not requisite for healthy growth.

The effect of the absence of boron on the structure of the stem and root of Vicia faba † may be summarized : the apical meristems die, the cells of the cambium hypertrophy and degenerate, or disintegration takes place without previous enlargement; the phloem and ground parenchyma frequently disintegrate; the xylem is poorly developed and, in extreme cases, breaks down.

The quantity of boron required for normal development is very small, I part of boric acid in 2,500,000 of water was found enough for the normal growth of the broad bean; but the concentration of the boric acid does not much matter, provided that an adequate total amount is supplied over a given period; this quantity, lowever, must not be excessive. The physiological rôle of boron is not yet decided; it is not able to replace any one of the essential elements of nutrition, but it would appear to be associated in some way with calcium. From the facts that a constant supply of boron is necessary and that in the plant it bccomes fixed, it is concluded that its action is not that of an ordinary catalyst.

* Brenchley and Thornton: "Proc. Roy. Soc.," B, 1925, 98, 373. Brenchley and Warington: "Ann. Bot.," 1927, 41, 167. Warington: id., 1923, 37, 629: 1926, 40, 27.

† Warington: "Ann. Bot.," 1926, 40, 27. 
Similarly Johnston and Dore * found that for tomato plants grown in water culture, normal growth is impossible if boron, in the form of boric acid, is absent. In boronstarved plants there is twice as much sugar in the leaves as compared with plants grown in a boron-containing medium, the breakdown in translocation being due presumably to the disintegration of the conducting tissues.

McHargue $†$ found comparable effects in Glycine hispida, the soy bean, when manganese was withheld from the culture medium. But Brenchley and Warington found that manganese was entirely without effect on this plant when deprived of boron; it, however, had a stimulating action on those plants supplied with boron. There may be some interrelation between boron and manganese such as occurs between other nutrient elements. $\ddagger$

Sommer and Lipman $\S$ find that boron is essential for the growth of the Windsor bean, buckwheat, flax, mustard and other plants, and zinc is indispensable for the dwarf sunflower and barley.

In view of the observation $\|$ that the administration of pure borax has harmful effects varying with the plant, the potato for example being more resistant than maize and bean, it would appear that the form in which the boron is administered may be of importance.

Mention has above been made of manganese; this metal has a wide occurrence in the plant and is possibly of universal distribution; it accumulates in those parts where metabolism is most active and in those regions which are known to be rich in vitamins such as the pericarp of cereal fruits.** It may possibly play the part of a catalyst, an idea which is supported by its association with certain oxidases. $\uparrow \dagger$ The

* Johnston and Dore: "Science," 1928, 67, 324.

† McHargue : " Journ. Agric. Res.," I 923, 37, 629.

‡ See, for example, Brenchley, Maskell and Warington: "Ann. Appl. Biol.,"' 1927, 14, 45.

§ Sommer and Lipman: "Plant Physiol.," I926, 1, 23 I.

|| Skinner, Brown and Reed: " U.S. Dept. Agric.," Bull. I I26, I923.

- Bertrand and Rosenblatt: "Compt. rend.," I921, 173, 333 ; "Ann. Inst. Pasteur," I 92 I, 35, 8I 5.

** McHargue: "Journ. Agric. Res.," I924, 27, 4I 7.

t† See Vol. I., p. 502 . 
amount of manganese required for good growth is extremely small ; an artificial manure containing but 25.5 parts of manganese sulphate per million added to the soil being sufficient to produce normal vegetative growth and fruit in the tomato.*

Similarly minute traces of calcium are important in the development of seedlings. $\dagger$

The above observations relate in the main to sand and water cultures grown in laboratory conditions; the following table, results obtained at Rothamsted, generally illustrates the action of various chemical fertilizers on field crops :-

WHEAT-(Average yield I 852-I9I2).

\begin{tabular}{|c|c|c|}
\hline & $\begin{array}{l}\text { Grain in } \\
\text { Bushels. }\end{array}$ & $\begin{array}{l}\text { Straw in } \\
\text { Cwts. }\end{array}$ \\
\hline Complete minerals . . . & $32 \cdot 1$ & $32 \cdot 9$ \\
\hline $\begin{array}{l}\text { Ammonium salts }+ \text { superphosphate } \\
\text { Ammonium salts }+ \text { superphosphate }+\end{array}$ & $22 \cdot 9$ & $22 \cdot 3$ \\
\hline sodium sulphate. & $29 \cdot I$ & $28 \cdot 0$ \\
\hline $\begin{array}{l}\text { Ammonium salts }+ \text { superphosphate }+ \text { po- } \\
\text { tassium sulphate } \cdot \cdot \cdot \cdot \\
\text { Ammonium salts }+ \text { superphosphate }+\end{array}$ & $31 \cdot 0$ & $31 \cdot 5$ \\
\hline magnesium sulphate . . & $28 \cdot 8$ & 28 \\
\hline
\end{tabular}

GRASS - (Cut for hay every year).

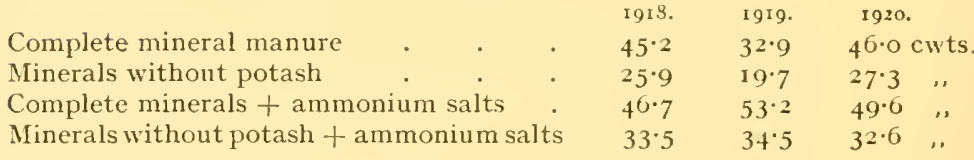

In this connection the relative abundance of colloids in the soil would appear to be of importance; thus Jennings $\S$ finds that colloids added to the culture medium promoted or depressed the growth of wheat seedlings according to the specific colloid employed and the concentration of the culture medium. Agar, for instance, in the presence of low concentrations of nutrient salts increases growth, but in high concentrations a depression obtains. Of inorganic colloids, ferric and aluminium hydroxides depress, whilst colloidal silica increases growth, doubtless because silica is much absorbed by the cereal grasses and possibly in this form. In vicw of the

\footnotetext{
* Schreiner and Dawson: "Journ. Ind. Eng. Clrem.," 1927, 19, 400.

+ Maquenne and Cerighelli : "Compt. rend.," 1922, 174, I 269.

$\ddagger$ For these we are indebted to Dr. W. Brenchley.

§ Jennings: " Soil Science," 1919, 7, 201.
} 
adsorptive properties of colloids, the depressing action of some examples may be due to their adsorbing mineral salts and thus rendering them unavailable for the use of the plant.

Further, in considering the action of inorganic compounds on growth, certain important aspects are to be remembered: the plant has a specific and a varictal physiology; a good crop of nettles indicates a high nitrogen content in the soil and varieties of barley differently respond to various types of manuring; * the inter-relationship of the various compounds concerned, carbohydrate and nitrogen for instance; and the fact that conditions which favour vegetative growth are not necessarily those for reproductive activity. An abundance of inorganic salts in the soil promotes vegetative activity, whilst a relatively small salt supply induces reproduction; but this only results provided that other conditions are satisfactory. Thus increase in growth is impossible for the green plant if carbon assimilation be of a low order of intensity, since carbohydrate is required for many purposes, structural, respirative, and as raw material for the elaboration of other compounds such as proteins. And for this last purpose nitrogen also is necessary; wherefore intense carbon assimilation in the absence of nitrogen-containing substances cannot lead to a growth commensurable with the intensity of carbohydrate formation. In fact, there is between nitrogen and carbohydrate a correlation, and growth is affected according to their ratio. Thus if carbon assimilation be increased by growing plants in an atmosphere enriched by the addition of carbon dioxide, whilst the nitrogen-containing salts of the soil are not increased, the ratio $\mathrm{C} / \mathrm{N}$ is high and the reproductive phase is induced; if, on the other hand, the ratio $\mathrm{C} / \mathrm{N}$ is low, the vegetative activity is intensified. $\dagger$ These results may, however, not occur if the ratio mentioned runs to extremes. Kraus and Kraybill $\ddagger$ in their experimental work on the tomato found that a very high $\mathrm{C} / \mathrm{N}$ ratio results in but little vegetative growth and but poor reproduction; a medium ratio gives

* Gregory and Crowther : "Ann. Bot.," 1928, 42, 757.

† Fischer: "Gartenflora," I916, 65, 232.

+ Kraus and Kraybill: "Oregon Agric. Exp. Sta.," I9I8, Bull. I 49. 
moderate vegetative growth and good reproduction; and when the $\mathrm{C} / \mathrm{N}$ ratio is very low, a vigorous vegetative growth and poor reproduction obtains. Thus the best results occur when these two factors are reasonably balanced.

This important work, which is well substantiated, stimulated investigation on this aspect of nutrition in relation to growth, and many papers have been published on this and cognate subjects. A summary of these will be found in the memoirs of Hicks and of Tincker. The former * is concerned with the carbon/nitrogen ratio in the wheat plant in which is traced the change in the ratio from the seedling to the grain. A large number of analyses show that the early stages of germination are characterized by a low $\mathrm{C} / \mathrm{N}$ ratio which steadily rises throughout the vegetative period; when sufficiently high, flowering occurs. Fruit development is characterized by a low $\mathrm{C} / \mathrm{N}$, the amount of nitrogen being high. Active meristematic tissues have a low ratio, which increases with age; and senescent tissues have a high $\mathrm{C} / \mathrm{N}$ ratio. For these reasons the conclusion is reached that the younger the tissue the lower is the $\mathrm{C} / \mathrm{N}$ ratio. From a consideration of the available evidence, Tincker $\dagger$ concludes that flower production is initiated by the metabolic balance in which the carbohydrate/ protein ratio lies within certain limits; the dislocation of this ratio, either by the excess or the deficiency of one component, retards flower production. Clearly the problem is involved with photo-periodicity, the period of illumination operating by altering the carbohydrate factor and, by its transpiration effect, the nitrogen content. Thus short-day plants subjected to a lessened period of illumination show a greater carbohydrate content, a lesser elongation of the axes, and the production of flowers; but when treated with long days, vegetative growth is promoted and reproduction is eliminated, presumably because the $\mathrm{C} / \mathrm{N}$ ratio is too low for flower production. For long-day plants, a lessened period of illumination increases the starch content and climinates flowering, possibly owing to the unsuitability of the available carbohydrate;

* Hicks : "New Phyt.," I 928, 27, I, Io8.

† Tincker : "Ann. Bot.," I925, 39, 721 . 
but in lengthened illumination some long-day plants, e.g. the radish, have more soluble earbohydrate in the shape of sugar and produce flowers.

From the present aspect the value of these observations lies in the fact that they provide another instance in the interaction of the various factors involved in growth: there is no virtue in increasing the one without duly considering the others; heavy manuring with nitrates, for instance, is mere waste if there be not adequate supplies of water, and adequate and proportionate supplies of both will not promote fruit formation in a greenhouse so dimly illuminated as to depress carbon assimilation.

\section{AUXIMONES.}

Bottomley* concluded from a large number of experiments that something more was requisite for the vigorous growth of a plant than is contained in the ordinary culture solution made up with mineral substances. These promoters of growth, the nature and composition of which are unknown, he termed auximones. Bottomley selected such plants as Lemna, Salvinia and Azolla which normally lead an aquatic existence and thus avoided the rather artificial condition inseparable from the cultivation of a terrestrial plant in an aqueous medium. For healthy growth he found that small amounts of organic matter are necessary: amongst the best results obtained were those in which an aqueous extract of bacterized peat had been added, but other organic substances, such as autoclaved Azotobacter and crude nucleic acid deriva. tives from raw peat, will also serve.

Bacterized peat is sterilized raw sphagnum peat decomposed by nitrogen fixing bacteria of the soil; such treated peat is considered to act either as a food substance or indirectly as an accessory food substance. The amount necessary for a positive result is so small that a body comparable to a vitamin is suggested. Thus Rosenheim $\dagger$ found that plants of Primula

* Bottomley : "Proc. Roy. Soc.," B, I917, 89, 481 ; "Ann. Bot.," I $920,34,345,353$. See also article in " The Exploitation of Plants," ed. by F. W. Oliver, London, 1917. Mockeridge : "Proc. Roy. Soc.," B, I917. 89,508 .

VOL. II.-I 4 
malacoides treated with an aqueous extract of $0 \cdot 18$ gram of bacterized peat grew taller than untreated plants. This aqueous extract contained $20 \mathrm{mg}$. of organic matter, of which only $\mathrm{I} \cdot 9 \mathrm{mg}$. represented nitrogen.

Bottomley's suggestion that nucleic acid derivatives are responsible for the auximonic action has been further examined by Mockeridge* who found that such bodies occur in many manurial composts and her cultural experiments indicated that the greater the decomposition of such manures, the more effective is a water extract of them in promoting growth. The conclusion is therefore reached that the free bases of nucleic acid are more effective than undecomposed nucleic acid. In a further investigation, $\uparrow$ it was found that the increase in the growth of Lemna minor was approximately proportional to the amount of nucleic acid derivatives added to the culture solution.

Azotobacter and Bacillus radicicola, nitrogen-fixing organisms, were the subjects in this investigation: it was found that sterilized cultures of Azotobacter increased the growth of Lemna, although the increase was not proportional to the amount of Azotobacter added. Autoclaved and autolyzed yeast similarly have growth-promoting powers, the autoclaved being more potent than the autolyzed. Yeast contains nucleic acid radicles and the bacteria mentioned also have the necessary radicles for the formation of nucleic acid.

Possibly auximones are connected with the synthesis of complex nitrogenous molecules, for their action on the nitrogen cycle organisms is to increase the rate of nitrogen fixation and nitrification and to depress the rate of denitrification. There is no doubt that the use of bacterized peat may give marked positive results in pot cultures, but to what extent the treatment is advantageous to field crops is doubtful. $\ddagger$

It must, however, be mentioned that evidence is not wanting to indicate that such auximones are not essential for plant growth, although they may have an accelerating action.\$

* Mockeridge : “ Biochem. Journ.," 1920, 14, 432.

† Mockeridge : “Ann. Bot.," I924, 38, 723.

† See Russell : “ Journ. Board Agric.," 1917, 24, I I.

§ See Clark: "Journ. Ind. Eng. Chem.," 1924, 16, 249; " Plant Physiol.," I926, I, 273. Saeger: "Journ. Gen. Physiol.," I925, 7, 517. 


\section{HORMONES.}

The study of regeneration, correlation, polarity and cognate subjects* leads to conclusions in some respects indefinite in that no tangible factor is discoverable that will account for the beginning or for the control of certain phenomena. A cambium cell divides; the daughter cell destined to become a permanent tissue element will develop into a phloem element if cut off on one side and into a xylem element if cut off on the opposite side; what is it that determines the fate of the cell? The leader of a spruce is negatively geotropic, the lateral branches are diageotropic; if the leader is removed, a lateral branch from the topmost whorl will change its habit, become negatively geotropic and carry on the functions of the leader. Why must the leader be removed before a change in tone of a plagiotropic shoot can be effected? The primordium of a lateral bud is laid down, and, apparently, all conditions are favourable for development, yet the bud remains dornant until the apex of the main shoot is removed, then the bud will immediately start its development. It is true that often the diversion of food will account for the subsequent phenomena, but in other instances such an explanation is inadequate and in such examples the question is: What is it that presses the trigger?

The subject properly is beyond the scope of an introduction to the physiology of metabolism of plants, but the introduction is desirable even though the acquaintance be not cultivated.

For long it has been known that very small quantities of various materials act as powerful stimulants; the extraordinary effect of minute traces of zinc on the growth of moulcis may be instanced. Animal physiologists recognize the effect of traces of substances in stimulating various activities, especially those associated with secretion. These substances are produced in one organ and stimulate another organ to which they are conveyed by the blood. Hence the

* See Bohn: "Compt. rend. Soc. biol.," I918, 81, 220. Farmer : " New Phyt.," I903, 2, I93, 21 7. Goebel: "Biol. Zentrlbl.," I9I6, 36, 193. Lang: "Brit. Ass. Rep.," I9I5, 701. Loeb: "Bot. Gaz.," I9I8, 65, 150; " Journ. Gen. Physiol.," I 919, 1, 337. 
idea of a chemical messenger, or, to use the current term, hormone.

Errera * was amongst the first of botanists to suggest that hormones play a part in the economy of the plant; his explanation of the changes in the spruce instanced above is that the apical shoot continually is secreting an inhibiting substance which is distributed to other parts of the plant, keeping them in their normal tone. The removal of the leader of the spruce removes the source of the inhibiting hormone, wherefore a near lateral shoot assumes the qualities and functions of the lost leader.

This idea was adopted by Loeb $\dagger$ who concluded from many observations on the development of buds and roots on the leaves of Bryophyllum calycinum that the apical bud secretes a hormone which inhibits the development of buds more basal in position. It is not until the apex is removed that the buds below will develop.

The degree of inhibition depends on the amount of hormone and the mass of the lateral bud; it is presumably for this reason that the inhibition may only extend to these primordia situated more immediately below the apex.

This account, brief though it be, will give some idea of the action of hormones; the hypothesis, in so far as it affects plants, however, is not universally accepted. Thus Fyson and Venkataraman $\ddagger$ can find no evidence in favour of the existence of sucl bodies, and Child and Bellamy § consider that inhibition is a question of the conduction of stimuli rather than the movement of tangible substances. Indeed, the evidence regarding the occurrence of hormones in plants is, perhaps, less conclusive than the proof of their existence in the animal; actually, hormones have never been demonstrated in the plant; their presence is inferred in order to explain

* Errera: "British Ass. Rep.," I904, 8I4. See also Armstrong: "Ann. Bot.," I9II, 25, 507.

† Loeb: "Bot. Gaz.," I91 5, 60, 249 ; 1916, 62, 293 ; " Science," 191 7, 46, 547. See also Reed and Halma: " Plant World," 1919, 22, 239.

¥Fyson and Venkataraman: "Journ. Indian Bot.," I920, 1, 337. 70, 249 .

§ Child and Bellamy: "Science," I919, 50, 362 ; "Bot. Gaz.," I920, 
certain very complicated physiological processes otherwise inexplicable.

Of recent years the study of the transmission of stimuli, in relation to correlation of growth and development, ${ }^{*}$ geotropism and heliotropism, by the movements of hormones, has resulted in the publication of a large number of observations a consideration of which is hardly possible without an account of the phenomena associated with irritability, a big subject outside the scope of a treatise on the metabolic processes of plants.

* See Haberlandt: "Sitz. Preuss. Akad. Wiss.," I921, 695, 861 ; “Beitr. Allegm. Bot.," I923, 2, I. Gilbert: "Bot. Gaz.," I926, 81, I. Reed: “Journ. Agric. Res.," I921, 21, 849. Snow : “Ann. Bot.," I923, 37, 43 ; I $924,38,163,84 \mathrm{I}$. Söding: "Jahrb. Wiss. Bot.," I $925,64,587$. Suebert: "Zeit. Bot.," I 925, 17, 49. Tschirch: "Vierteljahr. Natur. Ges. Zurich," I92I, 66, 201. Went: "Kon. Akad. Wetens. Amsterdam," I 926, 30, I. 



\section{INDEX.}

Abutilon Darwini, influence of water Aspergillus, respiration, I62.

on carbon assimilation, 15,16 .

Acer, development of photosynthetic power, 44.

- saccharinum, respiration, I5 $\mathrm{r}$.

Acetaldehyde in apple, 161 ; in seeds, i6r.

Acidity, effect on respiration, 134 .

Acrose, 6I.

Adaptation, complementary chromatic, 35 .

Aerobic respiration, 108.

Ajuga reptans, assimilation, I 70 ; respiration, $\mathrm{I} 7 \mathrm{O}$.

Alcohol production in apple, I6I; in seeds, $\mathrm{r} 6 \mathrm{r}$.

Alcoholic fermentation, 107, 153 , 155 .

Aldehydase, 90.

Aldehyde mutase, $14 \mathrm{I}$.

Algæ, assimilation of amides, 83 ; of formaldehyde, 59 .

Almond, fat formation, 72

Alpine plants, carbon assimilation, 29.

Amaranthus, respiration, ${ }_{5} 1$.

Amides, production, 94 .

Amino acids, oxidation, 137.

Anaerobic respiration, 108.

Anæsthetics, action on respiration, I 6 .

Andropogon halepensis, respiration, I 5 I.

Angiosperms, occurrence of nitrite, 88; reduction of nitrate, 90.

Anthocyanin and respiration, 113 , 134.

Antoxygen, 143.

Aponogeton, carbon assimilation, 32 .

Apple, alcohol and acetaldehyde in, 161 ; catalase activity, 152 ; respiration, I I 2, I6I, I63.

Aquatic plants, assimilation of formaldehyde, 59 ; carbon assimilation, 22, 32, 50 .

Arachis, formation of carbohydrates from fats, 74 ; germination, 72 .

Arctium, range in carbon assimilation, 50.

Asparagine, origin, 94.

Asparagus, respiration, 130.

A niger, action of anæsthetics on growth, IIS ; growth, I $7 \mathrm{I}$, I 88 ; nitrogen supply, 85 ; organic acids formed by, I04; respiration, 106, I 34.

Assimilation numbers, 43 .

Assimilatory quotient, 6 .

- ratio, 60,64 .

Atriplex, respiration, 136 .

Autocatalytic reaction, 175, I 78 .

Auximones, 209.

Avena sativa, growth, I96, I97, I98.

Azolla, growth, 209.

Azotobacter, growth, 210.

BACILLIARIALES, chromatic adaptation, 36.

Bacillus, respiration of Timothy grass, I 05 .

- botulinus, catalase, I 50.

- butylicus Fitzianus, fermentation. 79.

- coli, activity, I66; nitrogen supply, 84 ; oxidative activity, roo ; respiration, 165 .

- pyocyaneus, activity, I66; oxidative activity, 100.

-r radicicola, growth, 2 ro.

- subtilis, respiration, I $18,133$.

- tetanus, catalase, I50.

Bacteria, chromatic adaptation, 36 .

Bacterium aceti, oxidation, I 42.

Baeyer's theory of carbon assimilation, 56 .

Barley, electro-culture, 20I ; growth, 187 ; origin of protein, 96 ; respiration, II6, II 9.

Bean, respiration, $126,129,131,162$. Beet, diurnal range in carbon assimilation, 49 ; sugars of leaf, 53 ; zymase, I 53 .

Begonia, growth, 199.

Blackheart disease, 125.

Blackman reaction, 29.

Bomarea, carbon assimilation, 32 .

Boron and growth, 204.

Botrytis, growth, rgo.

Brassica, protein formation, 82 ; respiration, $\mathrm{I} 60$.

- alba, respiratory quotient, 103. 
Buckwheat, growth, I 72.

Butyric acid fermentation, I 54 .

CABBAGE, fat of, 70 .

Cactaceæ, respiration, 127 .

Calorific value, Ioo.

Cannabis, respiration, I68.

Carbohydrate, synthesis, 6 .

Carbon assimilation: Blackman reaction, 29; carbon dioxide, I6 ; chlorophyll, 42; efficiency index, 35 ; extreme temperatures, 29 ; external factors, I 4 ; diurnal range, 49; factors, $S$; formaldehyde, 59 ; illumination, 9, 30; influence of products, 49 ; influence of salts, 47 ; internal factors, 42 ; organic products, 50 ; origin of the oxygen, $58 ;$ rate, 7,8 ; raw materials, 14 ; structural factor, I2 ; temperature, 9; temperature coefficients, 27 ; time factor, 27; unknown factor, 45 ; water, I 4.

- dioxide, and carbon assimilation, IO, 16 .

- - diffusion, I7, I8.

- - effect of increase on assimilation, 24 .

- monoxide in carbon assimilation, 57 ; in respiration, 105.

- nitrogen ratio and growth, 207.

Carboxylase, I 52.

Carpinus betulus, heat of respiration, II 4 .

Catalase, I 49.

- and respiration, I50.

Catalpa bignonioides, absorption of carbon dioxide, I 7 .

Ceratophyllum, carbon assimilation, $22,50$.

Cicer arietinum, protein hydrolysis, 94.

Chlorella, carbon assimilation, 26, 28, 35,58 ; protein formation, 83 ; respiration, I33; temperature coefficient of carbon assimilation, 28.

Chloroform, effect on respiration, I I 7 .

Chlorogenic acid, $146,167$.

Chlorophyll and carbon assimilation, 42.

- peroxide, 58,65 .

Chlorophyllogen, 30 .

Chloroplasts and protein formation, 82.

Chromatic adaptation, 35 .

Cineraria stellata, carbon assimilation, 16.

Cladophora, carbon assimilation, 50.

Climate and growth, I 86.

Cocos, carbon assimilation, 24.

Colloids and growth, 206.
Combustion, 99.

Compensation point, 7 .

Complementary chromatic adaptation, 35 .

Compound interest law, 176 .

Corn, catalase of sweet, I 50.

Crassulaceæ, respiration, $\mathrm{IO}_{4}$.

Cucumis, growth, I74, I80, I99, I99, 204.

- sativa, carbon assimilation, 25; growth, I92.

Cucurbita, development of photosynthetic power, 44; growth, I 78, I79; protein formation, 82 ; respiration, 168 .

Cytochrome, I 46.

DARK phase of carbon assimilation, 32.

Dehydrase, 138.

Dehydrogenation, 138 .

Desiccation and sugar production, 54 .

Diameters, law of, 18.

Diffusion and evaporation, 2 I.

Drought and respiration, 132.

Echinocactus, respiration, 130.

Efficiency index of carbon assimilation, 35 .

Electrical energy and carbon assimilation, 40 .

Electro-culture, 20I.

Elm, assimilation number, 43.

Elodea, assimilation of formaldehyde, 59, 60; carbon assimilation, 22, 32 ; reduction of nitrate, 89 ; respiration, I33 ; temperature coefficient of carbon assimilation, 27. Endomyces vernalis, fat formation, 76 . Energy absorbed and energy utilized ratio, 35 .

- of fermentation, 107.

Enzyme of carbon assimilation, 46 . Enzymes of oxidation, I36.

Erythrina, nitrite in, 88 .

Ether, effect on respiration, i I 8.

Eucalyptus regnans, growth, I 86 .

Eurotium, assimilation of amides, 83.

Evaporation and diffusion, 21 .

FACTORs, interaction of, 13.

Fagus, traumatic reaction, I I 5 .

Fat-containing seeds, germination, 72.

Fat, conversion of carbohydrate into, 74; formation in Saccharomyces, 75 ; hydrolysis, 73 ; origin from carbohydrate, 71 ; origin from protein, 70 ; respiration of, 105 , I28, I68; synthesis, 69 ; translocation, 72 . 
Fatty acids, origin, 77 .

Feeding experiments with formaldehyde, 63 .

Fermentative processes, I06, I 52.

Flax, respiratory quotient, 103 .

Fontinalis, carbon assimilation, 10 , $22,23,32$.

Food and respiration, I $16,125$.

- calorific values, 69.

Formaldehyde and carbon assimilation, 59.

- hypothesis, 62.

- in leaves, 64 .

- photochemical production, 37 .

- polymerization to sugars, 60,63 .

- theory of carbon assimilation, 56 .

Formic acid hypothesis of carbon assimilation, 66.

Formose, 61.

Fraxinus, traumatic reaction, II 5.

Fungi, assimilation of amides, 83 ; growth, 188 ; nitrogen supply, 84 ; respiratory quotient, 106 .

Galanthus nivalis, sugars of leaf, $5 \mathrm{I}$; respiration, 129 .

Gentiana brevidens, sugars of leaf, 52.

Germination of fat-containing seeds, 72.

Glutathione, 146 .

Glycerol, origin, 75 .

Glycine hispida, growth, 204, 205.

Glycolysis, 163 .

Gossypium, growth, I79.

Grain, respiration of damp, I3I.

Grass, effect of fertilizers, 206.

Growth, 169; conditioning factors, I 87.

- and climate, I 86.

- - colloids, 206.

- - nuclei acid derivatives, 210.

- grand period of, I 74.

- in ultra-violet radiation, 200.

- influence of boron, 204.

- - - light, 194 .

- - manganese, 205.

- - nutrition, 203.

- - - temperature, 187.

- - - water, 202.

- - zinc, 205.

- inhibition by hormones, $2 \times 2$.

HEAT of combustion, xoo.

- - respiration, I I 4 .

Helianthus, absorption of carbon dioxide, 20; carbon assimilation, 32 ; development of photo-synthetic power, 44; growth, I79; protein formation, 183 ; respiration, I 16 , I 68 .

- annuus, rate of carbon assimilation, 8 ; respiration, IIII.
Helianthus tuberosus, carbon assimilation, 3 I ; effect of chloroform on respiration, 117 ; temperature coefficient of carbon assimilation, 27.

Hermidin, 146.

Heterohexose, 163.

Hevea brasilienses, growth, 186.

History of material, importance of, 26.

Hormones, 211.

Hydrocyanic acid and oxidation, I 38 .

- - protein synthesis, 98 .

- - - respiration, $143,144$.

Hydrogen, an essential fuel, 144.

- ion concentration and respiration, 134 .

Hydrolysis of fat, 73 ; of protein, 93.

Hypumm, respiration, 133.

Illumination and carbon assimilation, 9,30 .

Ionized air and carbon assimilation, 42.

- - - respiration, 119.

Iron, rôle in respiration, $\mathrm{I} 37$.

LACTACIDOGEN, 156.

Lactic acid fermentation, I 52.

Lactuca, protein formation, 82 .

Laminaria, effect of anæsthetics on respiration, II9; respiration, I33. I 64 .

Larmour's Law of Diameters, 18.

Law of Diameters, $x 8$.

Leaf, protein formation in, 81; temperature of, 30 .

Lemna, growth, 185, 209, 210.

Lepidium sativum, growth of radicle, 188.

Lespedeza, growth, 196.

Lichens, carbon assimilation, 29 ; respiration, 132 .

Light and respiration, I 35.

- - shade plants, carbon assimilation, IO.

- effect of quality of, on growtli, I 99.

- influence on growth, 194.

- range in wave-length used in carbon assimilation, 33 .

Lilac, carbon assimilation, 26.

Limiting factors, doctrine of, 8 ; interaction of, 9 .

Linum, respiration, $\mathbf{1} 68$.

Lipase, 75 .

Lobelia, growth, 199.

Lupin, asparagine in, 9.4 ; origin of protein, 96 ; respiration, 122, 128 ; zymase in, 153.

Lycopersicum, growtl, r8o. 
MA1ze, electro-culture, 20I ; growth, I 72 ; protein hydrolysis, 93 ; respiration, 13I. See Zea.

Manganese and growth, 205.

Mangold, sugars of leaf, $5 \mathrm{I}$.

Maquenne's hypothesis of carbon assimilation, 67 .

Mechanism of respiration, 159.

Mercurialis perennis, nitrate content, 87.

Methylenitan, 6r.

Milk, Schardinger reaction, I 40.

Moss, respiration, 132.

Mougeotia, carbon assimilation, 50.

Musa, sugars of leaf, 52 .

Muscle respiration, 166 .

Mushroom, respiration, 162.

Nasturtium, respiration, I 36.

- palustre, carbon assimilation, II.

Nereocystis Luctkeana, carbon monoxide formation, ro5.

Nitrate, occurrence in higher plants,

86; photochemical reduction, 92 ; reduction to nitrite, 89.

- reducing mechanism, I4I.

Nitrite, occurrence in higher plants, 87.

Nitrogen supply in protein synthesis, 84.

Nitrosomonas, respiration, 133, I34.

Nucleic acid derivatives and growth, 2 IO.

Nutrition, influence on growth, 203.

OAT, growth, I9S.

Olive, respiratory quotient, I03.

Onion, respiration, I64; traumatic reaction, II 5 .

Opuntia, assimilation, 29.

- tomentosa, assimilatory quotient, 6.

Organic acids and respiration, 104.

Oscillaria, chromatic adaptation, 36 .

Oxalis, carbon assimilation, II, I70; compensation point, 7 ; growth, I70 ; respiration, I36, I 70.

Oxidases, 148.

Oxidation, enzymes, 136 .

Oxygen and photosynthesis, 6 .

- origin in carbon assimilation, 58 .

PAONY, respiration, 130.

Parmelia physodes, respiration, I32.

Pea, growth, 190; heat of respiration, I14; origin of protein, 95 ; respiration, 122,164 .

Pear, growth, 179 .

Peat, bacterized, 209.

Pelargonium, respiration,

- zonale, carbon assimilation in ionized air, 42 ; nitrate in leaf, 82 ; respiration in ionized air, $\mathbf{I} 20$.
Penicillium, assimilation of amides,

83 ; respiration, 162.

- chrysogenum, respiration, I35.

Petunia, growth, 199.

Phæophyceæ, chromatic adaptation, 36.

Phæophytin, 65.

Phalaris arundinacea, carbon assimilation,

Phaseolus, carbon assimilation, 34, 47 ; decomposition products of proteins, 95 ; development of photosynthesis, $44 ;$ protein content of leaves, 81 ; protein formation, 82 .

- multiflorus, growth, $174,204$.

Phormidium foveolarum, carbon assimilation, 26 ; chromatic adaptation, 36 .

Phosphatidic acid, 70.

Photoelectric response, $4 \mathrm{I}$.

Photoperiodism, 196, 197, 208.

Photosynthesis, artificial, 37. See Carbon assimilation.

Phragmites, carbon assimilation, 50. Phycoerythrin, 36.

Phycomyces, growth, 197 ; respiration, I 26 ; respiratory quotient, Io6.

Physiological combustion, Ioo.

Picea, traumatic reaction, 115.

- excelsa, carbon assimilation, I2.

Pigment, respiratory, I 45.

Pineapple, catalase and oxidase, I 50.

Pinus sylvestris, carbon assimilation, I 2.

Pisum sativum, growth, I9o. See Pea.

Pleurococcus, assimilation of amides, 83.

Pneumococcus, catalase, I 50.

Pollination and respiration, I I 5.

Polygonum sacchalinense, radiant energy used by, 31 .

- Weyrichii, radiant energy absorbed, 31 .

Populus, assimilation number, 43 .

- canadensis, protein content of leaf, 81 .

Potamogeton, carbon assimilation, 22.

Potassium, action in protein formation, 86.

Potato, catalase, I50, I 52 ; growth, 192; nitrate reducing enzyme, 141 ; reduction of nitrate, 89 ; respiration, II 3, I $21,126,130$, I62, 192; sugars of leaf, 5I ; temperature effect on respiration, I2I ; traumatic reaction, II5 ; zymase, 153.

Prasiola crispa, respiration, 133.

Predetermination, $186,187$.

Primula, assimilation number, 43. 
Primula malacoides, growth, 209.

Protein and respiration, 127.

- fats formed from, 70 .

- formation and radiant energy, $\delta_{3}$.

- hydrolysis, 93.

- origin in seed, 95 .

- respiration, of, 167 .

- synthesis, 8I; nitrogen supply, 84.

- and hydrocyanic acid 98 .

Prumus, carbon assimilation, 32, 33 .

- laurocerasus, carbon assimilation, 9, 27, 29: respiration, $117,120$.

Pythiacystes atrophthora, growth, I 88.

Pyrus malus, reduction of nitrate, 89 .

RADIANT energy and carbon assimilation, 30 .

- - - protein formation, 83 .

Radio activity and carbon assimilation, $4 \mathrm{I}$.

Raphanus, respiration, 168 .

Raphidium, assimilation of amides, 83.

Reactive chlorophyll surface, 47 .

Reductase, 89.

Respiration, 99; action of anæsthetics, I 16 ; conditioning factors, I20; definition, roI ; effect of acidity, I34; effect of carbon dioxide, ro9; effect of ionized air, 119; effect of poisons, I64; enzymes involved, I36; heat evolved, Ir 4 ; influence of food, 125 ; influence of light, I35; influence of salts, I33; influence of water, I29; intensity, IIO ; meclianism, 159; rôle of iron, 137 ; stimulation, I I 4 ; van't Hoff's Law, I24; zymasic type, I6I.

- and age, I Io.

— - anthocyanins, II3, I34.

- - catalase, 150 .

- - enzyme action, I3I.

- - fats, I28.

- - glutathione, ${ }_{4} 8$.

— - organic acids, IO3.

- proteins, 127.

- - surface, II3.

— of fats, I05.

Respiratory index, I I I .

— pigments, I 45.

- quotient, 102.

Rhizoclonium, carbon assimilation, 50.

Rice, catalase activity, I 52 .

Ricinus, development of photosynthetic power, 44 .

Rubus, assimilation number, 43 .
Rumex acetosella, assinilation, I 70 ; respiration, 170.

- conglomeratus, nitrate content, 87.

Saccharomyces, alcololic fermentation, 107; fat formation, 75 ; nitrogen supply, 84. See Yeast.

Salts and carbon assimilation, 47 .

- influence on respiration, 133.

Salvia, effect of ether on respiration, I 8 .

Salvinia, growth, 209.

Sambucus, nitrate in leaf, 82.

- nigra, carbon assimilation, 170 ; compensation point, 7 ; respiration, I70

Sarcina, oxidase, 150.

Schardinger reaction, 140.

Seed, catalase activity, I 5 I maturation, 7I ; respiration, I3I.

Shade and sun leaves, carbon assimilation, 12.

- plants, carbon assimilation, IO, I 70 ; respiration, 136,170 .

Sinapis, assimilation of formaldehyde, 59; growth, I69.

- alba, carbon assimilation, I 70 ; compensation point, 7 ; respiration, 162, I 70 .

Snowdrop, respiration, I 29 ; sugars of leaf, 5I.

Solanum dulcamara, nitrate content, 87 ; reduction of nitrate, 90.

“Sore-skin" fungus, growth, I 89.

Soy, fat formation, 7I ; growth, I95. I 96,205 ; respiration, I 6 .

Sparmanina africana, carbon assimilation, I6.

Spirogyra, carbon assimilation, 50, 59; catalase activity, I5I.

Starch production in potato, $4^{8}$.

Stimulation of respiration, I 44.

Stomatal opening, rhythm, 2 I.

Structural factor in carbon assimilation, 12 .

Suaeda fruticosa, nitrate content, 86 . Succulents, assimilatory quotient, 6 ; respiration, $104, \mathrm{II}_{3}$.

Sugar, fermentation of, I07.

- and respiration, 126 .

- of carbon assimilation, the first, 50.

- production and desiccation, 54 .

Sugars of assimilating leaves, 50 .

- polymerized from formaldelyyde, 60,63 .

Sun and shade leaves, carbon assimilation, 12.

- plants, carbon assimilation, I70 ; respiration, $136,170$.

Sunflower, growth, i 79 ; protein

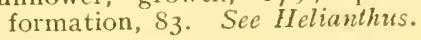


Surface catalysis, 137.
Synthesis of carboliydrate, 6 ; of fats, 69 ; of protein, 81 .

Temperature coefficient of carbon assimilation, 25 .

- influence on carbon assimilation, $9,25,29$; on growth, 187 ; on respiration, I 20.

- of leaves, 30 .

Tilia, assimilation number, 43 .

- europaca, sugars of leaf, 52 .

Time factor in carbon assimilation, 27.

Timothy grass bacillus, respiration, 105.

Tobacco, growth, 196.

Tomato, boron and growth of, 205 ; growth, I74, 207; reduction of nitrate, 90.

Torula, aerobic respiration, 158 .

Tradescantia, growth, 174 .

Translocation of fats, 72 ; of sugars, 49.

Traumatic stimulus of respiration, I 15 .

Trebouxia, respiration, 133 .

Trifolium, growth, 204 .

Tropaolum, assimilation of formaldehyde, 59; assimilation products, 56 ; protein formation, 82 ; respiration, I I 7, I29, I62; sugars of leaves, $51,52,54$.

Turgescence and respiration, 129.

ULTRA-VIOLET radiation and growth, 200 ; and photosynthesis, 37.

Ulva lactuca, carbon assimilation,

- rigida, temperature coefficient of carbon assimilation, 27.

VAN'T HOFF's law and carbon assimilation, 25 ; and growth, I 88 ; and respiration, 124 .

Vaucheria, assimilation, 55, 69.

Vetch, respiration, 127.

Vicia faba, effect of absence of boron, 204.

- respiration, 128.

Vitis, sugars of leaf, 52 .

WALNUT, fat formation, 72 ; growth, I 79 .

Warburg's theory of oxidation, 137.

Water, influence on carbon assimilation, I4; on growth, 202; on respiration, $\mathbf{I} 29$.

Wheat, catalase and oxidase, 150 ; electro-culture, 20I ; fertilizers, 206 ; growth, 192, 208 ; origin of protein in grain, 96 ; respiration, I 8 , I 22, I 27, I 28, I 3 I.

Wieland's theory of oxidation, 138 .

Willstätter and Stoll's assimilation numbers, 43 .

- - theory of carbon assimilation, 63 .

Xanthium, catalase activity, I5I.

Xerophytes, respiration, I 30.

YEAST, alcoholic fermentation, I 55 ; growth, I 80 ; source of glutathione, 146. See Saccharomyces.

Zea, development of photosynthetic power, 44; protein formation, 82. See Maize.

Zinc and growth, 205.

Zymase, 152.

Zymasic type of respiration, $\mathbf{1 6}$.

Zymasis, I6I. 




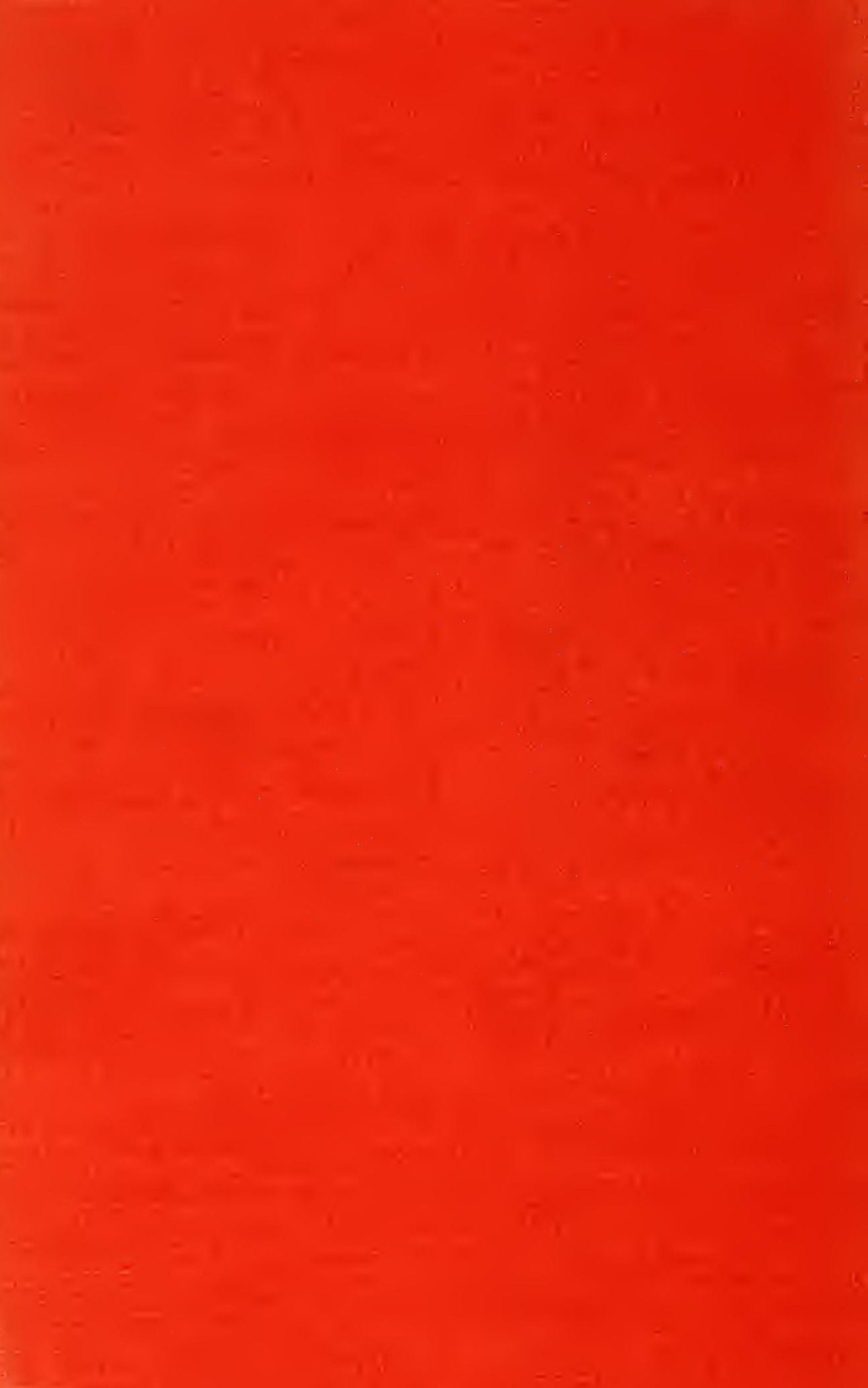

